\title{
Risco e doenças periodontais destrutivas em usuários de um Programa de Saúde da Família, São Paulo, 2.005.
}

Regina Auxiliadora de Amorim Marques

Tese apresentada ao Programa de Pós-Graduação em Saúde Pública da Faculdade de Saúde Pública da Universidade de São Paulo para obtenção do título de Doutor em Saúde Pública.

Área de concentração: Serviços de Saúde Pública

Orientador: Prof. Dr. Roberto Augusto Castellanos Fernandez

São Paulo 2.005

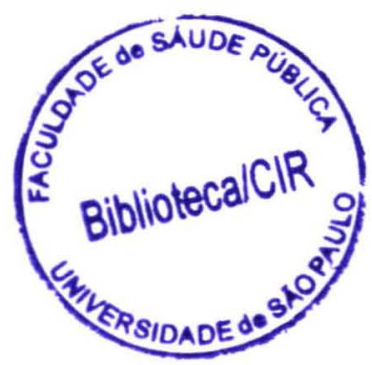




$$
46365 / 2005 \text { doc }
$$

Autorizo, exclusivamente para fins acadêmicos e científicos a reprodução total ou parcial desta tese, por processos fotocopiadores.

Assinatura:

Data: 
Ao Wilson,

carinhosamente, meu cúmplice...

Aos meus filhos, Pedro Henrique e Maria Luíza. 


\section{AGRADECIMENTOS}

Aos meus pais, Armindo e Eunice.

Ao meu orientador, Professor Dr ROBERTO AUGUSTO CASTELLANOS FERNANDEZ, pela compreensão e paciência, com o qual estabeleci uma relação de respeito e grande admiração, com muito carinho $\mathrm{e}$ amizade meus sinceros agradecimentos pela orientação, oportunidades, e incentivo permanente na realização deste meu trabalho acadêmico.

À Daiane Moura da Silva, pelo valor que atribuiu a este trabalho, pelo respeito, interesse e dedicação, além da contribuição em fases importantes deste estudo.

Aos amigos Marco Antonio R. de Albuquerque e Luzia Rita R. de Albuquerque, Ana Maria Cabral de Vasconcelos, Débora Rachel D. D. S. Ortega, Kátia Cristina Giraldez Esquivel Andrade, Maria Elizabeth Gatto, Leda Puelles.

À Tânia Isabel Bighetti Forni, amiga paciente, conselheira, pela ajuda e presença em momentos muito dificeis e decisivos.

Ao Dr Alexandre Nemes Filho e Dr Salvador Pugliese Jr.

À Dr $r^{\mathrm{a}}$ Maria Candelária Soares, Antonio Carlos Frias, Julie Martins e Vladen Vieira.

Ao Professor Dr José Leopoldo Antunes e Professoras $\mathrm{Dr}^{\mathrm{a}}$ Cássia M. Buchalla e $\mathrm{Dr}^{\mathrm{a}}$ Karina $\mathrm{B}$. Ribeiro pelo acolhimento em momentos difíceis, pelas sugestões e ajuda na análise estatística.

À Prof $\mathrm{Dr}^{\mathrm{a}}$ Maria da Luz Soares, pelas sugestões e revisão da versão em inglês do resumo deste estudo.

Aos pacientes, usuários PSF Santa Marcelina, e às equipes de examinadores e anotadores: CD Denise T. Tsuchida e Valéria C. de Oliveira; CD Fábio de M. Pugliano e ACD Fabio Chancaio Correia; CD Janaina de M. M. Duarte e ACD Patrícia Chancaio Correia; CD Márcio e ACD Rita; CD Marcus Vinicius Diniz Grigoletto e ACD Pricila de S. Nascimento; CD Hélder I. P. de Souza e ACD Cláudia Jacob, CD Wivian R. Fuzeti e ACD Jefferson L. Oliveira e Vítor Nori.

A todos os professores, pesquisadores, funcionários dos serviços de saúde e das Secretarias de Saúde, aos meus pacientes, amigos e pessoas, que de alguma forma, muitas vezes anônima, permitiram a conclusão deste trabalho. 


\title{
RESUMO
}

\author{
MARQUES RAA. Risco e Doenças Periodontais Destrutivas em um Programa \\ de Saúde da Família. São Paulo, 2.005). [Tese de Doutorado - Faculdade de \\ Saúde Pública da Universidade de São Paulo - FSP - USP].
}

Introdução: Muitos estudos apontam para a necessidade da identificação de fatores de risco para as Doenças Periodontais Destrutivas - DPD, importante causa de edentulismo em adultos. Realizou-se um estudo de caso controle, na zona leste do município de São Paulo em um Programa de Saúde da Família - PSF. Material e Método: Examinou-se 303 controles, indivíduos com periodonto normal, sangramento ou cálculo, e 318 casos, indivíduos com bolsas periodontais rasas e profundas, segundo critérios do Índice Comunitário Periodontal - CPI, eram pessoas de ambos os sexos, com idades entre 25 e 55 anos de idade. Investigou-se a influência das variáveis idade, sexo, estado conjugal, religião, naturalidade, ocupação, escolaridade e anos de estudo. Procurou-se identificar diabetes, distúrbios neurológicos e psíquicos, doenças ou estados imuno-depressivos quanto ao tempo de duração e uso de medicação. Investigou-se o uso de tabaco, tempo de uso, quantidades consumidas e grau de dependência de nicotina, medida pelo teste de Faggerströn, assim como o consumo de álcool, quantidades consumidas e a história de consumo na última semana, no último mês, no último ano, há 5,10 e 20 anos. Perda de inserção periodontal, medida pelo indicador de Perda de Inserção Periodontal - PIP, experiência de cárie coronária e radicular, uso e tipo de prótese e Índice de Higiene Oral Simplificado - IHOS complementaram a avaliação. Resultados: À análise de regressão múltipla, verificou-se que idade acima de 35 anos, sexo masculino, higiene deficiente, uso de próteses parciais e consumo de álcool no último ano foram independentes para as DPD $(\mathrm{p}<0,005)$, com incremento do risco. Conclusões: Verificou-se que além de sexo, idade, higiene deficiente e uso de próteses parciais fixas ou removíveis, o consumo do álcool no último ano são fatores associados ao risco para DPD.

DesCritores: Doenças Periodontais, Epidemiologia, Risco. 


\section{SUMMARY}

MARQUES RAA. Risk and Destructive Periodontal Diseases in a Program of Health of the Family. São Paulo, 2.005). [Tese de Doutorado - Faculdade de Saúde Pública da Universidade de São Paulo - FSP - USP].

Introduction: Many studies have suggested the need for the identification of risk factors for Destructive Periodontal Diseases (DPD), important cause of edentulism in adults. A control case study was carried out in the eastearn São Paulo city envolving a Family Health Program. Material and Method: This study examined 303 controls (individuals with normal periodontal tissues, bleeding or calculus) and 318 cases (individuals with periodontal pockets) according to criteria of the Community Periodontal Index. Individuals were of both genders, age 25 to 55 years. The influence of age, sex, marital status, religion, naturality, occupation, education and years of study was investigated. In this study, diabetes, neurological and psychic disturbances, imuno-depressive diseases (their stages and duration) and medication use were assessed. Tobacco use (amount and duration) and degree of nicotine dependence were measured by using the Faggerströn test. The history of alcohol consumption as to amount and frequency was also verified in the following periods: last week, last month, last year, and in the past 5, 10 and 20 years. Periodontal loss, measured by the indicator of Periodontal Loss, experience of coronary and root decay, prosthesis use and type and Simplified Index of Oral Hygiene were also evaluated. Results: In multiple regression analysis, it was verified that age above 35 years, male, deficient hygiene, use of partial prosthesis and alcohol consumption in the last year contributed to DPD ( $p<0,005)$, increasing their risk. Conclusions: It was verified that besides sex, age, deficient hygiene and use of fixed or removable partial prostheses, the consumption of alcohol in the last year were associated with risks for DPD.

DESCRIPTORS: Periodontal Diseases, Epidemiology, Risk. 


\section{ÍNDICE}

\section{INTRODUÇÃO}

1.2 Revista de Literatura

Aspectos Históricos sobre as Doenças Periodontais

Doenças Periodontais - Epidemiologia e Proposição de paradigmas Risco e Doenças Periodontais

\section{OBJETIVOS}

2.1 Objetivo geral

2.2 Objetivos Específicos

3. METODOLOGIA

3.1. Local do Estudo - PSF Santa Marcelina

3.2. Caracteristicas Sócio-Demográficas - PSF Santa Marcelina

3.3 Organização dos Serviços de Saúde - PSF Santa Marcelina

3.4 População de Estudo 60

3.5 Delineamento do Estudo 60

Definição e seleção dos casos

Definição e seleção dos controles

Critérios de exclusão

3.6 Identificação do número de Casos e de Controles

3.7 Variáveis de Estudo e Indicadores Utilizados

Variáveis Sócio-Demográficas

Variáveis relativas a condições e estados de Saúde Geral

Variáveis Relativas a Hábitos e Costumes

Variáveis Clínicas

3.8. Operacionalização da Pesquisa 
Treinamento - calibração de examinadores e anotadores

Instrumento de Coleta de Dados - ICD

Trabalho de Campo

Entrevista estruturada

Exames Bucais

3.9 Consolidação de dados e Análise estatística

3.10 Considerações Éticas

4. RESULTADOS 80

4.1 Coleta de Dado $\quad 80$

4.2 Análise Descritiva dos Resultados $\quad 81$

Variáveis Sócio Demográficas

Variáveis relativas a Condições e Estados de Saúde Geral

Variáveis relativas a Hábitos e Costumes

Variáveis Clínicas em Saúde Bucal

4.3 Testes de associação e Análise de Regressão:

Testes de associação - Análise bivariada

Análise de Regressão Múltipla

5. DISCUSSÃO

5.1. Trabalho de campo e Operacionalização da Pesquisa 116

5.2. Variáveis Sócio-Demográficas e Sócio-Econômicas 117

5.3. Condições e Estados - Variáveis Sistêmicas 126

5.4. Hábitos e Costumes 128

5.5.Variáveis Clínicas 135

5.6 Considerações Finais 141

6. CONCLUSÕES 142

7. REFERÊNCIAS BIBLIOGRÁFICAS 


\section{ANEXOS}

ANEXO 1 Termo de consentimento livre e esclarecido relativo à pesquisa "Risco e Doenças Periodontais Destrutivas em Usuários Adultos de um Programa de Saúde da Família, São Paulo,2.005”.

ANEXO 2 Ficha A - Sistema de Informações de Atenção Básica-Qualis Santa Marcelina.

ANEXO 3 Impresso de Triagens - Saúde Bucal - Qualis Santa Marcelina

ANEXO 4 Ficha Clínica - Saúde Bucal - Qualis Santa Marcelina

ANEXO 5 Instrumento de coleta de dados do estudo - "Risco e Doenças

Periodontais Destrutivas em Usuários Adultos de um Programa de Saúde da Família, São Paulo,2.005".

ANEXO 6 Codificação da Receita Federal para Ocupação

ANEXO 7 Bebidas alcoólicas, forma de apresentação e equivalência em doses de álcool absoluto

ANEXO 8 Máscara de digitação 


\section{TABELAS}

TABELA 1 População da zona leste do município de São Paulo, estimada pela 52 Secretaria Municipal de Planejamento de São Paulo, para o ano de 2.003, segundo subprefeituras e distritos administrativos correspondentes. São Paulo, 2.005.

TABEla 2 População de 25 a 59 anos de idade da zona leste de São Paulo 54 estimada pela Secretaria Municipal de Planejamento de São Paulo para o ano de 2.003, segundo sexo, subprefeituras e distritos administrativos correspondentes. São Paulo, 2.005.

TABEla 3 População de 20 a 59 anos de idade das famílias cadastradas no ano 56 de 2003 de área de abrangência segundo sexo e Unidade de Saúde da Família USF do PSF Santa Marcelina. São Paulo, 2.005.

TABELA 4 Número e porcentagem de exames realizados em usuários adultos, de 25 a 55 anos de idade, do PSF Santa Marcelina, em 2.003, segundo Unidade de Saúde. São Paulo, 2.005.

TABELA 5 Número e porcentagem de exames realizados em usuários adultos, de 25 a 55 anos de idade, do PSF Santa Marcelina, em 2.003, segundo critérios utilizados pelo Indicador do PSF e o indicador desta pesquisa. São Paulo, 2.005.

TABEla 6 Número e porcentagem de controle e casos entre os usuários adultos do PSF Santa Marcelina, em 2.003, segundo variáveis sócio demográficas. São Paulo, 2.005.

TABELA 7 Número e porcentagem de controle e casos entre os usuários adultos do PSF Santa Marcelina, em 2003, segundo variáveis relativas a estados e condições de saúde geral, relativas a diabetes, distúrbios neurológicos ou psíquicos e doenças auto-imune . São Paulo, 2005.

TABEla 8 Número e porcentagem de controles e casos entre os usuários adultos do PSF Santa Marcelina, 2003, segundo hábito de fumar dependência de nicotina.São Paulo, 2005 
TABELA 9 Número e porcentagem de controles e casos entre os usuários adultos, de 25 a 55 anos de idade, PSF Santa Marcelina, 2.003 segundo consumo de álcool e período considerado (na última semana, no último mês, no último ano, há 5 anos, há 10 anos e há 20 anos), São Paulo, 2.005.

TABELA 10 Teste de tendência para doenças periodontais destrutivas segundo consumo de álcool na última semana, de usuários adultos, de 25 a 55 anos de idade, PSF Santa Marcelina, 2.003. São Paulo 2.005.

TABELA 11 Teste de tendência para doenças periodontais destrutivas segundo consumo de álcool no último mês, de usuários adultos, de 25 a 55 anos de idade, PSF Santa Marcelina, 2.003. São Paulo 2.005.

TABELA 12 Teste de tendência para doenças periodontais destrutivas segundo 92 consumo de álcool no último ano, de usuários adultos, de 25 a 55 anos de idade, PSF Santa Marcelina, 2.003. São Paulo 2.005.

TABELA 13 Teste de tendência para doenças periodontais destrutivas segundo 92 consumo de álcool há 5 anos, de usuários adultos, de 25 a 55 anos de idade, PSF Santa Marcelina, 2.003. São Paulo 2.005.

TABELA 14 Teste de tendência para doenças periodontais destrutivas segundo 93 consumo de álcool há 10 anos, de usuários adultos, de 25 a 55 anos de idade, PSF Santa Marcelina, 2.003. São Paulo 2.005.

TABELA 15 Teste de tendência para doenças periodontais destrutivas segundo consumo de álcool há 20 anos, de usuários adultos, de 25 a 55 anos de idade, PSF Santa Marcelina, 2.003. São Paulo 2.005.

TABELA 16 Número e porcentagem de controles e casos entre os usuários adultos, de 25 a 55 anos de idade, PSF Santa Marcelina, 2.003 segundo sexo e maior valor do CPI. São Paulo, 2.005.

TABELA 17 Número, porcentagem e média de sextantes examinados em usuários adultos, de 25 a 55 anos de idade, de serviços de saúde, segundo sextante e condição periodontal medida pelo CPI. PSF Santa Marcelina em 2.003. São Paulo, 2.005. 
TABELA 18 Número, porcentagem e média de sextantes examinados. em 99 usuários adultos, de 25 a 55 anos de idade, PSF Santa Marcelina em 2.003, segundo sextante e perda de inserção periodontal medida pelo PIP.São Paulo, 2.005.

TABELA 19 Análise de Regressão Bivariada para as variáveis sócio- 103 demográficas em usuários adultos, de 25 a 55 anos, dos serviços de saúde do PSF Santa Marcelina em 2.003,. São Paulo, 2.005.

TABELA 20 Análise de Regressão Bivariada para variáveis relacionadas a 104 condições sistêmicas e estados, em usuários adultos, casos e controles, de 25 a 55 anos, dos serviços de saúde do PSF Santa Marcelina em 2.003,. São Paulo, 2.005.

TABELA 21 Análise de Regressão Bivariada para a variável tabaco em 105 usuários adultos, casos e controles, de 25 a 55 anos, dos serviços de saúde do PSF Santa Marcelina, em 2.003. São Paulo, 2.005.

TABELA 22 Análise de Regressão Bivariada para consumo de álcool na 106 atualidade, na última semana, no último mês, no último ano e há cinco anos avaliada em usuários adultos, de 25 a 55 anos, dos serviços de saúde do PSF Santa Marcelina, 2.003, casos e controles. São Paulo, 2.004.

TABELA 23 Análise de Regressão Bivariada para tipo de bebidas consumidas 108 entre usuários adultos, de 25 a 55 anos, dos serviços de saúde do PSF Santa Marcelina, 2.003, casos e controles. São Paulo, 2.004.

TABELA 24 Análise de Regressão Bivariada para as variáveis clínicas, em 110 usuários adultos, casos e controles, de 25 a 55 anos, dos serviços de saúde do PSF Santa Marcelina, 2.003, casos e controles. São Paulo, 2.004.

TABELA 25 Análise de Regressão Múltipla para as variáveis independentes 112 sócio demográficas, de hábitos e costumes e de condições clínicas em saúde bucal para Doenças Periodontais Destrutivas, em usuários adultos, de 25 a 55 anos, dos serviços de saúde do PSF Santa Marcelina, 2.003. São Paulo, 2.005. 


\section{QUADROS}

QUADRo 1 Fatores de risco putativos para doenças periodontais segundo 13 tipos de estudo.

QUADRo 2 Indicadores de Saúde Geral das Subprefeituras da zona leste da 57 cidade de São Paulo no ano de 2.002. São Paulo, 2.005.

QuAdro 3 Critérios e Códigos para o Índice Periodontal Comunitário - CPI, 68 Critérios e Códigos e para o Índice de Perda de Inserção Periodontal -PIP.

QuADro 4 Código de Registro e Condições da Coroa e da Raiz para Cárie 69 Dental.

QUADRO 5 Higiene do paciente segundo valores do IHOS.

QUADRo 6 Concordâncias intra e inter examinadores para o CPI e PIP 72 avaliadas pelo Kappa.

QUADRO 7 Variáveis primárias, dicotômicas e respectivas categorias relativas 76 a características sócio - demográficas.

QUADRO 8 Variáveis primárias, dicotômicas e respectivas categorias relativas 76 a estados e condições de saúde geral.

QUADRO 9 Variáveis primárias, dicotômicas e respectivas categorias relativas a hábitos.

QUADRo 10 Variáveis primárias, variáveis dicotômicas e respectivas 79 categorias referente às condições clínicas de saúde bucal.

QUADRo 11 Medidas de tendência central e de variabilidade da experiência de 100 cárie de coroa em usuários adultos de 25 a 55 anos do PSF Santa Marcelina, 2.003. São Paulo, 2.004. 


\section{FIGURAS}

Figura 1 Município de São Paulo - divisão geográfica por Distritos 49 Sanitários-DS - 41 DS, 2.002.

Figura 2 Município de São Paulo - divisão geográfica da cidade - 3151 Subprefeituras, 2.003.

Figura 3 Município de São Paulo - Subprefeituras da zona leste com 53 serviços do PSF Santa Marcelina.

Figura 4 Município.de São Paulo -Subprefeituras da zona leste-População 55 adstrita e Área de abrangência e serviços do PSF Santa Marcelina. 
$\mathrm{ACD}=$ Auxiliar de consultório Dentário

ACS $=$ Agente Comunitário de Saúde

AIDS - Adquired Imuno Deficience Syndrome - Síndrome da Imuno Deficiência Humana adquirida

ANOVA - Análise de Variância

AR T-Atraumatic Restaurations Tecnics

BIREME - Biblioteca Regional de Medicina

CAP ad PROSAN - Centro de apoio Psicossocial e Associação Pro Saúde Mental

CEDEBA - Centro de Diabetes da Bahia

CEBRID - Centro Brasileiro de Informações sobre Drogas

CD - Cirurgião Dentista

CDC - Center of Diseases Control - Centro de Controle de Doenças

CLAP - Comitê Latino Americano de Perinatologia

CEINFO - Centro de Informações

CITB - Coeficiente de Incidência de Tuberculose

CMI - Coeficiente de Mortalidade Infantil

CMCE - Coeficiente de Mortalidade por Causas Externas

CPI - Community Periodontal Index -Índice Periodontal Comunitário

CPITN - Community Periodontal Index and Treatment Needs

CPO - D - Índice de Dentes Permanents Cariados, Perdidos e Obturados

DATASUS - Banco de Dados do Sistema Único de Saúde

$\mathrm{DF}=$ degree of freedon -graus de liberdade

DIABETES MELLITUS ID - Diabetes Melitus insulino dependente

DIABETES MELLITUS NID - Diabetes Melitus não insulino dependente

DIC --Doenças Isquêmicas do Coração

DIEESE- Departamento Intersindical de Estatística e Estudos Sócio - Econômicos

DPD - Doenças Periodontais Destrutivas

EPM - Escola Paulista de Medicina

FDI - Féderation Dentaire Internationale- Federação Dentária Internacional

FMUSP - Faculdade de Medicina da Universidade de São Paulo 
FNT - Fator de Necrose Tumoral

FOB - USP - Faculdade de Odontologia da Universidade de São Paulo

FOUSP - Faculdade Odontologia Universidade da São Paulo

FSP - USP - Faculdade de Saúde Pública - Universidade da São Paulo

GUN- Gengivite Ulcerativa Necrotizante

GNA - Gengivite Necrotizante Aguda

GUNA - Gengivite Úlcero Necrosante Aguda

HIV- Human Imuno deficience vírus - Vírus da Imuno Deficiência Humana

IBGE - Instituto Brasileiro de Geografia e Estatística

IC $=$ Intervalo de confiança

ICD - Instrumento de Coleta de Dados

Ig - Imunoglobulina

IHOS - Índice de Higiene Oral Simplificado

IL - Interleucina

IP - Índice Periodontal de Russell

MPDC - Mortalidade por Doenças Crônicas

MS - Ministério da saúde

NR = Não Reportado, Não Relevante

NHANES -National Health and Nutrition Examination Survey - Inquérito Nacional de Exames de Saúde e Nutrição

OMS - Organização Mundial da Saúde

OPAS - Organização Panamericana da Saúde

OR - Odds ratio - Razão de Chances

OSI - Occupational Stress Indicator questionary -Questionário Indicador de Estresse

Ocupacional

PESS - periodontal emotional stress syndrome - Síndrome Periodontal do Estresse Emocional

PIGE - Phenytoin-induced gingival enlargment - Crescimento Gengival Induzido pela Fenitoina

IP - Índice Periodontal

PMNN - polimorfonucleares neutrófilos

PMSP - Prefeitura do Município de São Paulo 
PROSAN - Programa de Álcool

PROAD - Programa de Orientação e Atendimento a Dependentes

PPR - Prótese Parcial Removível

PSF - Programa de Saúde Família

PT - Prótese Total

SEMPLA - Secretaria de Planejamento

SES - SP - Secretaria de Estado da Saúde

Sig $=$ Significância estatística

SMS - Secretaria Municipal de Saúde

SUS - Sistema Único de Saúde

TRA - Técnica de Restauração Atraumática

THD - Técnico em Higiene Dental

TNF - Tumor necrosis factor

UBS - Unidade Básica de saúde

UNESP - Universidade Estadual Paulista

UNIAD - Unidade de Pesquisa em Álcool e Drogas

UNICAMP - FOP Universidade de Campinas - Faculdade de Odontologia de Piracicaba

UNIFESP - Universidade Federal de São Paulo

USF - Unidade de saúde da Família

USP - Universidade de São Paulo

WHO - World Health Organization 


\section{INTRODUÇÃO}

Com o declínio da cárie dentária, acredita-se que as Doenças Periodontais Destrutivas - DPD, ou simplesmente periodontites, devam ocupar o foco de atenção dos profissionais de saúde bucal, constituindo-se no principal problema de saúde pública nesta área (OPPERMAN e ROSSING 1.997, WHO 1.998 MANSILLA 1.998, JUARÉZ et al 1.999). Isto já é observado em países desenvolvidos, onde a cárie dentária já está controlada, mas estabelece relação de risco com as das doenças periodontais.

Grande número de estudos científicos, realizados nas décadas de 80 e 90 , vem comprovar observações clínicas de que a periodontite, embora seja precedida de gengivite, é uma doença à parte (BAELLUM et al 1.986 BAELLUM et al 1.996; AXTELIUS et al 1.998).

Existem muitas dúvidas relativas à patogênese das DPD, mas a mais importante é a que se refere à susceptibilidade.

Não há dúvida de que placa bacteriana ou biofilme, como preferem alguns autores, é essencial para o desenvolvimento da doença, apresentando vários estágios com diferentes padrões de evolução e de manifestações clínicas, mas considera-se estreita a interpretação das DPD pautada exclusivamente no modelo biológico.

No Brasil, um país emergente, com indicadores gritantes de desigualdade social, há grandes dificuldades no enfrentamento dos problemas de saúde, entre os quais os de saúde bucal. Estas dificuldades se devem às suas dimensões territoriais, à falta ou às incipientes políticas públicas de saúde e em outras áreas sociais, e à escassez de recursos destinados a estes setores.

A criação do Sistema Único de Saúde - SUS, no fim dos anos 80, tinha por objetivo elevar as condições de saúde de toda a população, expresso nos princípios doutrinários do sistema: a universalidade do acesso, a integralidade das ações em saúde $\mathrm{e}$, considerando as desigualdades sociais, a eqüidade.

Diante das diferenças regionais, da diversidade da demanda, do grau de organização local, entre outras, a implantação do SUS, na plenitude de seus princípios doutrinários, tem sido um enorme desafio. 
Como estratégia operacional desta implantação criou-se o Programa de Saúde da Familia - PSF, em franca expansão em muitas cidades brasileiras.

A identificação de grandes necessidades acumuladas em saúde bucal, principalmente na população adulta e idosa, tornou imprescindível a criação de serviços de saúde bucal como parte do PSF. Nos serviços públicos, em geral, o atendimento em saúde bucal desta população crescente, reflexo da transição demográfica, tem se limitado a gestantes ou a resolver problemas de urgência.

As doenças periodontais, apontadas como uma das causas do edentulismo em adultos, constituem focos infecciosos, podendo levar a implicações sistêmicas em indivíduos susceptíveis. As dificuldades no enfrentamento dessas doenças têm demonstrado a necessidade de aprofundar o conhecimento dos fatores intervenientes na ocorrência do agravo, despertando interesse de técnicos e administradores de serviços de saúde do PSF.

Assim como para o planejamento, a organização das ações de saúde geral, deve considerar além da atividade da doença, as condições de risco a que cada cidadão, família ou comunidade está submetida. Deve-se levar em conta situações de risco comuns a que as pessoas estão sujeitas, principalmente aquelas que acometem a família, núcleo primário das relações sociais.

Existem muitos estudos epidemiológicos sobre a prevalência das doenças bucais, importantes para o planejamento e organização de serviços de saúde. Entretanto, particularmente para as DPD, estes estudos não exploram os fatores reais, putativos ou indicativos de risco.

$\mathrm{O}$ grande número de fatores associados ao risco de instalação e progressão das DPD impõe a necessidade de seleção daqueles de real interesse para a implantação e organização de serviços de saúde bucal.

Pela escassez de estudos dessa natureza em nosso meio e, tendo em vista a necessidade dessas informações sobre risco para os serviços públicos de saúde, realizouse esta pesquisa em uma população SUS dependente, já conhecida, cadastrada e usuária de várias unidades de saúde do PSF implantado na zona leste da capital paulista.

Lembrando-se que estas doenças são um problema de saúde coletiva (CHAVES 
1.986) que leva à mutilação, com repercussão direta ou indireta na saúde geral e na dinâmica social, e a partir do conhecimento atual sobre as DPD e sobre os fatores de risco a elas associados, elaborou-se presente estudo.

Foram incluídas algumas variáveis já consagradas como de risco, e outras ainda merecedoras de investigação mais acurada, como é caso do álcool e de alterações sistêmicas.

Idade, sexo, naturalidade, estado conjugal, religião, ocupação, escolaridade foram selecionados como variáveis sócio-demográficas.

Avaliou-se a presença de diabetes, de distúrbios neurológicos e psíquicos, assim como de doenças auto-imune, tanto quanto ao tempo de duração quanto ao uso de medicação.

$\mathrm{Na}$ avaliação do risco para as DPD foram considerados o tabagismo e o consumo do álcool, assim como o tempo de duração do hábito e quantidades consumidas de álcool e de fumo.

Além das condições periodontais, perda de inserção periodontal, experiência de cárie, presença de biofilme na definição do padrão de higiene bucal, uso e tipo de prótese foram variáveis clínicas de saúde bucal importantes na identificação de fatores associados ao risco para as DPD.

Gestantes e pacientes soropositivos para o vírus da Imunodeficiência Humana Adquirida - vírus HIV, foram excluídos deste estudo por apresentarem peculiaridades na instalação e desenvolvimento das doenças periodontais em geral, inerentes às suas condições de saúde.

Este estudo não tem a pretensão de esgotar a discussão, ao contrário, os resultados encontrados devem suscitar outras iniciativas no mesmo sentido. Espera-se que possa contribuir no estudo do risco para as DPD, além de oferecer informações que serão úteis no planejamento e na organização dos serviços públicos de saúde, onde o risco seja um dos critérios utilizados na adoção de medidas de promoção de saúde ou de sua recuperação. 


\subsection{REVISTA DE LITERATURA}

Nos anos 50 a Organização Mundial da Saúde reuniu um grupo de consultores, que enumerou as alterações da saúde bucal consideradas problemas de saúde pública, entre as quais figuram a cárie e as doenças periodontais.

Um conjunto de critérios estabelece a prioridade relativa dos problemas de saúde pública, devendo se considerar o número de pessoas atingidas, a gravidade ou severidade $^{*(1)}$ do dano causado, a possibilidade de atuação eficiente, o custo percapita e o grau de interesse da comunidade (CHAVES 1.986)

Avanços técnicos e metodológicos, para diagnóstico e tratamento da cárie, têm levado a um marcante declínio na sua prevalência e gravidade ou severidade ${ }^{*(1)}$ (THYLSTRUP e FEJERSKOV 1.995, MALTZ e CARVALHO 1.997, WEYNE 1.997). Não dispondo de métodos de massa para as doenças periodontais estas passam a figurar como importante problema da saúde bucal em saúde pública.

\section{ASPECTOS HistóRICOS SOBRE AS DOENÇAS PERIOdONTAIS}

Registros paleontológicos indicam que o homem era vítima da doença periodontal desde os tempos pré-históricos. CARRANZA (1.979), afirma que as doenças periodontais eram a mais comum das enfermidades de que havia evidência nos corpos embalsamados dos egipcios, há 4.000 anos. Nas civilizações primitivas, demonstrou ser um problema de saúde presente em todos os povos e grupos etários.

\footnotetext{
"(1) Verificou-se que "severity is the quality of being severe" (SPEARS 1.998).

Em PARKER e SILVA (1.995) "Severity: noum; severity of the punishment, severity of her dress, grave"; severe: "adj: a severe illness, grave".

Em BÁRBARA et al (1.994) "severe" pode ser traduzido para o português por severo, austero, sério, grave, dificil, rigido

No Novo Dicionário Aurélio, Ed Nova Fronteira verifica-se que "severidade é ato severo, rigoroso, qualidade de estilo severo, sobriedade, inflexibilidade de caráter, aspereza, rigor". No mesmo dicionário "severo" é entendido como rígido, rigoroso, rígido de caráter, austero, grave, circunspecto, sério (FERREIRA 1.999)

Neste trabalho adotou-se a expressão "gravidade" para qualificar as doenças periodontais destrutivas, traduzidas do inglês "severity".
} 
Os Papiros Cirúrgicos de Ebers e Edwin Smith, documentos de grande importância na história da medicina e da odontologia, já revelavam a existência de especialistas no cuidado com os dentes, um certo conhecimento de doenças dos dentes e gengivas e da necessidade de tratá-las.

Tábuas de argila da civilização suméria, de 3.000 a.C., e na mais antiga obra médica chinesa, escrita por volta de 2.500 a.C. encontram-se descritas inflamações gengivais, abscessos periodontais e ulcerações gengivais com detalhes precisos.

Hipócrates de Cós, na Grécia, discutiu a etiologia da doença periodontal. Acreditava-se que a inflamação gengival pudesse ser produzida por acúmulo de cálculos e do que chamou de pituíta ${ }^{*}$, , ocorrendo hemorragia gengival, nos casos de doença persistente. Hipócrates refere-se ainda a alterações gengivais onde

“... as gengivas separam-se dos dentes $\mathrm{e}$ emitem um cheiro desagradável".

A remoção de indutos já figurava como uma das formas mais efetivas no tratamento das alterações gengivais, desde a Antigüidade. Tratamentos com ferros incandescentes, escalpelos, raspadeiras, limas, mel, ópio, óleo de rosas, loções adstringentes e pós-dentifrícios, vinho branco, sal torrado e substâncias aromáticas, além da recomendação de

$$
\begin{aligned}
& \text { “.. se mastigar peras e maças verdes, } \\
& \text { conservando o suco destas na boca..." (Aulus } \\
& \text { Cornelius Celsus, séc. I d.C), }
\end{aligned}
$$

são encontradas em documentos citados e reunidas em publicações sobre a história da odontologia e da medicina.

Vários documentos da Idade Média e Moderna descrevem técnicas e instrumentos para o tratamento de problemas observados na gengiva e nos dentes.

\footnotetext{
-(2) pituíta - humor branco e viscoso, segregado principalmente pelo nariz e brônquios (FERREIRA 1.999)
} 
A partir do século XVIII, a odontologia desenvolveu os primeiros sinais de curiosidade cientifica, identificando a doença periodontal crônica como uma doença que afetava gengivas, alvéolos e dentes.

No século XIX, medidas cirúrgicas para o tratamento da doença periodontal foram propostas e adotadas (CARRANZA 1.979, CALDAS e BERVIQUE 1.992).

No século $\mathrm{XX}$, por volta dos anos 50, um grande grupo de clínicos e cientistas surge em todo o mundo, contribuindo com descobertas que fundamentam muitos dos procedimentos e condutas adotados nas atuais práticas clínicas (CARRANZA 1.986, CALDAS e BERVIQUE 1.992).

Além das observações registradas em documentos históricos, alguns estudos publicados nos anos 90, realizados a partir de material arqueológico, têm demonstrado que a doença periodontal esteve presente desde os primórdios da humanidade.

Estudos recentes realizados por KERR (1.998a) e KERR (1.998b) e SAKASHITA (1.997), em crânios de ancestrais pré - históricos demonstram a Antigüidade da doença.

Durante muito tempo as doenças periodontais foram consideradas como de progressão lenta, contínua e linear durante a vida, do estado de gengivite para periodontite, com a perda progressiva do suporte periodontal até a perda do dente. Sabe-se atualmente que as doenças periodontais progridem em episódios agudos recorrentes com períodos relativamente curtos de destruição tecidual seguidos por períodos longos de remissão. A gengivite e periodontite são doenças diferentes, sendo apenas alguns poucos locais com gengivite que progridem para periodontite, não resultando em destruição inevitável. Sendo assim, é importante utilizar métodos epidemiológicos para identificar indivíduos susceptíveis à doença periodontal e a importância relativa destes grupos na média geral da doença.

A presença do biofilme dentário é indiscutivelmente necessária, mas não suficiente para a instalação de doenças periodontais, sejam estas reversíveis (gengivites) ou não (periodontites ou doenças periodontais destrutivas - DPD). Apesar da inegável necessidade das bactérias para iniciar as doenças periodontais de natureza inflamatória, a simples análise das características quantitativas e qualitativas do biofilme dental não consegue explicar as diferenças relativas à 
gravidade das lesões em diferentes indivíduos. O tabagismo entre outros hábitos, estados e condições sistêmicas constituem situações de risco para as doenças periodontais, mas também não esgotam as explicações, uma vez que muitos indivíduos submetidos a estas situações de risco não apresentam níveis significativos de doença periodontal. Por outro lado, não é incomum encontrarmos pessoas com bom controle de biofilme e com dificil resposta ao tratamento da doença.

É unânime entre os autores que as DPD ocorrem quando há migração do epitélio juncional para a superficie apical da raiz, junto à junção amelo-cementária (LÖE et al 1.965, LÖE et al 1.978, CARRANZA 1.979, LINDHE 1.985, GENCO et al 1.993, GENCO et al 1.998), entretanto a complexidade no seu tratamento e contenção de sua evolução extrapola o controle do biofilme e do cálculo.

A patogênese das DPD ainda não está totalmente elucidada, existem muitas dúvidas a este respeito, mas a susceptibilidade é a que na atualidade mais desperta o interesse dos pesquisadores. A resposta do hospedeiro à agressão microbiana sofre grandes variações, mas a susceptibilidade e a resposta imune podem ser uma das fontes mais prováveis desta variação (CARRANZA 1.979, GENCO et al 1.993, LINDHE 1.985, LLAMBIAS). Esta susceptibilidade se situa em torno de uma capacidade ou incapacidade de produzir anticorpos eficazes contra uma agressão microbiana específica, pode provavelmente estar dirigida por falhas nas respostas inflamatória inespecífica, imune ou reparadora.

A susceptibilidade à gengivite está mais provavelmente relacionada à quantidade de biofilme e, em alguns casos, aos níveis ou alterações hormonais. Estas alterações hormonais afetam a resposta ao biofilme, particularmente no que se refere à gravidade da gengivite, mas não são cruciais para a susceptibilidade as DPD. Do mesmo modo, fatores como o controle do diabetes e de hábitos como o fumo são indispensáveis na avaliação do risco de desenvolvimento das DPD. Estes fatores podem não ser os principais determinantes para a susceptibilidade, todavia podem exacerbar a condição, do mesmo modo que a precariedade da higiene bucal faria em um hospedeiro, com resposta imune ineficaz contra os microorganismos específicos e, desta maneira a erradicação de microrganismos específicos seria muito conveniente.

O que se sabe, porém, é que há muitas semelhanças antigênicas entre os 
microrganismos do biofilme, e sua grande maioria é comensal, além de muitos periodontopatógenos serem onipresentes. É, portanto, a resposta benéfica ou nociva do hospedeiro, crucial para determinar a susceptibilidade as DPD

Assim como outros agravos à saúde e doenças são decorrentes dos diferentes modos de vida das pessoas em sociedade, as doenças periodontais constituem eventos biopsicossociais. Resultam da interação entre as relações sociais e comunitárias, e entre aspectos físicos, comportamentais e psicológicos. (BARROS et al 1.988; PEREIRA 1.995; ROQUAYROL e ALMEIDA FILHO 1.999;.MEDRONHO et al 2.003)

Os fatores associados ao comportamento podem ser tidos como fatores de risco, e em algumas situações, podem ser controlados voluntariamente no intuito de prevenir o aparecimento de doenças e de sua evolução (PEREIRA 1.995; ROQUAYROL e ALMEIDA FILHO 1.999;.MEDRONHO, et al 2.003).

\section{Doenças Periodontais - Epidemiologia E Proposição de PaRAdigmas}

Em 1.955, MARSHALL-DAY et al, em um estudo realizado na Índia, com 1.187 indivíduos, onde se procurava estabelecer a diferença entre as gengivites e a DPD, verificaram uma relação inversamente proporcional entre o número de indivíduos com doença gengival, sem comprometimento ósseo e a idade, concomitante a um aumento no percentual de indivíduos com DPD crônica e o aumento da idade. No mesmo estudo os autores referem uma prevalência de $100 \%$ de DPD após os 40 anos de idade. Muitos outros estudos realizados no mesmo período reiteravam a alta prevalência de doença periodontal em adultos, e claras evidências do incremento de sua prevalência com a idade (LINDHE, et al 1.999).

Tornava-se evidente que DPD representava o estágio terminal de outros processos, que tinham início na juventude, e que causava a perda de dentes, tendo sido apontada como a principal causa da perda de dentes em adultos. (VIEGAS 1.965, LÖE et al 1.978, CARRANZA 1.979, AINAMO 1.985; LINDHE 1.985; GENCO et al 1.993; GREENE 1.993, LÖE e MORRINSON 1.993).

Em uma revista de literatura apresentada por SCHERP (1.964) a doença periodontal foi tida como um problema importante em saúde pública, afetando grande parte da população adulta acima de 35 anos. Era consenso que a doença 
periodontal se iniciava na juventude, a partir de uma gengivite, e que não tratada avançaria para uma periodontite progressiva. A gravidade da doença poderia ser explicada pela idade e pela higiene bucal do paciente.

Nas décadas de 60 e 70, as gengivites foram largamente estudadas e definidas como manifestações inflamatórias da gengiva marginal, desencadeadas pelo acúmulo de biofilme dentário, e as periodontites, como decorrentes de gengivites (LÖE et al 1.965, LÖE et al 1.978, CARRANZA 1.979, LINDHE 1.985, GENCO et al 1.993, GENCO et al 1.998, OPPERMANN e GOMES 1.999).

Observou-se, também nas décadas de 60 e 70, que as periodontites resultavam da inflamação dos tecidos de sustentação dos dentes, acompanhada de perda de inserção conjuntiva, representada pelo ligamento periodontal e osso alveolar (CARRANZA 1.79, LINDHE 1.985, GENCO et al 1.993, LÖE e MORRINSON 1.993, GENCO et al 1.998).

A partir dos anos 80 os estudos começaram a demonstrar alta variação nas condições periodontais entre diferentes populações. A prevalência da doença não era mais abordada por simples classificação de indivíduos "com doença" e "sem doença".

Verificando grandes diferenças no comportamento da doença entre os indivíduos, no próprio indivíduo, entre os dentes e até mesmo em diferentes sítios do mesmo dente, os pesquisadores exploraram mais detalhes a respeito da localização da doença, por sítios dos dentes, por tipo e gravidade dos defeitos ósseos encontrados.

BAELLUM, FEJERSKOV e KARRING (1.986), um grupo de pesquisadores dinamarqueses, em um estudo transversal avaliaram as condições periodontais de adultos tanzanianos, entre 30 e 69 anos de idade, e verificaram que apesar da grande quantidade de indutos (biofilme e cálculo) a profundidade de sulco à sondagem superior a $3 \mathrm{~mm}$ e a perda de inserção maior que $6 \mathrm{~mm}$ foi identificada em menos de $10,0 \%$ das superficies dentárias examinadas. Não havia distribuição uniforme da DPD na população, e não havia boa correlação entre a quantidade de biofilme e a doença periodontal. A maioria dos indivíduos apresentava problemas periodontais insignificantes, e apenas um pequeno grupo tinha sido afetado pela doença em estágio mais avançado. Dois anos depois, os mesmos autores avaliaram 1.131 
indivíduos no Quênia, com idades entre 15 e 65 anos e confirmaram os dados obtidos na Tanzânia (BAELLUM, FEJERSKOV e KARRING 1.988).

A periodontite acomete uma pequena parcela da população, é episódica e os surtos de progressão ocorrem em poucos locais, e em apenas alguns indivíduos, mesmo após muitos anos, por isso sua gravidade e prevalência aumentam com a idade (GENCO et al 1.998, KAVANAGH 1.998, OPPERMANN e GOMES 1.999, MANSÍLLA 1.998, JUÁREZ et al 1.999).

Em pelo menos 39 estudos citados por LINDHE, KARRING E LANG (1.999) comprova-se o apontado por Baellun, Fejerkov e Karring, em 1.986 e, posteriormente em 1.988. Diferentemente do que se acreditava as DPD acometiam apenas um pequeno grupo de pessoas, poucos indivíduos tinham sido afetados pela doença em estágio mais avançado, não havia distribuição uniforme da DPD na população.

Em 1.996, BAELLUN, CHEN, MANJI, LUAN, FEJERSKOV publicaram um estudo onde recalcularam os dados obtidos em 1.988, com os adultos do Quênia e em um outro grupo de adultos chineses, combinando com outros seis estudos realizados por outros pesquisadores, em diversos países. Os dados não foram suficientes para comprovar a generalização tradicional de que a prevalência e a severidade da doença periodontal são muito acentuadas nas comunidades africanas e asiáticas.

\section{Risco E DOEnÇAS PERIOdontais}

Os fatores locais de agressão (biofilme e cálculo) podem explicar grande parte dos casos, mas seguramente não podem explicar todos.

As grandes variações podem ser entendidas pela qualidade, e principalmente pela intensidade da resposta do hospedeiro à agressão. A efetividade e intensidade desta resposta, inclusive, são também responsáveis pela quantidade e qualidade do biofilme, viabilizando ou não determinados microorganismos.

Admite-se então que outros fatores, apesar não serem suficientes para provocar a doença, exacerbem ou inibam mecanismos endógenos que, somados à atividade microbiana, são decisivos no agravamento das doenças periodontais.

$\mathrm{O}$ atual paradigma sobre as doenças periodontais destrutivas coloca que estas 
não devem ser entendidas como conseqüência inevitável das gengivites, muito menos levam a consideráveis perdas dentárias. Verifica-se a necessidade de uma caracterização mais específica dos sinais em indivíduos que parecem ser mais suscetíveis.

As doenças periodontais são doenças infecto-contagiosas, crônicas e degenerativas, mas está demonstrado, não só para este agravo, que a presença dos agentes microbianos não é suficiente para que a doença se instale e progrida. Outros fatores, incluindo deficiências nutricionais, exposições tóxicas, estresse emocional e o impacto de condições sócio-econômicas e culturais interferem neste processo. Estes fatores estão associados à doença, aumentando a probabilidade desta evoluir sem, entretanto, serem seu agente causal. Podem ser modificados por uma intervenção, reduzindo a probabilidade de ocorrência da doença. A valorização de comportamentos, determinados socio-culturalmente, relacionados com o modo ou estilo de vida, exposições ambientais além de características inatas ou hereditárias, têm demonstrado íntima relação com várias doenças, inclusive com as periodontais, aumentando o risco ${ }^{*(3)}$ de sua ocorrência, constituindo, portanto, fatores de risco. A probabilidade do aparecimento de uma doença ou incapacidade varia, seja pela presença, ausência, intensidade ou combinação de fatores.

Fatores relacionados com a progressão da doença preexistente, danos ou seqüelas não devem ser considerados fatores de risco, mas sim fatores de prognóstico. São referidos como fatores de prognóstico aqueles por sua presença ou intensidade no curso da doença, ou por sua ausência, estão associados a diferentes prognósticos (PEREIRA 1.995).

\footnotetext{
•(3) Risco: grau de probabilidade da ocorrência de um determinado evento (PEREIRA 1.995).

Risco "probabilidade de ocorrência de um resultado desfavorável, de um dano ou fenômeno indesejado" (Organização Panamericana da Saúde - OPAS; Centro Latino Americano de Perinatologia e Desenvolvimento Humano - CLAP 1.998).
} 
É indiscutivel a participação dos determinantes sócio-econômicos, culturais e ambientais, além dos biológicos, no equilíbrio entre saúde e doença. Os fatores que produzem a doença são biológicos e ambientais, com significados sociais complexos. A sociedade, da forma como está organizada, embora ofereça proteção aos indivíduos, também determina muitos riscos de adoecer, bem como o maior ou menor acesso das pessoas às técnicas de prevenção das doenças e de promoção e recuperação da saúde. Diante das desigualdades sociais, a saúde dos grupos menos favorecidos socialmente pode vir a sofrer conseqüências adversas (alta prevalência de doenças evitáveis e a dificuldade de acesso aos serviços de saúde). (PEREIRA 1.995)

Muitos fatores de risco potenciais das doenças periodontais têm sido analisados em estudos transversais, favorecem evidências, mas precisam ser reafirmados por novos estudos, preferencialmente longitudinais que utilizem análises multivariadas para sua confirmação (LINDHE et al 1.999).

Idade, sexo, condições sócio econômicas, diabetes, uso do tabaco e determinadas bactérias têm sido apontadas com fatores de risco já conhecidos para formas mais graves das doenças periodontais.

Alterações nutricionais e hormonais, principalmente relacionadas com os hormônios femininos, na adolescência e na gravidez, o uso de drogas contraceptivas, assim como deficiências hormonais observadas na menopausa têm sido aventadas como fatores de risco potenciais. Situações onde a resposta imunológica esteja comprometida pela condição do indivíduo ou pelo uso de medicamentos, que interfiram de forma direta ou indireta na resposta imune como em algumas doenças sistêmicas, desequilíbrios psíquicos (distúrbios ansiosos ou depressivos), alterações emocionais, como o estresse, alterações neurológicas, consumo de drogas psicoativas, principalmente o álcool e o crack, têm sido relacionadas com DPD.

GENCO (1.996) apresentou o estado atual de conhecimento de fatores apontados como de risco para as doenças periodontais avaliados por estudos epidemiológicos transversais, caso controle e de coorte (quadro 1). 
QUADRO 1: Fatores de risco putativos para doenças periodontais segundo tipos de estudo.

\begin{tabular}{|c|c|c|c|}
\hline \multirow{2}{*}{ FATOR DE RISEO } & \multicolumn{3}{|c|}{ TIFO DE ESTIIDO } \\
\hline & 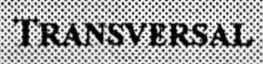 & C.450 conmirou. & Coorm \\
\hline \multicolumn{4}{|l|}{$\begin{array}{l}\text { ESPECIFICIDADE } \\
\text { MICROBIANA }\end{array}$} \\
\hline P gengivalis & $\operatorname{sim}$ & sim & sim \\
\hline B forsytus & $\operatorname{sim}$ & sim & sim \\
\hline P intermédia & $\operatorname{sim}$ & $\operatorname{sim}$ & $\operatorname{sim}$ \\
\hline $\begin{array}{l}\text { SExo } \\
\text { Masculino }\end{array}$ & $\mathrm{NR}^{1}$ & $\operatorname{sim}$ & $\mathrm{NR}^{1}$ \\
\hline IDADE & sim & $\operatorname{sim}$ & sim \\
\hline $\begin{array}{l}\text { DIABETES MELLITUS } \\
(\mathrm{NID})^{2}\end{array}$ & $\operatorname{sim}$ & $\operatorname{sim}$ & $\operatorname{sim}$ \\
\hline $\begin{array}{l}\text { DIABETES MELLITUS } \\
\text { (ID) }\end{array}$ & sim & $\operatorname{sim}$ & $\mathrm{NR}^{1}$ \\
\hline TABAGISMO & sim & $\operatorname{sim}$ & $\operatorname{sim}$ \\
\hline OSTEOPOROSE & $\operatorname{sim}$ & $\operatorname{sim}$ & $\mathrm{NR}^{1}$ \\
\hline $\begin{array}{l}\text { ESTRESSE } \\
\text { ANGUUSTIA, } \\
\text { AFLIÇÃO, } \\
\text { COMPORTAMENTO } \\
\text { ADAPTATIVO }\end{array}$ & $\operatorname{sim}$ & $\operatorname{sim}$ & $\mathrm{NR}^{1}$ \\
\hline $\begin{array}{l}\text { ALTERAÇÕES NOS } \\
\text { PMN }^{4}\end{array}$ & $\operatorname{sim}$ & $\mathrm{NR}^{1}$ & sim \\
\hline
\end{tabular}

$\mathrm{NR}^{1}=$ não reportados ou não relevante; $\mathrm{NID}^{2}=$ não insulino dependente; $\mathrm{ID}^{3}=$ insulino dependente; $\mathrm{PMN}^{4}=$ Polimorfonucleares neutrófilos.

Fonte: Adaptado de GENCO 1.996

As pesquisas em epidemiologia, especialmente no campo das doenças crônicas têm progredido através da análise da associação entre um fator e uma doença. Um fator será considerado causa contribuinte de uma doença se for parte de um complexo de circunstâncias no qual a freqüência da doença é aumentada pela sua presença e reduzida pela sua ausência.Neste sentido, alguns fatores associados às doenças periodontais destrutivas - DPD em discussão na literatura serão 
apresentados a seguir.

IDADE

Diversos estudos, alguns já citados anteriormente neste trabalho, têm salientado a importância da idade como fator modificador ou cofator de risco para as doenças periodontais. Esta variável, evidentemente, é avaliada em conjunto com outras, mas merece destaque quando se trata de estabelecer comparações entre estudos.

GOLDHABER e GIDDON (1.964), estudando gengivite ulcerativa necrosante aguda identificaram como grupo mais atingido pelos efeitos do tabaco nas doenças periodontais jovens do sexo feminino, em contraponto com uma série de estudos que se seguiram a esse.

Grande número de estudos de prevalência, realizados nos anos 70 e 80, indicavam a idade como fator de risco para as doenças periodontais, mas e evidenciou-se que a periodontite severa não era conseqüência natural da idade (PAPAPANOU et al 1.988).

NUNES e SLAVUTZKY (1.992) avaliando cabos e soldados do $3^{\circ}$ regimento de Cavalaria de Guarda Marechal Osório $8^{\circ}$ Batalhão Logístico, em Porto Alegre, fumantes e não fumantes, encontraram associação entre a idade e as condições periodontais $(\mathrm{p}<0,001)$.

No interior do estado de São Paulo, CAMPOS JÚNIOR et al (1.994), realizaram um estudo transversal com uma amostra aleatória com mais de 1.600 individuos, de ambos os sexos e idades entre 18 a 35 anos. O objetivo era avaliar as condições periodontais $\mathrm{e}$ as necessidades de tratamento usando o Índice de Necessidade de Tratamento Periodontal na Comunidade (CPITN) e identificando os indivíduos de alta susceptibilidade à doença periodontal. Os resultados mostraram que houve aumento da gravidade da doença com a idade, mas este aumento não foi homogêneo. Poucos indivíduos apresentaram valores altos do CPITN, doença mais grave, o que pode indicar a concentração da destruição. A partir desse estudo pode se identificar uma minoria de indivíduos considerados de alto risco para a doença periodontal, reforçando o paradigma atual sobre etiopatogênese das doenças periodontais 
Para a identificação dos indivíduos de alta susceptibilidade à doença periodontal, realizou-se no município de Bauru, São Paulo, um estudo transversal, usando índice CPITN, no qual foram examinados 1.633 individuos adultos jovens de ambos os sexos. Os resultados apontaram relação direta no aumento da prevalência e da gravidade da doença periodontal com a idade (KIM 1.992).

Em um estudo realizado pelo Department of Biomedical Sciences, em Marischal College, University of Aberdeen, UK, KERR (1.998a), utilizando material arqueológico da sociedade escocesa pré-histórica de indivíduos com idade maior ou igual a 10 anos, verificou que a gengivite foi a doença mais largamente instalada em adolescentes e adultos jovens. Em relação à periodontite, este mesmo estudo coloca que sua progressão era constante e a prevalência semelhante ao observado em estudos epidemiológicos recentes, sem evidências de que a prevalência da doença periodontal tenha sido maior em relação à sociedade moderna. Este mesmo autor publicou, no fim de 1.998, um outro estudo discutindo a prevalência de periodontite na população britânica, da pré-história até o século XIX, num período de 3.000 anos, examinando material esquelético de várias coleções arqueológicas. A conclusão foi semelhante à do estudo anterior: a prevalência da periodontite era diretamente proporcional à idade e é praticamente a mesma observada na atualidade (KERR $1.998 \mathrm{~b})$.

O Department of Preventive Dentistry, da Kagoshima University Dental School, Japan, (SAKASHITA et al 1.997), também analisou material arqueológico do período Yin-Shang, de tumbas de Anyang, China. Foram examinados 42 crânios de homens e 183 de mulheres, escravos e cidadãos, sendo retirados das escavações de 71 tumbas, utilizadas para sepultamento e de covas usadas para sacrifício. Não havia diferença nas condições de saúde bucal nos indivíduos jovens, fossem eles cidadãos ou escravos. Nos indivíduos mais velhos, as condições de saúde bucal eram melhores nos escravos, apontando diferenças sociais. Considerando jovens e adultos, a prevalência de doença periodontal aumentava com a idade, variando de 18,3 a $26,9 \%$.

Medidas para controle da cárie e da perda de dentes e o aumento da expectativa de vida da população, maior hoje do que no passado, implicam em um aumento no número de pacientes dentados na terceira idade, havendo assim uma 
necessidade e demanda crescentes para cuidados periodontais em pacientes com idade superior a 65 anos.

Mudanças fisiológicas associadas à idade podem ser observadas nos tecidos periodontais, o que leva à suspeita de que o avanço da idade poderia ser um fator de risco para a doença periodontal. A alta prevalência de uma ou mais doenças sistêmicas crônicas como o diabetes mellitus, doenças coronarianas e osteoporose, em pacientes idosos, podem não afetar os tecidos periodontais diretamente, mas requer uma conduta terapêutica periodontal mais cuidadosa e multidisciplinar. Os dados disponiveis apontam para o fato de que a idade avançada, por si só, não deve constituir uma contra-indicação para realizar qualquer procedimento terapêutico periodontal, mas estes devem ser criteriosamente planejados (ACEVEDO et al 2.001).

MACHION et al (2.000) avaliaram a influência do sexo e da idade na prevalência das bolsas periodontais. Separaram as fichas de 100 pacientes da clínica de periodontia Faculdade de Odontologia de Piracicaba da Universidade de Campinas - FOP UNICAMP segundo sexo e em três grupos etários. Os grupos etários eram 15 a 30 anos, 31 a 50 anos e acima de 50 anos. Bolsas com maior profundidade à sondagem foram encontradas em de pacientes com mais de 31 anos.

Segundo alguns autores a idade produz algum grau de perda de inserção, compatível com a saúde e a função, assim não pode se considerar fator de risco para as doenças periodontais (WENNSTRÖN 1.993, BROWN et al 1.994, FRANSSON 1.999, ACEVEDO et al 2.001).

\section{SEXO}

Os estudos que avaliam sexo e doenças periodontais são numerosos. As diferenças metodológicas e operacionais não permitem conclusões absolutas, mas há indicativos de que a prevalência das doenças periodontais deva ser muito semelhante entre homens e mulheres. Há, entretanto, uma diferença: nos homens as doenças periodontais são mais graves e mais extensas, manifestando-se em vários sítios e de forma mais avançada e destrutiva (WHO 2.000; MARQUES 2.000).

Uma das explicações plausíveis para esta diferença pode ser dada pela maior exposição a fatores de risco para essas doenças (MARQUES 2.000). 
Contrariando a grande maioria dos estudos GOLDHABER e GIDDON (1.964), examinaram 334 pacientes e demonstraram que o grupo mais susceptivel às doenças periodontais, sob os efeitos do tabaco, foi o de pacientes jovens e do sexo feminino.

FLORES DE JACOBY et al (1.989), FLORES DE JACOBY et al (1.991), GAMONAL et al (1.998), MACHION et al (2.000), citado anteriormente, entre outros autores identificaram maior prevalência de perda de inserção óssea e ligamentar, e conseqüentemente maior número de bolsas periodontais no sexo masculino.

\section{RAÇA OU ETNIA}

$\mathrm{Na}$ região de Contagem, estado de Minas Gerais, reside uma comunidade negra, conhecida como Comunidade Arturo's. Fundada por um escravo negro alforriado, esta comunidade mantém-se fiel às suas tradições culturais africanas, tanto na religião quanto no dialeto usado entre eles. A renda média de cada família gira em torno de 1 a 3 salários mínimos.

As características deste grupo populacional despertaram o interesse de pesquisadores da Universidade Federal de Minas Gerais que realizaram um estudo transversal avaliando condições e fatores de risco para doenças periodontais de todos os dentes de indivíduos com 13 anos de idade ou mais, em ambos os sexos.

Escolaridade, faixa etária e uso de tabaco apresentaram relação com a perda de inserção periodontal, enquanto que somente a idade se mostrou significativa no aumento da profundidade do sulco à sondagem (KATO SEGUNDO et al 2.004).

A prevalência de doenças periodontais nesta comunidade é semelhante àquela encontrada em outros locais e grupos populacionais, tanto no Brasil quanto em outros países (MARQUES 2.000), não se confirmando a hipótese de que este agravo seria mais prevalente e mais grave do que em outros grupos populacionais não negros. (KATO SEGUNDO et al 2.004).

LINDHEET et al (1.999) registraram que negros e filipinos apresentam maior prevalência de doenças periodontais, quando comparados a outros grupos populacionais. Isto não se confirma em boa parte dos estudos. Em publicação recente BORRELL et al (2.002), na Universidade de Columbia - EUA, acompanhando 
brancos americanos e negros, por um período de 15 anos (de 1.971 a 1.994) observaram diferenças nas condições periodontais entre os dois grupos étnicos, crescentes e piores nos negros. Estas, podem ser explicadas mais pelas diferenças sócio-econômicas, culturais e comportamentais do que exclusivamente pelas questões étnicas (BAELUM et al 1.986, BAELUM et al 1.988, BAELUM et al 1.988, BAELUM et al 1.993a, BAELUM et al 1.993b, EL NADEEF e, ADEGBENBO 1.995, BAELUM et al 1.995, BAELUM et al 1.996, PETERSEN e RAZANAMIHAJA 1.996, GAMONAL et al, 1.998, ROMAN e POP 1.998).

\section{OCUPAÇÃO E FATORES SÓCIO ECONÔMICOS}

As doenças variam em diferentes populações, sob a interferência de variáveis sócio - demográficas, sendo que há limitações no entendimento da interação entre estas variáveis e os agravos à saúde (SPOLSKY et al 2.000).

A inserção no mercado de trabalho e o tipo de ocupação podem ser um dos fatores sócio econômicos a se considerar no processo saúde doença periodontal.

CROUCHER et al (1.997) analisando fatores psicossociais identificaram o desemprego como variável de interesse nas doenças periodontais. Neste estudo os autores apontaram que esta variável associada a fatores psicossociais é importante determinante das periodontites (CROUCHER et al 1.997)

TOMITA et al (1.999) avaliaram a prevalência de cárie dentária e doença periodontal em trabalhadores de uma indústria alimentícia de Bauru-SP-Brasil para verificar a associação entre fatores ambientais no processo de trabalho e as condições de saúde bucal.

Foi realizado o levantamento das condições bucais junto a 156 trabalhadores, em uma amostra aleatória sistemática do total de funcionários de todos os setores. $\mathrm{O}$ grupo de estudo foi composto por funcionários da fábrica de chiclete e chocolate, e o grupo-controle foi formado por funcionários não submetidos à exposição constante a partículas de farinha e açúcar. Utilizaram-se os índices CPO-D (cárie dentária) e CPITN (doença periodontal), de acordo com a metodologia da OMS. Obteve-se um índice CPO-D de 15,73 para o grupo de estudo e 15,53 para o grupo-controle, não havendo diferença nos valores do indicador usado para cárie dentária entre os grupos. Quanto à doença periodontal, verificou-se que, no grupo de estudo, 17,0\% dos 
trabalhadores apresentavam cálculo, 60,0\% tinham bolsas de $4-5 \mathrm{~mm}$ de profundidade e $23,0 \%$ tinham bolsas de mais de $6 \mathrm{~mm}$. No grupo controle, a distribuição da amostra foi de $44,4 \%, 44,4 \%$ e $11,1 \%$, respectivamente. Os trabalhadores expostos a açúcares apresentaram níveis mais elevados de doença periodontal $(\mathrm{p}<0,0001)$, porém não de cárie.

Em Los Angeles, SPOLSKY et al (2.000) entrevistaram 240 imigrantes adultos de origem hispânica (mexicanos, centro - americanos e sul-americanos). Verificaram-se diferenças estatisticamente significativas nas médias do Oral Health Status Index - OHSI com variáveis demográficas (idade, educação, renda, e naturalidade), variáveis relativas aculturação (domínio do idioma inglês avaliando a capacidade de ler, falar e entender inglês) e com hábitos (consumo de álcool, controle mecânico do biofilme pela escovação e uso de fio dental). Tanto as variáveis demográficas quanto as variáveis clínicas para condições de saúde bucal (número de dentes cariados, perdidos e obturados, perda de inserção periodontal proximal) foram significativas, enquanto que as variáveis relativas a comportamentos não contribuíram para explicar o acúmulo de biofilme (Oral Health Status Index OHSI).

\section{FATORES GENÉTICOS}

A presença do biofilme bacteriano dental nos tecidos periodontais desencadeia uma resposta inflamatória. A exacerbação desta resposta pode estar sendo desencadeada pelo aporte de substâncias pró-inflamatórias. Muitas são as evidências de que as diferentes respostas entre hospedeiros aos agentes agressores são determinadas geneticamente, alterando marcadamente os níveis de extensão e progressão das doenças periodontais (MICHALOWICZ et al 1991a, MICHALOWICZ et al 1991b, HART e KORNMAN 1.997).

A herança genética, fator imutável, desempenha papel importante na doença periodontal. Determinados quadros periodontais, como as periodontites de estabelecimento precoce, a periodontite juvenil - PJ, e as periodontites refratárias e recorrentes, coincidem com distúrbios hereditários ou adquiridos principalmente no comportamento dos neutrófilos. (OLIVEIRA et al 1.997; ASSAF 1.999). 
Polimorfismos da interleucina-1 (IL-1), interleucina-1 $\beta$ (IL-1 $\beta$ ) e interleucina-1RN (IL-1RN) são genótipos que têm sido identificados como potenciais fatores de risco para destruição periodontal (MEISEL et al 2.002). Pacientes positivos para polimorfísmo na composição IL-1 $\alpha / \mathrm{Il}-1 \beta$ tiveram um risco aumentado de 2,7 vezes para doença periodontal e perda de dentes quando comparados a indivíduos negativos para estes polimorfismos (MC GUIRRE e NUMM 1.999).

Tem sido sugerido como possível fator de risco para a periodontite o polimorfismo no gene do fator de necrose tumoral- $\alpha$ (TNF- $\alpha$ ). Entretanto os estudos têm falhado em relacionar o polimorfismo deste gene com periodontite agressiva (SHAPIRA et al 2.001) e periodontite crônica (CRAANDIJK et al 2.002).

Um estudo recente em homens de meia idade demonstrou uma significativa associação entre o polimorfismo do receptor genotípico da vitamina D e perda óssea alveolar, perda de inserção clínica e perda de dentes (INAGAKI et al 2.003). HENNIG et al $^{128}, 2.003$ reiterou esta associação, entre este polimorfismo do receptor genotípico da vitamina $\mathrm{D}$ e a periodontite agressiva.

\section{CONDIÇÕES E ESTADOS DE SAÚDE GERAL}

\section{ALTERAÇÕES NUTRICIONAIS}

Estudos sobre dieta e doenças periodontais, baseados no conhecimento da patogênese da doença e, no papel do metabolismo ósseo na resposta inflamatória indicam que determinadas carências diminuem a habilidade dos tecidos periodontais no reparo.

CAMPOS et al (2.002) avaliaram o papel dos nutrientes na doença periodontal, e verificaram a interferência das vitaminas $A, C, D$ e dos minerais cálcio, fósforo, ferro e zinco na etiologia das doenças periodontais. A carência destes compostos pode afetar negativamente a instalação e progressão das doenças periodontais.

Considerando outros trabalhos verifica-se que o cálcio e a vitamina $\mathrm{C}$ são os nutrientes mais estudados.

NISHIDA et al (2.000b) nos Estados Unidos da América - EUA, em um estudo populacional com mais de 12 mil indivíduos verificaram que indivíduos de 
ambos os sexos, com idades entre 20 e 39 anos e nos homens de 40 a 59 anos de idade que ingeriram baixas quantidades de cálcio na dieta havia maior risco para as doenças periodontais. Este risco variou de 1,84 a 6,10\%.

NISHIDA et al (2.000a) e RUBINOFF (1.989) afirmam que a vitamina C tem um papel importante na manutenção da saúde gengival, e formas graves de avitaminose $\mathrm{C}$ podem causar escorbuto, além da carência desta vitamina aumentar o risco para as doenças periodontais entre os tabagistas e ex-tabagistas.

Obesidade e sobrepeso também parecem estar associados ao aumento do risco para as doenças periodontais uma vez que as citocinas pro inflamatórias e TNF produzidos pelos tecidos adiposos podem levar a um estado inflamatório crônico, aumentando o risco para estas doenças (GROSSI e HO 2.000; NISHIMURA e MURAYAMA 2.001).

\section{ALTERAÇÕES HORMONAIS}

DIABETES

A doença periodontal é um processo infeccioso que resulta em uma potente resposta inflamatória. Por ser uma entidade de caráter multifatorial diversos fatores de risco vêm sendo correlacionados, entre os quais a possível influência que a diabetes mellitus, doença metabólica que atinge grande parte da população mundial adulta, pode exercer sobre a incidência, prevalência e severidade da doença periodontal (SANTOS 1.998; DUARTE 2.000).

A diabetes apresenta 5 complicações clássicas que incluem microangiopatia, neuropatia, nefropatia, doença macrovascular a atraso na cicatrização das feridas. A doença periodontal tem sido conhecida como a $6^{a}$ complicação mais comum no paciente diabético, entretanto a Associação Americana de Diabetes tem levado em conta a periodontite como processo infeccioso que pode descompensar o paciente diabético.

Em estudos realizados desde a década de 60 vêm se observando um aumento na suscetibilidade, da prevalência e gravidade das doenças periodontais em pacientes com diabetes comparados aos indivíduos não diabéticos com irritação local similar (BELTING et al 1.964; DUARTE 2.000). 
Os mecanismos que parecem explicar a influência do diabetes nas doenças periodontais estão relacionados com a biofilme bacteriana, associada às altas concentrações de cálcio salivar e de glicose, à aderência, quimiotaxia e fagocitose dos polimorfonucleares neutrófilos - PMNN o que diminui a resistência às infecções, facilitando sua disseminação, alterações na resposta ao lipopolissacarídeo bacteriano, com produção exagerada de citocinas pró-inflamatórias que poderão levar a uma maior destruição do periodonto e a alterações na produção e síntese do colágeno (ALBANDAR 2.002).

Em grandes populações a diabetes do tipo 2 tem sido mostrada como um fator de risco significativo para a periodontite. A população de índios Pima do Arizona, que apresenta a maior taxa de diabete do tipo 2 do mundo, demonstrou uma maior de perda de inserção clínica e perda óssea alveolar nos diabéticos em relação aos não diabéticos, de aproximadamente 3 vezes maior, em todas as idades (EMRICH e al $1.991)$.

SELWITZ e al (1.998) examinaram 9.680 adultos dentados com idade de 30 a 90 anos, incluindo pessoas previamente diagnosticadas com diabetes mellitus tipo 2 e indivíduos que nunca tiveram esta condição diagnosticada. Após ajuste para outras condições os resultados mostram perda de inserção, profundidade de sulco à sondagem, recessão gengival e sangramento gengival sempre mais prevalentes no grupo dos diabéticos em relação aos não diabéticos. Da mesma forma, diabéticos apresentaram uma extensão significativamente maior de doença periodontal que os não diabéticos.

Em um estudo realizado em 1.998, SANTOS verificou que diabéticos com mau controle metabólico tiveram uma maior incidência de bolsas periodontais do que pacientes bem ou moderadamente controlados. O controle metabólico do diabético foi essencial para efetividade da terapia periodontal; observou-se ainda que a terapia periodontal reduziu as necessidades de administração de insulina pelo diabético ${ }^{(* 4)}$.

MONTEIRO e ARAÚJO (2.002) realizaram um estudo para avaliar a possível influência que o tempo de diagnóstico do diabetes mellitus teria sobre a severidade da doença periodontal. Assim, foi necessário avaliar os efeitos da redução do processo periodontal sobre os níveis glicêmicos de indivíduos portadores de diabettes mellitus tipo 2 , mediante o ensaio laboratorial da hemoglobina glicosilada. 
Para tanto, 54 indivíduos diabéticos tipo 2, metabolicamente controlados, assistidos pelo Centro de Diabetes da Bahia (CEDEBA), foram estratificados em dois grupos. O grupo I, formado por 28 diabéticos, diagnosticados a menos de 8 anos e, o grupo II, constituido por 26 indivíduos com no mínimo 8 anos de diagnóstico como diabético. Os dois grupos foram avaliados através de 5 parâmetros clínicos periodontais: índice de biofilme, presença de cálculo, sangramento à sondagem, profundidade de sondagem e nível de inserção clínica. A análise estatística dos dados clínicos coletados revelou um quadro clínico de destruição periodontal mais avançado nos indivíduos que constituíram o grupo II comparados aos do grupo I. (MONTEIRO e ARAÚJO 2.002).

Reiterando o apresentado DE LORENZO e DE LORENZO (2.002) ressaltam que a infecção periodontal parece comprometer o controle do diabetes.

BRITO e SEABRA (2.004) realizaram análise comparativa entre diabéticos e fumantes. Observaram que, apesar do diabetes ser apontada como fator de risco para o incremento da gravidade das doenças periodontais, nesse estudo em particular, comparativamente aos fumantes (grupo 2), a condição dos diabéticos (grupo 1) era melhor. As condições periodontais foram avaliadas pelo Índice Gengival, profundidade de sulco à sondagem e perda de inserção clínica. As piores condições, para os três parâmetros clínicos, estatisticamente significativos foram identificadas para os fumantes (grupo 2) em relação aos diabéticos (grupo 1) e em relação ao grupo não fumante e não diabético (grupo 3). As melhores condições foram observadas nos não diabéticos e não fumantes. Confirma-se neste estudo que tanto a diabetes quanto o hábito de fumar constituem fatores de risco para as doenças periodontais.

\footnotetext{
(4) Os antibióticos não devem ser usados como rotina no tratamento periodontal de pacientes diabéticos, mas podem ser administrados na presença de infecções e associados aos procedimentos periodontais invasivos com a finalidade de minimizar as complicações pós-operatórias. O mesmo pode ser dito no que refere ao uso de clorexedina como agente antibiofilme, que se mostrou efetivo como coadjuvante no tratamento periodontal destes pacientes (SANTOS 1.998)
} 


\section{PuBERDADE E ADOLESCÊNCIA}

A adolescência pode constituir um fator de risco para a doença periodontal, devido à permanência de sítios com profundidades de sulco aumentadas (RIBEIRAL 1.997).

Hábitos e costumes, relacionados ao comportamento, às relações psicossociais e à dieta certamente influenciam as alterações observadas no periodonto de adolescentes.

Fatores locais, que facilitem o acúmulo do biofilme ou dificultem a sua remoção, além de fatores anatômicos, determinados geneticamente ou por hábitos como conformação dos arcos dentários, posição dos dentes, quantidade de gengiva inserida, inserção de freios e bridas, hábitos parafuncionais, relacionados direta ou indiretamente a oclusopatias, ou até medidas terapêuticas, como o tratamento ortodôntico (RIBEIRAL 1.997) devem ser avaliados nos adolescentes na identificação precoce de alterações periodontais.

Não foram encontrados estudos que discutam a influência dos hormônios na adolescência e as doenças periodontais.

A condição periodontal e a presença das espécies $P$. gingivalis, $P$. nigrescens, T. denticola e A. actinomycetemcomitans, através do método do "slot immunoblot" em amostras salivares e de biofilme gengival, foram avaliadas em 50 indivíduos, divididos em adolescentes (grupo 1) e adultos jovens (grupo 2). A média do índice de biofilme do grupo 1 foi superior ao do segundo grupo, com diferença estatisticamente significativa. Quanto ao indice gengival todos os participantes apresentaram gengivite, sem diferença significativa entre os grupos. $\mathrm{Na}$ análise da gravidade da doença, prevaleceu o grau moderado, tanto para o índice de biofilme, representado por $76 \%$ dos indivíduos do grupo 1 e $96 \%$ do grupo 2 , como para o índice gengival representado por $100 \%$ dos indivíduos. A avaliação bacteriológica dos sítios subgengivais dos grupos 1 e 2 detectou a $P$. gingivalis em $32 \%$ dos indivíduos de ambos os grupos; a $P$. nigrescens em $80 \%$ e $88 \%$; o T. denticola em $12 \%$ e $24 \%$ e o A. actinomycetemcomitans em $72 \%$ e $80 \%$, respectivamente. Houve correlação significativa entre os patógenos e os parâmetros clínicos periodontais. Patógenos periodontais suspeitos foram identificados em adolescentes e 
adultos jovens, indicando que as faixas etárias analisadas podem ser o momento do estabelecimento de uma microbiota mais patogênica (AMORAS 2.001)

\section{GRAVIDEZ}

Durante a gravidez observa-se um aumento dos problemas periodontais muito provavelmente pelo aumento da freqüência de ingestão de alimentos e pela diminuição do controle mecânico de biofilme. Há também um aumento da proliferação de microrganismos, principalmente dos Bacteróides $s p$, por aumento do substrato fermentável relacionada aos dos hormônios femininos, abundantes neste período.

Há um aumento do risco para instalação e progressão das doenças periodontais neste período, constituindo um alerta para o aumento na vigilância e nos cuidados com a saúde bucal (GENCO 1.996, BRUNETTI 2.002).

\section{Menopausa, Ostepenia e Osteoporose}

A menopausa tem sido apontada como um fator de risco para a progressão das doenças periodontais, assim como outras alterações hormonais (TEZAL e al 2.000, CESCHIN 2.003).

Isto provavelmente se deva à diminuição da resposta imune, e perda de massa óssea.

A osteoporose é uma condição patológica relacionada à deficiência de estrógeno relacionada a sexo e idade, resultante de uma perda gradativa de conteúdo mineral dos ossos, a osteopenia, (GENCO et GROSSI 1.998). Esta condição pode aparecer principalmente nas mulheres aproximadamente 10 anos depois da menopausa e em alguns homens na andropausa. Há perda de massa óssea sistêmica, aumentando o risco de fraturas ósseas. Parece haver intima relação entre a diminuição dos níveis de estrogênio e a densidade óssea mineral

Considerando que a perda de osso alveolar é uma característica das periodontites a osteoporose grave poderia ser suspeita de levar a um agravamento nos casos de periodontite. Assim, pode-se considerar a osteoporose como forte indicador de risco para as doenças periodontais destrutivas. (JEFFCOAT e CHESNUT 1993, VON WORREN et al 1.994). 
VON WORREN et al (1.994) em um estudo comparativo entre 14 mulheres normais e 12 mulheres com fratura em decorrência de osteoporose verificou perda de inserção periodontal mais significativa nas mulheres com osteoporose

WACTAWSKI-WENDE et al (1.996) a partir de correlação entre altura da crista óssea alveolar e osteopenia demonstraram que a densidade óssea mineral do trocânter e do fềmur estava relacionada com a perda de inserção e perda óssea alveolar.

TEZAL et al (2.000) avaliando 70 mulheres pós-menopausa concluíram que a perda óssea sistêmica pode ser um indicador para destruição periodontal. Estes autores perceberam que a densidade óssea mineral está mais relacionada à perda óssea interproximal e menos à perda de inserção clínica.

Embora a doença periodontal seja uma doença localizada e a osteoporose uma condição sistêmica, ambas apresentam uma característica em comum, que consiste na perda óssea. Existe uma especulação de que pelo menos em parte a destruição periodontal pode ser influenciada por condições sistêmicas (WOLFF et al 1.994). Mas a extensão da relação entre as doenças periodontais e a osteoporose não está esclarecida.

Apesar de se identificar a possibilidade da osteopenia ser um fato de risco para as doenças periodontais há a necessidade de se realizar novos estudos, preferencialmente longitudinais para verificar se perda óssea esquelética e a densidade óssea mineral mandibular precedem o desenvolvimento das doenças periodontais.

\section{DOENÇAS AUTO - IMUNES}

O conhecimento atual da patogênese das doenças periodontais revela a importância que se deve atribuir a doenças ou estados de imunossupressão tanto na sua instalação quanto no seu agravamento.

Nas doenças de origem auto-imune desencadeia-se uma resposta dirigida a componentes teciduais normais.

Esta resposta resultante da produção de anticorpos voltados aos tecidos do hospedeiro pode funcionar como um agente direto de patogenicidade. Estes anticorpos podem também participar da agressão tecidual quando voltados à matriz 
extracelular. A recidiva de infecções gengivais facilita a ruptura da tolerância do organismo e permite a exposição dos antígenos do hospedeiro contra seus próprios tecidos. Há grande semelhança entre compostos microbianos e dos tecidos do hospedeiro o que pode facilitar a ação de linfócitos auto-reativos. Isto pode desencadear a contínua destruição do tecido conjuntivo gengival (GRENWALD e KIKWOOD 1.999, SILVA 2.004).

As doenças periodontais podem resultar de uma reação auto-imune local, mas deve-se considerar que indivíduos portadores de "defeitos em fagócitos" estão predispostos às DPD (GRENWALD e KIKWOOD 1.999, SILVA 2.004).

Alguns autores estudando o potencial imunológico dos tecidos gengivais chegaram a propor um indicador para avaliação do potencial imunológico desses tecidos, o índice de defesa imunológica gengival - (GUGELMIN et al 1.995). Este indicador está baseado na contagem simples de superficies gengivais e na presença e na quantidade de Imunoglobulina A - IgA

Indivíduos em estado ou condições, definitivas ou transitórias, de depressão da resposta imune devem receber orientações e cuidados periodontais permanentes. Entenda-se por condição definitiva de depressão da resposta imune as doenças auto imune crônicas, e condição transitória, o uso de medicamentos, estados emocionais ou de outra natureza que leve apenas temporariamente a uma diminuição da resposta imunológica.

\section{Distúrbios NEUROLÓgICOS E PSÍQuicos}

SOCRANSKY et al (1.984) afirmam que o número explosivo de hipóteses postuladas para as doenças periodontais tem estimulado pesquisas no sentido de que fatores do hospedeiro devem incrementar a probabilidade de falência do periodonto.

O próprio curso de distúrbios neurológicos e psíquicos, assim como os efeitos colaterais das drogas usadas no tratamento destas doenças parecem afetar a probabilidade de instalação e de desenvolvimento das doenças periodontais.

Drogas anticonvulsivantes como a fenitoína, nefedipina e a ciclosporina reduzem os níveis séricos de folatos e podem elevar a prevalência de hiperplasia gengival (Phenytoin-induced gingival enlargment- PIGE) em pacientes submetidos a estas drogas. 
MAJOLA et al (2.000) avaliaram 134 pacientes epiléticos da clínica Prince Mshiyeni Memorial Hospital, Durban, África do Sul, submetidos a tratamento com fenitoina. $\mathrm{O}$ acúmulo do biofilme, associado ao crescimento gengival induzido pela fenitoina, teve um efeito sinérgico sobre as doenças periodontais. Os consumos do tabaco e do álcool foram significativos, mas tiveram um efeito protetor em relação ao crescimento gengival induzido pela fenitoína. Quando idade, acúmulo de biofilme e não usar fenitoína foram considerados isoladamente não se verificou incremento da hiperplasia gengival, mas se tornam significativos estatisticamente quando combinados. A correlação entre os acúmulos de biofilme e PIGE sugerem que um efetivo e rigoroso controle do biofilme pode conter a hiperplasia gengival provocada pela fenitoina $(P I G E)$.

Fatores psicológicos influenciados pelo meio ambiente social também parecem alterar a susceptibilidade às doenças infecciosas, entre as quais estão as do periodonto.

Este conceito fomentou investigações na busca de associação entre fatores psicossociais e patologias periodontais (MARCENES e SHEIHAM 1.992, MOSS et al 1.996, VETTORE et al 2.002). Um dos primeiros trabalhos encontrados na literatura foi publicado em 1.976 por DE MARCO.

No Veterans Administration Hospital, em Cleveland, Ohio foram examinados 11 adultos jovens, veteranos da guerra do Vietnan, com idade entre 22 a 32 anos. Identificou-se grave perda de inserção óssea alveolar, e presença de bolsas periodontais com profundidade de 6 a $10 \mathrm{~mm}$, notadamente nos segmentos posteriores, sem que fatores locais justificassem a condição periodontal encontrada.

$\mathrm{O}$ único denominador comum entre os examinados era o grave estresse emocional associado aos serviços prestados no Vietnan. Sugeriu-se o nome de síndrome periodontal do estresse emocional - (periodontal emotional stress syndrome - PESS) a ser incluida como nomenclatura de classificação das doenças periodontais

O estresse é considerado uma resposta de ordem psicossocial do individuo frente a uma ameaça ou à percepção de mudanças. Esta resposta prepara o organismo adequadamente, mantendo a homeostasia, sendo essencial para a sobrevivência do indivíduo (KAPLAN 1.997, KAPLAN 1.998, KAPLAN 1.991, ASSAF 1.999). O 
estresse como outros distúrbios de comportamento pode alterar as defesas do hospedeiro, aumentando a vulnerabilidade às doenças associadas a mecanismos imunológicos, como infecção e doença autoimune (MONTEIRO DA SILVA et al 1.996)

Há dois modelos explicativos para a forma através da qual distúrbios ansiosos, estresse emocional e depressão podem influenciar a doença periodontal:

1. Modelo Biológico: o eixo hipotalâmico-pituitário adrenal promove a liberação de hormônios corticotrópicos pelo hipotálamo e, glicocorticóides pelo córtex adrenal, provocando a liberação de proteases e prostaglandina, deprimindo o sistema imune, e a resposta do hospedeiro frente à agressão.(LE RESCHE e DWORKING 2.002).

2. Modelo comportamental: alterações comportamentais que geram uma higiene bucal deficiente, mudanças de dieta e aumento do consumo de cigarros (GENCO et al 1.998, GENCO et al 1.999)

BENNATI et al (2.003) induziu destruição periodontal em ratos, administrou nicotina e dividiu os animais em 4 grupos: controle, estresse, nicotina, estresse e nicotina.

Os resultados demonstraram que somente o estresse não foi capaz de agravar a condição periodontal, mas associado à nicotina aumentava significativamente a destruição periodontal.

De modo geral os experimentos realizados em animais de laboratório evidenciam o efeito de diversos agentes estressores, principalmente no componente ósseo alveolar, sugerindo uma ação sistêmica do estresse (SOLIS et al 2.001).

VETTORE et al (2.002) procuraram identificar a relação de fatores psicossociais com a doença periodontal. Os estudos realizados abordaram diferentes doenças periodontais, bem como distintos fatores psicossociais, e tiveram considerável diversidade metodológica e amostral, permitindo diferentes conclusões.

Eventos estressantes têm demonstrado sua patogenicidade para as doenças periodontais e têm sido associados com o incremento da experiência de sintomas bucais tanto crônicos quanto agudos. 
Apesar disso as evidências científicas comprovam que fatores psicossociais são agentes predisponentes para a gengivite necrosante aguda, mas não são aceitos como fatores de risco para doenças periodontais destrutivas (VETTORE et al 2.002)

Mais estudos relacionando estresse e doenças periodontais são necessários, todavia sabe-se que há grandes dificuldades em quantificar e qualificar os níveis de estresse. Situações que são extremamente estressantes para um indivíduo, não o são para outros, modificando o curso do processo saúde doença periodontal.

Desde que o estresse foi relatado como doença associada ao local de trabalho e o estresse ocupacional pode ser quantificado pareceu apropriado investigar os efeitos do estresse ocupacional com o grau de saúde periodontal.

O estresse emocional foi medido por FREEMAN e GOSS (1.993) usando o Occupational Stress Indicator questionary - OSI - como preditor de risco para doenças periodontais, investigando 10 mulheres e 8 homens, com idade média de 39 anos, ocupando cargos importantes em uma grande companhia. Acompanhados por 12 meses, com avaliação periódica de suas condições clínicas, verificou-se por análise múltipla que houve incremento estatisticamente significativo das condições periodontais, sob as condições de estresse identificadas no grupo. Os autores reconhecem a necessidade de se realizar mais estudos onde possa se verificar a influência do estresse sob as condições periodontais.

Em 1.996, Freeman et al volta a publicar um artigo, divulgando os resultados de um novo estudo, agora realizado na Irlanda, onde foram examinadas 23 atendentes de consultório dentário, com 41,1 anos idade em média. Foram realizados dois exames com intervalo de 5,5 a 6 anos. Além do exame periodontal em quatro pontos, nas proximais de cada dente, foi também aplicado um questionário, respondido somente no segundo exame para avaliação retrospectiva de estresse ocupacional (LINDEN et al 1.996).

Houve um incremento da perda média de inserção periodontal entre os dois momentos de exame. Idade, menores scores no status sócio-econômico, baixa satisfação profissional e tipo de personalidade foram significativas à análise multivariada, podendo ser considerados preditores das doenças periodontais. Neste estudo os resultados da análise sugerem que o estresse ocupacional pode estar relacionado com a progressão das doenças periodontais. 
Ainda em 1.996, MOSS et al realizaram um estudo exploratório do tipo caso controle investigando fatores psicossociais e periodontite do adulto. Explorou-se a associação entre fatores sociais, tensões diárias e sintomas depressivos e doenças periodontais destrutivas em adultos. A partir de uma amostra inicial de 1.426 participantes foram identificados 71 casos e 77 controles. Identificou-se um risco três vezes maior $(\mathrm{OR}=2,847)$ para os que obtiveram valores mais altos que os seus semelhantes em medidas de tensão social. Também se identificou forte associação entre os niveis de anticorpos para Bacteroides forsytus, Porphyromonas gingivalis e Actinobacillus actinomycetencomitans, e níveis de depressão, principalmente nos casos de depressão moderada ou grave. O tabagismo foi significativo nos indivíduos "caso", que foram seguidos por um período de mais um ano; neste seguimento também se verificou aumento dos níveis de anticorpos para os microrganismos citados e o isolamento social foi o sinal de depressão mais evidente. Esse estudo exploratório foi importante para se identificar linhas de pesquisa no que se refere à investigação de fatores psicossociais como importantes no desenvolvimento das doenças periodontais destrutivas do adulto (MOSS et al 1.996).

Em um estudo caso controle, pareado por sexo e idade, com 100 indivíduos, verificou-se que, o impacto negativo de eventos da vida foi significativos no desenvolvimento das doenças periodontais, mesmo depois de ajustados por estado conjugal, biofilme e desemprego, que se também se mostraram significativas na análise bivariada. Os autores desse último estudo apontam que fatores psicossociais associados a comportamentos de risco quanto à saúde bucal são importantes determinantes das periodontites (CROUCHER et al 1.997)

AXTELIUS et al (1.998) hipotetizaram que desordens no sistema imune desencadeadas pelo estresse poderiam estar relacionadas à resistência à terapia periodontal. Foram comparados dois grupos de pacientes, casos e controles, que receberam tratamento periodontal, ambos formados por onze indivíduos. $\mathrm{O}$ grupo que respondeu bem ao tratamento periodontal tinha sofrido menor influência de fatores estressantes no passado. No grupo que teve resposta desfavorável à terapia periodontal identificou-se mais tensões psicossociais e indicadores de personalidade mais passiva e dependente. Os resultados parecem ser compreensíveis considerando as desordens que tensões provocam no sistema imune. O estudo realça a possível 
contribuição de fatores de tensão no contexto da resistência à terapia das doenças periodontais (AXTELIUS et al 1.998), devendo considerar situações de tensão no prognóstico das doenças periodontais.

GENCO et al (1.999) realizaram um estudo transversal com 1.426 indivíduos com idades entre 25 e 74 anos. Avaliou-se a relação entre estresse e doenças periodontais. Foram aplicados 5 questionários de avaliação psicossocial, com 130 perguntas abordando aspectos culturais, sócio-econômicos e psicossociais, propriamente ditos, para dimensionar características psicológicas e atitudes que incluem discretos eventos de vida e o impacto deles; avaliou-se estresse crônico ou tensões diárias; distress ${ }^{*}{ }^{(5)}$ ou angústia, estresse e comportamento adaptativo, estilos ou modos de reagir, desagrados e exaltações. A avaliação clínica foi feita identificando-se biofilme supragengival, cálculo subgengival, profundidade de bolsas à sondagem, nivel de inserção clínica, exame radiográfico, altura de crista ósseo alveolar, e 8 bactérias da flora subgengival. De interesse considerável é o fato de que comportamentos adaptativos, com comprovados níveis de contenção de problemas, podem reduzir o risco associado à tensão. Entretanto é preciso que estudos adicionais ajudem a estabelecer o curso de tempo de tensão, angústia e contenção de problemas com respeito ao começo e progressão de doença periodontal e os mecanismos que explicam esta associação (GENCO et al 1.999).

O estresse leva a um descuido com a higiene bucal, mudanças na dieta, aumento do consumo de tabaco, alteração da circulação sangüinea periférica, mudanças na saliva, desequilibrios endócrinos e diminuição da resistência do hospedeiro (GENCO et al 1.995).

Medir estresse é uma tarefa difícil (SOLIS et al 2.001, VETTORE et al 2.002). Os estudos abordam diferentes doenças periodontais, distintos fatores psicossociais e com grande variedade metodológica, correlacionam parâmetros clínicos periodontais com instrumentos de avaliação psicométricas (escalas de auto avaliação). Estes instrumentos nem sempre são adequados para se realizar um diagnóstico psiquiátrico, mostrando apenas a presença ou ausência de sintomas psíquicos.

ग(5) distress estado emocional relacionado à aflição, à tormenta, à angústia e à pobreza. (GENCO et al 
1.999). Em publicações de saúde mental é usual se aplicar a expressão stress referindo-se a distress

Apesar da falta de um diagnóstico mais operacional, os resultados dessas pesquisas podem ser entendidos pela associação existente entre estresse e diminuição da função imunológica (SOLIS et al 2.001; VETTORE et al 2.002).

No momento a escassez de avaliações longitudinais faz com que o estresse crônico associado a estas tensões seja um indicador de risco importante para doenças periodontais e não um fator de risco real. Assim, como o apontado por GENCO (1.996) e GENCO et al (1.999) novos estudos devem ajudar a compreender o papel do estresse e de outros distúrbios de comportamento na progressão das doenças periodontais

\section{HÁBITOS E COSTUMES}

\section{CONSUMO DE TABACO}

O uso do tabaco e a influência do hábito de fumar no desenvolvimento das doenças periodontais, alvo de interesse desde a década de 80 , foram um assunto controvertido por muito tempo.

Tem sido relacionado como fator de risco para ocorrência e progressão da doença periodontal, (ISMAIL et al 1.983; SALLUM et al 1.993; PAGE e BECK 1.997), mas somente nos últimos anos esta relação se estabeleceu de forma mais segura.

Estudos da década de 70 e 80 citados por SALLUM et al (1.993) demonstraram a importância do tabaco como fator predisponente ou interferente na patogenia periodontal. O uso do tabaco refletiu no aumento dos índices de depósitos dentários e de sangramento gengival, na qualidade do biofilme e na perda de inserção óssea e ligamentar, refletindo em aumento da profundidade de sulco à sondagem periodontal (BASTIAN e WAITE 1.978, FELDMAN 1.983, BERGSTRÖN e ELIASSON 1.987b, BERGSTRÖN e ELIASSON 1.987a, BERGSTRÖN 1.989 , GASPARINI 1998).

GOLDHABER e GIDDON (1.964)estudando gengivite ulcero necrosante e DINI e GUIMARAES aplicando o CPITN (1.995) em mais de 300 indivíduos demonstraram uma correlação positiva entre o número de cigarros fumados e os 
efeitos danosos à saúde periodontal, efeito dose resposta também verificado por GROSSI et al (1.994).

JOHNSON (1.999) verificou que o hábito de fumar pode ser responsável por metade dos casos de doença periodontal nos Estados Unidos da América - EUA. O autor afirma que o tabaco aumenta em 4 vezes o risco para as doenças periodontais; e que após 11 anos de cessação do hábito o risco é quase o mesmo que em não fumantes.

Segundo BERGSTRÖN et al (2.000) indivíduos que fumam menos de meio maço de cigarros por dia, menos de 10 cigarros (fumante leves) apresentavam um risco 4 vezes maior para as doenças periodontais em relação aos não fumantes, e os que fumavam de um maço a um maço e meio por dia (fumantes pesados), passavam a apresentar um risco seis vezes maior.

Segundo GENCO (1.996) e Genco RJ et al (1.998) o tabaco reduz a liberação de oxigênio e nutrientes para os tecidos gengivais, além dos efeitos sobre gestantes e parto prematuro e bebês de baixo peso ao nascer, aumento de incidência de problemas cardíacos e respiratórios, limitação do controle do diabetes.

TOMAR e ASMA utilizaram os dados de um estudo populacional (NHANES III - National Health and Nutrition Examination Survey) com 12.329 pessoas e verificaram que após ajuste para idade sexo, raça/etnia, educação e condição sócio econômica havia um aumento do risco para as doenças periodontais igual a 4,0 para os fumantes, e igual a 1,7 vezes para os ex-fumantes.

Em revista de literatura realizada por BARBOUR et al 1.997 afirma-se que o tabaco modifica a resposta do hospedeiro e tem impacto na saúde periodontal. Sumariza-se nessa publicação os efeitos do tabaco e dos produtos de sua combustão sobre as células e o sistema imune, conhecidos nos últimos dez anos. A interferência no funcionamento celular e na composição de substâncias, imprescindiveis para a defesa do hospedeiro é a base da ação do tabaco com ou sem combustão.

O tabaco também tem sido apontado como importante no prognóstico dos tratamentos periodontais e nas cirurgias para colocação implantes dentários.

NOGUEIRA FILHO et al (1.997) apontaram a necessidade de mais estudos sobre o papel do fumo como fator de risco para as doenças periodontais, as 
implicações no pós-operatório de cirurgias periodontais e implantes, e as associações do consumo de drogas como a maconha e o "crack", pelo paciente com periodonto comprometido.

LEONEL e TOMITA (1.999) rediscutiram os efeitos do fumo sobre a doença periodontal, seus efeitos sobre a resposta do hospedeiro e sobre o resultado do tratamento periodontal. Em torno de $30 \%$ dos pacientes adultos são fumantes, de forma que os dentistas envolvidos em tratamentos periodontais devem considerar o hábito, discutindo com eles os aspectos clínicos de tratamento e diagnóstico. A reparação do tecido ósseo requer uma boa circulação.

Nos trabalhos que analisaram a influência e o papel do fumo na DPD, no aumento da probabilidade de falhas em implantes dentais endósseos, encontrou-se uma percentagem maior desses problemas, com taxas nos usuários muitas vezes superiores a 25 por cento (máximo aceitável de acordo como a literatura). Isso ocorreu principalmente na região da maxila, com implantes curtos (7 $\mathrm{mm})$ e osso de qualidade tipo IV. Também é importante a constatação de que o abandono do hábito, mesmo que por curto tempo, aumenta significativamente o índice de sucesso nos implantes (LINDEN et al 1.999).

CORTELLI et al (2.001) realizaram um estudo para identificar a relação entre parâmetros clínicos, fumo e presença de Actinobacillus Actinomycetemcomitans em indivíduos com periodontite crônica.

Avaliou-se a correlação entre profundidade de sond . em (PS), Índice de Placa Bacteriana (IPI), Índice Gengival (IG), hábito de fumar e presença de $A$. actinomycetemcomitans em 87 indivíduos com periodontite crônica apresentando lesões moderadas a avançadas. Os resultados analisados pelo teste Qui-quadrado demonstraram associação entre PS e presença de Actinobacillus Actinomycetemcomitans, mas não houve associação entre fumo e presença desse microrganismo. Os valores médios de IPI e IG analisados pelo teste ANOVA não demonstraram associação com a presença do microrganismo. Indivíduos com periodontite crônica demonstram freqüentemente uma ocorrência de 10 a $50 \%$ dos casos de Actinobacillus Actinomycetemcomitans. Em razão do número elevado de fatores e virulência produzidos por Actinobacillus Actinomycetemcomitans, sugere-se 
uma maior prevalência e severidade da doença em sítios periodontais expostos a este patógeno (CORTELLI et al 2.001).

Segundo MARTINELLI et al (1.999), um maior número de sítios com profundidade de sondagem aumentada, maiores perdas de inserção periodontal e maiores perdas ósseas radiográficas foram encontradas em pacientes fumantes em comparação aos não - fumantes, independente dos níveis de controle de biofilme dentária.

O fumo é considerado importante fator predisponente para muitas doenças, incluindo-se as periodontopatias, uma vez que as doenças periodontais representam a inter-relação entre os fatores de virulência da microbiota subgengival sobre um hospedeiro susceptível (JARDIM JÚNIOR et al 1.998).

A freqüência de isolamento de três periodontopatógenos em indivíduos sadios e pacientes com doença periodontal, fumantes ou não, foi avaliada em pacientes com níveis variados de higiene bucal. Foram examinados 189 pacientes indivíduos sadios, dos quais 60 foram selecionados para análise microbiológica. Verificou-se que a freqüência de isolamento dos bastonetes anaeróbios produtores de pigmento negro, Fusobacterium nucleatum e bactérias produtoras de sulfeto de hidrogênio foi similar entre fumantes e não fumantes sendo mais elevada nos pacientes com doença periodontal. Já o Actinobacillus actinomycetemcomitans foi isolado mais freqüentemente em sadios fumantes do que sadios não fumantes (JARDIM JÚNIOR et al 1.998).

Segundo KENNEY (1.977) e GASPARINI (1.998), a diminuição do potencial de oxiredução na boca provocada pelo fumo pode favorecer o aumento da microbiota anaeróbica.

CORTELLI et al (2.001) examinando 87 indivíduos com periodontite crônica e com lesões moderadas e avançadas verificaram, a partir da avaliação do hábito de fumar, da profundidade de sulco à sondagem, do índice de biofilme e gengival que houve associação positiva entre a profundidade de sulco à sondagem e a presença de Actinibacillus actinomycetencomitans, e associação negativa entre o fumo e a presença deste microorganismo.

O impacto desfavorável do tabagismo, estatisticamente demonstrado em Saúde Pública, tem sido documentado em centenas de estudos epidemiológicos. No 
âmbito da saúde bucal, isto pode ser avaliado na evolução da doença periodontal, pela associação de casos avançados de periodontite em pacientes fumantes.

GOLDHABER e GIDDON (1.964), CLARKE et alli (1.981) citados por SALLUM et al (1.993) e LEONEL e TOMITA (1.999) verificaram que a nicotina leva a alterações circulatórias porque promove a liberação de epinefrina, aumenta sua concentração sangüinea, eleva a pressão, baixa a temperatura da pele, aumenta a pulsação e induz a vasoconstrição periférica.

Estes efeitos foram confirmados por LOESCHE (1.982) em um estudo de com gengivite úlcero necrosante aguda - $\operatorname{GUNA}^{*(6)}$ onde se demonstrou que o estresse emocional aumenta o consumo de tabaco com conseqüente aumento da liberação de epinefrina, hormônio corticoesteróide. Há vasoconstrição sistêmica, diminuição da oxigenação tecidual, redução do fluxo sangüíneo e interferência na cicatrização pós-cirúrgica (LEONEL e TOMITA 1999)

CLARKE e CAREY (1.985) encontraram importante redução do fluxo sangüíneo na crista gengival de humanos. Esta redução não se verificou de forma significativa em um estudo de BAAB (1.986). De forma geral o tabagismo inicia um ciclo de enfraquecimento da resposta imune, diminuindo o número de linfócitos $\mathrm{T}$ auxiliares, importantes para a célula B; reduz a concentração sérica de imunoglobulinas - IgM, IgA e IgG (JOHNSON 1.999, GASPARINI 1.998). Isto favorece o estabelecimento de uma microbiota subgengival anaeróbia, aumentando a citotoxicidade, a gravidade da doença e prejudicando a reparação tecidual (LINDEN et al 1.999). Segundo RAULIN et al (1.987) o tabaco afeta a capacidade de adesão dos fibroblastos gengivais na superficie radicular, o que justificaria o prejuízo na reparação tecidual, particularmente na migração, quimiotaxia e fagocitose de bactérias por parte dos leucócitos polimorfonucleares neutrófilos (PMNN) ${ }^{*}(7)$ além de degranulação de mastócitos (GASPARINI1 1.998, LEONEL e TOMITA 1.999 , HABER 1.994, MARTINELLI et al 1.999).

\footnotetext{
${ }^{*}$ (6) As abreviações GUN (gengivite ulcero necrosante) ou GNA (gengivite necrosante aguda) foram preconizadas pela American Periodontology Academy para designar o que se conheceu por muitos anos como GUNA - Gengivite ulcero necrosante aguda.

${ }^{\cdot(7)}$ Estes efeitos se devem principalmente a componentes da fase gasosa acroleína e cianeto
} 
O hábito de fumar age sobre o periodonto diminuindo a vascularização e alterando a resposta inflamatória e imunológica, por diminuição em torno de 50,0\% da função leucocitária, (KENNEY et alli 1.977, LEONEL e TOMITA 1.999).

BERGSTRÖN et al (1.991), HOLM (1.994) reiteraram os efeitos nocivos do hábito de fumar sobre o periodonto e apontam também as perdas dentárias.

Em um estudo, em Porto Alegre, com militares, soldados e cabos, NUNES e SLAVUTZKY (1.992) não se comprovaram que exista correlação entre o número de cigarros fumados por dia com a condição periodontal, ou com o fato de ser ou não tabagista. Neste estudo, de NUNES e SLAVUTZKY (1.992), assim como achados de GOUTSCHIN (1.990) não comprovaram a diminuição do sangramento na crista gengival por redução da circulação sangüínea, de 2 a 3 horas após fumar como afirmaram MARTINELLI et al (1.999), CLARK e CAREY (1.985), mas a condição periodontal estava mais relacionada à idade e ao tempo que o paciente não recebia tratamento periodontal.

A associação entre o tipo de fumo e os índices de doença periodontal foi avaliada por FELDMAN et al (1.983) em um estudo transversal. Nesse estudo salienta-se que o fumo do cachimbo difere do fumo do cigarro em $\mathrm{pH}$, freqüência de uso e presumivelmente pela via de absorção. A perda de inserção óssea foi significativamente maior em fumantes de cigarro do que em nos fumantes de cachimbo e charuto e os não fumantes

Estes resultados foram confirmados em um estudo de coorte, com seguimento por 20 anos e constam do relatório publicado em 1.999, pela American Periodntology Academy (JONHSON 1.999).

Há muitas evidências sobre os efeitos deletérios do tabaco sobre a saúde bucal, constituindo o maior fator de risco para as doenças periodontais conhecido na atualidade. Profissionais de saúde bucal devem socializar as informações sobre os efeitos nocivos do tabaco sobre os tecidos periodontais, assim como sua interferência negativa na terapia da doença periodontal, na tentativa de levar à supressão do hábito de fumar (CHAIM et al 1.998; MARTINELLI et al 1.999). 


\section{CONSUMO DE ÁlCOOL}

O álcool (etanol) é consumido moderadamente pela maioria das pessoas dados a seus efeitos relaxantes e de descontração (FRIEDLANDER et al 2.003).

O álcool exerce efeito sobre o sistema imunológico e certamente deve haver repercussão nas condições periodontais, mas, os estudos envolvendo álcool e doenças periodontais são muito esparsos (PITIPHAT et al 2.003).

A relação entre doenças bucais e sistêmicas tem sido descrita em estudos com humanos e animais. Entretanto há poucas informações na literatura odontológica descrevendo e sumarizando os efeitos do consumo crônico de álcool sobre os tecidos da cavidade bucal (LARATO 1.972).

Há uma série de explicações plausíveis para os efeitos do álcool sobre o risco de desenvolvimento de periodontites. Muitos estudos demonstram haver prejuizos na coagulação, no que se refere à protrombina e à vitamina $\mathrm{K}$, nos mecanismos de defesa relacionados ao sistema complemento e à capacidade de fagocitose dos neutrófilos, macrófagos e na função das células $\mathrm{T}$, incrementando a probabilidade de infecções, inclusive as periodontais (FRIEDLANDER et al 2.003; PITIPHAT et al 2.003, TEZAL et al 2.004).

Verificam-se, ainda, alterações no metabolismo ósseo, com aumento da reabsorção e diminuição da formação deste tecido, alterações metabólicas relacionadas ao complexo $\mathrm{B}$ e na síntese de proteínas, além dos efeitos tóxicos do álcool diretamente sobre os tecidos periodontais (FRIEDLANDER et al 2.003, PITIPHAT et al 2.003, TEZAL et al 2.4).

O consumo moderado de álcool reduz a função dos monócitos na produção de citoquinas, como o Fator de Necrose Tumoral alfa - TNF $\alpha$, interleucinas IL-1 e IL-6, o que pode aumentar a proliferação bacteriana. Entretanto quando o consumo de álcool é grande, demonstrou-se que a liberação dessas substâncias pelos monócitos no fluido crevicular está associada com a presença de periodontite.

Na Dinamarca, em 1.981, MOVIN em estudo caso-controle avaliou a relação entre doenças periodontais e cirrose hepática, em pacientes com idades entre 35 e 64 anos. Foram 30 pacientes "caso", entrevistados e examinados com diagnóstico conclusivo de cirrose hepática, e 45 pacientes "controle". 
Não se verificou correlação entre perda de inserção e perda dentária, assim como também não se verificou correlação entre perda de inserção e idade, em ambos os grupos, casos e controles.

Verificou-se que nos pacientes, com história de doença hepática há mais de 3 anos, a perda de inserção óssea alveolar e a quantidade de depósitos dentários eram maiores, quando os resultados foram avaliados segundo grupo etário e tempo de duração da doença hepática. Estes resultados sugerem que quando a doença hepática se agrava, as condições periodontais pioram, por influência da negligência com a boca e os dentes.

Assim como MOVIN (1.981), SANDLER e STAHL (1.960) citados por PITIPHAT et al (2.003) observaram o incremento da prevalência e da gravidade das doenças periodontais em pacientes com cirrose hepática e as atribuíram à higiene bucal precária. Outros estudos reportaram piora das condições periodontais em pacientes alcoolistas, com e sem cirrose hepática, em relação a pacientes saudáveis (DUNKLEY e CARSON (1.968), NOVACEK et al (1.995), citados por PITIPHAT et al 2.003).

Houve significância estatística entre consumo de álcool e doenças periodontais em trabalhadores japoneses da indústria, apenas na análise bivariada (SHIZUKUISHI et al 1.998).

As dificuldades apontadas em alguns trabalhos publicados residem em obter informações fidedignas sobre a história atual e pregressa de consumo de álcool, tanto a respeito da quantidade, da freqüência e dos tipos de bebidas consumidas, assim como na diminuição do autocuidado e da auto-estima, alterações psicoemocionais com difícil definição do momento que se iniciou uma ou outra trazidas pelo uso do álcool ou em conseqüência do uso deste.

Em 1.990, KRANZLER, BABOR e GOLDSTEIN procuraram estabelecer relações entre o consumo de álcool e processos patológicos em saúde bucal, particularmente com perdas dentárias. Realizou-se um estudo exploratório usando-se entrevista estruturada (WHO Composite Diagnostic Instrument) e questionário, para obtenção de dados sobre o consumo de álcool por dia, em um mês típico, assim como quantos dias o indivíduo haveria consumido álcool naquele mês, problemas advindos do consumo de álcool, comportamentais e de intoxicação, além de questões sobre e 
fatores de risco para o alcoolismo. Também foram avaliadas as condições de saúde bucal. A relação entre as perdas dentárias e o consumo prejudicial de álcool foi evidente nos individuos do sexo masculino com história de problemas de conduta. Os resultados demonstraram que tanto perdas dentárias, cárie dentária, quanto doenças periodontais apresentaram correlação significativa com os indicadores de consumo de álcool relatados. Estas evidências foram maiores em homens do que em mulheres, consistentes com algumas conseqüências identificadas em estudos médicos. Diante dos resultados apontou-se para a necessidade de estudos analíticos sobre consumo de álcool e problemas de saúde bucal.

Pesquisas subseqüentes devem beneficiar focalmente este grupo de alto risco.

Em 2.004, COPELAND et al publicaram os resultados de um estudo prospectivo de 10 anos, onde avaliaram a perda dentária em dois grupos populacionais: um em Baltimore, composto por 47 homens e 47 mulheres, com idades dentre 30 e 69 anos, e outro em Boston, composto por 481 veteranos, na mesma faixa etária do grupo anteriormente citado.

No primeiro grupo foram relacionados, a partir da experiência de cárie e doenças periodontais, idade, sexo, consumo de álcool e de tabaco com a predição de risco para perdas dentárias. No segundo, se relacionaram a mesmas variáveis; excluiu-se apenas a variável sexo. As condições periodontais foram medidas pela profundidade de bolsa à sondagem e sangramento gengival.

O consumo de álcool se mostrou significativo no modelo final, para ambos os grupos. A ingestão de dois ou mais drinques por dia demonstrou incrementar a perda dentária no grupo de veteranos. O mesmo consumo, no grupo de Baltimore, diminuía esta perda. Este resultado não se modificou quando o uso do tabaco foi incluído no modelo. Analisando-se separadamente os homens no grupo de Baltimore, observouse a associação entre a perda dentária e o consumo de dois drinques diários.

Em um estudo transversal com índios Navajos, adolescentes de 14 a 19 anos de idade, onde se procurou identificar os efeitos do tabaco e do álcool no aparecimento de leucoplasias e de problemas periodontais verificou-se que os indivíduos que consumiam álcool fumavam mais do que os que não consumiam álcool. A freqüência do consumo de álcool era inferior a uma vez por semana. Neste 
estudo não se verificou associação entre o uso dessas substâncias e os problemas periodontais (WOLFE e CARLOS 1.987).

PITIPHAT et al (2.003) acompanharam por 12 anos, uma coorte de 39.461 homens, profissionais de saúde, com idades entre 40 e 75 anos, sem periodontite no início do seguimento, em 1.986, e desfecho em 1.998

A ingestão de álcool foi avaliada a cada quatro anos através de um questionário de freqüência alimentar e as condições periodontais, validadas por exame radiográfico. Realizou-se análise multivariada, ajustada pela idade, hábito de fumar, diabete, índice de massa corpórea, atividade fisica, quantidade de calorias ingeridas. Durante o estudo, verificou-se o aparecimento de 2.125 casos de periodontite.

Verificou-se um risco relativo que variou com a quantidade de álcool ingerida por dia. Esta quantidade de álcool foi medida em gramas de álcool absoluto, comparando-se os indivíduos que ingeriam álcool e os que não ingeriam.

Para uma ingestão de 1,0 a 4,9 gramas álcool por dia o risco relativo foi de 1,24; para uma ingestão de 5,0 a 14,9 gramas de álcool por dia, o risco relativo foi de 1,18; quando a ingestão era de 15,0 a 29,9 gramas por dia o risco se manteve em 1,18; para uma ingestão igual ou maior que 30 gramas por dia, o risco chegou a 1,27.

Os resultados sugeriram que o consumo de álcool é um fator de risco modificador independente para periodontites.

TEZAL, GROSSI, HO e GENCO (2.004) durante o Third National Health and Nutrition Examination Survey - NHANES III, em uma amostra de 13.198 indivíduos de ambos os sexos, com 20 ou mais anos de idade, e com no mínimo 6 dentes naturais investigaram o consumo de álcool e sua influência na saúde bucal, particularmente nas doenças periodontais. O nível de inserção clínica e perda de inserção periodontal foram avaliados após ajuste pela idade, sexo, raça, escolaridade, renda, hábito de fumar, sangramento gengival e número de dentes remanescentes, independentemente do consumo de álcool.

$\mathrm{Na}$ análise de regressão verificou-se associação significativa entre o consumo de álcool semanal e a perda de inserção. O risco de perda de inserção (odds ratio) variou de 1,22 a 1,67, de acordo com número de drinques consumidos semanalmente (quantidade de álcool absoluto consumida), sendo de 1,22 para 5 drinques por 
semana, 1,39 para 10 drinques, 1,54 para 15 drinques e 1,67 para 20 drinques por semana.

Verificou-se uma moderada, mas consistente relação entre doses de álcool consumidas e doença periodontal. Não se verificou interação entre as quantidades de tabaco consumidas e uso de álcool.

SAKKI et al (1.995) avaliaram a associação entre modo de vida e doenças periodontais em 527 cidadãos finlandeses, dentados, com idade em torno de 55 anos. Reiterou-se que as condições periodontais eram mais graves no sexo masculino. A associação entre as variáveis sócio-econômicas e as doenças periodontais não foi significativa. As variáveis mais significativas no modelo múltiplo foram hábitos dietéticos, hábito de fumar, consumo de álcool e freqüência de escovação, excluindo sexo e variáveis sócio-econômicas.

Quando a variável sexo e variáveis sócio-econômicas eram incluídas na análise, o modelo tornava-se melhor, aumentando a significância.

\section{CONDIÇÕES CLÍNICAS EM SAÚDE BUCAL}

Uso de prótese, mobilidade dental, experiência de cárie, seqüelas de doença periodontal presença de bolsas periodontais e características anatômicas devem ser considerada na avaliação de risco e do prognóstico das doenças periodontais

\section{USO DE PRÓTESE}

Dentre as variáveis clínicas referidas na literatura, a mais polêmica tem sido o uso de próteses.

Autores diversos têm observado ao longo dos anos, que os processos destrutivos nos dentes e no periodonto de proteção e sustentação, de pacientes que usam Prótese Parcial Removível - PPR é mais elevado nos dentes que exercem a função de retentores da prótese. A prótese aumenta a retenção de biofilme em relação aos dentes naturais. Verificou-se também que a mau controle mecânico do biofilme dos dentes e das próteses agrava esses problemas.

DINI (1.995) estudou a associação entre o uso de prótese dental, índice de biofilme e condições periodontais, em população de trabalhadores de Usinas de Açúcar e Álcool de Araraquara, SP. 
Uma amostra de 528 trabalhadores com idades entre 18 e 64 anos, foi examinada por uma única examinadora, previamente calibrada, usando o CPITN. Os dados sobre uso de prótese dental (fixa e/ou removível) foram obtidos por exame clínico e o índice de biofilme de acordo com os critérios de Löe e Silness.

Os resultados mostraram associação estatisticamente significativa $(p<0,005)$ entre o uso de prótese dental e a presença de bolsas periodontais, com um risco de $4,95$ (odds ratio $=O R=4,95)$. Houve associação estatisticamente significativa $(\mathrm{p}<0,005)$ entre indice de biofilme e bolsas periodontais, com um risco de 21,58 (odds ratio $=O R=21,58)$.

Quando a variável índice de placa foi controlada o risco (odds ratio $=O R$ ) dos usuários de prótese apresentarem uma ou mais bolsas periodontais foi de 5,30.

ASCKAR et al (1.999) avaliaram as estruturas de suporte das próteses parciais removíveis - PPR de 38 pacientes acompanhados profissionalmente durante dois anos, através de reconsultas de 3 em 3 meses, para um programa de acompanhamento e preservação da saúde. Cada um dos indivíduos preencheu um questionário e um diário de ingestão alimentar. Avaliou-se a capacidade tampão e pH da saliva, submetendo-se a um exame bucal inicial, sendo a seguir, classificados quanto ao risco para a cárie. Após dois anos, com dados de novo exame bucal, encontrou-se diferença estatisticamente significativa para os índices de biofilme e mobilidade entre os dentes controle, retentores primários e secundários. $\mathrm{O}$ sangramento gengival não se mostrou significativo. O índice de biofilme foi reduzido em todos os dentes provavelmente devido ao programa de reconsultas. Nenhum dos dentes controle apresentou mobilidade, enquanto que $99,0 \%$ dos retentores secundários e 90,0\% dos primários apresentaram esta condição.

LELES et al (1.999) realizaram uma avaliação clínica do efeito do uso de próteses parciais removíveis - PPR sobre a condição dental e periodontal em 30 pacientes da Faculdade de Odontologia da Universidade Federal de Goiás, adultos com média de idade igual a 42 anos. Eram 25 mulheres e 5 homens. O tempo de uso destas PPR variou de 5 a 30 anos e não foi encontrada associação entre o tempo de uso das PPR e os índices de biofilme, a profundidade do sulco à sondagem e a mobilidade dental. Verificou-se presença de sangramento, cárie e cálculo, sendo que houve diferenças significativas nestas condições clínicas entre dentes retentores e 
controles. A restauração de áreas proximais e não apenas as PPR representam grande problema para o periodonto.

Próteses fixas unitárias e múltiplas também podem interferir na instalação e desenvolvimento das doenças periodontais. Sobre contornos e fechamento de espaços interdentários podem ser feitos desde que não dificultem o controle mecânico do biofilme dental. Alguns autores preconizam a confecção de ameias amplas e a modificação da curvatura das superficies proximais independente de questões estéticas que nem sempre podem ser priorizadas. Deve-se estabelecer um correto perfil de emergência para facilitar a limpeza intra-sulcular, além de criar superficies proximais suficientemente planas ou mesmo côncavas, no sentido oclusoapical que permitam o uso de escovas interdentais, principalmente nos dentes posteriores (BRUNETTI e PAGANI 1.987; TRISTÃO et al 1.989). 


\section{OBJETIVOS}

\subsection{OBJETIVo Geral}

Identificar fatores associados ao risco para Doenças Periodontais DestrutivasDPD na população adulta, de 25 a 55 anos de idade, cadastrada e usuária dos serviços públicos de saúde de um Programa de Saúde da Família - PSF instalado na zona leste da capital paulista, o PSF Santa Marcelina.

\subsection{OBJETIVOS ESPECÍFICOS}

Pretende-se na população adulta, de 25 a 55 anos de idade, usuária dos serviços de saúde do PSF Santa Marcelina:

1. Conhecer o risco associado ás DPD e as variáveis sócio-demográficas;

2. Conhecer o risco associado ás DPD e as condições sistêmicas como diabetes, distúrbios neurológicos ou psíquicos e doenças ou estados imunodepressores;

3. Conhecer o risco associado ás DPD e os hábitos como o consumo do tabaco e do álcool;

4. Conhecer o risco associado ás DPD e as variáveis clínicas como presença de cárie, coronária e radicular, uso de próteses e presença de biofilme. 


\section{MATERIAL E MÉTODO}

\subsection{Local do Estudo - PSF SANTA MARcelina}

Esta pesquisa científica se desenvolveu na zona leste da cidade de São Paulo, junto aos serviços de saúde do Qualis Santa Marcelina, instituição administrada pela Congregação das Marcelinas ${ }^{*}(8)$, hoje denominado PSF Santa Marcelina.

No Brasil, desde a década de 70 , muitas iniciativas para desenvolver e integrar ações de saúde e alcançar populações que concentravam grandes carências sociais e apresentavam os piores indicadores epidemiológicos, foram se somando, até que em novembro de 1.993, em um encontro de técnicos do Ministério da Saúde MS e especialistas com grande experiência na organização das ações e de serviços de saúde, elaboraram um documento onde foram apresentados alguns dos princípios e diretrizes de um programa que deveria, a partir de uma área geográfica delimitada, o território, identificar as condições de vida a que as pessoas desta área estavam submetidas, favorecendo ou não a instalação de agravos à saúde. Este programa ficou conhecido como Programa de Saúde da Família - PSF (MINISTĖRIO DA SAÚDE 1994).

O documento final daquele encontro foi publicado em setembro de $1.994 \mathrm{com}$ a finalidade de subsidiar a implantação do PSF em âmbito nacional (MINISTÈRIO DA SAÚDE 1994).

Em novembro de 1.995 a Secretaria da Saúde do governo do Estado de São Paulo - SES-SP, em consonância com o Ministério da Saúde - MS e a Casa de Saúde Santa Marcelina oficializaram um contrato que permitiu a implementação do PSF na capital paulista, em algumas unidades de saúde da rede estadual de serviços da zona leste, que foi denominado Qualis Santa Marcelina ${ }^{*}(9)$.

Contrataram-se inicialmente profissionais para compor as equipes "nucleares" de saúde da família, compostas por um médico (a), um enfermeiro (a), auxiliares de

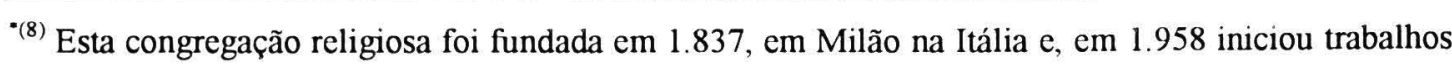
assistenciais na zona leste da cidade de São Paulo (Hospital Santa Marcelina ${ }^{130} 2.004$ ).

•(9) A denominação "Qualis" advém de Qualidade Total em Saúde
} 
enfermagem e agentes comunitários, como preconizado pelo Ministério da Saúde MS.

Em 1.998, três anos após a implantação das primeiras equipes "nucleares" do PSF, a saúde bucal passou a integrar as ações das equipes de saúde da família do PSF Santa Marcelina, no intuito de atender às necessidades em saúde bucal, evidentes na população já cadastrada e atendida pelas equipes "nucleares".

Do início do processo de desenvolvimento deste trabalho até sua finalização ocorreram muitas mudanças na organização dos serviços de saúde do PSF Santa Marcelina, gerando dificuldades e alterações de cronograma, refletindo em atrasos na etapa de execução da presente pesquisa.

No início do ano de 2.001, foram realizados contatos oficiais com a direção do PSF Santa Marcelina e seus representantes da Área Técnica de Saúde Bucal, firmando-se um acordo de cooperação técnico-científica para realização deste estudo.

Foi neste período que a cidade de São Paulo viveu um momento muito particular em relação a outros municípios brasileiros, porque o seu sistema de saúde se inseriu novamente no SUS, em meados de agosto do mesmo ano (2.001), acarretando a primeira mudança de relacionamento com novos responsáveis pelos serviços.

Nesta oportunidade, criaram-se, no município de São Paulo, 41 Sistemas Locais de Saúde, os então denominados Distritos de Saúde - DS (Figura 1).

Desencadeou-se a descentralização da saúde na cidade, em atendimento a um dos princípios organizacionais do SUS.

As Unidades de Saúde da Família - USF, do PSF Santa Marcelina passaram a responder sobre suas ações e serviços diretamente às diretorias dos Distritos Sanitários - DS de Itaquera, Guaianazes, Ermelino Matarazzo, Itaim Paulista, Vila Matilde, Cidade Tiradentes, Curuçá, que eram os gestores locais do SUS, e não apenas à direção do PSF.

Neste contexto, de grandes e profundas modificações, foi necessário negociar com os novos responsáveis pela gestão das USF do PSF a autorização para a continuidade dos trabalhos. 


\section{FIGURA 1}

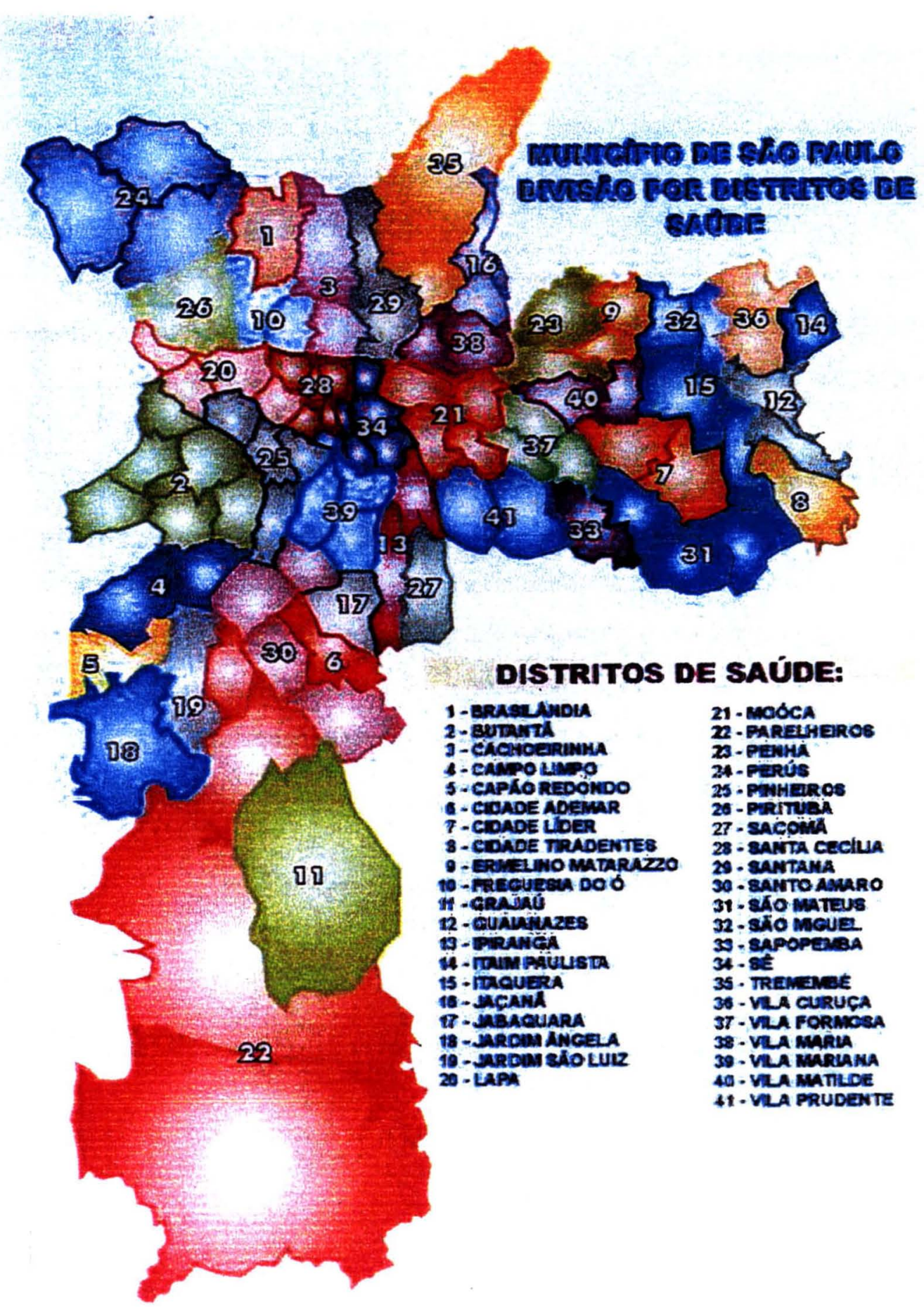

Município de São Paulo - divisão geográfica por Distritos Sanitários - DS - 41 DS, 2.002 .

Fonte: Secretaria Municipal da Saúde de São Paulo - SMS - CEINFO - 2.002. 
A cidade de São Paulo sofreu, ao final do ano de 2.003, outra reorganização geográfica e administrativa, quando foram criados as subprefeituras e o Qualis Santa Marcelina passou a ser denominado Programa de Saúde da Família - Santa Marcelina, PSF - Santa Marcelina.

Designou-se para cada subprefeitura um subprefeito que, por sua vez, nomeou assessores respondendo por coordenadorias, entre as quais as Coordenadorias de Saúde (Figura 2)

Alguns diretores de Distrito, agora Coordenadores de Saúde se mantiveram, outros foram substituídos e novamente houve a necessidade de rediscutir o projeto em cada subprefeitura, que nem sempre correspondia à divisão geográfica dos distritos de saúde.

Novos contatos se faziam, sempre que ocorriam modificações administrativas e políticas; retomava-se a pesquisa.

Assim, foi necessário realizar treinamentos a cada interrupção dos trabalhos no intuito de garantir a calibração dos examinadores e anotadores, que se mantiveram praticamente os mesmos durante todo o processo.

Todas as interrupções foram desgastantes e onerosas, sob diversos aspectos. 


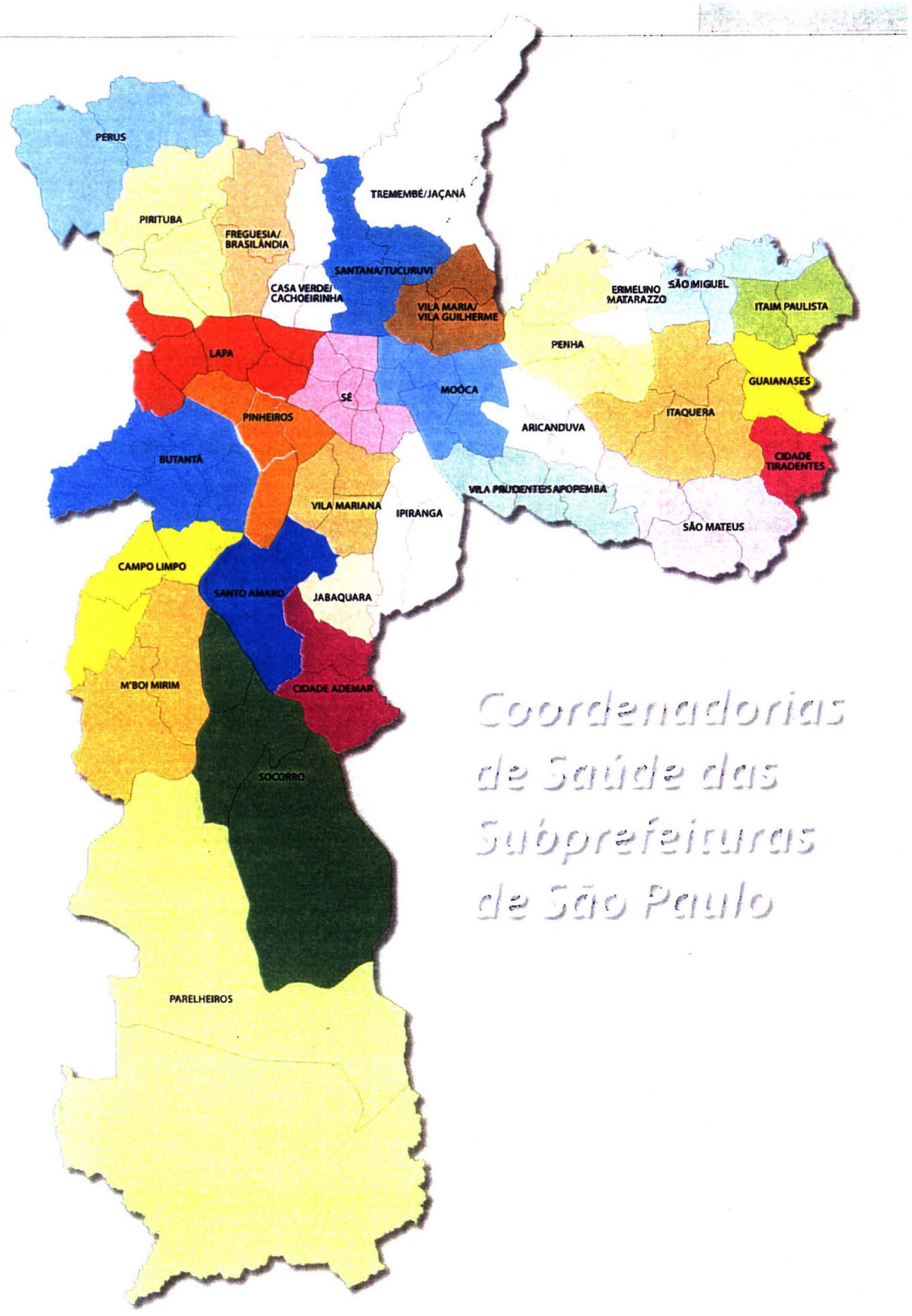

Município de São Paulo - divisão geográfica da cidade - 31 Subprefeituras, 2.003.

Fonte: Secretaria Municipal da Saúde de São Paulo - SMS CEINFO - 2.004. 


\subsection{Características Sócio-Demográficas - PSF Santa Marcelina}

A população da cidade de São Paulo, estimada para 2.003, pela Secretaria Municipal de Planejamento - SEMPLA - SP era de 10.710.990 habitantes. A população da zona leste, segundo estimativa do mesmo órgão para o mesmo período, era de 3.150 .647 habitantes, o que correspondia a $29,41 \%$ da população total do município (tabela 1).

Para a pesquisa presente foram consideradas as nove subprefeituras da zona leste onde havia serviços de saúde bucal do PSF Santa Marcelina,

TABela 1: População da zona leste do município de São Paulo, estimada pela Secretaria Municipal de Planejamento de São Paulo, para o ano de 2.003, segundo subprefeituras e distritos administrativos correspondentes. São Paulo, 2.005.

\begin{tabular}{|c|c|c|}
\hline SUBPREFEITURAS & DISTRITOS ADMINISTRATIVOS & POPULAÇÃo \\
\hline ARICANDUVA & Aricanduva, Carrão, Vila Formosa. & 259.339 \\
\hline CIDADE TIRADENTES & Cidade Tiradentes & 236.880 \\
\hline ERMELINO MATARAZZO & Ermelino Matarazzo, Ponte Rasa. & 205.295 \\
\hline GUAIANAZES & Guaianazes, Lajeado. & 278.494 \\
\hline ITAIM PAULISTA & Itaim Paulista, Vila Curuçá. & 382.969 \\
\hline ITAQUERA & $\begin{array}{l}\text { Cidade Líder, Itaquera José Bonifácio, } \\
\text { Parque do Carmo. }\end{array}$ & 505.547 \\
\hline PENHA & Arthur Alvim, Cangaíba, Vila Matilde. & 472.136 \\
\hline SÃO MATEUS, & Iguatemi, Jardim São Rafael. & 412.984 \\
\hline SÃo Miguel PAULISTA & Jardim Helena, São Miguel Paulista. & 397.003 \\
\hline TOTAL & & 3.150 .647 \\
\hline
\end{tabular}

Fonte: Secretaria Municipal da Saúde de São Paulo - SMS CEINFO - 2.003. 
Figura 3: Município de São Paulo - Subprefeituras da zona leste com serviços do PSF Santa Marcelina.

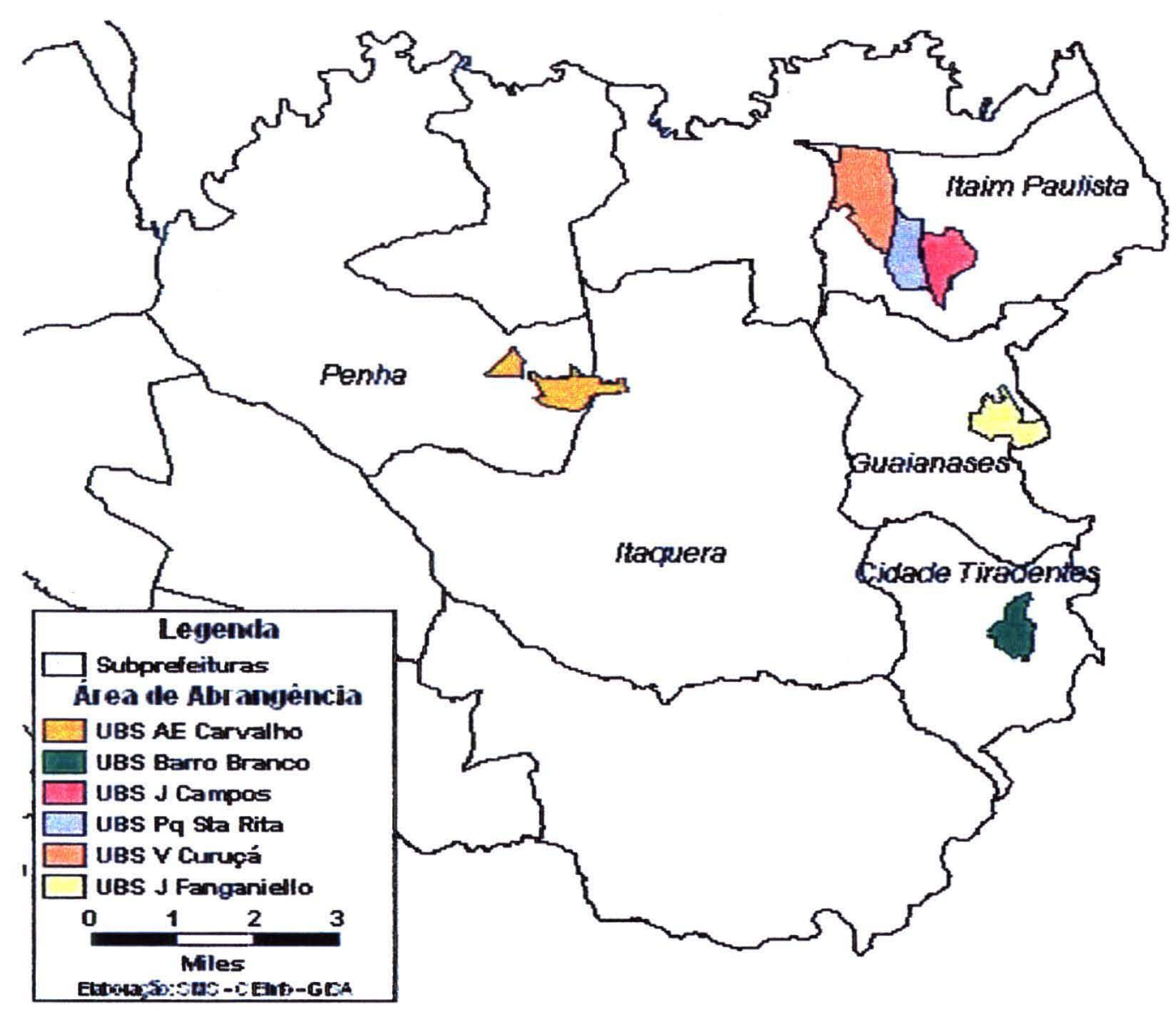

Fonte: Secretaria Municipal da Saúde de São Paulo - SMS CEINFO - 2.003. 
A população adulta de 25 a 59 anos de cada uma das subprefeituras é apresentada na tabela 2 e corresponde a $45,01 \%$ da população regional.

Os serviços do PSF Santa Marcelina são responsáveis pelo atendimento na área da saúde de aproximadamente 100 mil habitantes, correspondente a 3,12\% da população da zona leste da cidade de São Paulo. Na Figura 4 observa-se a área de abrangência e serviços do PSF Santa Marcelina.

TABela 2: População de 25 a 59 anos de idade da zona leste de São Paulo estimada pela Secretaria Municipal de Planejamento de São Paulo para o ano de 2.003, segundo sexo, subprefeituras e distritos administrativos correspondentes. São Paulo, 2.005 .

\begin{tabular}{|c|c|c|c|}
\hline \multirow[b]{2}{*}{ SUBPREFEITURAS } & \multirow[b]{2}{*}{ DISTRITOS ADMINISTRATIVOS } & \multicolumn{2}{|c|}{ SEXO } \\
\hline & & MASCULINo & FEMININO \\
\hline ARICANDUVA & Aricanduva, Carrão, Vila Formosa. & 57.639 & 65.562 \\
\hline CIDADE TIRADENTES & Cidade Tiradentes & 47.888 & 54.080 \\
\hline ERMELINO MATARAZZO & Ermelino Matarazzo, Ponte Rasa. & 45.352 & 50.189 \\
\hline GUAIANAZES & Guaianazes, Lajeado. & 57.362 & 60.833 \\
\hline ITAIM PAULISTA & Itaim Paulista, Vila Curuçá. & 79.429 & 86.398 \\
\hline \multirow{2}{*}{ ITAQUERA } & Cidade Líder, Itaquera & & \\
\hline & José Bonifácio, Parque do Carmo. & 109.804 & 121.020 \\
\hline \multirow{2}{*}{ PENHA } & Arthur Alvim, Cangaiba, & & \\
\hline & Vila Matilde. & 104.136 & 119.320 \\
\hline SÃo MATEUS & Iguatemi, Jardim São Rafael. & 90.542 & 94.968 \\
\hline SÃo Miguel PaUlista & Jardim Helena, São Miguel Paulista. & 83.826 & 89.826 \\
\hline SUB TOTAL & & 675.978 & 742.196 \\
\hline
\end{tabular}

Fonte: Secretaria Municipal da Saúde de São Paulo - SMS CEINFO - 2.003 
FiguRA 4: Munícípio.de São Paulo -Subprefeituras da zona leste - População adstrita $^{*(10)}$ e Área de abrangência e serviços do PSF Santa Marcelina.

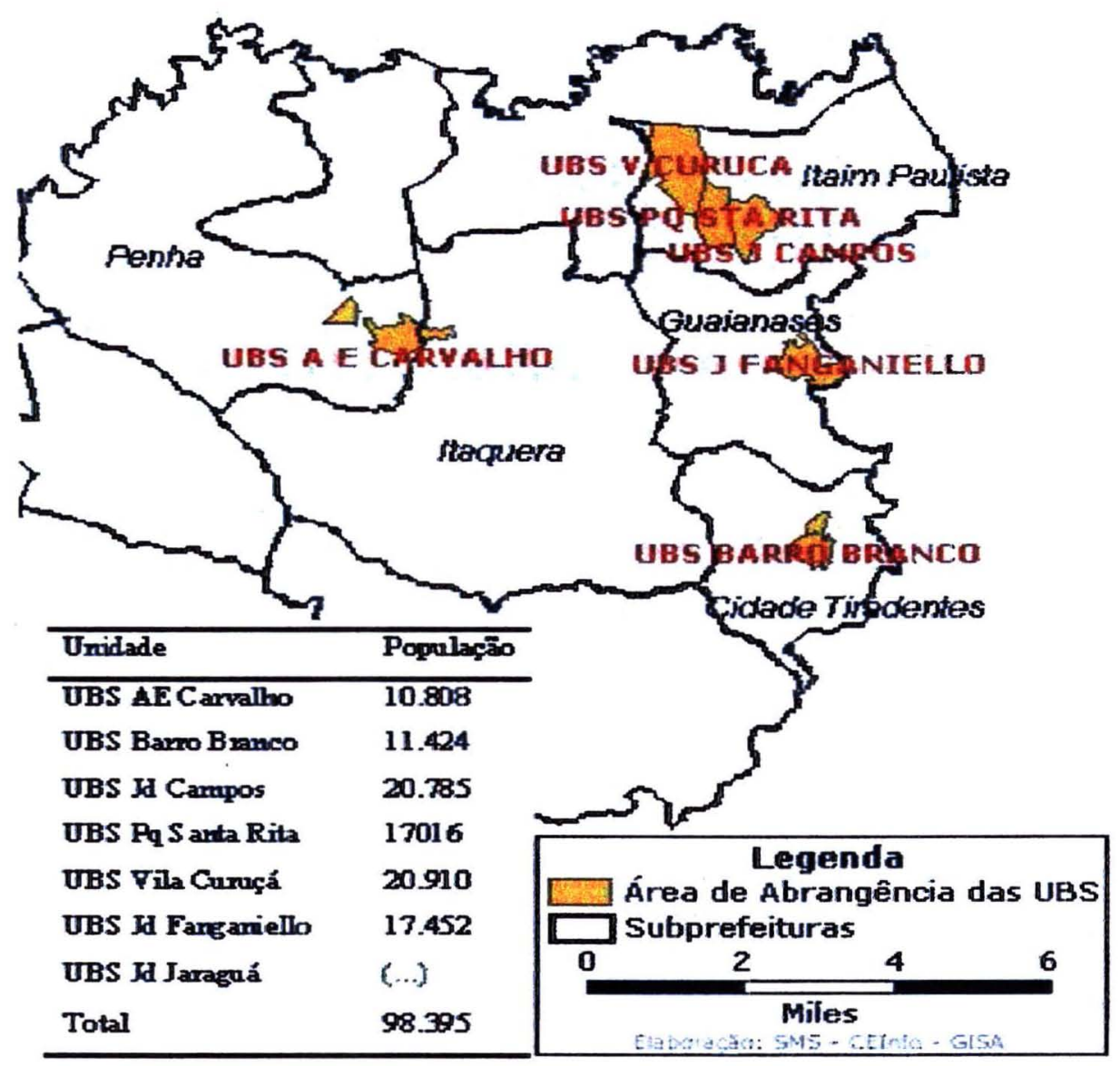

Fonte: Secretaria Municipal da Saúde de São Paulo - SMS CEINFO.2.004.

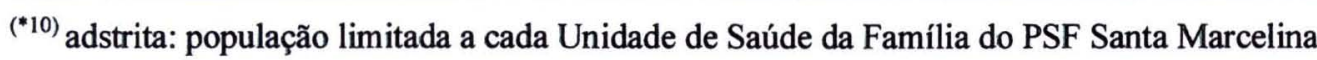


A tabela 3 apresenta dados fornecidos pelo PSF Santa Marcelina, referentes a fevereiro de 2004, a partir de estimativa fornecida pela Secretaria Regional de Saúde de São Paulo, DATASUS para o ano de 2.003 , da população geral cadastrada pelo PSF Santa Marcelina.

A população de estudo é parte da população apresentada na tabela 3, uma vez que se tomaram apenas os adultos de 25 a $55 \operatorname{anos}^{*(11)}$.

A população da faixa etária de interesse da pesquisa (adultos de 25 a 55 anos) corresponde a aproximadamente $1,84 \%$ da população total da zona leste da cidade de São Paulo e aproximadamente $60,00 \%$ da população cadastrada pelo PSF Santa Marcelina.

TABEla 3: População de 20 a 59 anos de idade das famílias cadastradas no ano de 2003 de área de abrangência segundo sexo e Unidade de Saúde da Família USF do PSF Santa Marcelina. São Paulo, 2.005.

\begin{tabular}{|c|c|c|c|c|}
\hline \multirow{2}{*}{ SUBPREFEITURAS } & \multirow{2}{*}{ UNIDADE DE SAÚDE } & \multicolumn{2}{|c|}{ SEXO } & \multirow[b]{2}{*}{ TOTAL } \\
\hline & & FEMININO & Masculino & \\
\hline CIDADE TIRADENTES & BARRO BRANCO & 3.166 & 2.673 & 5.839 \\
\hline GUAIANAZES & FANGANIELLO. & 4.318 & 4.047 & 8.365 \\
\hline \multirow[t]{4}{*}{ ITAIM PAULISTA } & JD CAMPOS & 5.279 & 4.829 & 10.108 \\
\hline & JD JARAGUÁ & 4.313 & 3.928 & 8.241 \\
\hline & PARQUE SANTA RITA & 4.775 & 4.264 & 9.039 \\
\hline & CURUÇÁ VELho & 5.108 & 4.574 & 9.682 \\
\hline PENHA & AE CARVALHO & 3.517 & 3.141 & 6.658 \\
\hline TOTAL & & 30.476 & 27.456 & 57.932 \\
\hline
\end{tabular}

Fonte: PSF Santa Marcelina

${ }^{*}(11)$ População de 20 a 59 anos é de $58,88 \%$ da população geral cadastrada, excluindo a UBS Jd Jaraguá que não dispunha da totalização dos cadastrados 
A região concentra um grande contingente de migrantes oriundos das regiões mais pobres do pais, principalmente do norte e nordeste, e apresenta alguns indicadores de saúde geral que refletem as condições de vida desta população (Quadro 2).

Em 2.002, o Coeficiente de Mortalidade Infantil-CMI, em todas as subprefeituras estava acima do valor considerado aceitável pela OMS, 10 óbitos/1000 nascidos vivos, salvo o CMI da subprefeitura de Pinheiros que foi de 9,5 óbitos /1.000 NV, mais de 2,5 vezes menor que o de Cidade Tiradentes quando as regiões são comparadas.

QUADRo 2: Indicadores de Saúde Geral das Subprefeituras da zona leste da cidade de São Paulo no ano de 2.002. São Paulo, 2.005.

\begin{tabular}{|c|c|c|c|c|c|}
\hline 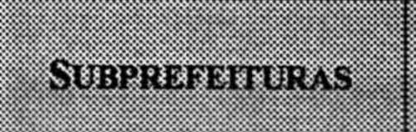 & 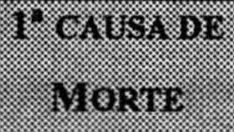 & 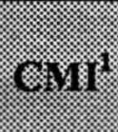 & $46+180$ & $211011^{3}$ & 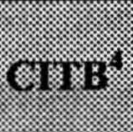 \\
\hline ARICANDUVA & $\mathrm{DIC}^{(5)}$ & 11,6 & 19,1 & 61,5 & 42,4 \\
\hline CIDADE TIRADENTES & Homicídios & 23,9 & $(\ldots)$ & 64,4 & 54,9 \\
\hline ERMELINO MATARAZZO & $\mathrm{DIC}^{(5)}$ & 13,7 & 22,4 & 66,7 & 80,4 \\
\hline GUAIANAZES & Homicídios & 16,1 & $(\ldots)$ & 104,0 & 74,9 \\
\hline ITAIM PAULISTA & $\mathrm{DIC}^{(5)}$ & 20,9 & 28,0 & 79,7 & 83,7 \\
\hline ITAQUERA & $\mathrm{DIC}^{(5)}$ & 14,5 & 28,4 & 78,3 & 71,9 \\
\hline PENHA & $\mathrm{DIC}^{(5)}$ & 13,8 & 23,7 & 63,6 & 64,0 \\
\hline SÃO MATEUS, & Homicídios & 17,4 & $(\ldots)$ & 95,2 & 53,7 \\
\hline São Miguel PaUlista & $\mathrm{DIC}^{(5)}$ & 15,4 & 29,8 & 104,0 & 76,5 \\
\hline
\end{tabular}

(1) CMI - Coeficiente de Mortalidade Infantil

(2) MPDC - Mortalidade por Doenças Crônicas

(3) CMCE - Coeficiente de Mortalidade por Causas Externas

(4) CITB - Coeficiente de Incidência de Tuberculose

(5) DIC - Doenças Isquêmicas do Coração

Fonte: Secretaria Municipal da Saúde de São Paulo - SMS CEINFO - SMS -SP, 2.002. 
Como primeira causa de morte (PCM) verificou-se que doenças cardiovasculares e cérebrovasculares foram importantes em 6 das 9 subprefeituras, reflexo da transição demográfica e epidemiológica que vive o país; A mortalidade por hipertensão arterial, doenças cardiovasculares, cérebro vasculares e diabetes, Doenças Crônico Degenerativas - (MPDC), reforçam a necessidade de ações de prevenção e controle destas doenças nas populações adulta e idosa; elevados Coeficientes de Mortalidade por Causas Externas (CMCE) revelam a violência da região; os homicídios figuram como primeira causa de morte em 3 das 9 subprefeituras. Coexiste com a situação, um elevado Coeficiente de Incidência de Tuberculose (CITB), moléstia infecto-contagiosa associada à baixa qualidade de vida da população local.

\subsection{ORganização dos SERviços de Saúde - PSF Santa Marcelina}

Como apresentado anteriormente, no início da criação do PSF Santa Marcelina realizava-se apenas atendimento médico, agendado a partir da identificação desta necessidade por Agentes Comunitários de Saúde - ACS em visitas domiciliares às famílias cadastradas da área/ micro área de abrangência do PSF Santa Marcelina.

Há em torno de 5 a 6 ACS para cada equipe de saúde da família. Esses ACS preenchem uma ficha - a Ficha A (Anexo 2), localizando e caracterizando detalhadamente o domicílio, identificando os moradores por idade, sexo, freqüência à escola, ocupação e morbidade referida, segundo critérios de interesse do serviço.

Segundo informações da coordenação de Saúde Bucal do PSF Santa Marcelina a implantação de serviços de saúde bucal foi gradativa. Até fevereiro de 2.001 as unidades de A E Carvalho, Santa Rita, Campos, Jaraguá e Fanganiello realizavam atendimento nessa área da saúde. Durante o ano de 2001 ampliou-se o atendimento em saúde bucal nas unidades Barro Branco e Curuçá Também em 2001, iniciou-se o atendimento utilizando-se a Técnica de Restauração Atraumática - TRA (Atraumatic Restaurations Tecnics - ART), somente em crianças de 0 a 4 anos, na Unidade Silva Teles.

Os serviços de saúde bucal do PSF Santa Marcelina realizam rotineiramente, em todos os seus pacientes, uma triagem em relação às condições de saúde 
periodontal, classificando os pacientes segundo os risco para as doenças periodontais.

Nesta triagem as condições de saúde periodontal são identificadas a partir de um indicador baseado no Índice Periodontal de Russell - IP e aplicado nos dentes índices ${ }^{*(12)} 1411263431$ 46, conforme apresentado no Anexo 3. Toma-se como base a presença de gengivite - código 1 (sangramento gengival), a presença de cálculo - código 2 , bolsas periodontais - código 6 e mobilidade dental - código 8 , ou ainda seqüelas da doença periodontal - código B.

Em todas as USF, com atendimento em Saúde Bucal, após a triagem de risco, registrada na ficha apresentada no Anexo 3, agenda-se o início do tratamento priorizando-se os pacientes de maior risco. Atualmente, para o serviço, são considerados de alto risco os indivíduos que apresentem nos dentes índices cálculo subgengival visível pelo afastamento ou por retração gengival, com bolsa periodontal, com ou sem mobilidade (código 6), ou ainda mobilidade irreversível e perda da função (código 8).

São de médio risco os indivíduos que apresentarem gengivite incipiente (código 1), elemento dental com cálculo (código 2), ausência de dentes no sextante (código $\mathrm{X}$ ) ou seqüelas de doença periodontal (código $\mathrm{B}$ ).

Apenas os indivíduos com periodonto sadio são considerados de baixo risco para as doenças periodontais.

$\mathrm{Na}$ ficha clínica de saúde bucal, são anotadas as informações sobre a saúde geral e condições dos dentes. Elabora-se então um plano de tratamento e são registrados os procedimentos realizados (Anexo 4).

Os tratamentos são realizados em módulos odontológicos, pelas equipes de saúde bucal.

\footnotetext{
•(12 Dente índice é o elemento dental identificado em estudos e que em conjunto com outros dentes indice, pode se inferir uma condição de saúde bucal.

Dentes Índice do Indicador usado pelos serviços de saúde bucal do PSF Santa Marcelina: 14112634 3146
} 


\subsection{POPUlaÇÃo de ESTUdo}

Identificou-se a população de estudo entre os usuários pertencentes a famílias cadastradas pelo PSF Santa Marcelina.

Uma vez realizada a identificação de risco para doenças bucais, todos os adultos, de 25 a 55 anos de idade, de ambos os sexos, pertencentes às famílias cadastradas na área de abrangência daqueles serviços, pertencentes a uma mesma área geográfica e condição sócio - econômica, que já tinham sido triados, que estavam iniciando seu tratamento odontológico foram convidados a participar do estudo.

\subsection{DELINEAMENTO do ESTUDO}

A partir de fundamentos em epidemiologia e dos artigos de WACHOLDER et al $(1.992 \mathrm{a}, 1.992 \mathrm{~b}, 1.992 \mathrm{c})$ delineou-se este projeto de pesquisa, um estudo observacional longitudinal retrospectivo, e, portanto retroanalítico, chamado estudo de caso-controle.

Esses estudos são indicados para se investigar associações em doenças de baixa incidência ou condições com período de latência prolongado, como é o caso das doenças periodontais. (PEREIRA 1.995, ROUQUAYROL e ALMEIDA FILHO 1.999, MEDRONHO et.003).

A identificação da doença periodontal destrutiva foi o marco inicial, e retroagindo no tempo foram investigados fatores associados ao risco no que se refere à instalação, aumento da gravidade e da extensão, e prognóstico do agravo de interesse.

Reconhecem-se algumas limitações próprias de estudos dessa natureza, como o seu reduzido poder descritivo quanto à estimação do risco e a vulnerabilidade a vieses de memória e de seleção, o que se reflete na complexidade da análise.

A escolha dos controles obedeceu à similaridade entre os casos, a não ser pela ausência da doença, uma vez que ambos, casos e controles, provêm da mesma área geográfica, guardam semelhanças sócio - econômicas e culturais, e foram atendidos no mesmo serviço. Procurou-se, assim, evitar vieses de seleção, conhecidos como bias de Berkson (MORABIA 1.997, ROUQUAYROL e ALMEIDA FILHO 1.999). 
Por motivos operacionais não foi feito o pareamento para idade, sexo e etnia entre casos prevalentes e controles.

A coleta de dados foi feita de modo a não alterar a rotina das unidades.

\section{DEFINIÇÃO E SELEÇÃO DOS CASOS}

Vários estudos discutem critérios para determinação de indivíduos doentes e de risco para doenças periodontais (KIM 1.992, CAMPOS JÚNIOR et al 1.992, CAMPOS JÚNIOR et al 1.994, KASSIRER 1.994, GROSSI et al 1.995, SANTANA e GUSMAN 1.998a, SANTANA e GUSMAN 1.998b, BARROSO et al 1.999).

A partir dos critérios discutidos pela literatura e com base na condição do periodonto encontrada no momento do exame definiu-se a condição de caso ou controle, sendo que os sextantes nulos não puderam ser considerados para discriminação de uma condição ou de outra.

Para que se tivesse uma noção do volume de "casos" e de "controles" utilizou-se os critérios do serviço para identificação preliminar de indivíduos com bolsas periodontais (doentes). Os indivíduos considerados de alto risco para as doenças periodontais foram inicialmente admitidos na pesquisa como "casos". Esta condição foi reavaliada no momento do exame.

A presença de bolsas periodontais, rasas ou profundas no momento do exame, foi soberana na definição da condição "caso" ou "controle".

Foram considerados "casos" os indivíduos adultos de ambos os sexos, de 25 a 55 anos, usuários do PSF Santa Marcelina, portadores de DPD, que apresentaram como pior condição bucal, em ao menos um dente índice dos sextantes, a presença de bolsas periodontais rasas, com profundidade de 4,0 a $5,5 \mathrm{~mm}$, ou bolsas periodontais profundas, 6,0 $\mathrm{mm}$ ou mais de profundidade, com ou sem mobilidade, migração patológica e/ou perda da função. A profundidade do sulco à sondagem foi tomada com a sonda WHO 621, recomendada pela OMS para estudos epidemiológicos, independente da perda de inserção periodontal observada pela exposição da junção amelo - cementária - JAC.

A seqüela de doença periodontal anterior como perda de inserção periodontal, com ou sem visualização da JAC pela migração apical da margem gengival e 
retração gengival, foi avaliada levando em conta a condição do periodonto no momento do exame.

\section{DEFINIÇÃO E SELEÇÃO DOS CONTROLES}

Da mesma forma que para a definição dos casos, os controles foram definidos com base nas referências da literatura.

Os controles também deram entrada na pesquisa a partir da sua classificação como de baixo ou médio risco para as DPD.

Estes só foram considerados controles desde que ao exame periodontal com utilização da sonda WHO 621 não se confirmasse a existência de bolsas periodontais.

Foram considerados "controles" os usuários adultos dos serviços de saúde do PSF Santa Marcelina, de 25 a 55 anos, de ambos os sexos, não portadores de doença periodontal destrutiva, e portanto "não doentes", que apresentavam como pior condição bucal, em ao menos um dente dos sextantes, sangramento ou cálculo, independente da perda de inserção periodontal, ou ainda que apresentaram como "pior condição" periodonto normal.

\section{CRITÉRIOS DE EXCLUSÃo}

Foram excluidos da amostra os pacientes que não atendiam os critérios descritos para casos e controles, e que sabidamente eram soro-positivos para o vírus HIV, sintomáticos ou assintomáticos para Síndrome da Imuno Deficiência Humana Adquirida - SIDA (Adquired Imuno Deficence Syndrome - AIDS).

As gestantes também foram excluídas do estudo, visto que a resposta inflamatória e imunológica aos microrganismos do biofilme dentário durante a gravidez se modifica.

Neste estudo, a sorologia positiva para o HIV e a gravidez poderiam ser fatores de confusão, por este motivo estas condições foram consideradas para a exclusão de indivíduos que participariam do estudo. 


\subsection{IDENTIFICAÇÃo do NÚMERO de CASOS E dE CONTROLES}

Optou-se por selecionar um controle para cada caso.

Estabeleceu-se um nível de significância, " $\alpha$ ", de 0,05 e o poder do teste, "1$\beta$ ", de 0,20 uma vez que seriam avaliados vários fatores associados ao risco, nos quais a freqüência relativa à exposição e o risco relativo hipotético entre os controles na população de estudo eram diferentes.

Apesar de, segundo DINI (1.995) e ASCKAR et al (1.999), entre outros autores, a exposição a um dos fatores associados ao risco a ser estudado, uso de prótese, girar em torno de $30 \%$, e o risco de desenvolver doença periodontal destrutiva (OR) ser de aproximadamente igual a 4,5, para populações adultas com condições sócio econômicas semelhante à população deste estudo, hipotetizou-se que a freqüência relativa à exposição a ser considerada seria de $10,0 \%$, e o risco médio entre os fatores poderia ser fixado em 2, 0 , com base em estudos anteriores já publicados (CHAIM e COPPI 1.998, TOMITA et al 1.999, LEONEL e TOMITA 1.999, MARTINELLI e PILATTI 1.999).

Fixados os valores necessários à identificação do número de indivíduos que deveria compor a amostra, consultando o apêndice A de SCHLESSELMAN (1.982) e as orientações de LWANGA e LEMESHOW (1.991) conclui-se que a amostra deveria ser composta por 282 casos e 282 controles. Levando-se em consideração a probabilidade de não resposta em torno de $10,0 \%$ arredondou-se para 300 casos e 300 controles.

Atenta às dificuldades encontradas na fase anterior à operacionalização da pesquisa, e tendo em vista serem 7 as equipes de examinadores /anotadores estabeleceu-se como meta a realização de 100 exames por equipe, sendo 50 casos e 50 controles; ao final do processo de coleta de dados deveria se ter 350 casos e 350 controles. 


\subsection{VARIÁVEIS DE ESTUDO E INDICADORES UTILIZADOS}

A seguir apresentam-se os indicadores adotados e as variáveis de estudo associadas ao risco de instalação e progressão das DPD.

\section{VARIÁVEIS SÓCIO-DEMOGRÁFICAS}

Aplicando uma entrevista estruturada (GIL 1996) foram identificadas como variáveis demográficas: idade (entre 25 e 55 anos), sexo, naturalidade, estado civil, religião.

Para caracterização sócio - econômica foi necessário inquirir qual a inserção do entrevistado no mercado de trabalho, natureza de sua ocupação ou ramo de atividade e sua ocupação principal, na atualidade. Para codificação dos dados de ocupação utilizou-se a tabela usada pela Receita Federal (Anexo 6).

Escolaridade e anos de estudo complementavam a caracterização sócioeconômica do entrevistado.

As categorias de cada uma dessas variáveis podem ser visualizadas no Anexo 5.

\section{VARIÁVEIS RELATIVAS A CONDIÇÕES E ESTADOS DE SAÚDE GERAL}

Também usando entrevista estruturada, procurou se identificar presença de diabetes, imunodepressão, distúrbios neurológicos e psiquícos, assim como o tempo de duração de cada um dessas alterações, o uso de medicamentos e o tempo de uso de medicamentos para cada uma dos problemas citados (Anexo 5).

\section{VARIÁVEIS RELATIVAS A HÁBITOS E COSTUMES}

CONSUMO DE TABACO

Identificou-se o consumo de tabaco, tanto no que se referiu ao hábito de fumar (cigarros industrializados ou de palha, charuto, cachimbo e outros) assim como o hábito de mascar tabaco, segundo a importância apontada pela literatura consultada a este respeito. Foi importante também identificar a quantidade de tabaco consumida diariamente. Procurou se conhecer o uso do tabaco sob a forma de cigarro industrializado, cigarro de palha, charuto e cachimbo. Indagou-se, ainda, o uso do 
tabaco sob outras formas, como o tabaco inalado (rapé) ou mascado (Nicotian tabacum ou tabaco, bétel ou bétele ${ }^{*(13)}$ ).

A seguir aplicou-se o Teste de Faggerströn para dependência de nicotina, no qual se consideraram fumantes todos os que declararam fumar até menos de um cigarro por dia. Neste teste o fumante respondeu a 6 questões objetivas, com alternativas pontuadas previamente. As questões identificaram a quantidade de cigarros consumidos ao dia e os momentos do dia onde a necessidade de fumar foi importante ou inevitável para ele.

Ao final, somaram-se os pontos de cada resposta e a variação de 0 a 4 pontos indicou uma dependência leve de nicotina; de 5 a 7 pontos a dependência foi média, e de 8 a 11 pontos considerou-se alta a dependência de nicotina.

No Anexo 5 pode-se identificar cada uma das questões deste teste e as respectivas alternativas de resposta e pontuação.

\section{CONSUMO DE ÁLCOOL}

Seguiu-se uma avaliação do consumo de álcool especificando categorias e forma de apresentação de cada um dos tipos de bebida. Foram discriminadas as bebidas fermentadas (cerveja em lata, em copo e em garrafa; vinho em taça e em garrafa; champanhe em taça) e destiladas (aguardente, vodka, rum, gim, grappa, uísque e licor).

Identificou-se a quantidade e freqüência semanal de consumo, o que permitiu o cálculo do número de doses de álcool absoluto consumido por semana para cada categoria de bebida.

\footnotetext{
*(13) bétel ou bétele: mistura em que entram folhas de bétel, tabaco e areca, usada para mastigar em algumas regiões tropicais. (FERREIRA 1.999).
} 
Os tipos de bebida, assim como as formas de apresentação e a equivalência de doses, basearam-se nos valores de referência preconizados pela OMS e adotados por serviços de recuperação de dependentes de álcool e drogas (PROAD, UNIAD), vinculados ao Departamento de Psiquiatria da Faculdade de Medicina da Universidade Federal de São Paulo - UNIFES P (Escola Paulista de Medicina EPM) e Faculdade de Medicina da Universidade de São Paulo - USP (CAP ad PROSAN) (Anexo 7).

A seguir avaliou-se a história de consumo de álcool do entrevistado, iniciando por identificar seu consumo na última semana. Considerou-se última semana como o período de segunda feira a domingo que antecedeu o questionamento, e não os últimos sete dias que antecederam a entrevista.

Questionou-se o consumo de álcool no último mês, sendo que este período referia-se ao período contado do dia 01 ao dia 30 ou 31 do mês anterior ao do que estava sendo realizada a entrevista, e não os últimos 30 dias que antecederam o questionamento.

Verificou-se o consumo de álcool no último ano, sendo que este se referiu ao período de janeiro a dezembro do ano anterior àquele em que se realizava a entrevista.

De forma análoga às apresentadas avaliou-se também o consumo de álcool do entrevistado há 5 anos, há 10 anos e há 20 anos. As perguntas e as alternativas de resposta sobre a história de consumo do álcool foram retiradas de questionários também usados pelos serviços de recuperação de usuários de drogas psicoativas e podem ser vistas no Instrumento de Coleta de Dados - ICD (Anexo 5).

Foi possível verificar o consumo de álcool em cada um dos períodos considerados.

\section{VARIÁVEIS CLÍNICAS}

\section{CONDIÇÕES PERIODONTAIS}

Em 1.987, após uma reunião do grupo de trabalho da OMS e da FDI em Praga, CUTRESS, AINAMO e SARDO-INFIRRI, publicaram orientações para o uso do CPITN em grupos populacionais. Nessa publicação recomendações para a forma de apresentação de dados e resultados, além de considerações sobre o tamanho 
da amostra a ser utilizado e seleção dos grupos etários, são descritos e justificados. A padronização da apresentação tabular dos resultados recomendada, onde devem ser incluídas informações sobre o número de indivíduos e sextantes desdentados, tem o intuito de permitir comparações internacionais. Quatro tabela básicas são recomendadas, através das quais se pode verificar prevalência, severidade, extensão e necessidades de tratamento (CUTRESS et al 1.987).

A apresentação dos resultados sobre condições periodontais foi feita seguindo as orientações publicadas por CUTRESS, AINAMO e SARDO-INFIRRI (1.987) ainda para o CPITN.

A condição de "caso" ou "controle" foi identificada aplicando-se os códigos e critérios do Community Periodontal Index - CPI, indicador recomendado pela OMS para estudos populacionais das doenças periodontais (WHO 1.997).

Os critérios e códigos do CPI (Quadro 4) correspondem à proposta pela OMS em 1.997, e são os mesmos anteriormente propostos para o Community Periodontal Index and Treatment Needs - CPITN, cuja praticidade e confiabilidade foi testada por inúmeros autores (AINAMO 1.985, DINI et al 1.995, DINI 1.996).

Críticas (OPPERMANN e RÖSSING 1.997, OPPERMANN e GOMES 1.999, JUÁREZ et al 1.999, LINDHE, KARRING e LANG 1997) e a avaliação de novas técnicas terapêuticas motivaram os técnicos da OMS a propor que além das informações sobre condições periodontais imediatas ao exame, também fosse avaliada a perda de inserção periodontal (BAELUM et al 1.996, BAELUM e PAPAPANOU 1.996, WHO 1.997).

Assim, a história pregressa de doença periodontal foi complementar à avaliação periodontal, medindo-se a perda de inserção periodontal pelo PIP, também preconizado pela OMS para estudos em populações (Quadro 3). 
QUADRo 3: Critérios e Códigos para o Índice Periodontal Comunitário - CPI, Critérios e Códigos e para o Índice de Perda de Inserção Periodontal -PIP.

\begin{tabular}{|c|c|c|}
\hline (6onsiges) & \multicolumn{2}{|c|}{ 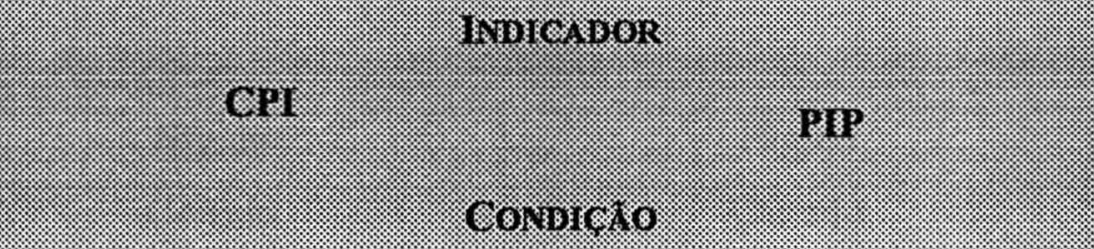 } \\
\hline 0 & Periodonto normal & $\begin{array}{c}\text { Perda de inserção de } 0 \text { a } 3 \mathrm{~mm} \\
\text { (CPI de } 0 \text { a } 3)\end{array}$ \\
\hline 1 & Sangramento & Perda de inserção de $4-5 \mathrm{~mm}$ \\
\hline 2 & Cálculo & Perda de inserção de $6-8 \mathrm{~mm}$ \\
\hline 3 & Bolsa rasa $(4-5 \mathrm{~mm})$ & Perda de inserção de 9-11 mm \\
\hline 4 & Bolsa profunda $(>$ ou $=6 \mathrm{~mm})$ & Perda de inserção $>12 \mathrm{~mm}$ \\
\hline $\mathrm{X}$ & Sextante excluído & Sextante excluído \\
\hline 9 & Sextante não examinado & Sextante não examinado \\
\hline
\end{tabular}

Fonte: WHO 1.997

\section{EXPERIÊNCIA DE CÁRIE}

A experiência de cárie coronária e radicular foi medida pelo Índice CPOD, de acordo com os códigos e critérios adotados pela OMS em 1.997, apresentados no Quadro 4 (WHO 1.997).

\section{USO DE PRÓTESE}

Verificou-se também o uso de qualquer tipo de prótese dentária, discriminando os tipos de peças protéticas encontradas em cada sujeito: próteses, totais ou parciais, únicas ou combinadas.

$\mathrm{Na}$ análise desta variável considerou-se o uso de próteses parciais como a condição de maior risco para as DPD. 
QUADro 4: Código de Registro e Condições da Coroa e da Raiz para Cárie Dental.

\begin{tabular}{|c|c|c|}
\hline 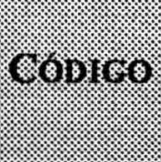 & 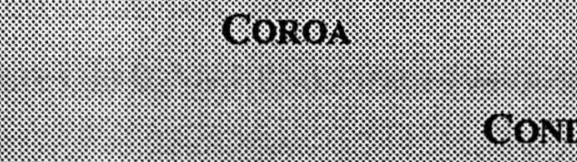 & I \\
\hline 0 & Hígido & Hígido \\
\hline 1 & Cariado & Cariado \\
\hline 2 & Restaurado e com cárie & Restaurado e com cárie \\
\hline 3 & Restaurado & Restaurado \\
\hline 4 & Perdido por cárie & Perdido por cárie \\
\hline 5 & Perdido por outra causa & Perdido por outra causa \\
\hline 6 & Com selante & Com selante \\
\hline 7 & $\begin{array}{l}\text { Coroa protética, apoio de prótese } \\
\text { ou implante }\end{array}$ & $\begin{array}{c}\text { Coroa protética, apoio de prótese } \\
\text { ou implante }\end{array}$ \\
\hline 8 & Não erupcionado & Não erupcionado \\
\hline $\mathrm{T}$ & Fratura ou trauma & Não se aplica \\
\hline 9 & Não examinado & Não examinado \\
\hline
\end{tabular}

Fonte: WHO 1.997

\section{PRESENÇA DE Placa BACTERIANA OU DE BIOFILME DENTÁRIO}

A presença de biofilme bacteriana ou biofilme dentário foi medida pelo Índice de Higiene Oral simplificado $\operatorname{IHOS}^{*(14)}$, já adotado na rotina dos serviços de saúde bucal do PSF Santa Marcelina e codificado como IP para este estudo.

Nessa oportunidade só se observou a quantidade de biofilme visível com evidenciador utilizado habitualmente pelo serviço, dividindo-se longitudinalmente as superficies vestibulares dos dentes índices em terços, a saber: terço mesial, terço médio e terço distal. (CARRANZA 1.979). Os valores encontrados foram registrados no Instrumento de Coleta de Dados - ICD.

Os dentes e superficies índices foram: superficies vestibulares dos primeiros molares superiores $(16,26)$, incisivos centrais superior direito (11) e inferior esquerdo (31) e superficies linguais dos primeiros molares inferiores (36 e 46). $\mathrm{O}$ IHOS do paciente foi calculado pela somatória dos valores atribuídos aos dentes e 
superficies- índices examinados dividindo-se, a seguir, esta somatória pelo número de superfícies examinadas. A classificação da higiene do paciente foi feita segundo os valores do IHOS (Quadro 5), podendo designá-la como boa (valores de 0,3 a 0,6), média (valores de 0,7 a 1,8) ou fraca (valores de 1,9 a 3,0) (CARRANZA 1.979).

QUADRO 5: Higiene do paciente segundo valores do IHOS

\begin{tabular}{|c|c|}
\hline 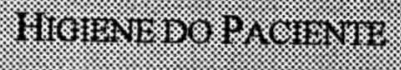 & 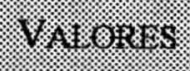 \\
\hline Boa & 0,3 a 0,6 \\
\hline Média & 0,7 a 1,8 \\
\hline Fraca & 1,9 a 3,0 \\
\hline
\end{tabular}

A discriminação das alternativas usadas para cada variável de estudo pode ser vista no Anexo 5.

\subsection{OperacionalizaÇão da Pesquisa}

Logo após capacitação das equipes a coleta de dados foi realizada em 7 Unidades de Saúde da Família - USF do PSF Santa Marcelina, a saber: AE Carvalho, Barro Branco, Curuçá Velha, Fanganiello, Jd Campos, Jd Jaraguá, Santa Rita.

Um (a) cirurgião (ã) dentista - CD e um (a) Atendente de Consultório Dentário - ACD ou Técnico (a) de Higiene Dentária - THD, de cada uma das sete Unidades de Saúde da Família - USF que prestava atendimento em saúde bucal à população cadastrada pelo serviço, foram treinados para exercer os papéis de examinador e anotador, respectivamente.

\footnotetext{
-(14) A presença de cálculo e a de biofilme dentário são usadas para compor o valor do IHOS. Nos serviços do PSF Santa Marcelina e neste estudo utilizou-se somente a presença de biofilme para o calcular este índice.
} 
Para dirimir dúvidas e resolver problemas durante a fase de coleta de dados estabeleceram-se contatos por telefone e realizou-se supervisão do trabalho de campo junto às equipes de saúde bucal.

\section{TREINAMENTO - CALIBRAÇÃO DE EXAMINADORES E ANOTADORES}

Os examinadores foram treinados por um processo de padronização de critérios diagnósticos e calibração, para melhor homogeneização dos resultados, segundo recomendações da OMS (CUTRESS et al 1.987, WHO 1.997). O treinamento dos profissionais que exerceram as funções de examinadores $\mathrm{e}$ anotadores foi oferecido em duas oportunidades:

Em setembro de 2.002 realizou-se uma atividade teórica de 4 horas, na USF Jardim Jaraguá, uma das Unidades de Saúde da Família - USF onde se realizaria a coleta de dados do projeto de pesquisa, familiarizando as equipes de saúde bucal do PSF Santa Marcelina com o projeto, oportunidade onde os cirurgiões dentistas e pessoal auxiliar foram convidados a participar do trabalho.

Os profissionais que manifestaram interesse em ser examinadores ou anotadores receberam no mesmo dia, no periodo da tarde e em mais uma manhã um treinamento para realização de um pré-teste do Instrumento de Coleta de Dados ICD, num total de 12 horas de treinamento teórico-prático.

As primeiras 4 horas de treinamento prático foram utilizadas conciliando aplicação, discussão dos critérios adotados na pesquisa e avaliação de discordâncias entre os examinadores, as 4 horas seguintes foram usadas para avaliação de discordâncias intra - examinador. Depois desta atividade de calibração os examinadores e anotadores realizaram 44 exames, a título de pré-teste do Instrumento de Coleta de Dados - ICD. A avaliação dos resultados do pré-teste levou a modificações do ICD e à necessidade de retomar o treinamento com uma carga horária maior.

Após as modificações necessárias no ICD, definiu-se a versão final e realizou-se novo treinamento dos examinadores e anotadores em abril de 2.003 .

Foram destinadas 16 horas de atividade de capacitação, sendo 4 horas de fundamentação teórica com discussão minuciosa do ICD. Investiu-se 12 horas na calibração dos examinadores e anotadores, com grande ênfase para o diagnóstico 
periodontal (CPI e PIP). Ao final do processo, utilizando-se a estatística Kappa e percentual de concordância, verificou-se a concordância intra-examinador e interexaminador tanto para o CPI quanto para o PIP. (Quadro 6). Esta concordância foi classificada como "quase perfeita" pelos parâmetros definidos por LANDIS e KOCH (1.977). Durante o processo de calibração foram salientadas e obedecidas as normas de biossegurança vigentes no país (MINISTÉRIO DA SAÚDE 2.000).

QUADRO 6: Concordâncias intra e inter examinadores para o CPI e PIP avaliadas pelo Kappa.

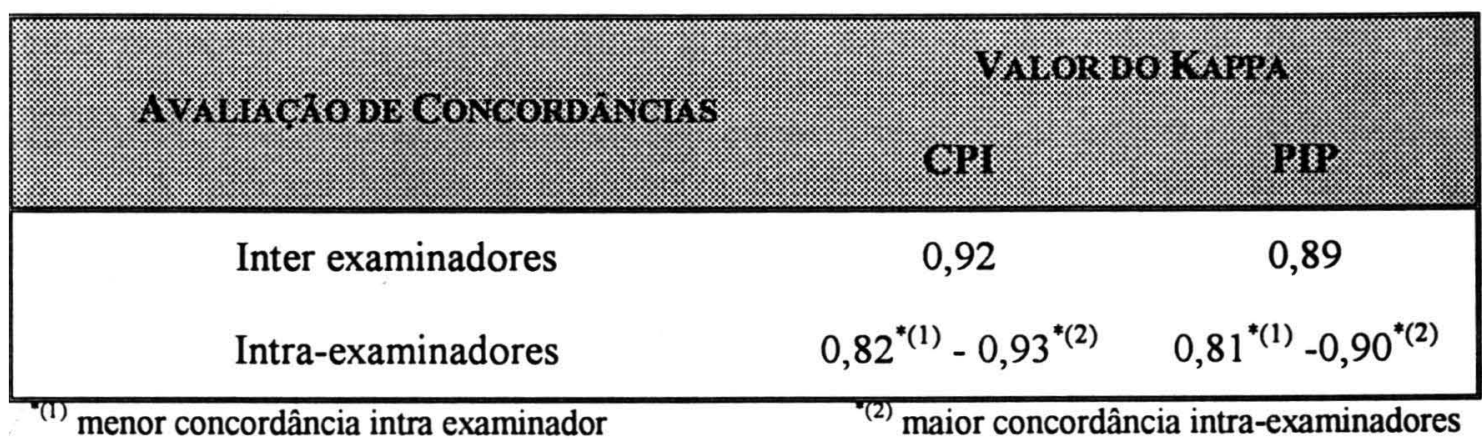

\section{INSTRUMENTO DE COLETA DE DADOS - ICD}

A versão final do formulário para coleta de dados para a pesquisa, denominado Instrumento de Coleta de Dados -ICD encontra-se no Anexo 5

\section{Trabalho de CaMPo}

\section{ENTREVISTA ESTRUTURADA}

Após leitura do termo de consentimento livre e esclarecido (Anexo 1) e anuência do paciente em relação à sua participação na pesquisa, o (a) anotador (a) realizava a sua identificação preenchendo-se os campos relativos ao nome completo, número do prontuário do paciente na USF, data de nascimento.

Para assegurar que os critérios de exclusão fossem atendidos, o cirurgião dentista iniciava a entrevista questionando a hipótese de gravidez e sorologia positiva para HIV. Foram dispensados os entrevistados que deram respostas afirmativas para estas questões. 
Com exceção das informações clínicas, todas as outras de interesse da pesquisa foram obtidas através da entrevista estruturada, conduzida pelo cirurgião dentista. As questões utilizadas e as alternativas de resposta constam do ICD (Anexo5).

\section{EXAMES BUCAIS}

Os exames intrabucais foram realizados logo após a entrevista.

Muitos estudos têm medido a perda de inserção utilizando sondas periodontais computadorizadas e pressão constante. Este recurso é encontrado apenas em grandes centros de pesquisa e dificilmente pode se disponibiliza o seu uso para estudos populacionais com amostras grandes, além da não indicação de seu uso nestes casos

A impossibilidade de deslocar o equipamento para o local do estudo, o reduzido número de exames a serem executados por período, além das dificuldades com a esterilização da sonda podem ser apontados como justificativa para o não uso deste recurso em estudos com grande número de indivíduos a examinar.

Para realização dos exames nos módulos odontológicos do PSF Santa Marcelina, a partir de agendamento prévio dos pacientes que concordaram em participar do estudo, foram utilizados espelhos clínicos planos e sonda periodontal WHO 621, ou sonda CPI, preconizada pela OMS (WHO 1997).

Inicialmente avaliou-se o padrão de higiene bucal do paciente pelo Índice de Higiene Oral Simplificado - IHOS. Identificava-se a condição de caso ou controle, a partir do CPI assim como a perda de inserção. A seguir realizava-se o exame das condições de cárie de coroa e de raiz, e o uso de próteses.

\subsection{CONSOLIDAÇÃo de dADOS E ANÁlise ESTATístiCA}

O programa para criação do banco de dados, assim como a máscara para a digitação foram criados a partir de aplicativos do software EPI INFO, versão $5.01 b^{*}(15)$, desenvolvido pelo Centers of Diseases Control, (CDC), para a OMS, em Atlanta, Geórgia, EUA, (DEAN et $\mathrm{al}^{80}$ 1.990). O banco de dados foi exportado para um software estatístico, o SPSS for Windows (Statistical Package for Social Sciences), versão 11.01, 2.001, a partir do qual se fizeram as análises estatísticas. 
Após coleta das informações realizou a conferência do preenchimento de todos os campos de cada um dos ICD e análise preliminar de consistência, transcrevendo-se, a seguir, cada um dos ICD para a máscara de digitação, no intuito de minimizar erros de digitação e os custos (Anexo 8). Foram feitas duas digitações, pelo mesmo digitador sem que o mesmo soubesse com antecedência que este procedimento seria adotado.

A análise descritiva foi realizada com determinação de medidas de tendência central (média e mediana) e percentis da distribuição de freqüências que serviram para estabelecer pontos de corte para posterior dicotomização das variáveis de estudo. Para analisar os dados obtidos, os casos foram recodificados como doentes. Foram considerados doentes os indivíduos que apresentaram, em ao menos um sextante, bolsas periodontais rasas (código 3 do $\mathrm{CPI}$ ) ou bolsas periodontais profundas (código 4 do CPI). Os controles foram codificados como não doentes e corresponderam àqueles indivíduos que apresentavam como pior condição em ao menos um sextante presença de cálculo (código 2 do $\mathrm{CPI}$ ), sangramento gengival (código 1do CPI) ou periodonto normal (código 0 do $\mathrm{CPI}$ ).

A perda de inserção foi dicotomizada e recodificada considerando com perda de inserção a presença de em ao menos um sextante com perda de inserção acima de $3 \mathrm{~mm}$ (código do PIP>=1); foram considerados sem perda de inserção os indivíduos que apresentaram o código 0 do PIP em todos os sextantes.

Para as variáveis de consumo de tabaco e de álcool, e para o IHOS criaram-se variáveis categorizando os valores numéricos, considerando as medidas de tendência central e a plausibilidade biológica como referências para categorização de novas variáveis.

Para o álcool e o tabaco consideraram-se as quantidades consumidas e intervalos de tempo de consumo, no intuito de explorar melhor os dados e avaliar a existência de associação com a condição "doente" (casos).

Particularmente para o álcool, e a posteriori, foram feitos testes de tendência para cada período e a condição periodontal encontrada, no intuito de verificar a implicação do aumento do consumo do álcool nas DPD.

Ainda estabelecendo uma relação entre as respostas do bloco referente à qualificação do consumo de álcool por período propôs-se uma variável dicotômica 
para conhecer a história pregressa de consumo de álcool do indivíduo e existência de DPD. Considerou-se na categoria de menor risco os indivíduos que declaram não ter consumido álcool ou consumi-lo ocasionalmente (etilistas sociais), desde a última semana até há 20 anos; e de maior risco, os que declararam grande consumo, com ou sem episódios de embriaguez, com ou sem controle.

Para a análise da presença de biofilme a partir d IHOS considerou-se biofilme presente quando o IHOS era maior ou igual a 1,0. Esta condição correspondeu a mais de 1/3 das superficies dentárias com biofilme, categoria de maior risco na dicotomização da variável.

$\mathrm{Na}$ análise bivariada realizou-se o teste de qui-quadrado e a estimativa da razão de chances (odds ratio $=\mathrm{OR}$ ) para cada uma das variáveis independentes e seus respectivos intervalos de confiança (IC 95,0\%). As variáveis que mostraram associação ou não na análise bivariada, em que o valor de $p$ era menor que 0,20 $(p<0,20)$ foram incluídas para construção do modelo múltiplo.

À análise de regressão logística múltipla, realizada a seguir, pode-se identificar quais as variáveis de risco independentes para a instalação e desenvolvimento do agravo em estudo, considerando $\mathrm{p}<0,005$.

Nos quadros 8 a 11 estão apresentadas as variáveis dicotômicas usadas na análise estatística e suas respectivas categorias, derivadas de variáveis utilizadas na coleta de dados (variáveis primárias).

\footnotetext{
*(15) Pretendia-se trabalhar os dados de experiência de cárie e condições periodontais a partir do EPI BUCO, programa de computador que depende desta versão do EPI INFO para realizar sua rotina de trabalho.
} 
QUADRO 7: Variáveis primárias, dicotômicas e respectivas categorias relativas a características sócio - demográficas.

\begin{tabular}{|c|c|c|c|}
\hline & & \multicolumn{2}{|c|}{ 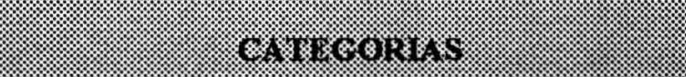 } \\
\hline Idade & Grupo etário & 25 a 34 anos & 35 a 55 anos \\
\hline Sexo & Sexo & Feminino & Masculino \\
\hline Naturalidade & Naturalidade & São Paulo & Outros locais \\
\hline Estado civil & Vida conjugal & Sem Vida conjugal & $\begin{array}{l}\text { Com Vida } \\
\text { conjugal }\end{array}$ \\
\hline Religião & Religião & Católico & Outros \\
\hline $\begin{array}{l}\text { Natureza da } \\
\text { Ocupação }\end{array}$ & Natureza da Ocupação & Tem trabalho & Não tem trabalho \\
\hline Ocupação & Ocupação e renda & $\begin{array}{c}\text { Tem trabalho e/ou } \\
\text { renda }\end{array}$ & $\begin{array}{c}\text { Não tem trabalho, } \\
\text { nem renda }\end{array}$ \\
\hline Escolaridade & Escolaridade & $\begin{array}{c}\text { Sabe ler e escrever } \\
\text { ou mais }\end{array}$ & Analfabeto \\
\hline Anos de estudo & Anos de estudo & Anos de estudo $>=1$ & Anos de estudo $<1$ \\
\hline
\end{tabular}

QUADRO 8: Variáveis primárias, dicotômicas e respectivas categorias relativas a estados e condições de saúde geral.

\begin{tabular}{|c|c|c|c|}
\hline 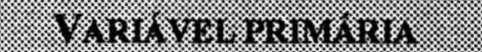 & 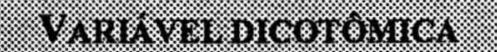 & \multicolumn{2}{|c|}{ 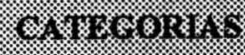 } \\
\hline Diabetes & Diabetes & Não & Sim \\
\hline $\begin{array}{c}\text { Distúrbios Neurológicos ou } \\
\text { Psíquicos }\end{array}$ & $\begin{array}{c}\text { Distúrbios Neurológicos ou } \\
\text { Psíquicos }\end{array}$ & Não & Sim \\
\hline Doenças Auto-imune & Doenças Auto-imune & Não & Sim \\
\hline
\end{tabular}


QUADRO 9: Variáveis primárias, dicotômicas e respectivas categorias relativas a hábitos

\begin{tabular}{|c|c|c|c|}
\hline 2. & Hit & \multicolumn{2}{|c|}{$(8)$} \\
\hline Uso do tabaco & Uso do tabaco & Não & Sim \\
\hline $\begin{array}{c}\text { Tempo de uso do } \\
\text { tabaco }\end{array}$ & $\begin{array}{c}\text { Tempo de uso do } \\
\text { tabaco }\end{array}$ & $\begin{array}{l}\text { Não fuma ou tempo } \\
\text { tabagista }<=5 \text { anos }\end{array}$ & $\begin{array}{l}\text { Tempo tabagista } \\
>5 \text { anos }\end{array}$ \\
\hline $\begin{array}{l}\text { Número de cigarros } \\
\text { consumidos por dia } \\
\text { Número tabaco } 2\end{array}$ & $\begin{array}{l}\text { Número de cigarros } \\
\text { consumidos por dia }\end{array}$ & $\begin{array}{c}\text { consumo }<=10 \\
\text { unidades }\end{array}$ & $\begin{array}{c}\text { consumo }>10 \\
\text { unidades }\end{array}$ \\
\hline Uso álcool & Uso álcool & Não & Sim \\
\hline $\begin{array}{c}\text { Consumo de álcool na } \\
\text { última semana }\end{array}$ & $\begin{array}{l}\text { Consumo de álcool } \\
\text { na última semana }\end{array}$ & $\begin{array}{c}\text { Abstinente ou } \\
\text { consumo uma vez ou } \\
\text { várias vezes na } \\
\text { semana }\end{array}$ & $\begin{array}{l}\text { Bebendo bastante } \\
\text { diariamente, com ou } \\
\text { sem embriagues }\end{array}$ \\
\hline $\begin{array}{c}\text { Consumo de álcool no } \\
\text { último mês }\end{array}$ & $\begin{array}{l}\text { Consumo de álcool } \\
\text { no último mês }\end{array}$ & $\begin{array}{l}\text { Abstinente ou } \\
\text { consumiu } \\
\text { ocasionalmente }\end{array}$ & $\begin{array}{c}\text { Bebendo várias } \\
\text { vezes ou direto, com } \\
\text { ou sem embriaguez }\end{array}$ \\
\hline $\begin{array}{c}\text { Consumo de álcool no } \\
\text { último ano }\end{array}$ & $\begin{array}{l}\text { Consumo de álcool } \\
\text { no último ano }\end{array}$ & $\begin{array}{c}\text { Abstinente ou } \\
\text { consumo ocasional }\end{array}$ & $\begin{array}{c}\text { Bebendo várias } \\
\text { vezes ou direto, com } \\
\text { ou sem embriaguez }\end{array}$ \\
\hline
\end{tabular}


QUADRO 9 (continuação): Variáveis primárias, dicotômicas e respectivas categorias relativas a hábitos.

\begin{tabular}{|c|c|c|c|}
\hline 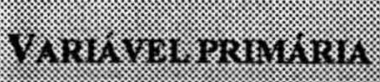 & & \multicolumn{2}{|c|}{ 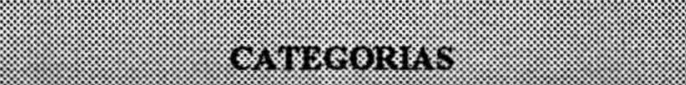 } \\
\hline $\begin{array}{l}\text { Consumo de álcool há } \\
\text { cinco anos }\end{array}$ & $\begin{array}{l}\text { Consumo de álcool } \\
\text { há cinco anos }\end{array}$ & $\begin{array}{c}\text { Abstinente ou } \\
\text { consumo ocasional }\end{array}$ & $\begin{array}{c}\text { Bebendo várias } \\
\text { vezes ou direto, com } \\
\text { ou sem de } \\
\text { embriaguez }\end{array}$ \\
\hline $\begin{array}{l}\text { Consumo de álcool há } \\
\text { dez anos }\end{array}$ & $\begin{array}{l}\text { Consumo de álcool } \\
\text { há dez anos }\end{array}$ & $\begin{array}{c}\text { Abstinente ou } \\
\text { consumo ocasional }\end{array}$ & $\begin{array}{c}\text { Bebendo várias } \\
\text { vezes ou direto, com } \\
\text { ou sem de } \\
\text { embriaguez }\end{array}$ \\
\hline $\begin{array}{c}\text { Consumo de álcool há } \\
\text { vinte anos }\end{array}$ & $\begin{array}{l}\text { Consumo de álcool } \\
\text { há vinte anos }\end{array}$ & $\begin{array}{c}\text { Abstinente ou } \\
\text { consumo ocasional }\end{array}$ & $\begin{array}{c}\text { Bebendo várias } \\
\text { vezes ou direto, com } \\
\text { ou sem de } \\
\text { embriaguez }\end{array}$ \\
\hline $\begin{array}{c}\text { História de consumo de } \\
\text { álcool }\end{array}$ & $\begin{array}{c}\text { História de consumo } \\
\text { de álcool }\end{array}$ & $\begin{array}{c}\text { Abstinente ou } \\
\text { consumo ocasional }\end{array}$ & $\begin{array}{c}\text { Bebendo várias } \\
\text { vezes ou direto, com } \\
\text { ou sem de } \\
\text { embriaguez }\end{array}$ \\
\hline
\end{tabular}


QUADRO 11: Variáveis primárias, variáveis dicotômicas e respectivas categorias referente às condições clínicas de saúde bucal.

\begin{tabular}{|c|c|c|c|}
\hline 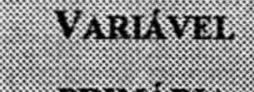 & 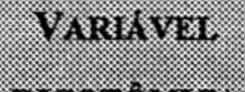 & \multicolumn{2}{|c|}{ 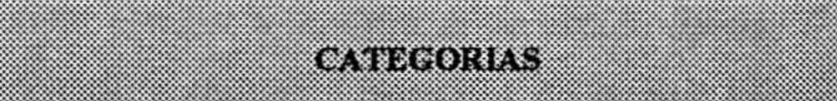 } \\
\hline $\begin{array}{l}\text { Cárie de coroa } \\
\qquad(>8)\end{array}$ & Cárie Coroa & Cárie Coroa $<8$ & Cárie Coroa >= 8 \\
\hline Cárie Raiz & Cárie Raiz & Cárie Raiz < 2 & Cárie Raiz $>=2$ \\
\hline Uso Prótese & Uso Prótese & $\begin{array}{c}\text { Não usa prótese ou usa só } \\
\text { PT }\end{array}$ & Usa 1 ou + PPR ou Fixa \\
\hline Biofilme & Biofilme & Biofilme $<1,0$ & Biofilme $>=1,0$ \\
\hline
\end{tabular}

\subsection{CONSIDERAÇões ÉTICAS}

Este estudo foi submetido à avaliação e aprovado pelo Comitê de Ética em Pesquisa da Faculdade de Saúde Pública da Universidade de São Paulo - FSP - USP.

Atendendo aos critérios exigidos pela Resolução 196, do Conselho Nacional de Saúde, de 10 de outubro de 1.996 todos os indivíduos identificados para participar do estudo foram previamente orientados em relação à finalidade da pesquisa e sua relevância; assim após esclarecimentos que se faziam necessários o indivíduo concordava ou não com a sua participação. Em caso afirmativo assinava o termo de consentimento livre e esclarecido que foi colocado como folha de rosto de cada uma das fichas (Anexo 1). 


\section{RESULTADOS}

\subsection{Coleta de Dados}

Das 700 pessoas que deveriam compor a amostra deste estudo apenas 629 pessoas atendiam os critérios de inclusão e aceitaram participar do estudo; houve a perda de 8 fichas e nenhuma recusa, sendo consideradas válidas as fichas de 621 indivíduos (tabela 4).

TABELA 4: Número e porcentagem de exames realizados em usuários adultos, de 25 a 55 anos de idade, do PSF Santa Marcelina, em 2.003, segundo Unidade de Saúde. São Paulo, 2.005.

\begin{tabular}{ccc}
\hline UNIDADE & EXAMES & \\
& $\mathbf{n}^{\mathbf{0}}$ & $\mathbf{\%}$ \\
\hline AE CARVALHO & 17 & 2,7 \\
BARRO BRANCO & 260 & 41,9 \\
CURUÇÁ VELHA & 55 & 8,9 \\
FANGANIELLO & 42 & 6,8 \\
JARAGUÁ & 44 & 7,1 \\
JARDIM CAMPOS & 99 & 15,9 \\
SANTA RITA & 104 & 16,7 \\
\hline TOTAL & $\mathbf{6 2 1}$ & $\mathbf{1 0 0 , 0}$ \\
\hline
\end{tabular}

A disponibilidade e o envolvimento das equipes de examinadores sofreu interferência das mudanças político-administrativas que ocorreram no PSF Santa Marcelina no decorrer do estudo, resultando em número diferente de exames em cada unidade de saúde.

Durante o rastreamento de risco realizado pelo serviço foram identificados 276 “doentes" (44,4\%), e 345 “não doentes" (55,6\%) (tabela 5).

Esta condição foi reavaliada pelo Índice de Condições Periodontais - CPI e foram então classificados definitivamente como "casos", 318 pessoas, portadoras de 
DPD - DPD, clinicamente diagnosticada pela presença de bolsas periodontais, e “controles", 303. (tabela 5).

TABELA 5: Número e porcentagem de exames realizados em usuários adultos, de 25 a 55 anos de idade, do PSF Santa Marcelina, em 2.003, segundo critérios utilizados pelo Indicador do PSF e o indicador desta pesquisa. São Paulo, 2.005.

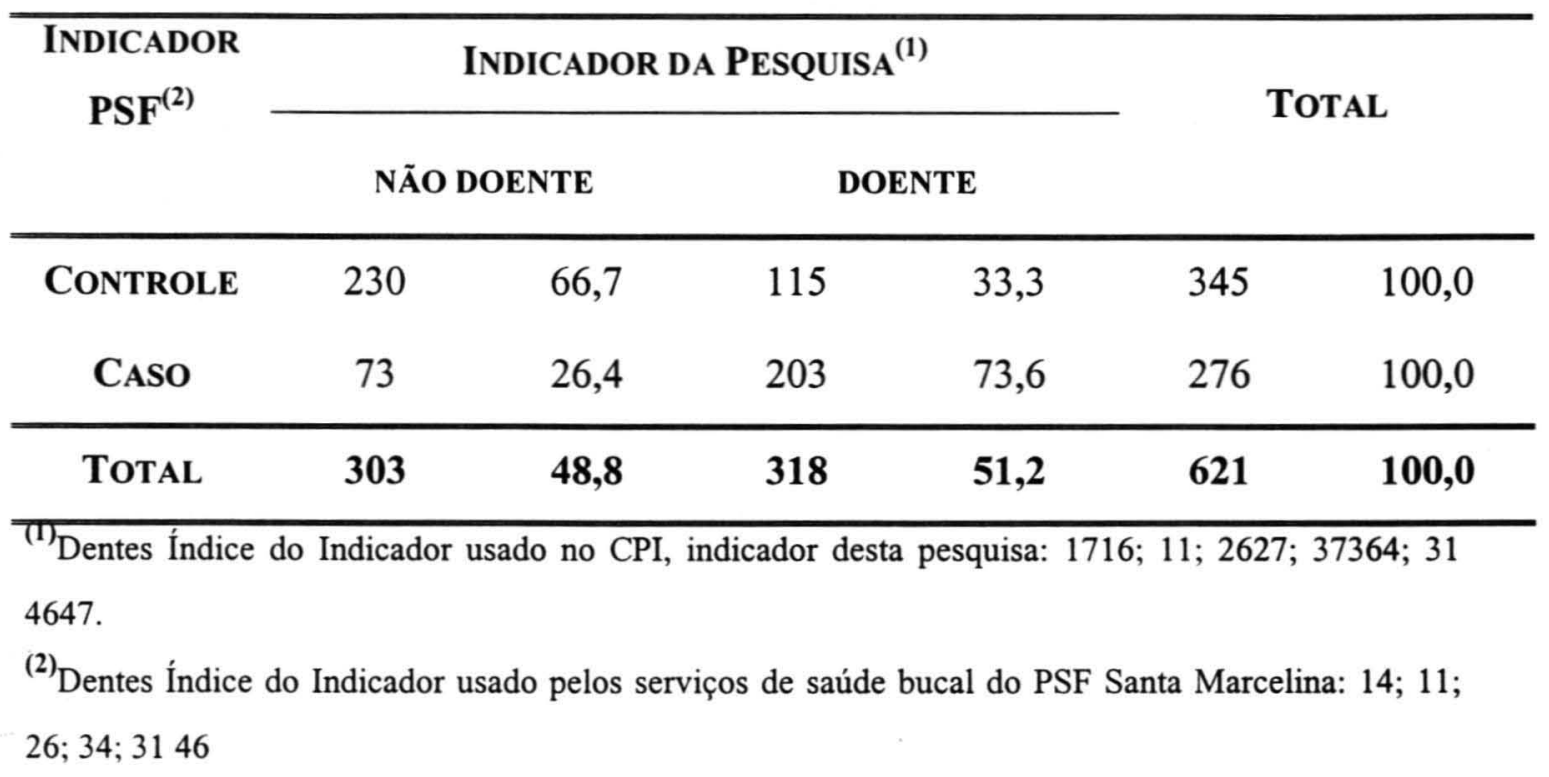

Medida pela estatística Kappa houve uma concordância de 0,396 entre as duas forma de se identificar "casos" e "controles" e "doentes" e "não doentes".

Segundo os parâmetros de confiabilidade LANDIS JR e KOCH (1.977), que estabeleceram uma escala de pontos para interpretar o coeficiente Kappa, definindo parâmetros para a maioria das situações encontradas verifica-se uma "fraca concordância" entre os métodos de avaliação periodontal usado pelo serviço e proposto pela pesquisadora.

\subsection{ANÁlise Descritiva dos RESUltados}

A análise descritiva dos resultados será apresentada de acordo com a classificação das variáveis independentes de estudo. 


\section{VARIÁVEIS SÓCIO DEMOGRÁFICAS}

Na tabela 6 apresenta-se a distribuição dos casos e controles segundo as variáveis sócio demográficas de interesse da pesquisa.

Do total de examinados 48,8\% eram controles e, 51, 2,0\% eram casos. Cabe salientar que $81,5 \%$ dos examinados tinham 35 ou mais anos de idade.

Havia 115 indivíduos com idade menor ou igual a 34 anos, sendo 72 casos $(36,5 \%)$ e 73 controles $(63,5 \%) ; 424$ examinados tinham de 35 a 44 anos de idade 236 casos $(55,7 \%)$ e 188 controles $(44,3 \%)$. Entre os 82 indivíduos com 45 e mais anos de idade 40 eram casos $(48,8 \%)$ e 42 controles $(51,2 \%)$.

Estabeleceu-se uma variável dicotômica para idade e assim verificou-se uma maior concentração de casos no grupo etário acima de 35 anos, com uma diferença de quase $10,0 \%$ entre casos $(45,5 \%)$ e controles $(54,5 \%)$.

Esta concentração deveu mais ao grupo de 35 a 44 anos do que aos com idade acima de 45 anos.

Das 621 fichas válidas, 70,7\% eram mulheres e 29,3\%, homens. Observou-se uma concentração de homens na condição de caso. Do total de homens (182), 69,2\% tinham DPD.

Quanto à naturalidade verificou-se que 47,6\% dos examinados eram da região nordeste do Brasil; $37,8 \%$ eram paulistas e 14,3\% oriundos de outras regiões do país; apenas dois indivíduos $(0,3 \%)$ eram estrangeiros. Entre os casos 34,6\% (110) eram paulistas.

Observou-se que $70,2 \%$ dos examinados tinham vida conjugal, sendo 50,0\% casados e $20,2 \%$ amasiados; dos $29,8 \%$ sem vida conjugal $19,2 \%$ eram solteiros, os demais eram separados, divorciados ou viúvos.

Utilizando-se a codificação da Receita Federal - Ministério da Fazenda (Anexo 6), quanto à Natureza da Ocupação, e, portanto, identificando o tipo de vínculo que o trabalhador tinha no mercado de trabalho, observou-se que profissionais liberais, autônomos ou sem vínculo de emprego (sem registro na carteira de trabalho) eram $32,0 \%$; menos de um quarto dos entrevistados $(23,7 \%)$ estão empregados no setor privado, com registro na carteira de trabalho; $13,4 \%$ eram servidores públicos, de autarquias ou fundações, ou de empresas de economia mista. Declararam estar desempregados e desocupados, 30,9\% dos entrevistados. 
Dicotomizando a variável verificou-se que entre os casos $46,9 \%$ não tinham trabalho ou renda e $53,1 \%$ tinham trabalho ou renda.

Quanto ao ramo de atividade ou Ocupação, conforme nomenclatura adotada pela Receita Federal - Ministério da Fazenda, (Anexo 6), verificou-se uma elevada concentração de trabalhadores de serviços $(41,7 \%)$; mais de $40,0 \%$ não puderam ser enquadrados em nenhum ramo de atividade, por exercerem atividades na economia informal ou estarem desempregados e desocupados; trabalhadores do comércio $(7,1 \%)$ e do setor industrial $(6,1 \%)$ figuram como um pouco mais expressivos em relação aos demais ramos de atividade.

Refinando a informação sobre ocupação, identificando a Ocupação Principal do entrevistado, expressão empregada pela Receita Federal - Ministério da Fazenda, (Anexo 7), das 249 pessoas do setor de serviços e assemelhados, 11,9\% eram empregados domésticos e 8,2\% eram prestadores de serviços de manutenção (pedreiros, encanadores, eletricistas, pintores, marceneiros, carpinteiros, mecânicos, serventes e técnicos da construção civil, técnicos de manutenção etc). Das atividades do setor industrial é mais notada a produção de roupas (7,3\%).

As 197 pessoas $(31,7 \%)$, que declararam estar sem renda própria no momento da pesquisa não puderam ser classificadas quanto ao ramo de atividade.

Quanto à escolaridade, 6,3\% dos entrevistados eram analfabetos, 68,3\% tinham até o primeiro grau completo, de $1^{\mathrm{a}}$ a $8^{\mathrm{a}}$ séries, hoje equivalente ao ensino fundamental. Um quarto dos examinados $(25,4 \%)$, declarou ter escolaridade igual ou superior ao segundo grau incompleto, atualmente equivalente ao ensino médio incompleto. À análise desta variável dicotomizada constatou-se que entre os casos $8,2 \%$ eram analfabetos. É importante observar que entre os 39 analfabetos houve o dobro de casos em relação aos controles. Nos indivíduos que sabem ler e escrever ou têm mais escolaridade o número de casos e controles se equivale.

Quando a escolaridade foi avaliada pelos anos de estudo, apenas 27 pessoas declararam não ter freqüentado à escola por nem mesmo um ano, o que corresponde a $4,3 \%$ do total de entrevistados. Entretanto $70,4 \%$ dos que não freqüentaram escola por pelo menos um ano tinham DPD.

Dos indivíduos que freqüentaram escola por um ano ou mais, a proporcionalidade entre casos $(50,3 \%)$ e controles $(49,7 \%)$ se manteve. 
TABELA 6: Número e porcentagem de controle e casos entre os usuários adultos do PSF Santa Marcelina, em 2.003, segundo variáveis sócio demográficas. São Paulo, 2.005 .

\begin{tabular}{|c|c|c|c|c|c|c|c|}
\hline \multirow{2}{*}{ VARIÁVEL } & \multirow{2}{*}{ CATEgorias } & \multicolumn{2}{|c|}{ CONTROLE } & \multicolumn{2}{|c|}{ Caso } & \multicolumn{2}{|c|}{ TOTAL } \\
\hline & & $\mathbf{n}$ & $\%$ & $\mathbf{n}$ & $\%$ & $\mathbf{n}$ & $\%$ \\
\hline \multirow[t]{2}{*}{ Grupo EtÁrio } & 25 a 34 anos & 73 & 63,5 & 42 & 36,5 & 115 & 100,0 \\
\hline & 35 a 55 anos & 230 & 45,5 & 276 & 54,5 & 506 & 100,0 \\
\hline \multirow[t]{2}{*}{ SEXO } & Feminino & 247 & 56,3 & 192 & 43,7 & 439 & 100,0 \\
\hline & Masculino & 56 & 30,8 & 126 & 69,2 & 182 & 100,0 \\
\hline \multirow[t]{2}{*}{ NATURALIDADE } & Paulistas & 84 & 42,3 & 110 & 56,7 & 194 & 100,0 \\
\hline & Não paulistas & 219 & 51,3 & 208 & 48,7 & 427 & 100,0 \\
\hline \multirow[t]{2}{*}{ VIDA CONJUGAL ${ }^{*}(1)$} & Sem vida conjugal & 96 & 51,9 & 89 & 48,1 & 185 & 100,0 \\
\hline & Com vida conjugal & 206 & 47,4 & 229 & 52,6 & 435 & 100,0 \\
\hline \multirow[t]{2}{*}{ TRABALHO E RENDA } & $\begin{array}{l}\text { Tem trabalho e/ou } \\
\text { renda }\end{array}$ & 201 & 46,9 & 228 & 53,1 & 429 & 100,0 \\
\hline & $\begin{array}{l}\text { Não tem trabalho e } \\
\text { nem renda }\end{array}$ & 102 & 53,1 & 90 & 46,9 & 192 & 100,0 \\
\hline \multirow[t]{2}{*}{ ESCOLARIDADE $^{*}(2)$} & $\begin{array}{l}\text { Sabe ler e escrever } \\
\text { ou mais }\end{array}$ & 289 & 49,8 & 291 & 50,2 & 580 & 100,0 \\
\hline & Analfabeto & 13 & 33,3 & 26 & 66,7 & 39 & 100,0 \\
\hline \multirow[t]{2}{*}{ ANOS DE ESCOLA } & 1 ano ou mais & 295 & 49,7 & 299 & 50,3 & 594 & 100,0 \\
\hline & Menos de 1 ano & 8 & 29,6 & 19 & 70,4 & 27 & 100,0 \\
\hline
\end{tabular}

"Tma pessoa não declarou seu estado civil e não pode ser classificada quanto à vida conjugal.

${ }^{*}(2)$ Duas pessoas não responderam a questão sobre escolariddade 
No que se refere à religião verificou-se um percentual predominante de católicos $(63,8 \%)$ e evangélicos $(29,6 \%)$. As freqüências das outras religiões foram inexpressivas.

\section{VARIÁveIS RElativas a Condições E Estados de SAÚde Geral}

Diabéticos, insulino - dependentes (ID) ou não (NID), foram identificados quanto ao tempo de duração da diabetes e do uso de medicação apropriada. Apenas 22 pacientes declararam ser diabéticos, sendo que apenas 14 faziam uso de medicação para compensar esta condição; os 8 restantes controlavam sua glicemia através da dieta (tabela 7). Quinze pessoas desconheciam sua situação em relação à diabetes ou não responderam a este quesito. Dos 22 pacientes com diabetes, 15 (68,2\% dos diabéticos) apresentavam DPD. O tempo de duração da diabetes variou de 4 meses a 17 anos.

Apenas 27 pessoas declararam estar sob acompanhamento de neurologista ou psiquiatra $(4,3 \%)$ e fazendo uso de medicação (tabela 7$)$. O tempo de duração da doença variou de 1 mês a 17 anos e o uso de medicação, de 1 mês a 35 anos. Entre os 27 indivíduos que declararam ter problemas neurológicos ou psíquicos havia 12 "casos" e 15 "controles".

Dezessete pessoas declararam ser portadores de doenças auto-imunes (gota, lupus, artrite reumatóide etc), sendo que 11 faziam uso de medicação imunodepressora, a base de cortisona ou similares (tabela 14). Três pessoas desconheciam sua condição sistêmica em relação a doenças auto-imunes ou não responderam esta questão. O tempo de duração da doença variou de 5 meses a 25 anos, e o de uso da medicação, de 1 mês a 10 anos. Foram encontrados 10 "casos" entre os 17 pacientes com doenças auto-imunes ou usando medicação imunodepressora. 
TABELA 7: Número e porcentagem de controle e casos entre os usuários adultos do PSF Santa Marcelina, em 2003, segundo variáveis relativas a estados e condições de saúde geral, relativas a diabetes, distúrbios neurológicos ou psíquicos e doenças autoimune. São Paulo, 2005.

\begin{tabular}{|c|c|c|c|c|c|c|c|}
\hline \multicolumn{2}{|c|}{$\begin{array}{c}\text { ESTADOS E CONDIÇõES DE SAÚDE } \\
\text { GERAL }\end{array}$} & \multicolumn{2}{|c|}{ CONTROLE } & \multicolumn{2}{|c|}{ CASO } & \multicolumn{2}{|c|}{ TOTAL } \\
\hline & & $\mathrm{N}$ & $\%$ & $\mathbf{N}$ & $\%$ & $\mathrm{~N}$ & $\%$ \\
\hline \multirow[t]{2}{*}{ DIABETES $^{*(1)}$} & Não & 291 & 49,8 & 293 & 50,2 & 584 & 100,0 \\
\hline & SIM & 7 & 31,8 & 15 & 68,2 & 22 & 100,0 \\
\hline \multicolumn{8}{|l|}{ NEUROLÓGICOS OU } \\
\hline PSíQuicos & SIM & 15 & 55,6 & 12 & 44,0 & 27 & 100,0 \\
\hline \multirow{2}{*}{$\begin{array}{l}\text { DOENÇA AUTO-IMUNE } \\
*_{(2)}\end{array}$} & NÃo & 294 & 48,9 & 307 & 51,1 & 601 & 100,0 \\
\hline & SIM & 7 & 41,2 & 10 & 58,8 & 17 & 100,0 \\
\hline
\end{tabular}

(1) 15 pessoas não sabiam se eram ou não diabéticas

*(2) 3 pessoas desconheciam sua condição sistêmica quanto a doenças auto-imunes.

\section{VARIÁVEIS RELATIVAS A HÁBITOS E COSTUMES}

\section{CONSUMO DE TABACO}

Investigou-se o hábito de fumar cigarros industrializados, cigarros de palha, charuto e cachimbo. Indagou-se ainda o uso do tabaco sob outras formas, como o tabaco em pó, que é inalado, (rapé), ou mascado, mastigado (Nicotian tabacum ou tabaco, bétel ou bétele). Aproximadamente $2 / 3$ dos examinados (74,7\%) não fumam, inalam (aspiram, cheiram) ou mascam tabaco.

Declararam ter parado de fumar 129 entrevistados. Entre os não fumantes houve uma proporcionalidade entre portadores de DPD (50,1\% casos) e sem este grau da doença ( $49,9 \%$ controles).

Fumar cachimbo ou charuto e mascar tabaco não foram hábitos encontrados entre os entrevistados neste estudo. 
Dos $25,4 \%$ examinados que declararam usar tabaco, apenas um fuma cigarro de palha, além do industrializado.

Entre os fumantes, $44,9 \%$ não tinham DPD e 55,1\% apresentavam a doença.

Dos 158 fumantes, $38(24,0 \%)$ fumam de 1 a 9 cigarros por dia, $76(48,1 \%)$ fumam de 10 a 19 cigarros por dia, $40(25,3 \%)$ fumantes consomem de 20 a 29 cigarros/dia, e apenas $4(2,6 \%)$ fumam 30 cigarros ou mais por dia.

Sessenta e cinco fumantes (47,4\% dos fumantes) têm o hábito há 21 ou mais anos; 42 (26,6\%) fumam de 16 a 20 anos. Assim, em torno de 25,0\% fuma há menos de 15 anos.

A dependência de nicotina foi obtida pelo teste de Faggerströn. Dependência leve de nicotina foi a condição de 73 indivíduos (46,2\%) 70 examinados $(44,3 \%)$ apresentaram média dependência e, 9,5\% (15 examinados) têm alta dependência de nicotina.

O tipo de dependência leve e média foi similar nos casos; dos 9 indivíduos que apresentavam alta dependência de nicotina apenas 3 tinham DPD.

A tabela 8 apresenta os resultados relativos ao hábito de fumar ou não, e dependência de nicotina.

TABELA 8 Número e porcentagem de controles e casos entre os usuários adultos do PSF Santa Marcelina, 2003, segundo hábito de fumar dependência de nicotina.São Paulo, 2005

\begin{tabular}{ccccccccc}
\hline HÁbITO & & \multicolumn{2}{c}{ CASO } & \multicolumn{2}{c}{ CONTROLE } & \multicolumn{2}{c}{ TOTAL } \\
\hline \multirow{2}{*}{ FUMA } & LEPENDÊNCIA & LEVE & 31 & 10,2 & 42 & 13,2 & 73 & 11,7 \\
& DE NICOTINA & MÉDIA & 31 & 10,2 & 39 & 12,3 & 70 & 11,3 \\
& & ALTA & 9 & 3,0 & 6 & 1,9 & 15 & 2,4 \\
NÃo FUMA & & 232 & 76,6 & 231 & 71,6 & 463 & 74,6 \\
\hline TOTAL & & & $\mathbf{3 0 3}$ & $\mathbf{1 0 0 , 0}$ & $\mathbf{3 1 8}$ & $\mathbf{1 0 0 , 0}$ & $\mathbf{6 2 1}$ & $\mathbf{1 0 0 , 0}$ \\
\hline \hline
\end{tabular}




\section{CONSUmo de Álcool}

Declararam consumir álcool $217(34,9 \%)$ entrevistados e destes, a grande maioria (191 pessoas $=88,0 \%$ ), consome tanto bebidas fermentadas quanto destiladas. Apenas 14 pessoas $(6,5 \%)$ consomem exclusivamente bebidas destiladas, e apenas $12(5,5 \%)$, exclusivamente fermentadas.

\section{CONSUMO DE BEBIDAS FERMENTADAS}

O consumo de cerveja foi declarado por $181(81,4 \%)$ pessoas; 107 pessoas consomem cerveja em lata, o que corresponde a 49,3\% dos consumidores de álcool, e o consumo semanal gira em torno de 1 e 12 latas; convertendo-se este consumo em doses de álcool absoluto há um consumo médio é de 2,27 doses álcool absoluto sob a forma de cerveja em lata. A mediana do consumo de álcool absoluto sob a forma de cerveja em lata, por semana, foi de 68,0 gramas.

O consumo de cerveja em copo é habitual em 37 indivíduos, sendo que há um consumo de no máximo 14 doses de álcool por semana sob a forma de cerveja em copo (190,4 gramas de álcool absoluto), e um consumo mediano de 2 doses semanais de cerveja em copo.

O consumo de álcool sob a forma de cerveja em garrafa foi declarado em 85 entrevistas. O consumo variou de 1 a 24 garrafas de cerveja por semana, o que representa um consumo máximo de 48 doses de álcool sob a forma de cerveja em garrafa (equivalente a 643,2 gramas de álcool absoluto). Apesar da amplitude de consumo verificou-se que aproximadamente 70,0\% consomem menos de 6 doses semanais de álcool sob esta forma de apresentação (80,4 gramas de álcool absoluto).

O vinho é consumido semanalmente por 38 entrevistados (17,5\%), sendo que mais de $2 / 3(76,3 \%)$ consomem até 2 doses semanais de álcool sob a forma de vinho. Para champanhe 32 pessoas declararam consumo semanal, e 62,5\% consomem uma dose de álcool semanalmente sob esta forma.

\section{Consumo de Bebidas Destiladas}

A aguardente foi a bebida destilada com maior número de consumidores $(n=$ 46), e 50,0\% destes, consomem no máximo 2 doses de álcool absoluto sob esta forma 
semanalmente; há, entretanto, consumidores de 49 doses de álcool semanal sob a forma de aguardente.

O uísque aparece como segunda bebida destilada consumida, mesmo assim apenas 7 pessoas declararam consumí-la. Este consumo variou de 1 a 7 doses semanais, sendo que mais de $70,0 \%$ dos consumidores de uísque consomem no máximo 2 doses por semana.

Três pessoas declararam consumir licor semanalmente; Encontrou-se apenas um consumidor de chope, outro para vodka, assim como para rum e gim e grappa..

\section{HistóRIA DE CONSUMO DE ÁlCOOL}

Todos os entrevistados, após o questionamento dos tipos de bebidas consumidas, responderam a questões que se referiam à sua história de consumo de bebidas alcoólicas (tabela 9), considerando o consumo na última semana, no último mês e último ano. Classificaram também o seu consumo há 5, 10 e 20 anos atrás.

Poucos foram os entrevistados que não responderam ou não souberam como classificar seu consumo de álcool nos períodos de referência (NSNR).

A resposta "abstinente" variou de $88,4 \%$ a $56,5 \%$; De $23,0 \%$ a $34,3 \%$ (em torno de um quarto) dos entrevistados consome álcool de forma ocasional, podendo ser considerados etilistas sociais. O hábito de consumir álcool em maior quantidade $\mathrm{e}$ freqüência mas com controle e sem episódios de embriaguez variou de 2,7 a 6,3\%. De $0,3 \%$ a 2,1\% (2 a 13) indivíduos declararam o consumo de álcool em grande quantidade, sem controle e com episódios de embriaguez, provavelmente pessoas dependentes de álcool (alcoolistas crônicos) ou que fazem uso abusivo desta droga. 
TABELA 9: Número e porcentagem de controles e casos entre os usuários adultos, de 25 a 55 anos de idade, PSF Santa Marcelina, 2.003 segundo consumo de álcool e período considerado (na última semana, no último mês, no último ano, há 5 anos, há 10 anos e há 20 anos), São Paulo, 2.005

\section{PERÍodo}

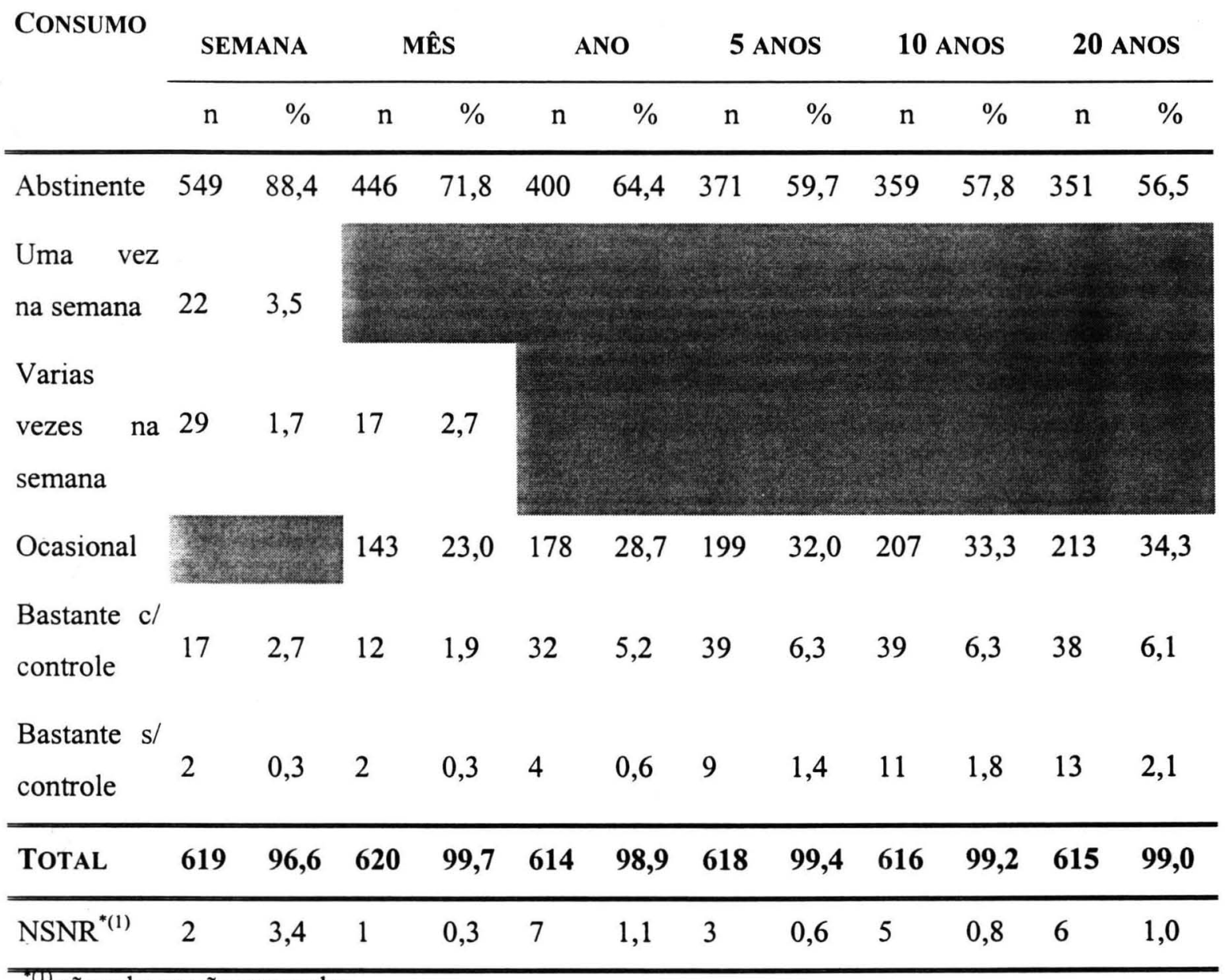

"(1) não sabe ou não respondeu

Ao teste de Qui Quadrado de tendência, realizado no aplicativo do EPI INFO versão $5.01 \mathrm{~b}$, obteve-se os resultados apresentados nas tabelas 10 a 15 . 
TABELA 10: Teste de tendência para doenças periodontais destrutivas segundo consumo de álcool na última semana, de usuários adultos, de 25 a 55 anos de idade, PSF Santa Marcelina, 2.003. São Paulo 2.005.

\begin{tabular}{|c|c|c|c|c|c|}
\hline \multirow{2}{*}{$\begin{array}{l}\text { CONSUMO DE } \\
\text { ÁLCOOL }\end{array}$} & \multicolumn{5}{|c|}{ ÚLTIMA SEMANa } \\
\hline & \multirow{2}{*}{$\frac{\text { CASOS }}{n}$} & \multirow{2}{*}{$\frac{\text { CONTROLES }}{\mathrm{n}}$} & \multirow{2}{*}{$\begin{array}{c}\mathbf{X}^{2} \\
\text { TENDÊNCIA }\end{array}$} & \multirow[t]{2}{*}{$\mathbf{p}$} & \multirow[t]{2}{*}{ OR } \\
\hline & & & & & \\
\hline ABSTINENTE & 283 & 266 & & & 1,00 \\
\hline UMA VEZ NA & 14 & 8 & & & 1,64 \\
\hline SEMANA & & & & & \\
\hline VARIAS VEZES NA & 21 & 8 & 6,807 & 0,00908 & 2,47 \\
\hline SEMANA & & & & & \\
\hline $\begin{array}{l}\text { BASTANTE C/ OU } \\
\text { S/ CONTROLE }\end{array}$ & 13 & 6 & & & 2,04 \\
\hline
\end{tabular}

TABELA 11: Teste de tendência para doenças periodontais destrutivas segundo consumo de álcool no último mês, de usuários adultos, de 25 a 55 anos de idade, PSF Santa Marcelina, 2.003. São Paulo 2.005.

\begin{tabular}{|c|c|c|c|c|c|}
\hline \multirow{3}{*}{$\begin{array}{l}\text { CONSUMO DE } \\
\text { ÁLCOOL }\end{array}$} & \multicolumn{5}{|c|}{ ÚLTIMO MÊS } \\
\hline & CASOS & CONTROLES & \multirow{2}{*}{$\begin{array}{c}\mathbf{X}^{2} \\
\text { TENDÊNCIA }\end{array}$} & \multirow[t]{2}{*}{$\mathbf{p}$} & \multirow[t]{2}{*}{ OR } \\
\hline & $\mathrm{n}$ & $\mathrm{n}$ & & & \\
\hline ABSTINENTE & 225 & 221 & & & 1,00 \\
\hline OCASIONAL & 73 & 70 & & & 1,02 \\
\hline $\begin{array}{c}\text { VARIAS } \\
\text { VEZES/SEMANA }\end{array}$ & 14 & 3 & 3,289 & 0,06973 & 4,58 \\
\hline $\begin{array}{c}\text { BASTANTE C/ OU S/ } \\
\text { CONTROLE }\end{array}$ & 9 & 5 & & & 1,77 \\
\hline
\end{tabular}


TABELA 12: Teste de tendência para doenças periodontais destrutivas segundo consumo de álcool no último ano, de usuários adultos, de 25 a 55 anos de idade, PSF Santa Marcelina, 2.003. São Paulo 2.005.

\begin{tabular}{|c|c|c|c|c|c|}
\hline \multirow{3}{*}{$\begin{array}{l}\text { CONSUMO DE } \\
\text { ÁlCOOL }\end{array}$} & \multicolumn{5}{|c|}{ ÚltiMo ANO } \\
\hline & CAsOS & CONTROLES & $\mathbf{X}^{2}$ & $\mathbf{p}$ & OR \\
\hline & $\mathrm{n}$ & $\mathrm{n}$ & TENDÊNCIA & & \\
\hline ABSTINENTE & 212 & 188 & & & 1,00 \\
\hline OCASIONAL & 75 & 103 & 0,067 & 0,79635 & 0,65 \\
\hline $\begin{array}{l}\text { BASTANTE C/ OU S/ } \\
\text { CONTROLE }\end{array}$ & 28 & 9 & & & 2,76 \\
\hline
\end{tabular}

TABELA 13: Teste de tendência para doenças periodontais destrutivas segundo consumo de álcool há 5 anos, de usuários adultos, de 25 a 55 anos de idade, PSF Santa Marcelina, 2.003. São Paulo 2.005.

\begin{tabular}{|c|c|c|c|c|c|}
\hline \multirow{3}{*}{$\begin{array}{l}\text { CONSUMO DE } \\
\text { ÁLCOOL }\end{array}$} & \multicolumn{5}{|c|}{ HÁ 5 ANOS } \\
\hline & CASOS & CONTROLES & $\mathbf{X}^{2}$ & $\mathbf{p}$ & OR \\
\hline & $\mathrm{n}$ & $\mathrm{n}$ & TENDÊNCIA & & \\
\hline ABSTINENTE & 203 & 168 & & & 1,00 \\
\hline OCASIONAL & 80 & 119 & & & 0,56 \\
\hline $\begin{array}{l}\text { BASTANTE C/ OU S/ } \\
\text { CONTROLE }\end{array}$ & 33 & 15 & 0,374 & 0,54065 & 1,82 \\
\hline
\end{tabular}


TABELA 14: Teste de tendência para doenças periodontais destrutivas segundo consumo de álcool há 10 anos, de usuários adultos, de 25 a 55 anos de idade, PSF Santa Marcelina, 2.003. São Paulo 2.005.

\begin{tabular}{|c|c|c|c|c|c|c|}
\hline \multirow{3}{*}{\multicolumn{2}{|c|}{$\begin{array}{l}\text { CONSUMO DE } \\
\text { ÁLCOOL }\end{array}$}} & \multicolumn{5}{|c|}{ HÁ 10 AnOS } \\
\hline & & \multirow[t]{2}{*}{ CASOS } & \multirow{2}{*}{$\begin{array}{l}\text { CONTROLES } \\
\mathrm{n}\end{array}$} & \multirow{2}{*}{$\begin{array}{c}\mathbf{X}^{2} \\
\text { TENDÊNCIA }\end{array}$} & \multirow[t]{2}{*}{$\mathbf{p}$} & \multirow[t]{2}{*}{ OR } \\
\hline & & & & & & \\
\hline ABSTINENTE & & 200 & 159 & & & 1,00 \\
\hline OCASIONAL & & 83 & 124 & 1,133 & 0,28708 & 0,53 \\
\hline $\begin{array}{l}\text { BASTANTE } \\
\text { CONTROLE }\end{array}$ & $\mathrm{Cl}$ & 33 & 17 & & & 1,54 \\
\hline
\end{tabular}

TABELA 15: Teste de tendência para doenças periodontais destrutivas segundo consumo de álcool há 20 anos, de usuários adultos, de 25 a 55 anos de idade, PSF Santa Marcelina, 2.003. São Paulo 2.005.

\begin{tabular}{|c|c|c|c|c|c|}
\hline \multirow{3}{*}{$\begin{array}{l}\text { CONSUMO DE } \\
\text { ÁLCOOL }\end{array}$} & \multicolumn{5}{|c|}{ HÁ 20 ANOS } \\
\hline & CASOS & CONTROLES & $\mathbf{X}^{2}$ & $\mathbf{p}$ & OR \\
\hline & $\mathrm{n}$ & $\mathrm{n}$ & TENDENCIA & & \\
\hline ABSTINENTE & 194 & 157 & & & 1,00 \\
\hline OCASIONAL & 85 & 128 & & & 0,54 \\
\hline $\begin{array}{c}\text { BASTANTE C/ } \\
\text { CONTROLE }\end{array}$ & 35 & 16 & 0,531 & 0,46618 & 1,77 \\
\hline
\end{tabular}




\section{VARIÁveis ClíniCAS EM SAÚde BUCAL}

\section{CONDIÇÕES PERIODONTAIS}

$\mathrm{Na}$ tabela 16 apresentam-se as freqüências absoluta e relativa da doença periodontal em seus diversos gradientes de gravidade ${ }^{*}(15)$.

A pior condição encontrada em cada indivíduo reflete a prevalência da doença (tabela 16), segundo critérios e orientações da OMS e FDI, para publicação de resultados sobre condições periodontais utilizando o CPITN (CUTRESS, AINAMO E SARDO-INFIRRI 1.987)

Verificou-se uma maior prevalência de doenças periodontais nos homens $(97,3 \%)$, considerando as alterações periodontais desde sangramento (gengivite) à presença de bolsas periodontais. A prevalência das doenças periodontais nas mulheres foi de $89,0 \%$.

No que se refere à gravidade, observou-se que a doença destrutiva acometeu $43,8 \%$ das mulheres e $69,3 \%$ dos homens. Apesar das mulheres terem apresentado doenças periodontais estas se manifestaram nas formas mais tênues.

${ }^{*}{ }^{(16)}$ A condição de sextantes nulos não foi computada para pior condição periodontal. 
TABELA 16: Número e porcentagem de controles e casos entre os usuários adultos, de 25 a 55 anos de idade, PSF Santa Marcelina, 2.003 segundo sexo e maior valor do CPI. São Paulo, 2.005.

\begin{tabular}{|c|c|c|c|c|c|c|c|c|c|}
\hline \multirow{3}{*}{$\begin{array}{c}\text { MAIOR VALOR } \\
\text { DO CPI } \\
0\end{array}$} & \multicolumn{6}{|c|}{ SEXo } & \multicolumn{3}{|c|}{ TOTAL } \\
\hline & \multicolumn{3}{|c|}{ FEMININO } & \multicolumn{3}{|c|}{ Masculino } & \multirow[b]{2}{*}{$\mathbf{n}$} & & \\
\hline & $\mathbf{n}$ & \% & & n & \% & & & \multicolumn{2}{|c|}{$\%$} \\
\hline \multicolumn{9}{|l|}{ (NORMAL) } & 100,0 \\
\hline $\begin{array}{c}1 \\
\text { (SANGRAMENTO) }\end{array}$ & 125 & 28,5 & 80,6 & 30 & 16,5 & 19,4 & 155 & 25,0 & 100,0 \\
\hline \multicolumn{10}{|l|}{2} \\
\hline $\begin{array}{l}\text { (FATORES DE } \\
\text { RETENÇÃO DE }\end{array}$ & 74 & 16,9 & 77,9 & 21 & 11,5 & 22,1 & 95 & 15,3 & 100,0 \\
\hline \multicolumn{10}{|l|}{ BIOFILME E } \\
\hline \multicolumn{10}{|l|}{ CÁlCULO) } \\
\hline \multicolumn{10}{|l|}{3} \\
\hline (BOLSAS RASAS & 128 & 29,2 & 63,4 & 74 & 40,7 & 36,6 & 202 & 32,5 & 100,0 \\
\hline \multicolumn{10}{|l|}{ ATÉ 5,5 MM) } \\
\hline \multicolumn{10}{|l|}{4} \\
\hline (BOLSAS & 64 & 14,6 & 55,2 & 52 & 28,6 & 44,8 & 116 & 18,7 & 100,0 \\
\hline \multicolumn{10}{|l|}{ PROFUNDAS 6,0 } \\
\hline $\mathrm{MM} \mathrm{OU}+)$ & & & & & & & & & \\
\hline TOTAL & 439 & 100,0 & 70,7 & 182 & 100,0 & 29,3 & 621 & 100,0 & 100,0 \\
\hline
\end{tabular}


A análise da extensão das doenças periodontais por sextante está na tabela 17.

O sextante 5 , que corresponde à região anterior inferior (dente índice 31), foi o que apresentou a melhor condição em relação aos demais sextantes, tendo maior freqüência para o código 0 do CPI, ou seja, mais freqüentemente estava com o periodonto normal.

O sextante 6 , que corresponde à região dos molares e pré-molares inferiores do lado direito (dentes índice 4647 ) apresentou sangramento com maior freqüência; a presença de fatores de retenção de biofilme e cálculo foi mais freqüente na região de incisivos e caninos inferiores, sextante anterior inferior (sextante 5, dente índice 31).

Bolsas rasas foi a condição mais freqüente no sextante 1 , região de molares e pré-molares superiores do lado direito (dentes índice 16 17), e bolsas profundas, no sextante 3 , região de pré-molares e molares superiores do lado esquerdo (dentes índice 26 27).

O sextante 4 se apresentou nulo com maior freqüência (região de pré-molares e molares inferiores do lado esquerdo, dentes índice 36 37).

Houve uma média de 1,1 sextantes nulos por indivíduo, e uma média de 1,4 sextantes apresentam bolsas rasas ou profundas.

Bolsas rasas ou profundas foram observadas em 25,0\% dos sextantes examinados nas mulheres, enquanto que nos homens esta condição compromete $41,2 \%$ dos sextantes. 
TABELA 17: Número, porcentagem e média de sextantes examinados em usuários adultos, de 25 a 55 anos de idade, de serviços de saúde, segundo sextante e condição periodontal medida pelo CPI. PSF Santa Marcelina em 2.003. São Paulo, 2.005.

\begin{tabular}{|c|c|c|c|c|c|c|c|}
\hline $\begin{array}{l}\text { Código do } \\
\text { SEXTANTE }\end{array}$ & 1 & 2 & 3 & 4 & 5 & 6 & \multirow{2}{*}{$\begin{array}{l}\text { MÉdia de } \\
\text { SEXTANTES }\end{array}$} \\
\hline DENTES ÍNDICE & 1716 & 11 & 2627 & 3637 & 31 & 4746 & \\
\hline \multicolumn{8}{|l|}{ CONDIÇÃO } \\
\hline \multirow[t]{2}{*}{0 (NORMAL) } & 90 & 234 & 98 & 146 & 230 & 118 & \multirow{2}{*}{1,5} \\
\hline & 14,5 & 37,7 & 15,8 & 23,5 & 37,0 & 19,0 & \\
\hline \multirow[t]{2}{*}{ 1(SANGRAMENTO) } & 160 & 103 & 140 & 148 & 148 & 163 & \multirow{2}{*}{1,4} \\
\hline & 25,8 & 16,6 & 22,5 & 23,8 & 23,8 & 26,2 & \\
\hline \multirow{2}{*}{$\begin{array}{c}2 \text { (RETENÇÃO DE } \\
\text { BIOFILME E } \\
\text { CÁLCULO) }\end{array}$} & 38 & 46 & 50 & 50 & 123 & 62 & \multirow{2}{*}{0,6} \\
\hline & 6,1 & 7,4 & 8,1 & 8,1 & 19,8 & 10,0 & \\
\hline \multirow{2}{*}{$\begin{array}{c}3 \text { (BOLSAS RASAS } \\
\text { ATÉ 5,5 MM) }\end{array}$} & 149 & 91 & 144 & 113 & 89 & 119 & \multirow{2}{*}{1,1} \\
\hline & 24,0 & 14,6 & 23,2 & 18,2 & 14,3 & 19,2 & \\
\hline 4 (BOLSAS & 49 & 26 & 58 & 21 & 24 & 23 & \multirow{2}{*}{0,3} \\
\hline $\begin{array}{l}\text { PROFUNDAS } \\
\text { 6,0MM OU }+ \text { ) }\end{array}$ & 7,9 & 4,2 & 9,3 & 3,4 & 3,9 & 3,7 & \\
\hline \multirow[t]{2}{*}{ Nulos } & 135 & 121 & 131 & 143 & 7 & 136 & \multirow{2}{*}{1,1} \\
\hline & 21,7 & 19,5 & 21,1 & 23,0 & 1,2 & 21,9 & \\
\hline \multirow[t]{2}{*}{ TOTAL } & 621 & 621 & 621 & 621 & 621 & 621 & \multirow[t]{2}{*}{6,0} \\
\hline & 100,0 & 100,0 & 100,0 & 100,0 & 100,0 & 100,0 & \\
\hline
\end{tabular}




\section{PERDA DE INSERÇÃo PERIOdONTAL}

A tabela 18 apresenta a perda de inserção medida pelo PIP encontrado na população de estudo.

Foram destacados os percentuais mais elevados em cada uma das condições.

O sextante 5, região de incisivos e caninos inferiores foi o que se apresentou mais freqüentemente sem perda de inserção periodontal.

Perdas em torno de 4 a $5 \mathrm{~mm}$ e de 6 a $8 \mathrm{~mm}$ foram identificadas no sextante 1 , na região de pré-molares e molares superiores do lado direito.

Grandes perdas de inserção, a partir de $9 \mathrm{~mm}$, foram mais freqüentes no sextante 3 , região de pré-molares e molares superiores do lado esquerdo.

O sextante 4 foi o que esteve nulo ou sem condições de exame para perda de inserção com maior freqüência.

Realizou-se a estatística Kappa para perda de inserção e DPD Houve uma moderada concordância entre perda de inserção e doenças periodontais destrutivas $(0,582)$. 
TABELA 18: Número, porcentagem e média de sextantes examinados, em usuários adultos, de 25 a 55 anos de idade, PSF Santa Marcelina em 2.003, segundo sextante e perda de inserção periodontal medida pelo PIP.São Paulo, 2.005.

\begin{tabular}{|c|c|c|c|c|c|c|c|}
\hline $\begin{array}{l}\text { CóDIGO do } \\
\text { SEXTANTE }\end{array}$ & 1 & 2 & 3 & 4 & 5 & 6 & $\begin{array}{c}\text { MÉDIA } \\
\text { DOS }\end{array}$ \\
\hline DENTES ÍNDICE & 1716 & 11 & 2627 & 3637 & 31 & 4746 & $\begin{array}{l}\text { SEXTAN } \\
\text { TES }\end{array}$ \\
\hline \multicolumn{8}{|l|}{ CONDIÇÃO } \\
\hline 0 & 258 & 376 & 262 & 322 & 428 & 317 & \multirow{2}{*}{3,2} \\
\hline $\begin{array}{l}\text { S/ PERDA } \\
\text { INSERÇÃO }\end{array}$ & 41,5 & 60,6 & 42,2 & 51,9 & 68,9 & 51,0 & \\
\hline 1 & 124 & 66 & 110 & 110 & 99 & 115 & \multirow[b]{2}{*}{1,0} \\
\hline PERDA 4-5 MM & 20,0 & 10,6 & 17,7 & 17,7 & 15,9 & 18,5 & \\
\hline 2 & 79 & 45 & 84 & 40 & 74 & 45 & \multirow[b]{2}{*}{0,6} \\
\hline PERDA 6-8 MM & 12,7 & 7,2 & 13,5 & 6,5 & 11,9 & 7,2 & \\
\hline 3 & 19 & 10 & 26 & 4 & 6 & 5 & \multirow{2}{*}{0,1} \\
\hline PERDA 9-11 MM & 3,1 & 1,6 & 4,2 & 0,6 & 1,0 & 0,8 & \\
\hline 4 & 6 & 3 & 8 & 2 & 5 & 1 & \multirow{2}{*}{0,0} \\
\hline PERDA > 12 MM & 1,0 & 0,5 & 1,3 & 0,3 & 0,8 & 0,2 & \\
\hline \multirow[t]{2}{*}{ Nulos CPI1 } & 135 & 121 & 131 & 143 & 9 & 138 & \\
\hline & 21,7 & 19,5 & 21,1 & 23,0 & 1,5 & 22,3 & \\
\hline & 621 & 621 & 621 & 621 & 621 & 621 & \multirow{2}{*}{6,0} \\
\hline TOTAL & 100,0 & 100,0 & 100,0 & 100,0 & 100,0 & 100,0 & \\
\hline
\end{tabular}




\section{EXPERIÊNCIA DE CÁRIE \\ CÁRIE DE COROA}

A média de dentes atacados por cárie - CPO-D foi de 18,57 e o componente perdido é o de maior peso (média de dentes perdidos $=10,64$ ). Verificou-se que $9,8 \%$ dos examinados eram desdentados totais em uma das arcadas e a média de dentes presentes foi de 21,33 , sem, entretanto, avaliar se são dentes funcionais ou não.

No quadro 7 encontram-se as medidas de tendência central e de variabilidade para experiência de cárie na população de estudo.

Entre os casos 43,7\% tinham um CPO-D acima da média do grupo de estudo, avaliando a condição dos casos em relação a coroas cariadas verificou-se que $10,4 \%$ tinham 8 ou mais dentes com coroas cariadas.

QUADRO 12: Medidas de tendência central e de variabilidade da experiência de cárie de coroa em usuários adultos de 25 a 55 anos do PSF Santa Marcelina, 2.003. São Paulo, 2.004.

\begin{tabular}{|c|ccc|}
\hline CONDIĆÁO & MÉdIA & MEDIANA & DESVIOPADRAOO \\
\hline CARIADO & 3,28 & 3,00 & 3,12 \\
OBTURADO & 4,65 & 3,00 & 4,93 \\
PERDIDO & 10,64 & 9,00 & 6,84 \\
CPO- D & 18,57 & 19,00 & 6,52 \\
\hline
\end{tabular}

\section{CÁRIE DE RAIZ}

A presença de cárie radicular variou de 0 a 13 dentes com raízes atacadas, com uma média igual a 0,64 . Encontravam-se restaurados de 1 a 7 dentes com raízes atacadas, uma média de 0,10 .

Entre os casos, $10,1 \%$ tinham 2 ou mais raízes com cárie. 


\section{USO DE PRÓTESE}

Dos 621 examinados 427 indivíduos não usavam nenhum tipo de prótese. $(68,7 \%)$.

Entre as 184 pessoas que usavam algum tipo de prótese, 54 usavam exclusivamente prótese total superior, sendo que 45 eram mulheres.

Em torno de $1 / 5$ dos examinados $(22,5 \%)$ usavam próteses parciais removíveis, fixas ou combinadas, em sua maioria do sexo feminino: $34,4 \%$ das mulheres usavam algum tipo de prótese, contrastando com apenas 23,6\% dos homens.

Entre os casos $28,9 \%$ usavam próteses.

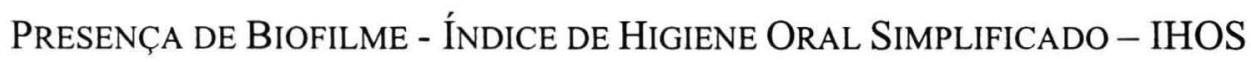

O IHOS revelou que $56,0 \%$ dos examinados apresentavam uma boa higiene no momento em que foram examinados ( $\mathrm{IHOS}=0,00$ a 0,99 ). Esta condição foi mais freqüente nas mulheres $(60,6 \%$ das examinadas $)$.

A higiene classificada como média (IHOS $=1,00$ a 1,99 ) foi a condição de $34,8 \%$ dos examinados e higiene ruim ( $\operatorname{IHOS}=2,00$ a 3,00), a de $9,2 \%$.

Dos controles, $70,0 \%$ tinham o IHOS menor que 1,0 , enquanto que $57,2 \%$ dos casos tinham o IHOS acima deste valor. 


\subsection{Testes de associaÇão e ANÁlise de Regressão:}

Os resultados dos testes de associação (análise bivariada) e da análise de regressão múltipla serão apresentados de acordo com a classificação das variáveis de estudo, assim com foi feito para a apresentação da análise descritiva.

Os resultados dos testes de associação (análise bivariada) estão nas tabelas 19 a 24; a análise múltipla consta das tabela 25 a 27.

\section{TESTES DE ASSOCIAÇÃO - ANÁLISE BIVARIADA}

VARIÁVEIS SÓCIO DEMOGRÁFICAS.

Os resultados da associação entre "casos" e "controles" e as variáveis independentes sócio demográficas estão na tabela 19.

Verificou-se associação significativa entre os casos e sexo, variável sócio demográfica de maior significância estatística neste estudo ( $p<0,001$ e $\operatorname{IC}_{95,0 \%}[2,01$; $4,18])$, havendo maior risco para o sexo masculino $(\mathrm{OR}=2,89)$.

Também houve associação significativa entre o agravo e grupo etário $(\mathrm{p}<0,001$; IC $95,0 \%[1,37 ; 3,17])$. Ter acima de 35 anos elevou em torno de duas vezes o risco para o desenvolvimento das doenças periodontais destrutivas $(\mathrm{OR}=2,09)$.

Não houve associação entre as doenças periodontais destrutivas com religião ou com estado conjugal.

A natureza da ocupação ou a condição de não ter ocupação e nem renda não demonstrou associação significativa, com p $=0,148$ e IC $95,0 \%[0,55 ; 1,10]$ e p $=1,10$ e IC ${ }_{95,0 \%}[0,80 ; 1,51]$, respectivamente. 
TABEla 19: Análise de Regressão Bivariada para as variáveis sócio-demográficas em usuários adultos, de 25 a 55 anos, dos serviços de saúde do PSF Santa Marcelina em 2.003,. São Paulo, 2.005.

\begin{tabular}{|c|c|c|c|c|c|c|c|}
\hline VARIÁVEL & \multicolumn{2}{|c|}{ CONTROLES } & \multicolumn{2}{|c|}{ Casos } & $\mathbf{p}$ & OR & IC $95,0 \%$ \\
\hline \multicolumn{8}{|l|}{ SEXO } \\
\hline FEMININO & 247 & 56,3 & 192 & 43,7 & 0,000 & 2,89 & {$[2,01 ; 4,18]$} \\
\hline MASCULINO & 56 & 30,8 & 126 & 69,2 & & & \\
\hline \multicolumn{8}{|l|}{ GRUPOETÁRIO } \\
\hline 25 A 34 ANOS & 73 & 63,5 & 42 & 36,5 & 0,000 & 2,09 & {$[1,37 ; 3,17]$} \\
\hline 35 A 55 ANOS & 230 & 45,5 & 276 & 54,5 & & & \\
\hline \multicolumn{8}{|l|}{ VIDA CONJUGAL } \\
\hline SEM VIDA CONJUGAL & 96 & 51,9 & 89 & 48,1 & 0,301 & 1,20 & {$[0,84 ; 1,72]$} \\
\hline COM VIDA CONJUGAL & 206 & 47,4 & 229 & 52,6 & & & \\
\hline \multicolumn{8}{|l|}{ RELIGIÃO } \\
\hline CATÓLICO & 112 & 49,8 & 113 & 50,2 & 0,711 & 1,06 & {$[0,77 ; 1,48]$} \\
\hline OUTRAS & 191 & 48,2 & 205 & 51,8 & & & \\
\hline \multicolumn{8}{|l|}{ NATUREZA DA OCUPAÇÃO } \\
\hline TEM TRaBalHo E RENDA & 201 & 46,9 & 228 & 53,1 & 0,148 & 0,78 & {$[0,55 ; 1,10]$} \\
\hline NÃO TEM TRABALHO NEM & 102 & 53,1 & 90 & 46,9 & & & \\
\hline \multicolumn{8}{|l|}{ RENDA } \\
\hline \multicolumn{8}{|l|}{ OCUPAÇÃO } \\
\hline TEM OCUPAÇÃO & 185 & 49,7 & 187 & 50,3 & 0,567 & 1,10 & {$[0,80 ; 1,51]$} \\
\hline SEM OCUPAÇÃO & 118 & 47,4 & 131 & 52,6 & & & \\
\hline \multicolumn{8}{|l|}{ ESCOLARIDADE } \\
\hline SABE LER E ESCREVER OU + & 289 & 49,8 & 291 & 50,2 & 0,046 & 1,99 & {$[1,00 ; 3,94]$} \\
\hline ANALFABETO & 13 & 33,3 & 26 & & 66,7 & & \\
\hline \multicolumn{8}{|l|}{ ANOS ESCOLA } \\
\hline$>=1$ & 295 & 49,7 & 299 & 50,3 & 0,042 & 2,34 & {$[1,01 ; 5,44]$} \\
\hline$=0$ & 8 & 29,6 & 19 & 70,4 & & & \\
\hline
\end{tabular}


A associação entre escolaridade a as doenças periodontais destrutivas foi significativa com $\mathrm{p}=0,046$ e IC $95,0 \%[1,00 ; 3,94]$; a razão de chances se eleva ao dobro $(\mathrm{OR}=1,99)$. Quando se avaliou escolaridade em anos na escola também se verificou associação significativa ( $p=0,042$ e IC $95,0 \%[1,01 ; 5,44])$ e a razão entre as chances de se desenvolver a doença sofreu incremento $(\mathrm{OR}=2,34)$.

\section{VARIÁVEIS RELATIVAS A CONDIÇÕES E ESTADOS DE SAÚdE GERAL}

Não se verificou associação estatisticamente significativa entre o diabetes, tampouco os transtornos neurológicos ou psíquicos ou as doenças auto-imunes e as doenças periodontais destrutivas no grupo populacional avaliado(tabela 20).

TABELA 20: Análise de Regressão Bivariada para variáveis relacionadas a condições sistêmicas e estados, em usuários adultos, casos e controles, de 25 a 55 anos, dos serviços de saúde do PSF Santa Marcelina em 2.003,. São Paulo, 2.005.

\begin{tabular}{lcccccccc}
\hline \multicolumn{1}{c}{ VARIÁVEL } & & CONTROLES & \multicolumn{1}{c}{ CASOS } & p & OR & IC 95,0\% \\
\hline DIABETES & & & & & & & & \\
& NÃO & 291 & 49,8 & 293 & 50,2 & 0,097 & 2,13 & {$[0,85 ; 5,30]$} \\
& SIM & 7 & 31,8 & 15 & 68,2 & & & \\
\hline $\begin{array}{l}\text { DISTÚRBIOS NEUROLÓGICOS } \\
\text { OU PSÍQUICOS }\end{array}$ & NÃO & 288 & 48,5 & 306 & 51,5 & 0,472 & 0,75 & {$[0,35 ; 1,64]$} \\
& SIM & 15 & 55,6 & 12 & 44,0 & & & \\
\hline & & & & & & & & \\
\hline DOENÇAS AUTOIMUNES & & & & & & & & \\
& NÃO & 296 & 48,9 & 308 & 51,1 & 0,524 & 1,37 & {$[0,52 ; 3,65]$} \\
& SIM & 7 & 41,2 & 10 & 58,8 & & & \\
\hline \hline
\end{tabular}




\section{VARIÁVEIS RELATIVAS A HÁBITOS E COSTUMES}

A análise bivariada dos hábitos ou costumes de consumir tabaco e álcool e as doenças periodontais destrutivas constam das tabelas 21,22 e 23.

\section{CONSUMO DE TABACO}

Não houve associação estatisticamente significativa entre variável uso do tabaco com as doenças periodontais destrutivas $(p=0,255)$, e evidentemente também não se verificou o mesmo com a variável dependência de nicotina (tabela 20).

Estabeleceram-se diversos pontos de corte para testar a associação entre o tempo de uso do tabaco, o número de unidades consumidas diariamente e as doenças periodontais destrutivas, todavia sem encontrar associação significativa.

TABEla 21: Análise de Regressão Bivariada para a variável tabaco em usuários adultos, casos e controles, de 25 a 55 anos, dos serviços de saúde do PSF Santa Marcelina, em 2.003,. São Paulo, 2.005.

\begin{tabular}{|c|c|c|c|c|c|c|c|}
\hline \multirow{2}{*}{$\frac{\text { USO do TABACO }}{\text { NÃO }}$} & \multicolumn{2}{|c|}{ CONTROLES } & \multicolumn{2}{|c|}{ Casos } & \multirow{2}{*}{$\frac{\mathbf{p}}{0,255}$} & \multirow{2}{*}{$\frac{\mathbf{O R}}{1,23}$} & \multirow{2}{*}{$\begin{array}{c}\text { IC 95,0\% } \\
{[0,86 ; 1,77]}\end{array}$} \\
\hline & 231 & 76,2 & 229 & 74,2 & & & \\
\hline SIM & 72 & 23,8 & 88 & 27,8 & & & \\
\hline
\end{tabular}




\section{CONSUmo de Álcool}

Na tabela 22 estão apresentadas as análises bivariadas com o álcool.

TABELA 22: Análise de Regressão Bivariada para consumo de álcool na atualidade, na última semana, no último mês, no último ano e há cinco anos avaliada em usuários adultos, de 25 a 55 anos, dos serviços de saúde do PSF Santa Marcelina, 2.003, casos e controles. São Paulo, 2.004.

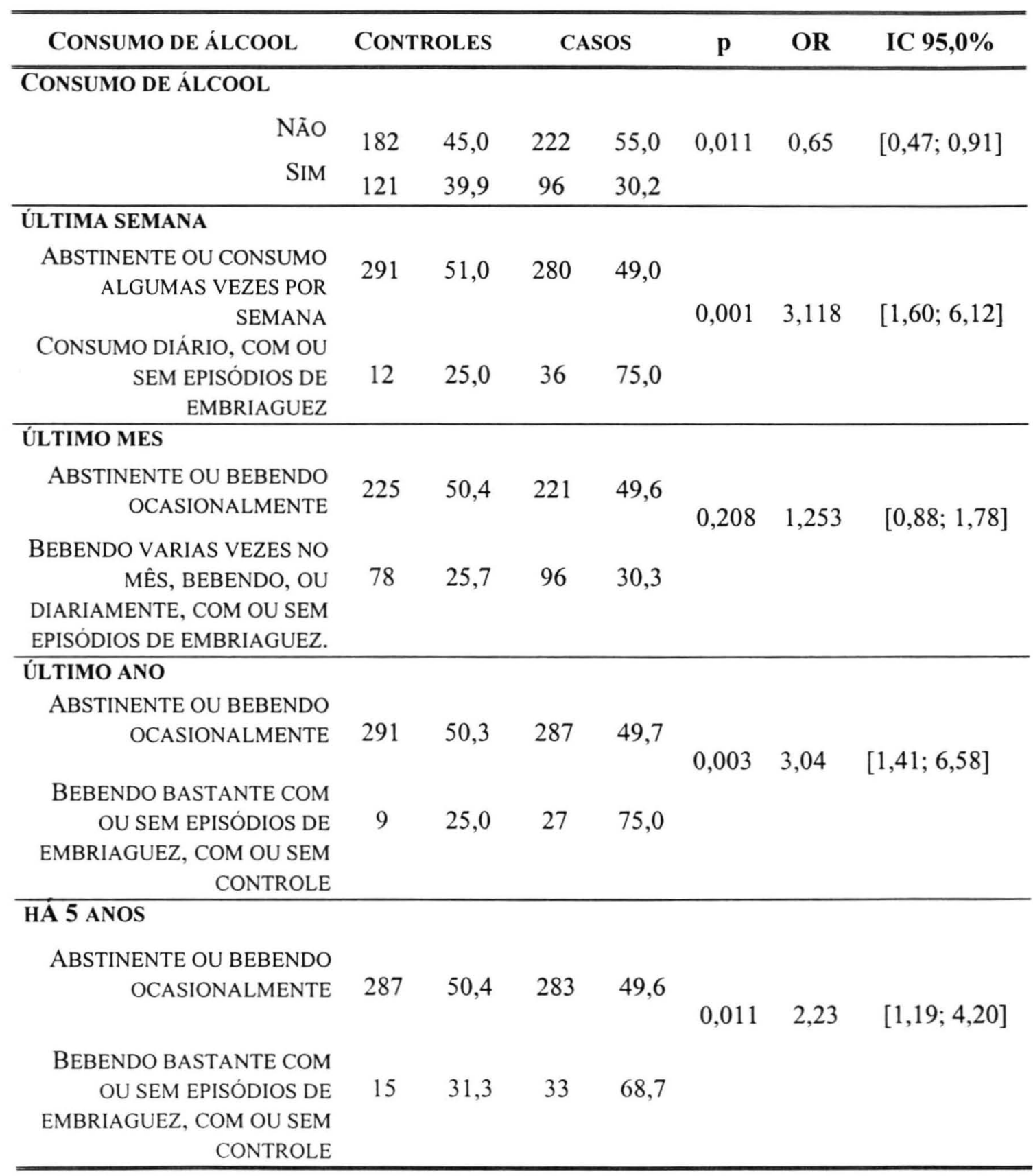


TABELA 22 (continuação): Análise de Regressão Bivariada para consumo de álcool há dez anos, há vinte anos e história pregressa de consumo de álcool, avaliada em usuários adultos, de 25 a 55 anos, dos serviços de saúde do PSF Santa Marcelina, 2.003, casos e controles. São Paulo, 2.004.

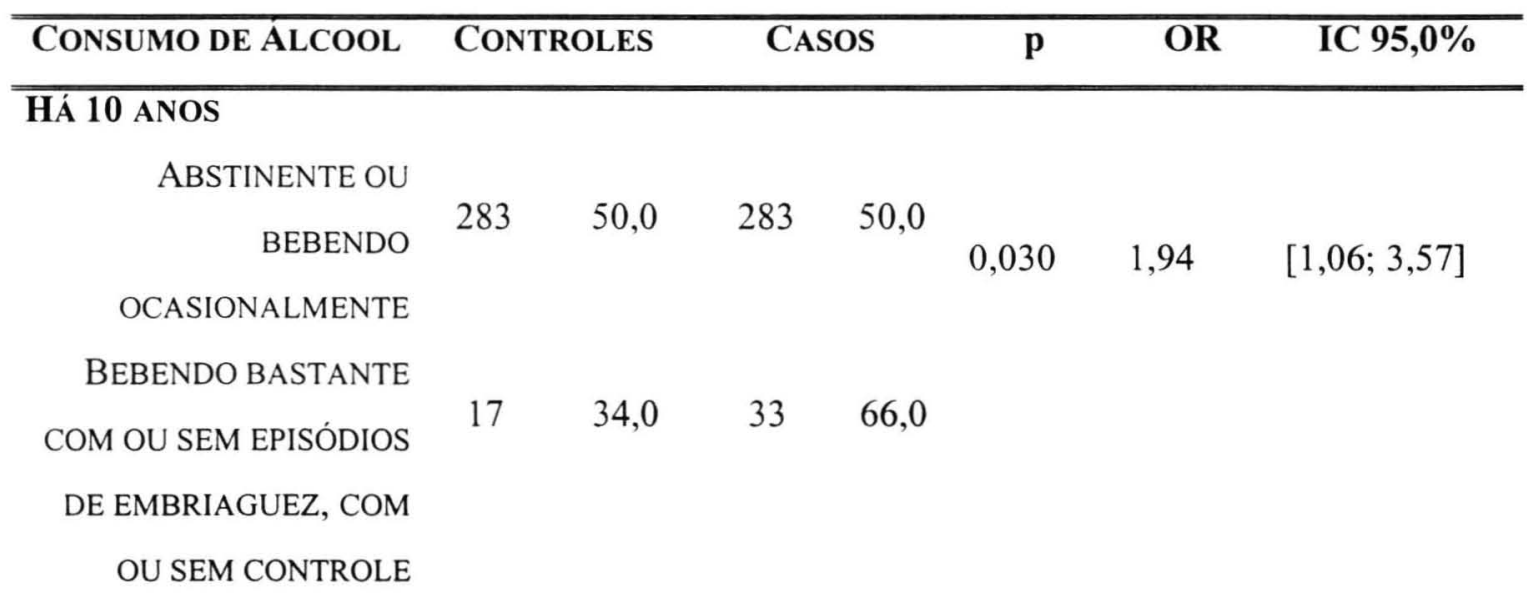

\section{HÁ 20 ANOS}

\begin{tabular}{|c|c|c|c|c|c|c|c|}
\hline $\begin{array}{r}\text { ABSTINENTE OU } \\
\text { BEBENDO }\end{array}$ & 157 & 44,7 & 194 & 55,3 & 0,016 & 0,67 & {$[0,49 ; 0,93]$} \\
\hline $\begin{array}{l}\text { OCASIONALMENTE } \\
\text { BEBENDO BASTANTE } \\
\text { COM OU SEM EPISÓDIOS } \\
\text { DE EMBRIAGUEZ, COM } \\
\text { OU SEM CONTROLE }\end{array}$ & 144 & 54,5 & 120 & 45,5 & & & \\
\hline HISTÓRIA PREGRESSA & & & & & & & \\
\hline DE CONSUMO & & & & & & & \\
\hline $\begin{array}{l}\text { ABSTINÊNCIA OU } \\
\text { CONSUMO OCASIONAL }\end{array}$ & 144 & 43,8 & 185 & 56,2 & 0,008 & 0,65 & {$[0,47 ; 0,89]$} \\
\hline GRANDE CONSUMO & 158 & 54,5 & 132 & 45,5 & & & \\
\hline
\end{tabular}


O tipo de bebidas consumidas não se mostrou estatisticamente significativo para as DP destrutivas (tabela 23).

TABELA 23: Análise de Regressão Bivariada para tipo de bebidas consumida entre usuários adultos, de 25 a 55 anos, dos serviços de saúde do PSF Santa Marcelina, 2.003, casos e controles. São Paulo, 2.004.

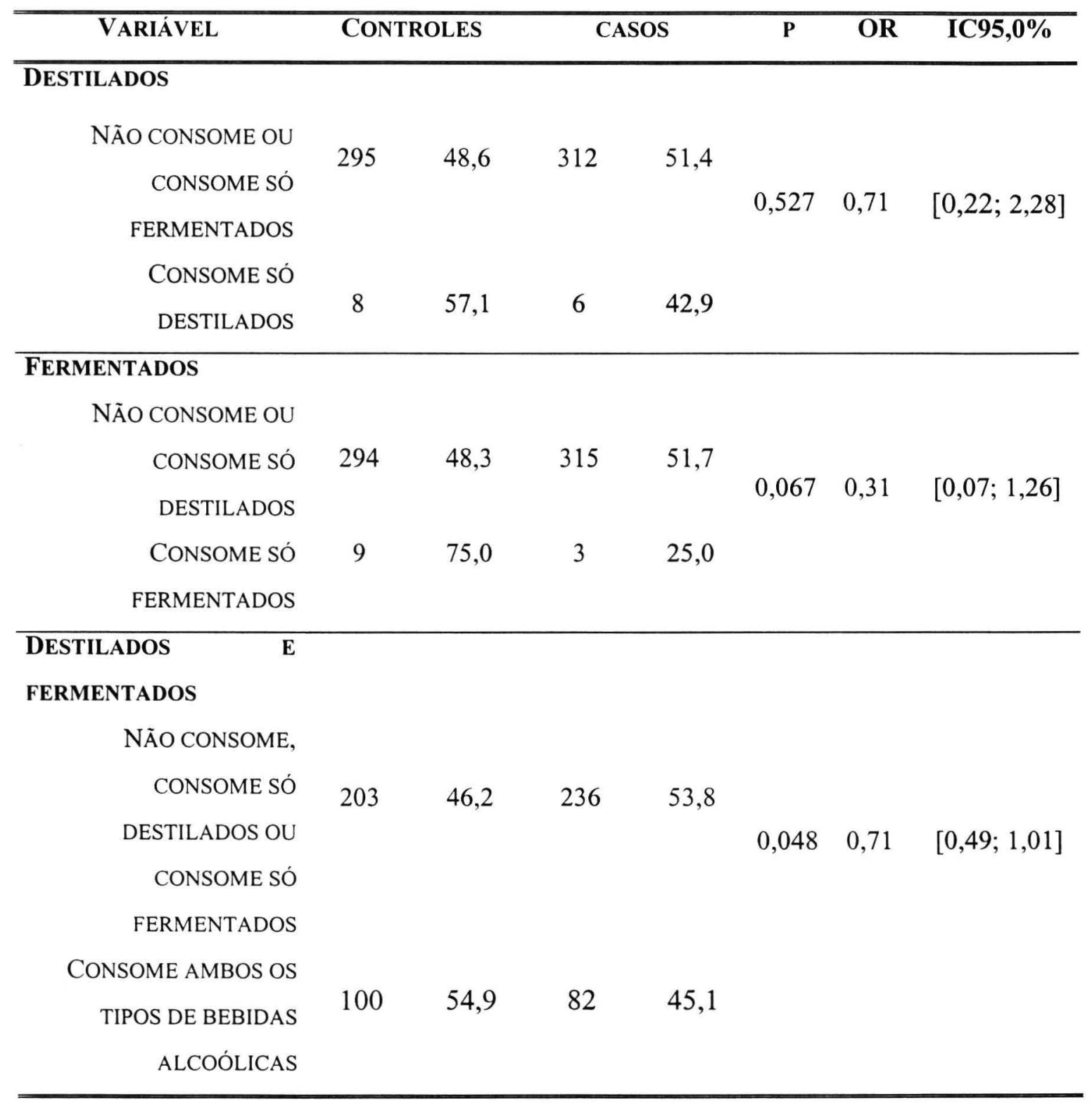




\section{VARIÁVEIS CLÍNICAS}

A perda de inserção esteve fortemente associada à presença das doenças periodontais destrutivas $(\mathrm{p}<0,0001, \mathrm{OR}=18,30$ e IC $95,0 \%=[11,89 ; 28,13)$.

Para apresentação dos resultados a variável referente à presença de biolfilme foi dicotomizada, utilizando-se vários pontos de corte. Houve associação significativa entre a DPD (casos) e qualquer quantidade de biofilme ( $p<0,0001)$. A presença de biofilme a partir de $1 / 3$ triplica o risco para as doenças periodontais destrutivas. $(\mathrm{OR}=3,12 ; \mathrm{IC} 95,0 \%[2,24 ; 4,34]$.

Identificou-se a experiência de cárie dentária, examinando-se as coroas e raízes dentárias, mas não houve associação significativa para a ter ou não ter dentes com cárie coronária $(\mathrm{p}=0,186)$. Entretanto quando o número de dentes com coroas cariadas era maior ou igual a 8 verificou-se associação estatisticamente significativa $\left(\mathrm{p}=0,011\right.$, IC $\left._{95,0 \%}=[1,18 ; 4,18].\right)$.

Para cárie radicular, a partir de 2 dentes com raízes cariadas, a associação foi significativa $(\mathrm{p}=0,026)$.

Tanto a presença de cárie coronária $(\mathrm{OR}=2,22)$, quanto de radicular $(\mathrm{OR}=$ $2,07)$ elevam o risco ao dobro para as doenças periodontais destrutivas.

Não houve associação entre o uso de uma ou mais próteses parciais, fixas ou removíveis ( $\left.\mathrm{p}=0,110 ; \mathrm{IC}_{95,0 \%} 0,93 ; 2,00\right)$ e as doenças periodontais destrutivas. 
TABela 24: Análise de Regressão Bivariada para as variáveis clínicas, em usuários adultos, casos e controles, de 25 a 55 anos, dos serviços de saúde do PSF Santa Marcelina, 2.003, casos e controles. São Paulo, 2.004.

\begin{tabular}{|c|c|c|c|c|c|c|c|}
\hline VARIÁVEL & \multicolumn{2}{|c|}{ CONTROLES } & \multicolumn{2}{|c|}{ CASOS } & p & OR & IC $95,0 \%$ \\
\hline SEM PERDA & 208 & 86,0 & 34 & 14,0 & 0,000 & 18,30 & {$[11,89 ; 28,13]$} \\
\hline COM PERDA & 95 & 25,1 & 284 & 74,9 & & & \\
\hline \multicolumn{8}{|l|}{ BIOFILME } \\
\hline BIOFILME $<1,00$ & 212 & 60,9 & 136 & 39,1 & 0,000 & 3,12 & {$[2,24 ; 4,34]$} \\
\hline BIOFILME $>=1,00$ & 91 & 33,3 & 182 & 66,7 & & & \\
\hline \multicolumn{8}{|l|}{ CÁRIE DE COROA } \\
\hline CÁRIE DE COROA $<8$ & 288 & 50,3 & 285 & 49,7 & 0,011 & 2,22 & {$[1,18 ; 4,18]$} \\
\hline CÁRIE DE COROA $>=8$ & 15 & 31,3 & 33 & 68,7 & & & \\
\hline \multicolumn{8}{|l|}{ CÁRIE dE RAIZ } \\
\hline RAIZ CARIADA $<=2$ & 287 & 50,1 & 286 & 49,9 & 0,026 & 2,07 & {$[1,08 ; 3,74]$} \\
\hline RAIZ CARIADA $>2$ & 16 & 33,3 & 32 & 66,7 & & & \\
\hline \multicolumn{8}{|l|}{ USO DE PRÓTESE } \\
\hline $\begin{array}{r}\text { NÃO USA OU USA SÓ } \\
\text { PT }\end{array}$ & 243 & 50,5 & 238 & 49,5 & 0,110 & 1,36 & {$[0,93 ; 2,00]$} \\
\hline $\begin{array}{r}\text { USA } 1 \text { OU } 2 \text { PPR OU } \\
\text { FIXA }\end{array}$ & 60 & 42,9 & 80 & 57,1 & & & \\
\hline
\end{tabular}




\section{ANÁlise de REgRessão Múltipla}

O modelo final ${ }^{*(n)}$ consta da tabela 25 e foi construído pelo método stepwise incluiu as variáveis independentes sócio demográficas, relacionadas aos hábitos, particularmente ao consumo de álcool, e variáveis clínicas de saúde bucal que na análise bivariada apresentaram $\mathrm{p}<0,20$.

Optou-se por incluir na construção do modelo a variável consumo de tabaco apesar do valor de p ser 0,255 e IC $95,0 \%[0,86 ; 1,77]$. Testou-se também a interação entre uso de tabaco e uso álcool, uso de tabaco e consumo de álcool no último ano, há 5 , há 10 e há 20 anos.

$\mathrm{k}$ 
TABELA 25: Análise de Regressão Múltipla para as variáveis independentes sócio demográficas, de hábitos e costumes e de condições clínicas em saúde bucal para Doenças Periodontais Destrutivas, em usuários adultos, de 25 a 55 anos, dos serviços de saúde do PSF Santa Marcelina, 2.003. São Paulo, 2.005.

\begin{tabular}{lcccc}
\hline OR bruta & OR & IC $95,0 \%$ & p \\
Vajustada & & & \\
\hline \hline
\end{tabular}

SEXO

$\begin{array}{rrrr}\text { FEMININO } & 1,00 \\ \text { MASCULINO } & 2,89 & 2,96 \quad[1,94 ; 4,54] \quad 0,000\end{array}$

GRUPOETÁRIO

\begin{tabular}{|c|c|c|c|}
\hline 25 A 34 ANOS & 1,00 & & \\
\hline 35 A 55 ANOS & 2,09 & 2,00 & {$[1,27 ; 3,14]$} \\
\hline
\end{tabular}

\section{BIOFILME}

HISTÓRIA PREGRESSA DE CONSUMO

$\begin{array}{rr}\text { IP0 } 1<1,00 & 1,00 \\ \text { IP01 }>=1,00 \quad 3,12 & 2,55 \quad[1,78 ; 3,65] \quad 0,000\end{array}$

ABSTINÊNCIA OU CONSUMO OCASIONAL

1,00

GRANDE CONSUMO

$0,65 \quad 0,53 \quad[0,35 ; 0,78] \quad 0,001$

USO DE PRÓTESE

\begin{tabular}{|c|c|c|c|c|}
\hline NÃO USA OU USA SÓ PT & 1,00 & & & \\
\hline USA 1 OU 2 PPR OU FIXA & 1,36 & 1,55 & {$[1,03 ; 2,34]$} & 0,036 \\
\hline $\begin{array}{r}\text { ABSTINENTE OU BEBENDO } \\
\text { OCASIONALMENTE }\end{array}$ & 1,00 & & & \\
\hline $\begin{array}{l}\text { BEBENDO BASTANTE COM EPISÓDIOS DE } \\
\text { EMBRIAGUEZ COM OU SEM CONTROLE }\end{array}$ & 2,23 & 2,88 & {$[1,204 ; 6,863]$} & 0,017 \\
\hline
\end{tabular}




\section{DisCuSSÃo}

Há um número significativo de estudos epidemiológicos transversais indexados na literatura nacional e internacional gerando grande quantidade de informações sobre a prevalência das doenças periodontais.

De importância irrefutável, dados de prevalência de cárie e doenças periodontais obtidos a partir de estudos realizados pela Faculdade de Saúde Pública da Universidade de São Paulo -FSP -USP e a SES-SP (SES - SP 2.003), além dos dados preliminares do "Projeto SB Brasil 2003 - Condições de Saúde Bucal da População Brasileira - 2002-2003", têm sido utilizados para o planejamento das ações locais, associados a técnicas de rastreamento de risco para estas e outras doenças bucais. (FSP - USP e SES - SP 1998; SES - SP 2003 MS 2004)

BAELLUN e PAPAPANOU (1.996), não acreditam que seja absolutamente necessário se descrever a prevalência e a incidência de doenças periodontais em todas as populações, embora as informações a este respeito sejam importantes para planejamento de serviços. Segundo os mesmos autores a tarefa mais importante é a de identificar fatores de risco para o desenvolvimento da doença, mas o impacto de ações sobre estes fatores ainda está por ser documentado.

Aponta-se para uma carência de estudos que abordem a questão dos fatores de risco, reais ou putativos, das doenças periodontais (LINDHE, KARRING e LANG 1.999, ASKAR et al 1.999, ASSAF 1.999, CLAFFEY e GJERMO 2.001), e sugere-se que se realizem estudos longitudinais que comprovem o papel desses fatores relacionados às doenças periodontais. GILTHORPE et al (2.000) entre outros autores defendem a necessidade da realização de análise análises multivariadas nesses estudos.

Esta necessidade de identificar e avaliar a importância de determinadas caracteristicas dos individuos, condições sistêmicas e estados de saúde geral, hábitos e costumes assim como valorizar a história pregressa e atual de saúde bucal no que se refere ao risco para instalação ou progressão das doenças periodontais motivou a realização deste estudo.

O "baixo" custo relativo, a velocidade de execução, a disponibilidade de alguns registros e a possibilidade de se detectar e comprovar a exposição ao risco influenciou a escolha do estudo (COLIMON 1.990, MEDRONHO et al 2.003). 
Os estudos de caso controle procuram identificar a história pregressa de exposição a fim de estabelecer relação causal e investigar a concomitância de fatores de exposição (PEREIRA 1.995). Esta leitura retroanalitica dos níveis diferenciais de exposição a um ou mais supostos fatores pode levar à descoberta de que elevam ou reduzem o risco, prevenindo ou provocando doenças, explicando a ocorrência das doenças. Nestes estudos é possível quantificar o risco associado a cada fator, individualmente analisado ou em combinação com outros fatores.

Optou-se pela realização de um estudo de caso controle considerando suas indicações e vantagens, sem deixar de ponderar as limitações e possibilidade de erros. Segundo ROTHMAN (1.986) todo estudo epidemiológico é um exercicio de medição, podendo se admitir que nenhum é absolutamente livre de erros.

Reconhecem-se algumas limitações próprias de estudos dessa natureza, como o seu reduzido poder descritivo quanto à estimação do risco e a vulnerabilidade a vieses de memória e de seleção, o que se reflete na complexidade da análise.

Para garantir a acurácia, a reprodutibilidade e a desconfusão, como recomendado por WALCHOLDER (1.992a, 1.992b, 1.992c), adotaram-se alguns cuidados. Alguns vieses foram totalmente controlados, outros parcialmente, e isso não pode ser desconsiderado na análise dos resultados. As medidas adotadas para controlar alguns vieses, minimizando-os, serão discutidas a seguir.

Um dos vieses é o de seleção (bias de Berkson). A identificação de casos e controles pode ser considerada uma das maiores dificuldades desse tipo de estudo, que pode levar a uma falta de comparabilidade.

Em relação ao número de exames proposto (350 casos e 350 controles) foi possivel validar 621 (318 casos e 303 controles), garantindo-se proporções semelhantes de casos e controles.

Durante a concepção do projeto ponderou-se as dificuldades a se encontrar na operacionalização da pesquisa, por isso não foi feito o pareamento por idade e sexo.

Houve percentuais iguais de casos e controles entre os individuos de 25 a 34 anos e de 45 a 55 anos. No grupo de 35 a 44 anos há uma diferença em torno de $10,0 \%$ para os casos, mas esta diferença não comprometeu a proporcionalidade desejada no final do estudo, que era a de um caso para cada controle. Apesar da 
proporcionalidade garantida não se pode afirmar que esta corresponde ao que acontece naquela população.

A prevalência de doenças periodontais destrutivas, com presença de boisas prơundas, gira em torno de 12,0 a $15,0 \%$; a ocorrência de alterações gengivais, incluindo desde sangramento à presença de bolsas rasas, na população adulta, em boa parte dos estudos gira em torno de 70,0\% (BAELLUM et al 1.995, BAELLUM et al 1.996, BAELLUM e PAPAPANOU 1.996, GAMONAL et al 1.998, GENCO 1.998).

Poucos são os estudos longitudinais encontrados na literatura com doenças periodontais destrutivas. Entre os estudos longitudinais os mais freqüentes são os de coorte, com duração e amostras de dimensões variadas.

$\mathrm{O}$ que se pode afirmar é que o número de examinados (casos e controles) deste estudo é consideravelmente maior, quando comparado com os números de examinados em outros estudos de caso controle encontrados.

Para garantir a acurácia da comparabilidade e controlar o viés de aferição, tanto os individuos considerados casos quanto os controles desconheciam sua condição de doente ou não doente, a medida da exposição para casos e controles foi realizada da mesma forma. A maior parte dos examinados não tinha conhecimento da presença da doença periodontal, mas não todos.

No intuito de controlar o viés de memória as perguntas da entrevista estruturada foram elaboradas, em uma seqüência lógica, estimulando os entrevistados a lembrar de sua história em relação a cada um dos quesitos necessários à identificação da intensidade da exposição aos fatores putativos de risco (PEREIRA 1.995). As entrevistas se desenvolveram a partir de uma série de perguntas, ordenadas segundo o assunto a que se referiam, de forma que se considerasse o menor esforço mental possivel por parte do entrevistado.

$O$ uso de imagens (fotografias) das bebidas e das diversas formas de apresentação foi um outro recurso utilizado para controlar o viés de memória. Ainda para garantir uma maior confiabilidade nas respostas, além da finalidade operacional a escolha de examinadores do serviço procurou valorizar o vinculo existente entre os examinadores e os usuários. A abordagem de questões delicadas, inerentes aos distúrbios neurológicos e psiquicos e as questões sobre consumo de álcool demonstraram haver a necessidade um vinculo do entrevistado com o seu 
examinador. Aspectos inerentes à forma de abordagem destas questões e cuidados com a linguagem a ser usada foram exaustivamente discutidos durante o treinamento e a calibração, a fim de minimizar distorções, aumentar a fidelidade nas respostas e garantir a reprodutibilidade e validade (PEREIRA 1.995).

Sabe-se, entretanto, que fatores psicológicos, sócio-culturais e até mesmo emocionais podem interferir nas respostas dos entrevistados, o que dificulta o controle deste viés.

Para não criar uma solução de continuidade na rotina das unidades de saúde, entrevistas e exames foram realizados em consonância com as demais atividades da clínica, gerando um certo cansaço, conflitos internos e desgaste emocional. Mas a oportunidade de participar deste estudo, oferecida às equipes de saúde bucal, reverteu em um aprimoramento técnico e sensibilização dos profissionais

Em relação aos hábitos, particularmente com consumo de álcool, a validade de dados recordados no passado foi garantida por um periodo pregresso de até 20 anos (CEBRID 2.000, CARLINI 2.002), uma vez que os examinados tinham entre 25 e 55 anos de idade. Tanto para os mais jovens quanto para os mais velhos foi possivel admitir algum consumo de álcool no periodo desde a última semana até o periodo mais longinquo.

Os vieses de processamento da informação podem acontecer por erros de codificação, transcrição, digitação ou programação (PEREIRA 1.995), podendo levar a distorções nos resultados. Para minimizar este viés a pesquisadora realizou a conferência do preenchimento, análise de consistência e transcrição dos questionários para uma máscara de digitação. A programação foi feita usando-se o recurso check (CHK) do EPI INFO 5.01, garantindo-se a entrada somente de determinados códigos. Ao final da digitação identificaram-se alguns erros que foram corrigidos pela própria pesquisadora. Nova digitação foi feita pelo mesmo digitador, sem que o mesmo soubesse que se tratavam dos mesmos dados. Confrontaram-se os dois bancos de dados na intenção de se identificar diferenças entre eles e corrigi-las, tornando os dois bancos idênticos.

$\mathrm{O}$ digitador poderia ter incorrido em erro no mesmo campo nos dois bancos de dados. Antes de iniciar a análise dos dados foram tiradas as frequências e 
construidas tabelas para mais uma vez identificar inconsistências. Com estes cuidados procurou-se minimizar o viès de processamento das informações.

\subsection{Trabalho decampo e OPERacionalização da PESQUisa}

No planejamento logístico deste estudo ficou estabelecido com a coordenação de saúde bucal dos PSF Santa Marcelina que cada equipe seria responsável pela execução de 100 exames, sendo 50 casos e 50 controles. As mudanças politicoadministrativas que ocorreram durante o trabalho de campo deste estudo influenciaram o processo, e já tendo iniciado os trabalhos, um dos examinadores se desligou do PSF Santa Marcelina; em outras unidades, ora a equipe, ora a direção da unidade oscilava em seu envolvimento com o estudo, onerando o estudo, já sem financiamento, gerando grande desgaste.

Os indicadores das condições de vida e de saúde da população daquela região da cidade permitem afirmar que a população estudada guarda grandes semelhanças sócio-econômicas e culturais entre si e com populações SUS - dependentes de outras regiões da cidade de São Paulo. Sendo assim e levando em conta não haver comprometimento metodológico da pesquisa propôs-se que as equipes de saúde bucal compensassem entre si o número de exames que seria perdido. A proposta foi aceita e pode-se se verificar, à consolidação dos resultados, uma discrepância no número de exames realizados por cada uma das equipes.

Os serviços do PSF Santa Marcelina realizam um rastreamento de risco para as principais doenças bucais, adotando metodologia que permite alta cobertura populacional. A iniciativa e os resultados obtidos têm sido de grande valia para a organização local e têm despertado o interesse de muitos outros serviços. Realizar a identificação do estado de saúde doença periodontal não está incorporada à prática clinica da grande maioria dos cirurgiões dentistas, além de não haver consenso entre os autores de qual seria o padrão ouro (gold standart) para diagnóstico periodontal (DE POMMEREAU et al 1.992; SAFKAN-SEPPALA e AINAMO 1.992, THORSTENSSON e HUGOSON 1.993; BOSCH e ANGMAR-MANSSON 2.000; KINANE 2.000, HETHERINGTON e WHITE 2.004).

Neste estudo procurou-se garantir um preparo dos examinadores no sentido de se aproximar ao máximo da real condição periodontal apresentada pelos 
examinados, sensibilizando e estimulando o uso da sonda periodontal. fazendo com que o olhar para as condições periodontais se tornasse uma rotina. Este olnar mais atento deve permitir um diagnóstico precoce de alterações periodontais e deve desencadear a proposição de ações educativas que instrumentem e sensibilizem a população a adotar cuidados essenciais na preservação de sua saúde bucal.

\subsection{VARIÁVEIS SÓCIO-DEMOGRÁFICAS E SÓCIO-ECONÔMICAS}

Levando-se em consideração a desigualdade social e o quadro epidemiológico expresso pelos indicadores apresentados, e apesar de não se dispor de estudos epidemiológicos em saúde bucal da população desta região em particular, pode-se perceber que as necessidades acumuladas em saúde bucal desta população são elevadas. Isto se confirma quando da triagem de risco para doenças bucais, procedimento programático adotado periodicamente pelos serviços de saúde bucal do PSF Santa Marcelina.

Diferentes fatores e suas interações podem ser importantes em grupos populacionais distintos, e parecem ter influência na expressão das doenças, entre as quais as periodontais. Estas observações não são exclusivas deste estudo, mas têm sido identificadas em outros, o que é perfeitamente compreensivel, dada à teoria de determinação social da doença (FORSTER e LAURELL 1.982, BARROS 1.988, YUNES 1.992).

As experiências de vida e as condições individuais, ligadas a hábitos, costumes ou estados de saúde geral são conseqüências da qualidade de vida. Além de sexo, estado conjugal e religião, a intima relação entre ocupação, escolaridade e anos de estudo pode ser indicativa dos modos de vida, refletem a capacidade de usufruir bens e serviços, inclusive os de saúde. Considerando os determinantes ambientais do processo saúde doença permite-se afïmar que até mesmo naturalidade possa exercer influência nesse processo.

Neste estudo, verificou-se que a associação entre as variáveis sexo e idade se manteve na análise com outros fatores (análise múltipla). Entretanto, posto que aspectos inerentes à caracterização demográfica e sócio-econômica podem ser apontados como variáveis preditoras de risco para muitos agravos, entre eles as DPD deve-se considerar a necessidade de novas investigações que explorem inserção no 
mercado de trabalho e ocupação, escolaridade e anos de estudo com diferentes abordagens, visto que se nesta pesquisa estas variáveis se mostraram associadas às DPD quando analisadas individualmente.

IDADE

Foram examinados adultos com 25 anos de idade e mais, verificou-se que as doenças periodontais se agravavam com a idade, em consonância com o que se verifica em grande parte dos estudos consultados (VIEIRA 1.991, KIM, 1.992, CAMPOS JÚNIOR et al 1.992, CAMPOS JÚNIOR et al 1.994, BOURGEOIS et al 1.997).

As profundas iniqüidades em saúde que se observam na vida adulta têm sido reconhecidas como conseqüências das condições de vida a que as pessoas estão submetidas. $\mathrm{O}$ acúmulo de efeitos adversos à saúde e suas conseqüência s poderiam explicar em parte o que se observou neste estudo, à semelhança do que foi referido por PERES (2.002) como "teoria do acúmulo de riscos no curso da vida". WENNSTRÖN et al (1.993), BROWN et al (1.994), FRANSSON et al (1.999) ACEVEDO et al (2.001), afirmam que a idade não é fator de risco para as doenças periodontais. A idade produz algum grau de perda de inserção, mas isto é compativel com a saúde e a função.

Grande número de estudos de prevalência tem associado à idade como fator de risco relacionado às doenças periodontais, mas a periodontite severa não é conseqüência natural da idade nem é a principal causa de perdas dentárias (PAPAPANOU et al 1.988, ACEVEDO et al 2.001).

As periodontites destrutivas abarcam um grupo heterogêneo de pacientes, e não constituem uma entidade clinica simples, mas podem ser consideradas um grupo de enfermidades com vários fatores envolvidos (LAVANDEIRA e BERMOLEN, 2.002).

NUNES e SLAVUTZKY (1.992) encontraram forte correlação entre idade e condições periodontais em cabos e soldados, fumantes e não fumantes. MACHION et al (2.000) estudando a influência do sexo e da idade na prevalência das bolsas periodontais verificaram maior profundidade de bolsas à sondagem em maiores de 31 anos. 
No presente estudo, em particular, verificou-se uma concentração $10,0 \%$ maior de casos nos individuos acima de 35 anos. Houve significância estatística tanto na análise univariada quanto na múltipla, em ambas o valor de $p<0,005$, e o risco se eleva em quase três vezes nos individuos do grupo acima de 35 anos, o que vem de encontro com estudos que evidenciam a influência da idade no aumento do risco para as doenças periodontais, e que pode estar relacionado com a teoria de acúmulo de riscos ao longo da vida.

Mesmo tendo trabalhado com uma amplitude grande de idades pode-se verificar que a proporcionalidade entre os casos e controles, no grupo de 25 a 34 anos e de 45 a 55 anos se manteve. A diferença residiu no grupo de 35 a 44 anos.

SEXO

Nas unidades do PSF Santa Marcelina não há a preocupação de garantir proporcionalidade no acesso aos serviços a homens e mulheres.São admitidos todos os cadastrados da área de abrangência. É feita busca ativa de cadastrados, para comprometimentos em saúde bucal, particularmente para os que apresentarem lesões suspeitas de câncer bucal.

Verificou-se maior número de mulheres examinadas e entrevistadas $(70,7 \%)$, como é freqüente nos serviços de saúde (MACHION et al 2.000). As mulheres geralmente estão mais atentas (RUSSEL 1.957 citado por MACHION et al 2.000) e procuram mais os cuidados com a sua saúde e dos filhos, quando comparadas aos homens.

Confirmou-se neste estudo mais uma vez que a prevalência das doenças periodontais é quase sempre a mesma em ambos os sexos, a diferença reside na severidade e na extensão das doenças. Nos homens a doença periodontal costuma ser mais extensa e mais grave (FLORES DE JACOBY et al 1.989, FLORES DE JACOBY et al 1.991, MACHION et al 2.000, MARQUES, 2.000).

BROWN (1.990) encontrou um aumento de 1,5 no número de bolsas periodontais em homens em todas as faixas etárias analisadas; STOLTENBERG et al (1.993) não encontrou diferenças na prevalência entre os sexos, mas demonstrou maior profundidade de sondagem em homens. 
Neste estudo os homens apresentaram pior higiene bucal, 54,9\% apresentaram acumulo de placa em mais de um terço das superfícies dentárias, enquanto que esta condição foi observada em $39,4 \%$ das mulheres. Os homens parecem apresentar pior controle do biofilme dentário, maiores quantidades de depósitos dentários (biofilme e cálculo), menor freqüência ao dentista (STOLTENBERG e et al 1.993) e maior exposição a outros fatores putativos de risco como álcool e tabaco (CHEN e RUBINSON 1.992, MACHION et al 2.000).

Nesta pesquisa isto se reafirma tendo em vista que há um percentual maior de homens com DPD $(69,2 \%)$; estes foram classificados como caso, o que pode também ser produto da procura tardia dos serviços de saúde, momento em que a doença está mais avançada; $22,3 \%(98)$ das mulheres declararam fazer uso de tabaco, enquanto este hábito foi declarado por $34,3 \%(62)$ dos homens; $26,9 \%$ (118) das mulheres consomem álcool contrastando com $54,4 \%$ (99) dos homens. Tendo em vista os fatores de exposição pode se suspeitar que as DPD se apresentem com maior grau de comprometimento e maior número de individuos do sexo masculino.

Houve associação estatisticamente significativa $(\mathrm{p}<0,005)$ entre a variável sexo, categoria masculino, e as doenças periodontais; o risco (odds ratio) foi de 2,89 na análise univariada. A significância e o risco em torno de 3,0 se mantiveram na análise múltipla. Os valores observados no grupo de estudo são quase o dobro do encontrado por BROWN em 1.990.

\section{ESTADO CONJUGAL}

A grande maioria dos estudos com doenças periodontais não identifica o estado conjugal dos participantes.

Esta condição social pode alterar os niveis de tensões diarias, uma vez quem constitui familia apresenta mais preocupações com o sustento e a manutenção dos seus dependentes, devendo em várias situações adequar seu comportamento interpessoal para manter seu trabalho e renda.

As preocupações alteram o estado psicoemocional com reflexos na resposta imune (CROUCHER et al 1.997).

As relações no trabalho exigem que se desenvolva a capacidade de tolerância e adaptação (comportamentos adaptativos) frente às dificuldades encontradas, tanto 
para manter a fonte de renda, seja ela com ou sem vinculo empregaticio, quanto para lidar com lideres, subalternos, clientes ou iregueses.

O cansaço gerado pela jornada de trabalho associado às tensões corrobora com diminuição do autocuidado (SAKKI et al 1.995, SHIZUKUISHI et al 1.998).

FREEMAN e GOSS (1.993), LINDEN, MULLALLY e FREEMAN (1.996) MOSS et al (1.996), GENCO et al (1.995) e GENCO et al (1.999) realizaram estudos discutindo as relações do estresse gerado nas relações de trabalho e de tensões diárias, além de comportamentos adaptativos no agravamento das doenças periodontais, e encontraram resultados significativos, muito embora em nenhum dos trabalhos fique claro se o estado conjugal foi variável de estudo.

Apesar da ponderação de todos estes aspectos, neste estudo não houve associação estatisticamente significativa do estado conjugal com a presença de DPD.

Somente no estudo de CROUCHER et al (1.997) foi apresentada significância estatistica do estado conjugal com as doenças periodontais.

\section{NATURALIDADE}

Conhecer a naturalidade da população de estudo teve mais importância descritiva, do que analitica.

Grande parte da população da região onde desenvolveu o estudo é migrante, oriunda das regiões mais pobres do pais. Praticamente a metade $(49,0 \%)$ dos entrevistados era migrante.

Natural e historicamente explicada, a migração é um fenômeno que se desencadeia em busca de melhores condições de vida.

À análise univariada não se verificou associação significativa entre as doenças periodontais e ser migrante. Desta forma, esta variável não foi inserida no modelo múltiplo.

Nativos de uma das regiǒes mais pobres do planeta, os filipinos, são apontados como de risco para a maior prevalência das doenças periodontais (LINDHE, KARRING e LANG 1.997).

Assim como "o local de origem", ou naturalidade, a etnia é apontada como relevante no risco para doenças periodontais em estudos norte-americanos (BORREL et al 2.002) e escandinavos (DRAKE et al 1.995). 
As condicões socio-econômicas têm sido evidenciadas como de maior reievância no risco para as doenças periodontais, mais do que a origem filipina ou a etnia (COHEN et al 1.995, GAMONAL et al 1.998, PETERSEN e RAZANAMIHAJA 1.996, KATO SEGUNDO et al 2.004), razão pela qual se optou por não inserir neste estudo a variável etnia, mas valorizaram-se aspectos que pudessem refletir as condições sócio-econômicas da população estudada

\section{OCUPAC̣ÃO, NATUREZA DA OCUPAC̣ÃO E OCUPAC̣ÃO PRINCIPAL}

Os indicadores de desemprego vêm sofrendo elevação em todo o pais e nos grandes centros.

Segundo o Departamento Intersindical de Estatistica e Estudos Sócio Econômicos - DIEESE (2.005), na região metropolitana do municipio de São Paulo, atinge a taxa de $21,7 \%$ de desempregados (a partir de dados do periodo de 1996 a 1.999). Esta condição associada a outros indicadores sociais se reflete nas condições de saúde e doença, torna-se importante verificar a inserção da população de estudo no mercado de trabalho.

Nos processos saúde doença ocupação e renda são determinantes sócioeconômicos a se considerar (TOMITA et al, 1.999).

Grande parte dos estudos opta por identificar a renda per capita da familia ou do individuo e não discute ocupação ou o papel do desemprego nas doenças periodontais

Com baixa qualificação profissional, a população de estudo encontra uma grande dificuldade de inserção no mercado de trabalho. Exercem atividades da economia informal, ou mesmo ocupações que não exigem grande qualificação.

Estas atividades geram uma baixa renda e limitam o acesso a bens e serviços, com repercussão nas condições de saúde; e de interesse neste estudo, a saúde bucal.

Verificou-se número de entrevistados sem vínculo empregaticio, mas com alguma ocupação e renda. Entre esses a ocupação principal se concentrou no setor de serviços e pode estar subjetivamente associada ao desemprego da população usuária dos serviços do PSF Santa Marcelina, incrementando os indicadores da economia informal. 
MANOR et al (1.997) afirma que muitas medidas têm sido usadas para medir posição socioeconômica, sendo que todas têm suas limitações e, portanto, tem sido recomendado utilizar pelo menos duas delas.

Os indicadores de ocupação escolhidos nesta pesquisa não foram suficientes para demonstrar associação com o risco de desenvolver doenças periodontais destrutivas.

Não houve associação entre não ter ocupação ou renda e ser considerado doente para as doenças periodontais $(\mathrm{p}=0,148)$.

Este resultado talvez possa ser explicado pelas semelhanças sócioeconômicas do grupo de pessoas examinadas. A doença destrutiva neste grupo pode estar sendo influenciada por outros fatores que não exclusivamente ocupação e renda, até porque as doenças periodontais são processos crônicos, de longa duração, e estar sem ocupação e renda, espera-se ser uma condição transitória.

Em outros estudos talvez seja importante identificar a história pregressa de desemprego ou a renda per capita familiar ao longo dos últimos 5, 10 ou 20 anos.

$\mathrm{O}$ desemprego foi apontado como significativo para as doenças periodontais no estudo de CROUCHER et al (1.997). Esta condição aumentou o nivel de estresse emocional, das tensões, da angústia e levou alguns individuos a quadros depressivos com implicação nas doenças periodontais.

\section{ESCOLARIDADE E ANOS DE ESTUDO}

BREIL (1.992) entre outros autores faz referência à relação entre escolaridade e ocupação no mercado de trabalho.

Nesta pesquisa quando a escolaridade foi avaliada separando-se os analfabetos daqueles que sabiam ler e escrever ou tinham mais escolaridade verificou-se associação significativa com o agravo $(p=0,046)$, e o risco foi de 1,99 .

Vários pontos de corte foram estabelecidos para testar a associação entre anos de estudo e DPD. A associação foi significativa quando se avaliaram os individuos que não tinham freqüentado a escola por nem mesmo um ano. Esta associação foi significativa e aritmeticamente maior que a avaliação anterior para escolaridade ( $\mathrm{p}=$ 0,042 ), e o risco foi de 2,34 
Resultados semelhantes para escolaridade foram observados por SPOLSKY et al (2.000), BORRELL et al (2.002), KATO SEGUNDO et al (2.004), entre outros.

No modelo múltiplo a escolaridade, avaliada pelo analfabetismo ou por anos de estudo $<1$, perdeu a significância estatisticá.

\section{RELIGIÃO}

Não foram encontrados estudos com doenças bucais que incorporassem a variável religião em seus resultados. Esta variável é encontrada em estudos de saúde mental, que avaliam hábitos e consumo de drogas (CEBRID 2.000, CARLINI et al 2.002).

A opção religiosa também pode ser indicativa da inserção sócio-econômica de uma comunidade. Sabe-se que algumas seitas religiosas congregam um grande número de fiéis de camadas sociais menos privilegiadas. Pessoas de baixa renda, baixa escolaridade e em busca de soluções para os seus problemas, como o desemprego, recorrem à religião. Assim, não propriamente a religião, mas novamente os determinantes sócio-econômicos justificariam a associação com o agravo de interesse.

$\mathrm{Na}$ análise bivariada entre religião e DPD não houve associação estatisticamente significativa.

\subsection{CONDIÇÕES E ESTADOS - VARIÁVEIS SISTÊMICAS}

Quadros sistêmicos ou doenças auto-imunes que prescindem do uso de drogas imunossupressoras constituem um alerta para as doenças periodontais (CURY et al 2.003).

A gravidez e a Síndrome da Imuno Deficiência Humana Adquirida - AIDS são condições que sabidamente alteram o quadro das doenças periodontais, por esta razão, gestantes e soro positivos para o virus da imunodeficiência humana - HIV foram previamente excluidos da pesquisa.

Distúrbios ansiosos e depressivos, assim como agravos que levem o paciente ao uso prolongado de drogas de ação neurológica ou psíquica (ansiolíticos, antidepressivos, hipnóticos, anticonvulsivante etc), também têm sido pesquisados por diversos autores como importantes na determinação do risco para as doenças 
periodontais (FREEMAN e GOSS 1.993, LINDEN et al 1.996, MOSS et al 1.996. MAJOLA et al 2.000)

Estados ou condições, permanentes ou transitórias, que levem o paciente a uma diminuição de sua resposta imunológica podem alterar significativamente a instalação, progressão e aumento da severidade ou gravidade das doenças periodontais (FOX 1.992, FIGUEIREDO 2.001, ALBANDAR 2.002, PERUZZO et al 2004, SILVA 2.004).

Estas condições têm sido apontadas pela literatura como significativas e foram objetos de investigação neste trabalho.

\section{DIABETES}

O diabetes tem sido objeto de debate como uma condição sistêmicas associada ao risco para as doenças periodontais (GENCO 1996, ACEVEDO et al 2.001).

PAPAPANOU e LINDHE (1.999) apresentaram oito estudos epidemiológicos, de caso controle e de prevalência, 4 realizados nos EUA e 4 em paises europeus, avaliando doenças periodontais em diabéticos e não diabéticos.

Em apenas três estudos não se observaram diferenças estatisticamente significativas nas condições periodontais de pessoas diabéticas e saudáveis. Os demais estudos demonstraram que os diabéticos apresentavam condições periodontais mais graves

EMRICH et al (1.991) em uma amostra de 1.342 Pima Indians, com idade de 15 anos ou mais, empregando análise multivariada verificaram que o diabetes triplica o risco de desenvolver doença periodontal quando comparados a pacientes com metabolismo normal do açúcar.

$\mathrm{O}$ diabetes é uma sindrome plurimetabólica e age promovendo diversas manifestações em diversos sistemas. Há dois tipos de diabetes: o tipo I ou juvenil que acomete aproximadamente $10,0 \%$ dos diabéticos e o diabetes tipo II, nos $90,0 \%$ restantes. Estes são geralmente adultos a partir de 40-45 anos.

No diabético o pâncreas diminui ou pára de produzir insulina o que leva o paciente a uma hiperglicemia crônica. Segundo a OMS citada em artigo de 
divulgação da APCD (SILVA, 2.004) deve haver 180 milhões de diabéticos no mundo, 12 milhões no Brasii.

O diabetes de longa duração, inicio precoce e controle metabólico inadequado pode conferir um risco elevado para as doenças periodontais destrutivas (SAFKANSEPPALLA e AINAMO 1.992).

O diabetes dificulta a resposta imune facilitando a evolução das doenças periodontais. Há um aumento da quantidade de enzimas catabólicas, mediadores inflamatórios, interleucinas e fatores de necrose tumoral $\alpha$, resultando em aumento dos osteoclastos e evidente aumento da reabsorção óssea. A colagenase, também em concentrações mais elevadas nestes pacientes, despolimeriza o colágeno destruindo o ligamento periodontal.

Quando os niveis sanguineos de açúcar permanecem elevados a hemoglobina se liga ao açúcar e forma pequenos trombos (AGES - advanced glycated endproducts) nas paredes dos vasos dificultando a saída de células de defesa e o transporte de nutrientes. Quanto mais elevados os niveis de hemoglobina glicosada maior a dificuldade dos tecidos, inclusive os periodontais, apresentarem uma defesa vascular insatisfatória (GARCIA et al 1.998, DE POMMEREAU at al 1992; THORTENSSON e HUGSON 1.993).

Saliente-se que processos infecciosos também podem descompensar o diabetes e, portanto é imprescindivel diagnosticar e controlar doenças periodontais nestes pacientes.

Dos 22 individuos com diabetes neste estudo, 15 apresentavam doença periodontal destrutiva, mas não se constatou associação estatisticamente significativa do diabetes com as doenças periodontais destrutivas $(\mathrm{p}=0,097)$.

Estes resultados contrariam o observado por FOX (1.992), BELTING et al (1.964), DUARTE (2.000).

BRITO et al (2.004) comparou fumantes, não fumantes e diabéticos quanto ao risco para as doenças periodontais. E apesar do diabetes constituir uma condição extremamente desfavorável os quadros clínicos piores foram observado no grupo de fumantes. Os diabéticos ficaram em condição intermediária entre os fumantes e não fumantes. 
A população diabética de usuários do PSF Santa Marcelina deve ser objeto de novos estudos. Até que isto possa ser feito, deve-se priorizar este grupo de pacientes no que tange ao risco de comprometimento sistêmico por infecções dentárias ou periodontais.

\section{DISTÚRBIOS NEUROLÓGICOS E PSIQQUICOS}

Distúrbios neurológicos, transtornos do humor, estresse emocional e outros quadros em saúde mental que levem o paciente ao uso prolongado de ansiolíticos, antidepressivos, hipnóticos, anticonvulsivantes etc, têm sido apontados pela literatura como de interesse no conhecimento dos fatores de risco para as doenças periodontais (DE MARCO 1.976, SOLIS 2.001, VETTORE et al 2.002).

$\mathrm{O}$ crescimento gengival observado em pacientes submetidos a drogas anti convulsivantes (fenitoina, nefedipina, ciclosporina) dificulta o adequado controle do biofilme e pode favorecer a instalação e progressão de doenças periodontais. A maioria dos antidepressivos e ansioliticos provoca diminuição do fluxo salivar e alterações na resposta imune.

Neste estudo 27 pessoas estavam em tratamento com neurologista ou psiquiatra, ou ainda faziam uso de medicação. Entre estes individuos, 15 eram controles. À análise univariada não se observou associação significativa entre os individuos que declararam estar sob acompanhamento e/ou medicação para distúrbios neurológicos ou psiquicos e as DPD $(p=0,472)$.

As evidências cientificas comprovam que fatores psicossociais além de distúrbios neurológicos são agentes relacionados com o risco para doenças periodontais, mas não são aceitos como fatores de risco reais (VETTORE et al 2.002). Em concordância com GENCO et al (1.999) mais estudos são necessários para que se entenda quando alterações psiquicas passam a interferir no curso das doenças periodontais e quais os mecanismos explicariam esta relação.

\section{DOENÇAS OU ESTADOS AUTO-IMUNES}

Está demonstrado que a resposta imune é um dos fatores mais importantes, senão o de maior importância, na instalação e progressão das DPD. 
Quadros sistêmicos ou doenças auto-imunes que prescindem do uso de drogas imunossupressoras, condições transitórias ou definitivas constituem um alerta para as DPD (GREENWALD e KIRKWOOD 1.999, SILVA 2.004). A interferência na resposta imune pode incrementar o risco para as DPD (GREENWALD e KIRKWOOD 1.999, DE LORENZO e DE LORENZO 2.003). Na análise de resultados desta pesquisa não se verificou associação estatisticamente significativa entre as DPD e as condições de imunodepressão $(\mathrm{p}=0,524)$.

Acredita-se que também para a imunodepressão, provocada pelo uso prolongado de medicação ou por doenças imunodepressoras sejam necessários novos estudos que se ocupem particularmente destas questões, no intuito de identificar o real papel desses quadros sistêmicos no processo saúde-doença periodontal.

\subsection{HÁBITOS E COSTUMES}

TABACO

Um número relativamente grande de estudos tem analisado múltiplos fatores e indicadores apontados como de risco para as doenças periodontais. Entre esses fatores, o tabaco é o que acumula maior número de estudos e de evidências (ARBES et al 2.001). O consumo de tabaco tem sido estudado como fator de risco desde a década de 70 .

Neste estudo o uso do tabaco foi investigado como variável de controle no risco para as DPD, visto que são numerosas as evidências de sua implicação.

Somado a isso, um estudo realizado com indios navajos apontava um maior consumo de álcool em tabagistas (WOLFE e CARLOS 1.987). Observação semelhante foi apontada no estudo de PITIPHAT et al (2.003). Sendo assim, pretendeu-se também identificar a existência de interação, efeito sinérgico ou multiplicativo, entre tabaco e álcool, como já se está esclarecido para o câncer bucal.

BERGSTRÖN (1.989) considerou fumantes pessoas que fumavam mais de 10 cigarros por dia, o que pode significar fumar, em média, um cigarro a cada 2 horas. O mesmo autor classifica os fumantes em leves, moderados e pesados na dependência do número de cigarros consumidos por dia. 
Segundo os criterios do teste Faggerströn para dependência de nicotina, aplicado nos entrevistados, consideraram-se fumantes todos os que fumam, em média, até menos de um cigarro por dia.

A plausibilidade biológica de uma associação entre o tabagismo e as doenças periodontais advém dos efeitos potenciais das substâncias relacionada ao cigarro, como a nicotina, o monóxido de carbono e o cianeto de hidrogênio. Estas substâncias agem como vasoconstritores provocando isquemia dos tecidos, redução da resposta vascular inflamatória e do reparo celular e tecidual. O reparo tecidual parece também sofrer interferência dos produtos tóxicos sobre macrófagos e fibroblastos, retardando-o.

Estudos empregando análises multivariadas revelam que a condição periodontal é pior em fumantes do que em não fumantes e não pode ser atribuida à quantidade ou à qualidade do biofilme dental (DAMÉ 1.996)

A maior prevalência das doenças periodontais em tabagista é incomparavelmente maior do que aquela atribuida a outros fatores ou condições de risco como o diabetes (HART et al 1.995, COPE et al 2.000, BRITO et al 2004).

Em um estudo de metanálise ${ }^{*(17)}$ dos dados de estudos sobre associação do tabagismo e condições periodontais verificou-se que o tabagismo acarretou um risco total elevado, estatistica e biologicamente significativo para as doenças periodontais destrutivas (PAPAPANOU 1.996).

O tabagismo, por si só, é capaz de aumentar em até duas vezes a velocidade de progressão das doenças periodontais e, a interrupção do hábito reverte em um retardo da progressão da perda óssea

No presente estudo não se verificou associação significativa entre o tabagismo, avaliado segundo a existência do hábito $(\mathrm{p}=0,255)$, o número de cigarros $(\mathrm{p}=0,869)$ e as doenças periodontais.

\footnotetext{
${ }^{*}(17)$ Metanálise é um método estatístico que combina resultados de diferentes estudos com propósitos semelhantes a fim de obter um maior poder global para revelar associações biologicas que existem. mas são difíceis de ser detectadas. (PAPAPANOU 1.996)
} 
Pindborg (1.947), Ludwick e Massler (1.932) e Brandtzaeg e Jannsonh (1.964) citados por SALLUM et al (1.993) também referiram não encontrar associação entre o tabaco e inflamação periodontal. Resultados semelhantes foram encontrados por NUNES e SLAVUTZKY (1.992).

NUNES e SLAVUTZKY (1.992) não encontram correlação entre o fato do paciente ser ou não fumante ou com o número de cigarros fumados, mas a correlação se estabeleceu de forma significativa entre a idade e o tempo que o pacientes estava sem tratamento periodontal.

\section{ÁLCOOL}

Desde a década de 70, aponta-se para necessidade de investigar os efeitos do álcool sobre o periodonto, entretanto poucos estudos foram realizados avaliando estes hábitos e as doenças periodontais. Nas bases de dados consultadas não foram encontrados estudos nacionais ou latino-americanos sobre o álcool como fator de risco para as doenças periodontais.

Passados mais de 30 anos, reiterando o observado, no inicio dos anos 70, por LARATO (1.972), poucos estudos examinaram a possibilidade de relação entre o consumo de álcool e doenças periodontais, apesar da plausibilidade biológica.

Álcool e drogas ilicitas como cocaina, maconha, crack entre outras parecem ter efeitos sobre os tecidos periodontais.

A dificuldade em obter dados confiáveis sobre o consumo das substâncias citadas pode ser uma das justificativas para a existência de poucos estudos sobre o risco que o álcool e as outras drogas exercem sobre as DPD.

Implicações de ordem moral, entre outras, fazem com que os usuários de álcool, uma droga lícita, se intimidem ao ter que dar informações sobre o seu consumo pessoal. Com as drogas ilicitas as dificuldades podem ser ainda maiores. Os boletins do CEBRID (CEBRID 2.000, CEBRID 2.001, CEBRID 2.002, CEBRID 2.003, CEBRID 2.004) o estudo de FERRARI, (2.001), considerações apresentadas por FORMIGONI et al (1.999) fazem alusão a estas dificuldades, garantem e reforçam a necessidade de deixar claro para os entrevistados que o sigilo será absoluto, mas mesmo tendo isto garantido as dificuldades são muitas. Estas foram constatações registradas no relatório final de um estudo pioneiro, de âmbito nacional 
realizado pelo CEBRID - Centro Brasileiro de Informações sobre Drogas, ligado à Universidade Federal de São Paulo - UNIFESP (CARLINI et al 2.002). Existem tecnicas e instrumentos já validados para obtenção dessas informações que subsidiam o trabalho dos profissionais de saúde mental.

Observam-se usuários de álcool em todas as idades, o que é incomum para as drogas ilícitas. Tendo em vista a teoria do acúmulo de riscos ao longo da vida (MANOR 1.997) pode se esperar que os individuos mais velhos, submetidos condições de vida desfavoráveis, com hábitos que podem corroborar no incremento do risco para as DPD, como se suspeita que o álcool seja, apresentem piores condições periodontais. Os usuários de drogas ilicitas geralmente são jovens, e nos jovens os quadros periodontais instalados são de baixa gravidade e extensão. Todavia não se deve descartar a hipótese de que mesmo nestas pessoas as drogas ilicitas possam estar associadas com o risco para as DPD.

Todos os examinados responderam questões sobre seu consumo de bebidas alcoólicas. Com auxilio de material ilustrado (Anexo 7) foi possivel discriminar o tipo de bebida e a sua forma de apresentação para o consumo. Posteriormente calculou-se o número de doses de álcool absoluto consumido semanalmente usando a tabela de referência (Anexo 7).

O consumo de álcool na vida foi avaliado de forma subjetiva. Procurou-se identificar a quantidade e freqüência de consumo de álcool na última semana, no último mês, no último ano, há 5, 10 e 20 anos.

Dos 621 entrevistados $1 / 3$ declarou consumir álcool $(n=217=34,9 \%)$, os demais se disseram não fazê-lo com freqüência semanal na atualidade Houve associação significativa entre este uso do álcool e as DPD ( $\mathrm{p}=0,011)$, mas o seu efeito nesta análise foi de proteção. Como não se identificou as quantidades e periodicidade de consumo, e para alguns agravos à saúde pequenas quantidades de álcool podem não ter um efeito maléfico verifica-se a necessidade de aprofundar o conhecimento a este respeito.

Avaliando o consumo de álcool na vida, desde a última semana até há 20 anos, verifica-se que 290 pessoas $(46,8 \%)$ fizeram uso de álcool, sem considerar as quantidades ou a periodicidade. Os resultados da análise bivariada para esta variável foram novamente significativos e o efeito protetor. Reitera-se a necessidade de 
investigar quais as quantidades e freqüência, em periodos anteriores ao da investigação, a fim de se verificar se este efeito se confirma.

As questões sobre o consumo na última semana e último mês intentavam identificar o perfil de consumo sem muito significado para a ocorrência do agravo, tendo em vista a necessidade de exposição crônica.

Durante a análise de cada um dos momentos (última semana, último mês, último ano, há 5, 10 e 20 anos) observou-se que a resposta "abstinente" variou de $88,4 \%$ a $56,5 \%$; De $23,0 \%$ a $34,3 \%$, em torno de um quarto, dos entrevistados consome álcool de forma ocasional, podendo ser considerados etilistas sociais. $\mathrm{O}$ hábito de consumir álcool em maior quantidade e freqüência, mas com controle e sem episódios de embriaguez variou de 2,7 a $6,3 \%$. De $0,3 \%$ a 2,1\% (2 a 13) individuos declararam o consumo de álcool em grande quantidade, sem controle e com episódios de embriaguez, provavelmente pessoas dependentes de álcool (alcoolistas crônicos) ou que fazem uso abusivo desta droga.

A identificação da dependência ou do uso abusivo do álcool como doença psiquica, o conhecimento dos efeitos danosos do álcool sobre o organismo e as conseqüências para a sociedade tornaram o alcoolismo um problema de saúde pública (CHRISTEN 1.983, FORMIGONI 1.999, FRIELANDER et al 2.003, PITIPHAT et al 2.003).

Os efeitos do álcool na saúde bucal vão além do acúmulo de depósitos dentários, até porque estes acúmulos constituem fator importante, mas por si só não explicam grande parte das doenças periodontais.

Nestes pacientes há comprometimento do fluxo salivar (FRIELANDER et al, 2.003), aumento do risco de infecções resultantes das alterações dos mecanismos de defesa relacionadas ao sistema complemento e à dinâmica dos PMNN (FRIELANDER et al 2.003, PITIPHAT et al 2.003), além dos comprometimentos circulatórios e de coagulação.

Nas análises bivariadas, onde se considerou "beber bastante, diariamente ou com grande freqüência, com ou sem episódios de embriaguez, com ou sem controle" como a condição de maior risco verificou-se associação estatisticamente significativa com as DPD com incremento do risco em torno de duas vezes em todos os periodos considerados, exceto no periodo "há 20 anos". Neste periodo novamente se observou

\section{BIBLIOTECA/CIR FACULDADE DE SAÚDE PÚBLICA UNIVERSIDADE DE SÁO PAIIII}


associação e efeito protetor do álcool. Estes resultados podem ter sofrido viés de memória. Os individuos mais jovens podem não ter caracterizado adequadamente seu consumo há 20 anos.

Resultados semelhantes foram observados apenas na análise bivariada do estudo de SHISUKUISH et al 1.998.

O incremento do consumo de álcool em cada periodo as DPD foi analisando por testes de tendência. Verificou-se que os risco para as DPD não se altera $(O R=$ $1,00)$ para os que declararam não consumir álcool ("abstinente"). Houve um aumento do risco (OR), em torno de duas vezes, com o aumento da freqüência ou da quantidade consumida, na última semana. Nos outros periodos não se verificou significância estatística $(\mathrm{p}>0,005)$ no teste de tendência entre o aumento do consumo de álcool e as DPD.

Analisando a freqüência de consumo na atualidade, considerando a freqüência de 1 a 7 dias por semana, o número de doses de álcool absoluto ingerido variou de 1 a 53, ou seja, de 13,4 a 710,2 gramas de álcool absoluto por semana (1 dose $=13,4$ grs de álcool absoluto).

SAKKI et al (1.995) e TEZAL et al (2004) identificaram correlação entre o número de drinques ou a quantidade de álcool absoluto ingerida semanalmente e a perda de inserção periodontal.

Não se avaliou neste estudo a associação entre perda de inserção e as quantidades de álcool absoluto ingeridas, tampouco entre estas quantidades e as DPD.

Os diferentes tipos de bebidas consumidas, destiladas ou fermentadas, a exclusividade do consumo de destilados ou de fermentados, ou o consumo de ambos não revelou associação com a presença da doença periodontal.

Consumir exclusivamente bebidas fermentadas ou destiladas, ou a combinação de ambas deve ser cuidadosamente analisado. A "opção" pode refletir estilos ou modos de vida diferentes.

Analisando consumidores de vinho e cerveja, por exemplo, ambas bebidas fermentadas, pode-se afirmar que aqueles que bebem cerveja têm modos de vida diferentes dos que bebem vinho. A mesma leitura pode ser feita para consumidores de aguardente e de uisque ou vodca. 
Estas observacões também foram ponderadas por SAKKI et al (1.995) e TEZAL et al (2.004).

PITIPHAT et al (2.003), em estudo longitudinal de 12 anos, encontrou diferenças estatisticamente significativas entre o consumo de cerveja, vinho branco, vinho tinto e cerveja. Houve um risco relativo maior para as doenças periodontais nos consumidores de vinho tinto, seguido pelos de licor. O risco relativo dos para os consumidores de cerveja ficou aquém dos de vinho branco.

Considerando a significância estatística verificada nas análises bivariadas de consumo do álcool nos vários periodos referidos construiram-se vários modelos múltiplos. Os consumos na última semana e no último não foram incluídos nos modelos múltiplos por não representarem cronicidade de exposição.

Analisando os residuos dos modelos construidos pelo teste de Hosmer e Lemeshow decidiu-se pelo melhor modelo (Hosmer-Lemeshow $=0,817$ ), que consta da tabela 25 , nos resultados deste estudo.

No modelo múltiplo o consumo de álcool na vida, considerando todos os periodos, desde a última semana até há 20 anos, se manteve associado às DPD, com efeito protetor. Identificar a história pregressa de quantidades consumidas talvez possa explicar o que se observou como "proteção". consumo de álcool no último ano foi significativo $(\mathrm{p}=0,017)$ e incrementou o risco em $2,88(\mathrm{OR}=2,88)$.

Neste estudo o consumo de álcool no último ano constituiu fator de risco associado às DPD, independentes do grupo etário e de sexo, do acúmulo de biofilme e uso de próteses parciais.

Estes resultados sinalizam a necessidade de avaliação de outros grupos populacionais onde eventualmente a freqüência, as quantidades, ou até mesmo o tipo de bebida consumida possam confirmar o observado. Outros estudos de caso controle, ponderando qual o periodo pregresso mais adequado para se tomar como ponto de partida para estas análises de associação ou estudos de coorte seriam muito adequados para se estudar longitudinalmente os efeitos do álcool sobre o periodonto. 


\subsection{VARIÁVEIS CLÍNICAS}

CPI

No presente estudo foram identificados $8,5 \%$ dos individuos com periodonto saudável e $25,0 \%$ dos examinados apresentaram sangramento. Ao avaliar cada uma das condições codificadas pelo CPI verifica-se que o percentual de individuos saudáveis está em consonância com os dados da literatura.

Os achados no estudo clássico de LÖE, ANERUD, BOYSEN e SMITH (1.978) sobre a história natural das doenças periodontais, no Sri Lanka, com plantadores de chá, reafirmado por muitos outros sinalizou para uma expectativa em torno de 10,0\%, de individuos sem manifestação alguma de doença periodontal.

Observou-se um baixo percentual de individuos com fatores de retenção de biofilme e cálculo ( $15,3 \%$ ). Bolsas rasas foram encontradas em $32,5 \%$ dos individuos e bolsas profundas em 18,7\%. A doença grave, com destruição periodontal importante também está de acordo com os dados do estudo clássico referido, e confirmado por vários autores.

A média de sextantes saudáveis foi de 1,5; fatores de retenção de biofilme e cálculo estiveram em média em 0,5 dos sextantes; bolsas rasas em 1,1 e apenas 0,3 sextantes em média apresentavam bolsas profundas.

A condição de sextantes nulos não foi computada para pior condição periodontal uma vez que o critério para considerar um sextante nulo foi o de não haver dentes no sextante e, portanto não há periodonto. O sextante também foi considerado nulo quando havia dentes, mas sem condições de serem examinados, por grande destruição ou por outros motivos.

A partir da recomendação do uso do CPITN para levantamentos epidemiológicos, passou-se a discutir quais as metas que poderiam ser formuladas a partir do percentual de individuos ou sextantes que seria considerado aceitável para cada um dos grupos etários, em cada uma das condições do CPITN.

Citado por MARQUES (2.000) em 1983, Frandsen colocava:

“.. uma das preocupações durante estudos epidemiológicos com CPITN deve ser a de conhecer qual a proporção de indivíduos com 
um minimo de 2 ou 3 sextantes com CPITN igual a $0^{\prime \prime}$.

$\because$ esta pergunta está relacionada à recomendação que diz que 3 sextantes saudáveis devem ser considerados como uma medida de atenção pessoal aceitável".

BARMES e LEOUS (1.986) não se sentiam seguros de propor metas numéricas para adultos. Sugeriram que se discutisse qual a porcentagem de individuos adultos afetados, na faixa etária de 35 a 44 anos, e o número de bolsas por pessoa.

O Japão é um dos paises que mais tem realizado estudos com o CPITN, o que permitiu uma reorganização dos serviços e a proposição de metas regionais. Neste pais no grupo etário de 35 a 44 anos a prevalência de bolsas profundas, deve ser menor que $5,0 \%$.

Segundo BOURGEOIS et al (2.000) e PETERSEN et al (1.994) tem se recomendado a proposição de metas regionais tendo em vista diferenças culturais e condições sócio econômicas diversas.

Diante do exposto e tendo em vista a população da qual faz parte o grupo de caso e controles deste estudo pode-se inferir que muito deve se investir na preservação de periodontos saudáveis ou com doença insipiente. Muito mais deve ser feito para a recuperação dos comprometimentos periodontais graves

Seria muito conveniente propor metas em saúde bucal, particularmente para a saúde periodontal de adultos, a serem alcançadas nos próximos 10 anos.

As submetas propostas para adultos, pelo WHO Regional Office for Europe para 2.015, podem ser um referencial teórico que pode ser tomado como base para a elaboração de propostas.

Estas serão mais factiveis na medida em que se possa realizar um estudo epidemiológico loco-regional para o conhecimento da prevalência atual das doenças periodontais. 
Deve ficar implicita a necessidade de avaliar os recursos regionais para melhoria dos serviços de atenção primária e implantação de serviços de atençào secundária $\mathrm{e}$, a indispensável e evidente necessidade de investimentos na qualidade de vida da população da regiào.

PIP

Pode-se encontrar perda de inserção em individuos com periodonto sadio, contudo esta condição comumente acompanha individuos com a doença em atividade ou em periodos de remissão e deve ser cuidadosamente analisada.

Realizou-se a estatística Kappa para perda de inserção e doença periodontal destrutiva. Houve uma moderada concordância entre perda de inserção e doenças periodontais destrutivas $(0,582)$.

A perda de inserção esteve associada à presença das doenças periodontais destrutivas. $(\mathrm{p}<0,0000)$ e que pode se considerada uma evidência da presença de doença.

Não houve associação significativa entre perda de inserção e uso de tabaco ou do álcool, nem interação entre as variáveis relativas a estes hábitos e a perda de inserção conjuntiva.

\section{EXPERIĖNCIA DE CÁRIE}

CÁRIE DE COROA

OPPERMAN e ROSSING (1.997) e LLAMBIAS (1.999) entre muitos outros autores apontam a experiência de cárie como condição importante na avaliação de risco para as doenças periodontais.

A capacidade de reter biofilme dentário assim como o aumento da dificuldade na sua remoção deve ser considerado quando da avaliação de risco para as doenças periodontais. Assim tornou-se necessário avaliar a presença de cavidades de cárie, de restaurações e de dentes perdidos na população estudada, em consonância com o apontado por muitos autores.

A média de dentes atacados por cárie - CPO-D for de 18,57, abaixo do valor médio nacional encontrado no último levantamento epidemiológico, SB Brasil- 2003 
(MS 2.004) para a população adulta de 35 a 44 anos, em que o CPO-D foi igual a 20,33 .

Nesta população de estudo o componente perdido foi o de maior peso. A media de dentes perdidos foi 10,64, também abaixo do resultado dos dados nacionais. No "Projeto SB Brasil 2003 - Condições de Saúde Bucal da População Brasileira - 2002-2003", (MS 2.004) a média de dentes perdidos para adultos de 35 a 44 anos foi de 11,92 .

Não foi possivel identificar a causa das perdas dentárias e por este motivo considerou-se a perda como tendo ocorrido por cárie. Somente quando o paciente já perdeu dentes por doenças periodontais é que ele refere a este fato.

Nesta população verificou-se que $9,8 \%$ dos examinados eram desdentados totais em uma das arcadas. O número médio de dentes presentes no grupo de estudo foi de 21,33 , mas não foi identificado se eram dentes funcionais ou não.

$\mathrm{Na}$ análise bivariada a cárie mostrou associação significativa com as doenças periodontais quando atingia 8 ou mais coroas $(p=0,011)$ e elevou o risco acima de duas vezes $(O R=2,22)$. Esta condição perdeu a significância na análise múltipla.

\section{CARIE RAIZ}

A exposição radicular proveniente da erupção ativa ou em conseqüência à perda de inserção como seqüela de doenças periodontais, associada ou não a trauma oclusal, pode expor o cemento dentário, mais vulnerável aos sucessivos desafios cariogênicos e parece levar ao incremento de cárie radicular.

Esta situação pode também ser considerada preditora de risco para as doenças periodontais pelo aumento da retenção de biofilme e da dificuldade em removê-lo adequadamente.

Investigou-se a presença de lesões de cárie radicular, uma vez que pode haver um aumento da prevalência deste tipo de lesão em pacientes com perda de inserção e exposição radicular.

A presença de cárie radicular variou de 0 a 13 dentes com raizes atacadas, com uma média igual a 0,64 . Encontravam-se restaurados de 1 a 7 dentes com raizes atacadas, uma média de 0,10 . 
O relatório do MS (2.004) apresenta uma média nacional de raizes cariadas iguai a 0,32 , para a população adulta do grupo etário de 35 a 44 anos, e restauradas iguais a 0,04 .

$\mathrm{Na}$ análise univariada verificou-se significância estatistica a partir de 2 dentes com raizes cariadas $(p=0,026$.) e o risco foi igual a $2,01 \quad(O R=2,01)$. Não se confirmou a significância estatistica no modelo múltiplo.

\section{USO DE PRÓTESES}

Os estudos de ASCKAR et al (1.999), LELES et al (1.999) e MUNIZ et al (1.999) o uso de próteses demosntrou relação com o de risco para as doenças periodontais.

No presente estudo não usar prótese, ou usar prótese total em um dos arcos dentários não esteve associado ao risco para as DPD $(\mathrm{p}=0,3851)$.

Como o acúmulo de biofilme é menor e o seu controle se torna mais fácil em individuos que usam prótese total em um dos arcos e não usam próteses removiveis estes foram considerados como categoria de menor risco para as DPD.

Verifica-se um aumento da retenção de biofilme em portadores de próteses parciais, fixas e removiveis, sendo nesta última, clinicamente mais significativa.

Além de maior retenção de biofilme nos dentes vizinhos ao espaço protético, a carga recebida por estes elementos dentais também compromete o ligamento periodontal, mormente quando a distribuição de esforços não é feita adequadamente.

$\mathrm{Na}$ análise univariada o uso de próteses parciais não foi significativo, com o valor de $\mathrm{p}=0,110$, mesmo assim esta variável foi inserida no modelo múltiplo.

No modelo múltiplo o uso de prótese parciais no grupo estudado esteve associado ao risco para as DPD $(\mathrm{p}=0,036)$, e aumenta em $55,0 \%$ o risco para as DPD, ajustado por sexo masculino, idade acima de 35 anos, presença de placa em mais de 1/3 das superficies dentárias e consumo de álcool no último ano.

Resultados semelhantes foram encontrados por SEEMANN et al (1.963), CARLSSON et al (1.976), MARKKANEN et al (1.987), YUSOF et al (1.994), DINI (1.995), ASKAR et al (1.999), KURTIS et al, 2.003, entre outros autores.

As próteses parciais removiveis - PPR têm sido associadas ao incremento das doenças periodontais sendo importantes preditores de risco para este agravo. 
Verifica-se que principalmente nos retentores das PPR há maior susceptibilidade à progressão das doenças periodontais do que os outros dentes (KURTIS et al 2.003). As PPR aumentam a retenção do biofilme, desencadeiam um incremento dos niveis de IL-1 $\beta$ com reflexo nos parâmetros clínicos periodontais.

Alguns estudos apontam correlação entre os indices de biofilme e gengival em pacientes com PPR, mas não se verifica correlação importante com os niveis de inserção (KURTIS et al, 2.003).

\section{INDICE DE HIGIENE ORAL MODIFICADO - IHOS}

Tanto na prática clínica quanto em estudos populacionais os dados que se referem ao controle mecânico de biofilme, principalmente quanto à freqüência da escovação não condizem com a condição clínica que o paciente apresenta no momento em isto è perguntado, independentemente do tamanho da amostra. A retenção de biofilme, assim como o aumento da dificuldade na sua remoção deve ser levado em conta quando da avaliação de risco para as DPD. Optou-se por utilizar o IHOS, assim como MARCUS et al (2.000) para a partir deste indicador discutir a presença de biofilme.

O biofilme dentário ou placa bacteriana é fator etiológico da cárie e das doenças periodontais, é importante para desencadear a instalação das doenças periodontais, mas não é condição suficiente para a sua progressão e agravamento. São muitos os autores que encontram evidências desta afirmação podendo citar as observações de EL NADEEF e ADEGBENBO (1.995).

Tal como NUNES e SLAVUTZKY 1.992, SAKKI et al 1.995, SHIZUKUISHI et al 1.998, KATO SEGUNDO et al 2.004 e, como tem sido observado, na imensa maioria dos estudos, a presença de biofilme esteve associada às doenças periodontais com elevada significância estatística $(\mathrm{p}<0,0000)$. $O$ risco foi três vezes maior para a presença de biofilme em mais de 1/3 das superficies dentárias $(\mathrm{OR}=3,12)$. No modelo múltiplo tanto o risco $(\mathrm{OR}=2,55)$ quanto a significância se mantiveram $(\mathrm{p}<0,005)$. 


\subsection{CONSIDERACÕES FinaIS}

Dados epidemiológicos permitem afirmar que as pessoas tendem a manter maior quantidade de dentes do que seus ancestrais. Verifica-se que o numero de edientados tem sofrido redução nos últimos 20 anos. Deve-se esperar que as estimativas da prevalência das doenças periodontais sofram elevação em vez de redução, considerando a perda de cumulativa de inserção clinica que demanda necessariamente à terapêutica periodontal.

$\mathrm{Na}$ literatura, encontram-se evidências da relação de risco do diabetes, distúrbios neurológicos ou psíquicos e doenças ou estados imuno-depressivos com as DPD. Entretanto, para estas condições sistêmicas, na população deste estudo, não houve esta associação.

No grupo de individuos examinados o consumo do álcool esteve associado às DPD, isto não ocorreu com o uso do tabaco.

Pode se verificar para o álcool que o consumo e a temporalidade deste consumo estão associados às doenças periodontais, elevando o risco em até três vezes, se este consumo, pelo menos no último ano, for abundante e freqüente.

A experiência de cárie coronária ou radicular não foi uma condição associada ao risco neste estudo. Mas apresentar 1/3 ou mais superficies com biofilme e o uso de próteses parciais fixas ou removiveis é fator associado ao risco para as DPD no entre os casos e controles desta pesquisa.

Sugere-se que além da condição periodontal apresentada no momento da triagem de risco realizada pelos serviços do PSF Santa Marcelina o consumo de álcool e tabaco, uso de próteses parciais, sexo e idade fossem incorporadas na identificação do risco para as DPD.

Sugere-se ainda que os individuos que apresentarem bolsas periodontais ou mobilidade limitante da função e todas as caracteristicas consideradas de maior risco neste estudo devam ter prioridade na recuperação de sua saúde bucal.

Aqueles que apresentarem bolsas periodontais e mobilidade limitante da função, sem as caracteristicas acima identificadas podem vir a constituir um grupo de risco, mas colocado como grupo de risco imediatamente abaixo do descrito no parágrafo anterior. 
Sinteticamente: idade acima de 35 anos, sexo masculino, consumo de álcool freqüente e abundante no último ano, superfícies dentárias com a presença de 1/3 ou mais de biofilme, uso de próteses parciais foram fatores associados ao risco para as DPD na população adulta de 25 a 55 anos, usuária dos serviços do PSF Santa Marcelina, mas novos estudos que investiguem estas condições e o risco para as doenças periodontais são necessários para que se a confirmem os resultados obtidos. 


\section{Conclusões}

Presença de placa em mais de um terço das superfícies dentárias e uso de próteses parciais removíveis entre as variáveis relativas a condições clínicas, sexo e idade como variáveis sócio-demográficas, e consumo de álcool no último ano entre as variáveis inerentes aos hábitos são fatores associados ao risco para as DPD, na população adulta, de 25 a 55 anos de idade, cadastrada e usuária do o PSF Santa Marcelina, serviço público de saúde de um Programa de Saúde da Família - PSF, instalado na zona leste da capital paulista.

Diabetes, distúrbios neurológicos ou psíquicos, doenças ou estados imunodepressores e consumo de tabaco não foram identificados como fatores associados ao risco para as DPD na população estudada. 


\section{REFERÊNCIAS BIBLIOGRÁFICAS}

1. Acevedo RA; Batista LHC; Trentin MS; Shibli JA. Tratamento periodontal no paciente idoso. Rev Odontol Passo Fundo, 2.001; 6(2):57-62.

2. Ainamo J. Epidemiologia da doença periodontal. In: Lindhe J, Tratado de Periodontologia Clínica. Rio de Janeiro; 1.985.p 41-53.

3. Albandar JM. Global risk factors and risk indicators for periodontal disease. Periodontol 2.000.2.002; 29:177-206.

4. Amoras ACB. Avaliação da condição periodontal e da prevalência de bactérias periodontopatogênicas em amostras de saliva e placa subgengival de adolescentes e adultos jovens. [Dissertação apresentada à Universidade de São Paulo- Faculdade de Odontologia de Bauru para obtenção do título de mestre].Bauru. 2.001. 143p.

5. Asckar EM, Vieira LF, Bonachela WC. Estudo longitudinal de pacientes portadores de próteses removíveis (PPR) em relação aos dentes controles, retentores primários e retentores secundários, com acompanhamento profissional. Odontol USF 1.999; 17 (jan-dez): 63-77.

6. Assaf AV. Fatores de Risco para a doença periodontal. RBO 1.999; 56(6):291-94.

7. Axtelius B; Söderfeldt B; Nilsson B, Edwardsson S; Attströn R. Therapyresistant periodontitis. Psychological characteristics. J Clin Periodontol. $1.998 ; 25: 482-491$.

8. Baab DA. Oberg PA, Hollow GA. Gingival blood flow measured with a laser doppler flowmeter. J Periodontol Res. 1.986; 21:73-85.

9. Baellum V, Chen X, Manji F, Luan WM, Fejerkov O. Profiles of destructive periodontal disease in different populations. J Periodontal Res. 1.996, 31:1626.

10. Baelum V, Papapanou PN. CPITN and the epidemiology of periodontal disease. Comm Dent Oral Epidemiol 1.996; 24(6): 367-8.

11. Baelum V; Fejerkov O. Karring T. Oral Hygiene. Gingivitis and periodontal breakdown in adult Tanzanians. J Periodontol Res 1.986;21:221-32.

12. Baelum V; Fejerkov O. Karring T. Periodontal disease in adult Kenyans. J Clin Periodontol 1.988; $15: 445-52$. 
13. Baelum V; Fejerkov O; Manji F; Wanzala P. Influence of CPITN partial recording on estimates of prevalence and severity of various periodontal conditions in adults. Comm Dentistry and Oral Epidemiol. 1.993a; 21:35459.

14. Baelum V; Fejerkov O; Manji F; Wanzala P. Validity of CPITN's assumptions of hierarchical occurrence of periodontal conditions in a Kenyan population aged15-65 years. Comm Dentistry and Oral Epidemiol. 1.993b; 21:347-53.

15. Baelum V; Fejerkov O; Manji F; Wanzala P. Relationship between CPITN and periodontal attachment loss findings in adult population. $\mathbf{J}$ Clin Periodontol. 1.995; 22:146-52.

16. Baelum V; Luan WM; Fejerskov O; Xia C. Tooth mortality and periodontal conditions in 60-80 years old Chinese. Scandinavian J Dent Res.1.988; 21:354-59.

17. Bárbara L, Burman A, Medeiros H, Camargo M, Collins M, Mauro EWW, Borba FS, Bazzoli MB, Oliveira ATP, Almeida EF, Brockhausen IG, Ferreira NM. Michaelis. Dicionário Inglês /Português. São Paulo. Ed Melhoramentos. 1.994.

18. Barbour SE; Nakashima K; Zhang JB; Tangada S; Hahn CL; Schenkein HA; Tew JG. Tobacco and smoking: environmental factors that modify the host response (immune system) and have an impact on periodontal health. Crit Rev Oral Biol Med. 1.997; 8(4):437-60.

19. Barmes DE, Leous PA. Assessment of periodontal status by CPITN and its applicability to the development of long-term goals on periodontal health of the population. Int Dent $\mathbf{J}$ 1.986; 36:177-81.

20. Barros OM, Luna EJA, Medina NH, Oliveira MB, Vranjac A. Doença e desigualdade social - Tracoma em Bebedouro. São Paulo. 1.986. São Paulo 1.988 [projeto mimeo].

21. Barroso EC, Campos Júnior A, Mendonça JAG. Análise da placa bacteriana subgengival em pacientes de risco à doença periodontal e sua capacidade previsora de perda de inserção periodontal. Rev Odontol Bauru 1.999; $7(3 / 4): 77-84$ 
22. Bastiaan RJ, Waite IM. Effects of tobacco smoking on plaque development and gingivitis. J. Periodontol. 1.978; 49(9):480-5.

23. Belting CM, Hiniker JJ, Dummett CO. Influence of diabetes mellitus on the severity of periodontal disease. J Clin Periodontol. 1.964; 18:476-80.

24. Benatti BB, Nogueira filho GR, Sallum AW, Nociti Júnior FH. Stress may enhance nicotine effects on periodontal tissues. An in vivo study in rats. $\mathbf{J}$ Periodontal Res. 2.003; 38:351-353.

25. Bergströn J, Eliasson S, Dock J. Exposure to tobacco smoking and periodontal health. J Clin Periodontol. 2.000; 27:61-8.

26. Bergströn J, Eliasson S, Preber H. Cigarette smoking and periodontal bone loss. J Periodontology. 1.991; 62:242-46.

27. Bergströn J, Eliasson S. Noxious effects of cigarette smoking on periodontal health. J Periodontol Res. 1.987b; 22(6):513-7.

28. Bergströn J, Eliasson S. Cigarette smoking and alveolar bone height in subjects with a high standard of oral hygiene. J Clin Periodontol. 1.987a; 14(8):466-9.

29. Bergströn J. Cigarette smoking as risk factor in chronic periodontal disease. Community Dent Oral Epidemiol. 1.989; 17(5):245-7.

30. Borell LN; Burt B; Gillespie BW; Lynch J; Neighbors H. Periodontitis in the United States: beyond black and white. J Public Health. 2.002; 62(2):92101.

31. Bourgeois DM; Doughan B, Kassak K. Oral health status and treatment needs of 35-44-year old adults in Lebanon. Int Dent J. 2.000; 50(6):395-9.

32. Bourgeois D, Hescot P, Donry J. Periodontal conditions in 35-44 years old adults in France. J Periodontol Res. 1.997; 32(7): 570-4.

33. Breilh J. Bases da Epidemiologia Social. [curso - II Congresso Brasileiro de Epidemiologia, 13 al7 de julho de 1.992, Belo Horizonte, Minas Gerais, Brasil].1(1):28-36.

34. Brito MCT, Seabra EG. Estudo clínico de análise comparativa das condições entre pacientes fumantes e pacientes diabéticos. Periodontia, 2.004; 14(1):10-6. 
35. Brown LF; Beck JD; Rozier RG. Incidence of attachment loss in communitydwelling older adults. J Periodontol. 1.994; 65:316-23.

36. Brunetti RF; Pagani C. Terapia protética em pacientes portadores de doença periodontal avançada. Rev APCD. 1.987; 47(4):224-7.

37. Brunetti, MC. A infecção periodontal associada ao parto pré termo e baixo peso ao nascer. [Tese apresentada à Universidade de São Paulo Faculdade de Saúde Pública da para obtenção do título de Doutor em Saúde Pública. São Paulo, 2.002].

38. Caldas EW, Bervique JA. Avaliação crítica do INTPC (Índice de Necessidades Terapêuticas Periodontais na Comunidade). RGO. 1.992; 40(3): 191-4.

39. Campos Júnior A, Pazzanezzi E, Greghi SLA, Nahás D, Ponce CG, Vieira LCC, Navarro MFL. Análise da influência de variáveis exploratórias conjunturais e individuais na situação de saúde periodontal medida pelo CPITN. Periodontia 1.992; 1(1):28-36.

40. Campos Júnior A, Pazzanezzi E, Kim SH, Navarro MFL, Souza SLS. Identificação de grupos de risco à doença periodontal na população de Bauru, São Paulo. Rev Fac Odontol Bauru. 1.994; 2(1):20-8.

41. Carlini EA, Galduróz JCF, Noto AR, Nappo AS. I Levantamento domiciliar sobre uso de drogas psicotrópicas no Brasil Estudo envolvendo as 107 maiores cidades do país - 2001. Secretaria Nacional Antidrogas. Centro Brasileiro de Informações sobre Drogas Psicotrópicas - CEBRID Universidade Federal de São Paulo - UNIFESP. Escola Paulista de Medicina - EPM . Departamento de Psicobiologia. São Paulo. 2.002

42. Carlsson GE. Studies in partial dentures prosthesis. IV Final results of 4-year longitudinal investgation of dentogengival supported partial dentures. Acta Odontol Scand. 1.974; 45:651-659

43. Carranza Júnior F. Epidemiologia das doenças gengival e periodontal. In Carranza Júnior F. Periodontia Clínica de Glickman $5^{\circ}$ ed Rio de Janeiro: Editora Guanabara; 1.979. p 290-319

44. Centro Brasileiro de Informações sobre Drogas Psicotrópicas CEBRID. 2.000; Boletins 40-42. 
45. Centro Brasileiro de Informações sobre Drogas Psicotrópicas CEBRID. 2.001; Boletins 43-45.

46. Centro Brasileiro de Informações sobre Drogas Psicotrópicas CEBRID. 2.002; Boletins 46

47. Centro Brasileiro de Informações sobre Drogas Psicotrópicas - CEBRID. 2.003; Boletins 47-50.

48. Centro Brasileiro de Informações sobre Drogas Psicotrópicas - CEBRID. 2.004; Boletins 51.

49. Ceschin A. A menopausa: Fator de risco para progressão das doenças periodontais? Revista APCD. 2.003; 57(1):57.

50. Chaim LAF, Coppi LC. Hábito de fumar e suas conseqüências nocivas aos tecidos bucais. Avaliação do nível de conscientização de futuros profissionais de odontologia. Rev ABO Nac. 1.998; 6(3): 149-52.

51. Chaves MM. Problemas.In: Odontologia Social 3ed; Rio de Janeiro: Artes Médicas. 1.986.p 23-98

52. Chen MS, Rubinson L. Preventive dental behavior in families: a national survey. JADA. 1.982; 105:43-6. (1.992),

53. Christen AG. Dentistry and the alcoholic patient. Symposium on the patient with increased medical risks. Dent Clin North America. 1.983; 27(2):34161 .

54. Claffey $\mathrm{N}$, Gjermo $\mathrm{P}$. A periodontia moderna revista com base na evidência. [Curso proferido durante o XIX Congresso de Periodontologia Gramado RS, Brasil 18-21 de abril de 2.001].

55. Clarke NG, Carey SE. Etiology of chronic periodontal disease: an alternative perspective. J Am Dent Assoc. 1.985; 110:689-91.

56. Colimon KM. Estudios de casos y controles. In Colimon KM. Fundamentos de epidemiología. Madrid Ediciones Díaz de Santos. 1.990. p 155-68.

57. Cope G, Nayar P, Holder R, Brock G, Chapple I. Near-patient test for nicotine and its metabolites in saliva to assess smoking habit. Ann Clin Biochem. 2.000; 37(Pt5):666-73.

58. Cohen HDS, Fisher R, Mann J. Periodontal treatment needs and oral hygiene among Ethiopian immigrants. Int Dent J. 1.995; 45(3):204-8 
59. Copeland LB; Krall EA; Brown LJ; Garcia RI; Streckfus CF. Predictors of tooth loss in two US adult population. J Public Health Dent, 2.004; 64(1):31-7.

60. Cortelli SC; Cortelli JR; Jorge AOC. Relação entre parâmetros clínicos, fumo e presença de Actinobacillus actinomycetencomitans em indivíduos com periodontite crônica. Rev Odontol UNESP, 2.001; 30(2):201-214.

61. Craandljk J, Krugten MV, Verweij CL. Tumor necrosis factors-alpha -TNF- $\alpha$ gene polymorphimsm in relation to periodontites. J Clin Periodontol. 2.002; 29:28-34.

62. Croucher R; Marcenes WS; Torres MCMB; Sheiham A. The relationship between life- events and periodontitis. A case-control study. J Clin Periodontol; $1.997 ; 24(39-43$.

63. Cury PR; Sallum EJ; Sallum EA; Sallum AW. Medicina Periodontal: Fatores Sistêmicos de Risco para a Doença Periodontal. Revista APCD, 2.003; $57(2): 125-8$.

64. Cutress TW, Ainamo J, Infirri JS. The community periodontal index of treatment needs (CPITN) procedure for population groups and individuals. Int Dent J 1.987; (37): 222-33.

65. Damé JAM. Monitoração da progressão da doença periodontal em pacientes fumantes e não fumantes sem tratamento da doença periodontal. Bauru - São Paulo - Brasil 1996 [Dissertação de mestrado apresentada á Faculdade de Odontologia de Bauru - Universidade de São Paulo]. 1.996.

66. De Lorenzo JL, De Lorenzo A. Existe predisposição genética para doença periodontal severa? Periodontia. $2.003 ; 13(8): 26-34$.

67. De Lorenzo JL, De Lorenzo A. Manifestações sistêmicas das doenças periodontais: prováveis repercussões. Rev APCD.2.002; 56(3):211-4.

68. De Marco TJ. Periodontal emotional stress syndrome. J Periodontol. 1.976; 47(1-3):67-8.

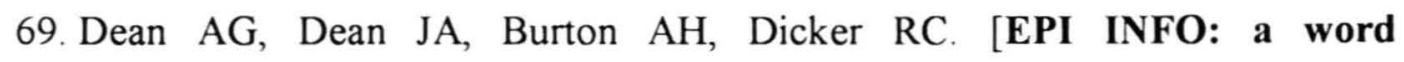
processing, database and statistics program for epidemiology on microcomputers.] version 5.01b.Centers for Disease Control. Atlanta-CDC, 
Georgia, USA; 1.990.

70. Departamento Intersindical de Estatística e Estudos Sócio Econômicos DIEESE. Taxas de desemprego, por sexo (em \%). Regiões metropolitanas e Distrito Federal - 1.996-99. Projeções populacionais baseadas em dados censitários - IBGE. Contagem populacional 1.996 e censo demográfico 2.000. In Pesquisa Emprego Desemprego - PED. [Capturado de http://www.dieese.org.Br/au/2.001/4/pg75-75pdf]. Disponível em $14 / 01 / 2.005$.

71. De Pommereau V, Dargent-Pare C, Robert JJ, Brion M. Periodontal status in insulin-dependent diabetic adolescents. J Clin Periodontol, 1.992; 19:62832.

72. Dini EL, Camargo MAA, Montandon AAB. Condições periodontais e necessidades de tratamento em pacientes do Centro Municipal de Saúde "Raphael Sorbo", Araraquara, São Paulo - 1.995. Rev Bras Odont. 1.997; 54(4): 194-7

73. Dini EL, Guimarães LOC. El tabaco y las periodontopatías. Bol Oficina Sanit Panam. 1.995; 119(4):299-304.

74. Dini EL, Neves LHM. Avaliação de confiança do CPITN em levantamentos epidemiológicos de condições periodontais. Rev Odonto UNESP. 1.996; 25(1): 109-18

75. Dini EL. Condições periodontais: associações com indicadores de risco e proposta de programas de prevenção e tratamento para trabalhadores de usinas de açúcar e álcool de Araraquara - SP. São Paulo. 1.993 [Tese de doutorado Faculdade de Saúde Pública da Universidade de São Paulo].

76. Dini EL. Uso de prótese dental, índice de placa e condições periodontais. Rev Odont UNESP. $1.995 ; 24(1): 161-7$.

77. Drake CW, Hunt RJ, Koch GG. Three-year tooth loss among black and white older adults in North Carolina. J Dent Res. 1.995; 74(2):675-80.

78. Duarte MT. Diabetes aumenta o risco de doença periodontal. Rev ABO. $2.000 ; 8(4): 206-7$

79. Emrich LJ, Shlossman M, Genco RJ. Periodontol disease in non-insulin dependent diabetes mellitus. J Periodontol. 1.991; 62:123-30. 
80. El Nadeef MAI, Adegbenbo AO. National servey of periodontal status and treatment among Nigerians. Int Dent J. 1.995; 45(3): 197-203.

81. Faculdade de Saúde Pública da Universidade de São Paulo. Núcleo de estudos e Pesquisas de Sistemas de saúde (NEPESS). Secretaria de Estado da Saúde de São Paulo - SES-SP. Relatório final do "Levantamento epidemiológico em saúde bucal: Estado de São Paulo, 1.998. São Paulo. Disponível através: http:www.saúde.sp.gov/saúde bucal [30/04/2.000].

82. Feldman RS, Bravacos JS, Rose CL. Association between smoking different tobacco products and periodontal disease indexes. J Periodontol.1.983; 54(8):481-7.

83. Ferrari, A A. Fatores de Risco para Transtornos Decorrentes do Uso de Substâncias Psicoativas em Adolescentes. [Tese apresentada à Universidade Federal de São Paulo - Escola Paulista de Medicina para obtenção do título de Doutor em Medicina. São Paulo, 2.001].

84. Ferreira $\mathrm{ABH}$. Novo Dicionário da Língua Portuguesa. São Paulo. Nova Fronteira. $3^{\text {a }}$ Edição, 1.999.

85. Figueiredo $\mathrm{CM}$ Aspectos imunológicos e genéticos no diagnóstico periodontal [Conferência proferida no XIX Congresso Brasileiro de Periodontologia Gramado RS Brasil 18-21 de abril de 2.001].

86. Flores-de-Jacoby L, Bruchmann S, Mengel R, Zafiropoulos GG. Periodontal conditions in Rio de Janeiro, Federal Republic of Germany, measured by CPITN. Comm Dent Oral Epidemiol 1.991; 9:127-28.

87. Flores-de-Jacoby L, Zafiropoulos GG, Weichsler SS. Periodontal conditions in Hesse, Federal Republic of Germany, measured by CPITN. Comm Dent Oral Epidemiol 1.989; 17:307-9.

88. Formigoni MLOS, Castel S. Álcool e drogas. Escalas de avaliação de tratamentos de dependência de drogas: aspectos gerais. Rev Psiqu Clin. Ed Especial. 1.999; 26(1): [37 telas]. Capturado de www.hcnet.usp.br/ipq/revista/r261/artigo(5).htm. disponível em 30/07/2.002

89. Forster AC. Hospitalizações e classes sociais. Ribeirão Preto.[Extraído da tese de doutoramento apresentada à Faculdade de Medicina de Ribeirão Preto - Universidade de SãoPaulo]. (mimeo).1.982. 
90. Fox $\mathrm{CH}$. New considerations in the prevalence of periodontal disease. Curr Opin Dentist. 1.992; 2: 5-11.

91. Fransson C. Differences in the inflammatory response in young and old human subjects during the course of experimental gingivitis. $\mathbf{J}$ Clin Periodontol. 1.999; 26:453-60.

92. Freeman R; Goss S. Stress measures as predictors of periodontal disease-a preliminary communication. Com Dent Oral Epidemiol. 1.993; 21:176-7.

93. Friedlander AH; Marder SR; Pisegna JR; Yagiela JA. Alcohol abuse and dependence: psychopathology, medical management and dental implications. J Am Dent Assoc. 2.003;134(6):731-40.

94. Gamonal JA, Lopez NJ, Aranda W. Periodontal conditions and treatment needs, by CPITN, in the 35-44 and 65-74 years old population in Santiago, Chile. Int Dent J. 1.998; 42(2): 96-103.

95. Gasparini DO. Relación el cigarrillo y la enfermedad periodontal. Rev Circ Odontol Ros. 1.998; 64(1):35-8.

96. Genco R. Current view of risk factors for periodontal diseases. J Periodontol. 1.996; 67 (10): 1041-49.

97. Genco RJ et al. Periodontal diseases: Epidemiology and diagnosis. Consensus Development Conference. J Am Dent Assoc. 1.998; 129 (Sep. Suppl.): 9S$14 \mathrm{~S}$.

98. Genco RJ, Goldman HM, Cohen DW. Periodoncia. México. Editora Interamericana; 1.993.

99. Genco RJ, Ho AW, Kopman J, Grossi SG, Tedesco LA. Models to evaluate the role of stress in periodontal disease. Ann Periodontal. 1.995; 3(1):288302.

100. Genco RJ; Ho AW; Grossi SG; Dunford RG; Tedesco LA Relationship of stress, distress and inadequate coping behaviors to periodontal disease. J Periodontol. 1.999; 70(7-9):711-23.

101. Gil AC. Como Elaborar Projetos de Pesquisa 3ed. São Paulo: Ed Atlas S.A .1.996. 
102. Gilthorpe MS, Griffiths GS, Maddick IH, Zamzuri AT. The application of multilevel modeling to periodontal research data. Community Dent Health, 2.000; 17(4):227-35.

103. Goldhaber P; Giddon DB. Present concepts concerning etiology and treatment of acute necrotizing ulcerative gingivitis. Am Dent J. 1.964; $14: 468$.

104. Goutschin J. Sgan Cohen HD, Donchin M, Brayer L, Soskolne. Association of smoking with periodontal treatment needs. $\mathbf{J}$ periodontol.1.990; 61(6):364-67.

105. Greene JC. Principios generales de epidemiologia y metodos para medir prevalencia y gravedad de la enfermedad periodontal. In: Genco RJ, Goldman HM, Cohen DW. Periodoncia. México. Editora Interamericana. 1.993. p99-107

106. Greenwald RA, Kirkwood K. Adult periodontitis as a model for rheumatoid arthritis with emphasis on treatment strategies. J. Reumatol. $1.999 ; 26(8): 1650-3$.

107. Grossi SG, Genco RJ, Machtei EE, Ho AW, Koch G, Dunford R, Zambon JJ, Hausmann E. Assessment of risk for periodontal disease. II Risk indicators for alveolar bone loss. J Periodontol. 1.994 66(1):23-9.

108. Grossi SG, Ho AW. Obesity, insulin resistance and periodontal disease. (abstract). J Dent Res. 2.000; 79:625.

109. Gugelmin MCMS, Ito IY, Maia G.Criação do Índice de defesa imunológica gengival - GIDI para avaliação do potencial imunológico da gengiva e o possível risco para a doença periodontal. Braz Dent J. 1.995. 6(2):95-102

110. Haber J. Smoking as a major risk factor for periodontites. Curr Opin Periodontol. 1.994. 12-18

111. Hart GT, Brown DM, Mincer HH. Tobacco use and dental disease. J Tenn Dent Assoc. 1.995 75(2):25-7.

112. Hart TC; Kornman KS. Genetic Factors in the pathogenesis of periodontites. Periodontol 2.000. 1.997; 14:202-15.

113. Hennig BJ, Parkhill JM, Chapple IL. Association of a Vitamin D 
receptor gene polymorphism with localized early-onset periodontal disease. $\mathbf{J}$ Periodontol. 2.003; 70:1.032-38.

114. Hetherington I, White DA. The diagnostic accuracy and reproducibility of school dental screening using an index of treatment need. Community Dent Health 2.004, 21(2):170-4.

115. Holm G. Smoking as an additional risk for tooth loss. J Periodontol $1.994 ; 65: 996-1.001$

116. Hospital Santa Marcelina - Congregação das Marcelinas. Histórico. [Capturado de http://www. maternidadesantamarcelina.com.br]. Disponivel em 06/07/2.004.

117. Inagaki K, Krall EA, Fleet JC. Vitamin $\mathrm{C}$ receptor alleles, periodontal disease progression and tooth loss in VA dental longitudinal study. $\mathbf{J}$ Periodontol. 2.003; 74:161-67.

118. Ismail AL, Burt BA, Eklund AS. Epidemiological patterns of smoking and periodontal disease in the United States. J Am Dent Assoc. 1.983; 106:617-623.

119. Jardim Jr EG; Zanoli T; Pedrini D. O Tabagismo como fator de risco para as doenças periodontais: Aspectos Microbiológicos. Rev Fac Odontol USP, 1.998; 12(4)315-21.

120. Jeffcoat M, Chesnut C. Systematic osteoporosis and oral bone loss. Evidence shows increases risk factors. JADA. 1.993; 124:49-56.

121. Johnson GK. Tabacco: use and the periodontal patient. American Academy Periodontology. J Periodontol. 1.999; 70:1.419-27.

122. Juárez RP, Lucas G, Lucas ON. Evaluación del indice periodontal tratamiento de la comunidad. Rev Cir Argent Odontol. 1.999; 28(185): 2630.

123. Kaplan H I, Sadock B J, Grebb J A. Compêndio de Psiquiatria Ciências do Comportamento e Psiquiatria Clínica. Artes Médicas. Porto Alegre; 1.997.

124. Kaplan H I, Sadock B J. Manual de Psiquiatria Clínica - 2ed Art Méd. Porto Alegre. 1.998. 
125. Kaplan HB. Social physiology of the immune system: a conceptual framework and review of the literature. Social Sciences and Medicine. $1.991 ; 33: 909-23$

126. Kassirer B. Smoking as a risk factor for gengival problems, periodontal problems and caries. Univ Tor Dent J. 1.994; 7(1):6-10.

127. Kato Segundo T; Ferreira EF; Costa JE. A doença periodontal na comunidade negra dos Arturo's, Contagem, Minas Gerais, Brasil. Cad Saúde Pública. 2.004; 20(2): [12 telas]. Capturado http:/ www. Bireme.br / Scielo Public Healthl [5/09/2.004].

128. Kavanagh DA. The incidence of periodontal disease and its impact on future dental practice. Periodontology. 1.998; 25(9): 435-40.

129. Kenney EB, Kraal JH, Saxe SR, Jones J. The effect of cigarette smoke on human oral polymorphonuclear leucocytes. J Periodontol Res. 1.977; $12: 227-34$.

130. Kerr NW. Prevalence and natural history of periodontal disease in prehistoric Scots (pre-900 AD). J Periodontol Res. 1.998a;33(3):131-7.

131. Kerr NW. Prevalence and natural of periodontal disease Britain from prehistoric to modern times. Br Dent J.1.998b;185(10):527-35.

132. Kim SH. Identificação de grupos de risco à doença periodontal na população de Bauru. Bauru - São Paulo - Brasil 1.992 [Dissertação de mestrado apresentada à Faculdade de Odontologia de Bauru - Universidade de São Paulo].

133. Kinane DF. Periodontal diagnostics. Ann R Australas Coll Dent Surg 2.000, 15:34-41.

134. Kranzler HR Babor TF; Goldstein L; Gold J. Dental Pathology and alcohol-related indicators in an outpatient clinic sample. Community Dent Oral Epidemiol; 1.990; 18(4):204-7.

135. Kurtis B; Tüter G; Korkmaz T; Yücel A; Serdar M; Özcan G. Clinical examination and Interleukin $-1 \beta$ levels in gengival crevicular fluid in patient treated with Removable Partial Dentures. Int J Prostodont. 2.003; 16(1)5963. 
136. Landis JR, Koch GG. The measurement of observed agreement for categorical data. Biometrics. 1.977; 33:159-174

137. Larato DC. Oral Tissue Changes in the Chronic Alcoholic. J Periodontol. 1.972; 43(7-12): 772-3.

138. Lavandeira H; Bermolen M. Enfermedad Periodontal Refractaria.

Estado Actual. Rev Assoc Odontol Argent, 2.002; 90(2):133-139.

139. Le Resche L, Dworking SF. The role of stress in the inflammatory disease, including periodontal disease: review of concepts and current findings. Periodontol 2.000. 2.002; 30:91-103.

140. Leles CR; Melo M; Oliveira MMM. Avaliação clínica do efeito da Prótese Parcial Removível sobre a condição dental e periodontal de desdentados parciais. ROBRAC, 1.999; 8(25):14-8.

141. Leonel F, Tomita NE. O fumo e a doença periodontal. Rev ABO Nac $1.999 ; 7(5): 294-7$

142. Linden GJ; Mullally BH; Freeman R. Stress and the progression of periodontal disease. J Clin Periodontol. 1.996; 23:675-80.

143. Linden MSS, Flores MDZ, Trentin MS, Linden LAS. Fumo: fator de risco no periodonto e na implantodontia? Rev Odont Passo Fundo.1.999. $4(1): 33-8$.

144. Lindhe J, Karring T, Lang NP. Periodontia Clínica e Implantologia

Oral. Rio de Janeiro Guanabara Koogan; 1.999.

145. Lindhe J. Tratado de Periodontologia Clínica. Rio de Janeiro. Editora Interamericana; 1.985.

146. Llambias SF. Factores de riesgo de las enfermedades periodontales. Periodoncia. 1.999. 9(2): 147-58.

147. Löe H, Morrinson E. Epidemiologia de la enfermedad periodontal. In:

Genco RJ, Goldman HM, Cohen DW. Periodoncia. México. Editora Interamericana; 1.993. p 109-19.

148. Löe HT, Anerud A, Boysen H, Smith M. The natural history of periodontal disease in man. Study design and baseline data. J Periodont Res $1.978 ; 13(6): 550-72$.

149. Löe HT, Theilade E, Jensen SB. Experimental gingivitis in man. J 
Periodont. 1.965; (36): 177-87.

150. Loesche WJ, Syed SA, Laughon BE, Stoll J. The bacteriology of acute necrotizing ulcerative gingivitis. J Periodontol. 1.982. 53(4):223-30.

151. Lwanga SK, Lemeshow S. Case-control studies. In Lwanga SK, Lemeshow S Sample size determination in health studies. A pratical manual. WHO Geneva 1.991. p 9-11.

152. Machion L, Freitas PM, César Neto JB, Nogueira Filho GR, Nociti Júnior FH. A influência do sexo e da idade na prevalência de bolsas periodontais. Pesq Odont Bras. 2.000;14(1):33-7.

153. Majola MP, McFadyen ML, Connolly C, Nair YP, Govender M, Laher MHE. Factors influencing phenytoin-induced gingival enlargement. J Clin Periodontol. 2.000; 27(7):506-12.

154. Maltz M, Carvalho J. Diagnóstico da doença cárie. In Kriger L, coordenador. Promoção de saúde bucal. São Paulo; (SP): Artes Médicas; 1.997. p 69-92.

155. Manor O, Matthews S, Power C. Comparing measures of health inequality. Soc Sci Med, 1.997. 4(5):761-71.

156. Mansilla MG. Diagnótico periodontal revelador. Rev Circ Odont Ros $1.998 ; 64(1): 17-20$.

157. Marcenes WS, Sheihan A. The relationship between work stress and oral health status. Society Scientific Medicine. 1.992; 35:1.511-20.1992

158. Marcus M, Coulter ID, Der Matirosian C Atchinson KA. In an empirical test of valid minority population. J Dent Res. 2.000; 79(12):198388.

159. Markkanen H, Paunio I, Tuominen R, Rajal M. Smoking and periodontal disease in the Finnish population aged 30 years and over. J Dent Res. 1.987 64(6):932-5.

160. Marques RAA. Condições de saúde periodontal no município de São Paulo em 1.986 e 1.998.São Paulo; 2.000. [Dissertação de Mestrado Faculdade de Saúde Pública da Universidade de São Paulo].

161. Marshall-Day CD; Stephens RG; Quigley LFJ. Periodontal disease: prevalence and incidence. J Periodontology. 1.955; 26:185-203. 
162. Martinelli LF, Pilatti. O fumo e a doença periodontal. Rev Paul Odontol. 1.999; 21(1):28-32.

163. Mc Guirre MK, Numm M. Prognosis versus actual outcome. VI The effectiveness of clinical parameters and IL-1 genotype in accurately predicting prognoses and tooth survival. Periodontol. 1.999; 70:49-56.

164. Medronho R, Carvalho CM, Block KV, Luiz RR, Werneck GL. Epidemiologia. São Paulo. Ed Atheneu. 2.003.

165. Meisel P, Timm R, Drombrowa. Smoking and polymorphism of interleukin-1 gene cluster in patient with periodontal disease. J Periodontol $2.002 ; 73: 27-32$.

166. Michalowicz BS, Aeppli DP, Kuba RK. A twin study of genetic variation in proportional radiographic alveolar bone height. J Dent Res; $1.991 \mathrm{a} ; 70: 1431-35$.

167. Michalowicz BS, Aeppli DP, Kuba RK. A twin study of genetic variation in proportional radiographic alveolar bone height. J Dent Res; 1.991b; 62:293-99.

168. Ministério da Saúde - MS . Secretaria de Atenção à saúde Departamento de atenção Básica. Coordenação Nacional de Saúde de saúde Bucal. Projeto SB Brasil 2.003. Condições de Saúde Bucal da População Brasileira 2.002-2.003. Resultados Principais. Brasília 2.004.

169. Ministério da Saúde. Controle de infecções e a prática odontológica em tempos de Aids - Manual de condutas. Brasília - DF, 2.000.

170. Monteiro AMD'A, Araújo RPCG. Diabetes mellitus tipo 2 e a doença periodontal. RGO. 2.002. 50(1):50-4.

171. Monteiro da Silva. Psychosocial factors and adult onset rapidly progressive periodontites. J Clin Periodontol. 1.996; 23(8):789-94.

172. Morabia A. case-control studies in clinical research: Mechanism and prevention of selection bias. Preventive Medicine. 1.997; 26:674-77.

173. Moss ME; Beck JD; Kaplan H; Offenbacher S; Weintraub JA; Koch GG; Genco RJ; Machtei EE; Tedesco LA. Exploratory case-control analysis of psychosocial factors and adult periodontitis. J Periodontol. 1.996; 67(10): 1.060-69. 
174. Movin S. Relationship between periodontal disease and cirrhosis of the liver in humans. J Clin Periodontol. 1.981; 8:450-58.

175. Muniz AE; Vieira LF; Bonachela WC. Estudo Longitudinal de Pacientes Portadores de Próteses Parciais Removiveis(PPR) em Relação aos Dentes Controles secundários, com Acompanhamento Profissional. Odontologia - USF - Bragança Paulista. 1.999; 17:63-77.

176. Nishida M, Grossi SG, Dunford RG. Dietary vitamin C and the risk for periodontal disease. J Periodontol. 2.000a; 71:1.215-23.

177. Nishida M, Grossi SG, Dunford RG. Role of Dietary calcium and the risk for periodontal disease. J Periodontol. 2.000b; 71:1.257-66.

178. Nishimura F, Murayama Y. Periodontal Inflammation and insulin resistance - lessons from obesity. J Dent Res. 2.001;80: 1.690-94.

179. Nogueira Filho GR, Tramontina VA, Pereira SLS, Sallum EA, Nociti Jr FH, Toledo SW. Sallum AW. O Fumo como Fator de Risco à Doença Periodontal. Periodontia, 1.997; 6(1):20-3.

180. Nunes LSL, Slavutzky. O Papel do Tabagismo na Doença Periodontal.

Rev Odontol Porto Alegre, 1.992, 33(1):36-8.

181. Oliveira GC, Parreira LA, Avelar LRC, Costa FO. Periodontite Refratária: Entidade Distinta ou Condição Clínica Temporária? . Rev CROMG, 1.997; 3(2):97-107.

182. Oppermann R, Rössing CK. Prevenção e tratamento das doenças periodontais. In: Kriger L (coordenador) ABOPREV. Promoção de Saúde Bucal São Paulo (SP): Artes Médicas; 1.997. p 255-81.

183. Oppermann RV, Gomes SC. Periodontia em saúde pública. In: Tunes UR, Rapp GE (coordenadores). SOBRAPE. Atualização em Periodontia e Implantodontia. São Paulo (SP): Artes Médicas; 1.999. p 17-28.

184. Page RC, Beck JD. Risk assessment for periodontal disease. Int Dent J. 1.997; 47:61-87.

185. Papapanou PN, Lindhe J. Epidemiologia da Doença Periodontal. in Lindhe J, Karring T, Lang NP (editores) Tratado de Periodontia Clínica e Implantologia Oral. Rio de Janeiro. Editora Guanabara Koogan, 1.999. p 43-65. 
186. Papapanou PN. Periodontal Diseases: Epidemiology. Ann periodontol $1.996 ; 1(1): 1-36$.

187. Papapanou PN; Wennström JL; Gröndahl K. Periodontal status in relation to age and tooth type. A cross-sectional radiographic study. J Clin Periodontol. 1.988; 15:469-78.

188. Parker J, Silva MSM. English Dictionary for Password - Kerman semi-bilingual Dictionary Speakers Portuguese. Martins Fontes De Ltda. 1.995 .

189. Pereira MG Epidemiologia: teoria e prática. Rio de Janeiro: Guanabara Koogan, 1.995.

190. Peres, MAA. Determinantes Sociais e biológicos do Período Perinatal e da Primeira Infância na Prevalência e Severidade da Cárie Dentária em Crianças de 6 anos de idade. [Tese apresentada à Universidade de São Paulo - Faculdade de Saúde Pública para obtenção do título de Doutor em Saúde Pública. São Paulo, 2.002].

191. Petersen PE, Christensen LB, Moller IJ, Johansen KS. Continuous improvement of oral health in Europe.J Ir Dent Assoc. 1.994; 40(4): 105-7.

192. Petersen PW, Razanamihaja N. Oral health status of children and adults in Madagascar. Int Dent J. 1.996; 46(1):41-6.

193. Peruzzo DC; Nogueira Filho GR; Nociti Jr FH; Casati MZ; Sallum EA. Marcadores, Indicadores e Fatores de Risco da Doença Periodontal. Periodontia. 2.004; 14(1):23-9.

194. Pitiphat W; Merchant AT; Rimm EB; Joshipura KJ. Alcohol consumption increases periodontitis risk. J Dent Res. 2.003; 82(7): 509-13.

195. Raulin L, McPherson J, McQuade M, Hanson B. The effect of nicotine on the attachment of human fibroblasts to glass and human root surfaces in vitro. J Periodontol. 1.988; 59:318-25.

196. Ribeiral MBC. Avaliação periodontal após tratamento ortodôntico. [Dissertação apresentada à Universidade Federal do Rio de Janeiro para obtenção do título de mestre]. Rio de Janeiro.1.997. 174p.

197. Roman A, Pop A . Community periodontal index and treatment needs values (CPITN) in a factory worker group in Cluj-Napoca, Romania. Int 
Dent J. 1.998; 48(2): 123-5.

198. Rothman KJ. Epidemiologia Moderna. Madrid, Ediciones Diaz de Santos S.A, 1986.

199. Rouquayrol MZ, Almeida Filho N. Epidemiologia e Saúde.5ed. Rio de Janeiro: Editora Medsi, 1.999.

200. Rubinoff AB, Latner PA, Pasut LA. Vitamin C and oral health. J

Canadian Dent Assoc. 1.989; 55:705-7

201. Safkan-Seppala B, Ainamo J. Periodontal conditions in insulin dependent diabetes mellitus. J Clin Periodontol, 1.992; 19(1):24-9.

202. Sakashita R, Inoue M, Inoue N, Pan Q, Zhu H. Dental disease in ChineseYin-Shang period with respect to relationships between citizens and slaves. Am J Phys Anthropol. 1.997; 103(3): 401-8.

203. Sakki TK, Knuuttila MLE, Vimpari SS, Hartikainen MSL. Association of lifestyle with periodontal health. Comm Dent Oral Epidem $1.995 ; 23(3): 155-8$.

204. Sallum AW; Castro NS; Sallum EA; Graner E. Fumo e Doença Periodontal - uma revisão. Periodontia. 1.993; 1(2):70-2.

205. Santana RB, Gusman HCS, Santana RLB. Fatores anatômicos relacionados com a etiologia das lesões de furca - Parte I. Rev Bras Odontol. 1.998a. 55(5):280-285.

206. Santana RB, Gusman HCS, Santana RLB. Fatores anatômicos relacionados com a etiologia das lesões de furca - Parte II. Rev Bras Odontol. 1.998b. 55(6):335-39.

207. Santos FM. Tratamento periodontal em pacientes diabéticos. [Tese apresentada à Universidade Federal de Minas Gerais - Faculdade de odontologia para obtenção do título de especialista]. Belo Horizonte, 1.998; $43 \mathrm{p}$.

208. Scherp HW. Current concepts in periodontal disease research: Epidemiological contributions. J Am Dent Ass. 1.964; 68:667-75.

209. Schlesselman JJ. Case-Controls Studies - Design, Conduct, Analysis. New York, Oxford .Oxford University Press. 1.982. 
210. Secretaria Municipal da saúde de São Paulo - SMS-SP. Centro de Informações - CEIinfo. Boletim CEInfo Subprefeituras dados 2.002.

211. Secretaria Municipal da saúde de São Paulo - SMS-SP. Centro de Informações - CEIinfo. Boletim CEInfo Subprefeituras dados 2.003.

212. Secretaria Municipal da saúde de São Paulo - SMS-SP. Centro de Informações - CEIinfo. Painel de Monitoramento Municipal Dados de 2.002 e 2.003. Edição dezembro de 2.003.

213. Secretaria Municipal da saúde de São Paulo - SMS-SP. Centro de Informações - CElinfo. Painel de Monitoramento Municipal Dados de 2.002 e 2.003. Edição Março de 2.004.

214. Selwitz RH, Albandar JM, Harris MI. Periodontol disease in diagnosed diabetes US population 1.988-1.994. J Dent Res. 1.998; 77:2.139.

215. Seemann SK. Study of the relationship between periodontal disease and wearing of partial dentures. Aust Dent J. 1.963; 8:206-11.

216. Shapira L, Stabholz A, Harris MI. Genetic polymorphism of the tumor necrosis factor- alfa promoter region in families with localized early-onset periodontites. J Periodontol Res. 2.001; 36:183-186.

217. Shizukuishi S, Hayashi N, Tamagawa H, Hanioka T, Maruyama S, Takeshita T, Morimoto K. Lifestyle and periodontal health status of Japanese factory workers. Ann Periodontol.1.998; 3(1): 303-11.

218. Silva SR. Medicina Periodontal: a arte da Integração. Rev APCD. $2.004 ; 58(1): 7-17$

219. Socransky SS, Hafagee AD, Goodson J, Lindhe J. new concepts of destructive periodontal disease. J Clin Periodontol. 1.984; 11:21-32.

220. Solis ACO; Lotufo RFM; Lotufo Neto F. Influência do estresse sobre as doenças periodontais. RPG Revista Pós Grad; 2.001;8(1):76-82.

221. Spears RA. NTC's American English Learner's Dictionary. NTC Publishing Group.1.998.

222. Spolsky VW; Marcus M; Coulter ID; Der-Martirosian; Atchinson KA. An empirical test of the validity of the Oral Health Status Index (OHSI) on a Minority Population. J Dent Res. 2.000; 79(12):1.983-1988.

223. Statistics Package for Social Sciences - SPSS - versão $11.0-2.001$ 
224. Stoltenberg JL, Osbon JB, Pihlstron BL, Hardie NA, Aeppli DM, Huso BA, Bakdash MB, Fischer GE. Prevalence of periodontal disease in a health maintenance organization and comparisons to the national survey of oral health. J Periodontol. 1.993; 64(9):853-58.

225. Ten Bosch JJ, Angmar-Mansson B. Characterization and validation of diagnostic methods. Oral Sci 2.000, 17:174-89.

226. Tezal M, Grossi SG, Ho AW, Genco RJ. The effect of alcohol consumption on periodontal disease. J Periodontol. 2.001; 72(2):183-9.

227. Tezal M, Wactawski-Wende J, Grossi SG. The relationship between bone mineral density and periodontites in postmenopausal women. $\mathbf{J}$ Periodontol. 2.000; 71:1.492-98.

228. Tezal M; Grossi SG; Ho AW; Genco RJ. Alcohol consumption and periodontal disease. The Third National Health and Nutrition Examination Survey. J Clin Periodontol. 2.004; 31(7)484-8.

229. Thorstensson H, Hugoson A. Periodontal disease experience in adult long-duration insulin-dependent diabetics. J Clin Periodontol, 1.993; 20(5):352-8.

230. Thylstrup A, Fejerskov O. Cariologia Clínica. 2 ed. São Paulo: Editora Santos, 1.995 .

231. Tomar SL, Asma S. Smoking-attributable periodontites in the United States. Findings from NHANES III. National Health and Nutrition Examination Survey. J Clin Periodontol. 1.994; 65:1.134-38.

232. Tomita NE, Cordeiro R, Mendonça J, Senger V, Lopes ES. Saúde bucal dos trabalhadores de uma indústria alimentícia do centro oeste paulista. Rev Fac Odontol Bauru. 1.999; 7(/2): 67-71.

233. Tristão GC; Carvalho JCM; Pustiglioni FE; Saito T. Prótese: Controle da placa bacteriana. Prótese: Modificação do contorno proximal em função do controle da placa bacteriana. Rev APCD, 1.989; 43(4): 179-82.

234. Universidade de São Paulo. Faculdade de Saúde Pública. Biblioteca/ Centro de Informações e Referência em saúde pública. Guia de apresentação de Teses. São Paulo. Plano A Gráfica e Editora. 1.998. 
235. Vettore MV; Leão ATT; Silva AAM; Quintanilha RS; Lamarca GA. A relação de fatores psicossociais com a doença periodontal. RBO, 2.002; 59(6) 418-22.

236. Viegas AR. Odontologia sanitária São Paulo: Faculdade de Saúde Pública da Universidade de São Paulo (FSP-USP); 1.965. tomo IV. p 9-70.

237. Vieira LCC. Análise da influência de variáveis diversas na situação de saúde periodontal da população de Bauru - São Paulo - Brasil 1991 [Dissertação de mestrado apresentada á Faculdade de Odontologia de Bauru Universidade de São Paulo].

238. Von Worren N, Klausen B, Kollerup G. Osteoporosis: a risk factor in periodontal disease. J Periodontol. 1.994; 65:1.134-38.

239. Wactawski-Wende J, Grossi SG, Trevisan M. The role of osteopenia in bone loss and periodontal disease. J Periodontol. 1.996; 67:1.076-84.

240. Walcholder S; McLaughlin JK; Silverman DT; Mandet JS. Selection of Controls in Case-Control Studies. I Principles. American Journal of Epidemiology. 1.992a; 135(9):1.019-28.

241. Walcholder S; McLaughlin JK; Silverman DT; Mandet JS. Selection of Controls in Case-Control Studies. II Types of Controls. American Journal of Epidemiology. 1.992b; 135(9):1.029-41.

242. Walcholder S; McLaughlin JK; Silverman DT; Mandet JS. Selection of Controls in Case-Control Studies. III Design Options. American Journal of Epidemiology. 1.992c; 135(9):1.042-50.

243. Wennström JL. Periodontal condition of adult regular dental care attendants. A years longitudinal study. J Clin Periodontol. 1.993; 20:714722 .

244. Weyne SC. A construção do paradigma de promoção de saúde - um desafio para as novas gerações. In Kriger, L. coordenador ABOPREV Promoção de Saúde Bucal. São Paulo: Editora Artes Médicas; 1.997. p1-26. 245. Wolfe MD; Carlos JP. Oral health effects of smokeless tabacco use in 1.987; 5(4): 230-5. Navajo Indian adolescents. Community Dent Oral Epidemiol,

246. World Health Organization-WHO. Collaborating Center for Oral 
Health Services Research. University of Groningen, Gieten, The Netherlands. The Periodontal Disease Problem. A comparison between industrialize and developing countries. Int Dent J 1.998; 48 (3 Suppl. 1): 221-32.

247. World Health Organization-WHO. Geneva Oral Health Surveys.

Basic Methods. $4^{\text {th }}$. Edition. England: WHO Library Cataloguing in Publication Data; 1.997.

248. World Health Organization-WHO. WHO Global Oral Data Bank, 1 January 1994 Oral Health Country Profile Program /Oral Health School of Dentistry, Niigata University, Japan [87 screens]. Available from http://www.who.gov/oral health [2.000 feb20].

249. Yunes J. Qualidade de vida e indicadores de saúde: Revendo Conceitos. [Mesa redonda - II Congresso Brasileiro de Epidemiologia, 13 al7 de julho de 1.992, Belo Horizonte, Minas Gerais, Brasil].

250. Yusof SK; Isa Z. Periodontal Status of teeth in contact with denture in removable partial dentures wearers. J Oral Rehabil. 1.994; 21:77-86. 
Anexos 


\section{UNIVERSTADE DE SÃO PAULO - USP \\ FACULDADE DE SAÚdE PÚBLICA - FSP \\ AVALIAÇAO dE FATORES DE RISCO PARA DOENÇAS PERIOdÓNTAIS EM USUÁRIOS DO QUALIS SANTA MARCELINA}

Prezado(a) senhor(a),

Apesar da cárie set identificada como a principal causa da perda de dentes, em adultos as doenças que afetam as geugivas tém sido apoutadas como mais importantes, priucipahmente após os 35 a 40 anos.

As doenças que afetam as gengivais são chamadas de doenças periodontais, conhecidas pela população como "piorréia".

Comegam com o acúmulo de placa bacteriana, ficam mais graves com o aparecimento do cálculo ou tánaro, levando a destruição do osso que suporta os dentes. Esta destruiçãa é beuta e progride ao longo da vida, praliciamente sem que o paciente perceba o que está aconteciendo.

Se o problema não for identificado e tratado a tempo, a destruição do osso de suporte leva os dentes à mobilidude e à perda.

O hábito de fumar, o uso de alguns medicamentos, a diabetes entre outros fatores pode acelerar a progression das docopass periodontivs.

Os servipos de saúde do Qualis Santa Marcelina verificaram na população que atendem um grande número de adultos com problemes periodontais. É importante que sejam identificados os motivos que têm levado à progressio e agravamento dessas doenças, para que se possa adotar modidas de prevencão e controle, uiminuindo as perdas de dentes en aduhtos por doenças periodontais. motivos.

O Sr(a) foi identificado como uma das pessoas para participar de um estudo para avaliar esses

Strõo feilas algumas pergunlas sobre sua saúde e um exame da cavidade bucial, alendendo rigorosamente às normas e recomendaços do Ministério da Saúde e da Organização Mundial da Saúde.

Os profissionais que farũo as perguntas e os exames foram especialmente treinados. Nenhum material, produto ou substancin ou técnica serẩ utilizados.

Os casos de doença periodontal, identificados duraute o exane, e que, após avaliação clínica cuidadosa, apresentem condiçðes de tratamento não cirúrgico, com as técnicas disponiveis no Qualis Santa Marcelina, alé o momento, sẽ̃̃o acompanhados e terão assistência assegurada (exceto prólese).

$\Lambda s s i m$, pedimos sua colaboração, autorizando nossa solicitacão de que o $\operatorname{Sr}(a)$ responda a algumas perguntas sobre sua saúde e permita a realicaciono de um exame mais delalhado de suas condicõos de saúde bucal.

Querendo mais informacoũes, por favor ligue para lekefone ou então fale pessoalmente com ele(a) na

Conlando com seu apoio, agradeciemos antecipadamente, em nome de todos os que se proucupam e se dedicam 'a melhorar a saude da nossa população.

Atenciosamente,

Prof. Dr Roberto Augusto Castellanos Fernandez Regima Auxiliadora de Amorim Marques

AUTORIZAÇÃO

Após ter sido informado(a) sobre as características da pesquisa

"Avaliaçăo de fatores de risco para doenças periodontais em usuários dos secrviços de saúde do Qualis Santa Maroclina",

ACEIIO responder as perguntas sobre minha sadide e AUTORLCO a realização do exame bucal.

Nome.

Assinatura. 
ANEXO 2

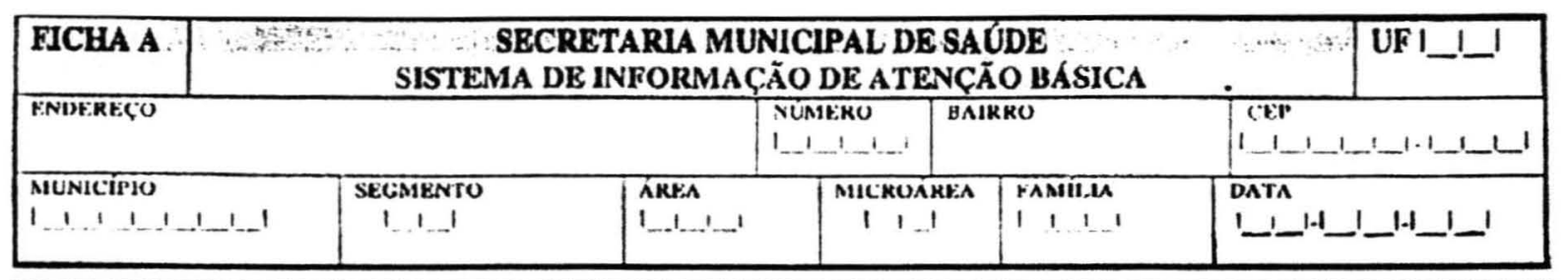

\begin{tabular}{|c|c|c|c|c|c|c|c|}
\hline \multicolumn{8}{|c|}{ CADASTRO DA FAMÍLIA } \\
\hline \multirow{2}{*}{$\begin{array}{c}\text { PESSOAS COM IS ANOS OU MALS } \\
\text { NOME }\end{array}$} & \multirow{2}{*}{$\begin{array}{l}\text { DATA } \\
\text { NASC. }\end{array}$} & \multirow[t]{2}{*}{ IDAUE: } & \multirow[t]{2}{*}{ SExo } & \multicolumn{2}{|c|}{ ALFABETIZADO } & \multirow[t]{2}{*}{ ocupacAo } & \multirow{2}{*}{ 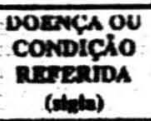 } \\
\hline & & & & inst & ספס & & \\
\hline & & & & & & & \\
\hline & & & & & & & \\
\hline & & & & & & & \\
\hline & & & & & & & \\
\hline & & & & & & & \\
\hline & & & & & & & \\
\hline & & & & & & & \\
\hline & & & & & & & \\
\hline & & & & & & & \\
\hline & & & & & & & \\
\hline & & & & & & & \\
\hline
\end{tabular}

\begin{tabular}{|c|c|c|c|c|c|c|c|}
\hline \multirow{2}{*}{$\begin{array}{l}\text { PESSONS DE OA IA ANOS } \\
\text { NOME }\end{array}$} & \multirow[t]{2}{*}{$\begin{array}{l}\text { DNTA } \\
\text { NASC. }\end{array}$} & \multirow[t]{2}{*}{ WADE } & \multirow[t]{2}{*}{ SEXO } & \multicolumn{2}{|c|}{$\begin{array}{c}\text { FREQLENTA } \\
\text { A ESCOLA } \\
\end{array}$} & \multirow[t]{2}{*}{ DCUPAÇXo } & \multirow{2}{*}{ 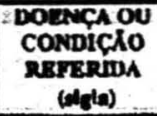 } \\
\hline & & & & sim & niso & & \\
\hline & & & & & & & \\
\hline & & & & & & & \\
\hline & & & & & & & \\
\hline & & & & & & & \\
\hline & & & & & & & \\
\hline & & & & & & & \\
\hline & & & & & & & \\
\hline & & & & & & & \\
\hline & & & & & & & \\
\hline & & & & & & & \\
\hline & & & & & & & \\
\hline
\end{tabular}

\begin{tabular}{|c|c|c|}
\hline \multicolumn{3}{|c|}{ Siglas para a indicação das doenças elou cundị̄öes referidas } \\
\hline $\begin{array}{l}\text { ALC - Atcoolismo } \\
\text { CHA - Chagas } \\
\text { DEF - Deficiência } \\
\text { IHA - Diabetes }\end{array}$ & 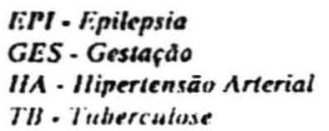 & $\begin{array}{l}\text { HAN - Hanseniase } \\
\text { MAL - Malária }\end{array}$ \\
\hline
\end{tabular}




\section{ANEXO 3}

\section{SECRETARIA DE ESTADO DE SAÚDE \\ COORDENÁDORIA DE SAÚdE DA REGIĀO METROPOLITANA DA GRANDE SÃO PAULO}

\section{DIREÇÃO REGIONAL DE SAÚDE I CAPITAL}

ATENÇÃO INDIVIDUAL EM SAÚDE BUCAL - AVALIAÇÃO DO RISCO

UNIDADE DE SAÚDE

NRS/Qualis

NOME:

IDADE:

N 9 DO PRONTUÁRIO

\section{Critérios de risco:}

\begin{tabular}{|c|c|c|c|c|c|c|}
\hline \multirow{2}{*}{$\begin{array}{l}\text { Classifi } \\
\text { Caçio }\end{array}$} & \multicolumn{2}{|r|}{ Cárie } & \multicolumn{2}{|r|}{ Doença Periodontal } & \multicolumn{2}{|r|}{ Tecidos Moles } \\
\hline & Cód. & Critérios & Cód. & Critérios & Cód. & Critérios \\
\hline $\begin{array}{c}\text { Baixo } \\
\text { risco } \\
\end{array}$ & $\mathbf{A}$ & 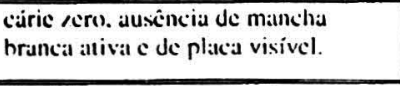 & $\mathbf{0}$ & $\begin{array}{l}\text { clemento com periedonto } \\
\text { siadie. }\end{array}$ & n & $\begin{array}{l}\text { Individuo com lecidos } \\
\text { moles sadies. }\end{array}$ \\
\hline \multirow{4}{*}{$\begin{array}{l}\text { Médio } \\
\text { risco }\end{array}$} & \multirow[t]{2}{*}{ B } & \multirow{2}{*}{$\begin{array}{l}\text { história pregressa de cárıe } \\
\text { tratada adequad.. ausência de } \\
\text { manchia hrimcia c de placa visivcl }\end{array}$} & 1 & $\begin{array}{l}\text { elemento com gengivite } \\
\text { incipiente. }\end{array}$ & \multirow{4}{*}{1} & \multirow{4}{*}{$\begin{array}{l}\text { Individuo com lesiess } \\
\text { suspeltas em tecidus } \\
\text { moles (bordas } \\
\text { regulares e coloração } \\
\text { esbranquiçada ou } \\
\text { qualquer alteração de } \\
\text { mucosia com mais de } 14 \\
\text { dias de cxistência) } \\
\end{array}$} \\
\hline & & & 2 & elemento cons cálculo & & \\
\hline & \multirow[b]{2}{*}{ C } & \multirow{2}{*}{$\begin{array}{l}\text { Cavid. de ciric crinicas. } \\
\text { ausencia de mancha hrancale de } \\
\text { placia visivel. }\end{array}$} & $\mathbf{x}$ & auséncia de dentes no sextiante & & \\
\hline & & & B & $\begin{array}{l}\text { equiela de dençä periodontal } \\
\text {.mberiur }\end{array}$ & & \\
\hline \multirow{3}{*}{$\begin{array}{l}\text { Allo } \\
\text { risco }\end{array}$} & D & 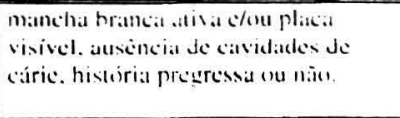 & \multirow[t]{2}{*}{6} & 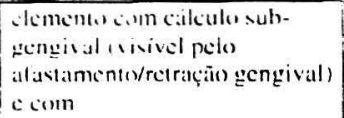 & \multirow{3}{*}{2} & \multirow{3}{*}{ 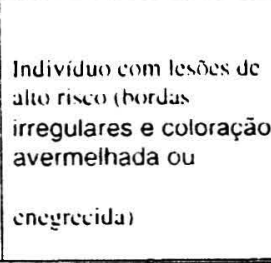 } \\
\hline & E & $\begin{array}{l}\text { cavidades de cárie agudas, } \\
\text { mancha branca ativa elou flaca } \\
\text { visivel. }\end{array}$ & & $\begin{array}{l}\text { mohiludade reversivel ou } x \mathrm{~cm} \\
\text { :mbil:dadic }\end{array}$ & & \\
\hline & $\mathbf{F}$ & 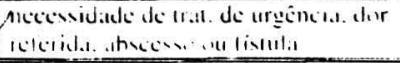 & 8 & 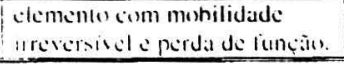 & & \\
\hline
\end{tabular}

\begin{tabular}{|c|c|c|c|c|c|c|c|c|c|c|c|}
\hline $\begin{array}{l}\text { Ciric } \\
\text { 7ero } \\
\end{array}$ & $\begin{array}{l}\text { Plica } \\
\text { vivivel } \\
\end{array}$ & $\begin{array}{r}\text { Hivi du } \\
\text { cirric Irat } \\
\end{array}$ & & $\begin{array}{l}\text { Nancha } \\
\text { hr. atival } \\
\end{array}$ & $\begin{array}{l}\text { Curid. } \\
\text { cronica } \\
\end{array}$ & $\begin{array}{l}\text { Curid. } \\
\text { Agudal } \\
\end{array}$ & Ligencia & $\begin{array}{c}\text { Classitī- } \\
\text { Cacáo }\end{array}$ & $\begin{array}{l}\text { Risco } \\
\text { cárie }\end{array}$ & \multirow{2}{*}{$\begin{array}{l}\text { Data do } \\
\text { exame }\end{array}$} & \multirow[b]{2}{*}{$\begin{array}{l}\text { Assinattura/ } \\
\text { CRO }\end{array}$} \\
\hline & & & & & & & & & & & \\
\hline 16 & 11 & 24 & it & 31 & 36 & $\begin{array}{l}\text { Classifi- } \\
\text { cacão }\end{array}$ & Risco DP & \multicolumn{2}{|c|}{ Obs. Tec. Moles } & $\begin{array}{l}\text { Classifī- } \\
\text { cação }\end{array}$ & $\begin{array}{c}\text { Risco } \\
\text { Tec. moles }\end{array}$ \\
\hline & & & & & & & & & & & \\
\hline
\end{tabular}

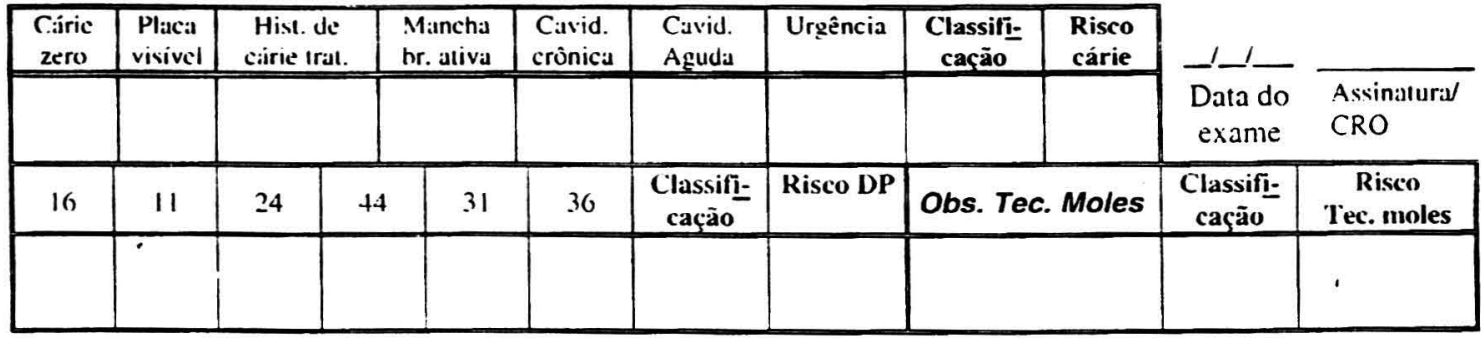



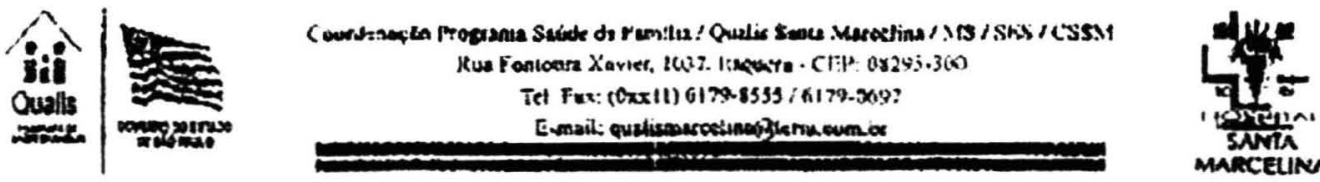

FICHA CLINICA - SAUDE BLICAL

Nome:

Data Nascimento _-i_... Area Micro-área N.• Familia

ANAMNESE

Listória intédica

( ) Alergias - Qunis

() Insuficiência condiaca

( ) Hipertensão

( ) Diabetes

() Hemorragia

( ) Cestanto meses

() Outros problenias de saúde - Quals

( ) Medicamentos em uso:

Trabagismo ( ) Sim () Nho

(.) Aleitamento materno exclusivo meses

( ) Mamadeira noturna veres/noite

( ) Suç̧o de dedos ( ) Uso da chupcta ( ) Reapirador bucal

( ) Problomas ortodônticos

Agua SABESP ( ) Sim ( ) Nao

Uso do creme dental nuoretado ( ) Sima ( ) Nfio

Uso do to dental ( ) Sim ( ) Nlso

Cadastrado cm procedimentos colotivos em escola ( ) Sima ( ) Näo

Limpeza/escovagho verestdis

Dieta : ( ) Rica om doces e carboidratos ( ) Balanceudu

Placa Bacteriana ( ) Localizada/porca ( ) generalizada/pouca

( ) Localteada/muita ( ) gencralizadaimuita

Aproximacho no risce

( ) Baixo risco ( ) Médio risco ( ) Médiolalto risco ( ) Alto Risco ( ) Scucro Risco

Clessificaço:

( ) $A 0$ ( ) A ( ) B ( ) C ( ) D ( ) Du

Indleaçăo do atividade Colctiva:

( ) Grupo Odonto Bcbe

( ) Fluorterapia de

sessses com THD

() Pluortorapla de _ sessbes domicillares enm ACS da Micro área

( ) Retorno + Fiuorterapia no mes do

( ) Outros. Espectacar: 


\section{UNIVERSIDADE DE SÃO PAULO - USP \\ FACULDADE DE SAÚDE PÚBLICA - FSP}

"Risco e Doenças Periodontais Destrutivas em Usuários de um Programa de Saúde da Familia, São Paulo, 2.005.

Roberto Augusto Castellanos Fernandez (Orientador)

1. DATA

Regina Auxiliadora de Amorim Marques(Doutoranda - pesquisadora)

\begin{tabular}{|c|c|c|c|}
\hline \multicolumn{3}{|l|}{ 2. Unidade de Saúde } & \multirow[t]{2}{*}{ 3. Ficha Número } \\
\hline 4. $N^{\circ} d o$ prontuário & 5. Examinador & 6. Anot & \\
\hline \multicolumn{4}{|c|}{ IDENTIFICAÇÃO DO PACIENTE } \\
\hline \multicolumn{4}{|l|}{ 7. Nome do paciente } \\
\hline (1) Feminino & (2) Masculino & \begin{tabular}{|l|} 
9. Data \\
Nascimento............./19....
\end{tabular} & 10.Idade \\
\hline \multicolumn{4}{|c|}{ 11. CLASSIFICAÇÃO 'DE RISCO DE DP SEGUNDO CódIGO DO IP (QUALIS) } \\
\hline $\operatorname{ALTO}(\mathrm{)}$ & \multicolumn{2}{|c|}{ MÉDIO ( ) } & $\operatorname{BAIXO}()$ \\
\hline \multicolumn{2}{|c|}{ 12. CASO ( ) } & \multicolumn{2}{|c|}{ 12. CONTROLE ( ) } \\
\hline CASO: dentes índice do IP codificado & n 6,8 ou $B$ & CONTROLE: dentes índice do & codificados com 0,1 ou 2 \\
\hline
\end{tabular}

\begin{tabular}{|c|c|c|c|}
\hline \multicolumn{3}{|l|}{ 13. Naturalidade } & 14. UF \\
\hline \multicolumn{3}{|c|}{$\begin{array}{l}\text { 15. Estado civil } \\
\text { (0)solteiro (1)casado (2)divorciado (3)separado (4) viúvo (5)amasiado }\end{array}$} & Estciv \\
\hline \multicolumn{3}{|c|}{$\begin{array}{l}\text { 16. Natureza da Ocupação } \\
\text { (1) Empregado em empresa do setor privado } \\
\text { (2) Profissional liberal ou trabalhador sem vínculo de emprego } \\
\text { (3) Empregador titular ou proprietário de empresa } \\
\text { (4) Servidor público da administração direta } \\
\text { (5) Servidor público de autarquia e fundação } \\
\text { (6) Funcionário de empresa pública ou de economia mista } \\
\text { (7) Declarante que tem rendimentos de capital, inclusive aluguel } \\
\text { (8) Não especificados nas classes anteriores } \\
\text { (9) Desempregado e desocupado }\end{array}$} & Natocup \\
\hline \multicolumn{3}{|c|}{$\begin{array}{l}\text { 17. Ocupação Principal } \\
\text { (1) Trabalhador das profissões científicas, técnicas, artísticas e assemelhados } \\
\text { (2) Membros dos três poderes, servidores civis e militares } \\
\text { (3) Trabalhadores administradores e assemelhados } \\
\text { (4) Trabalhadores do comércio e assemelhados } \\
\text { (5) Trabalhadores de serviços e assemelhados } \\
\text { (6) Trabalhadores agricolas, florestas, extração e assemelhados } \\
\text { (7) Trabalhadores da produção industrial } \\
\text { (9)Trabalhadores não especificados nas classes anteriores }\end{array}$} & Ocupaçăo \\
\hline \multicolumn{3}{|c|}{$\begin{array}{l}\text { 18. Ocupação Principal } \\
\text { Descrever abaixo a ocupação e codificar com } 3 \text { dígitos no campo ao lado a ocupação principal do } \\
\text { paciente consultando o anexo } 1 \text {. }\end{array}$} & \begin{tabular}{|l|} 
Ocuprin \\
\end{tabular} \\
\hline $\begin{array}{l}\text { 19. Escolaridade } \\
\text { (1) analfabeto } \\
\text { (4) } 1^{\circ} \text { grau completo } \\
\text { (7) } 3^{\circ} \text { grau incompleto }\end{array}$ & $\begin{array}{l}\text { (2) sabe ler e escrever } \\
\text { (5) } 2^{\circ} \text { grau incompleto } \\
\text { (8) } 3^{\circ} \text { grau completo }\end{array}$ & $\begin{array}{l}\text { (3) } 1^{\circ} \text { grau incompleto } \\
\text { (6) } 2^{\circ} \text { grau completo } \\
\text { (9) pós-graduação } \\
\text { (0) NSNR }\end{array}$ & \begin{tabular}{|l} 
Escolar \\
\end{tabular} \\
\hline \multicolumn{3}{|c|}{ 20. Quantos anos você freqüentou a escola? } & Anoesc \\
\hline
\end{tabular}




\begin{tabular}{|ll|}
\hline 21. Religião de sua preferência & \\
(1)não tem & (2)afro-brasileira \\
(4)orientais & (5)protestante \\
(7)israelita & (8)espirita \\
\hline
\end{tabular}

21. Religião de sua preferência

(1) não tem

(7)israelita

22. Você está grávida?

(0) não

(1) $\operatorname{sim}$

ESTADOS E CONDIÇÕES: GESTAÇĀO E AIDS
(2) Não sabe

(3)católica

(6)evangélica

(9)islâmica

(9) Não se aplica

23. Você já fez exame de sangue para o vírus HIV / Você já fez exames para AIDS?

(0) não

(1) $\operatorname{sim}$

24. Qual foi o resultado?

(0) negativo

(1) positivo

(2) janela imunológica

(3)Não sabe

(9) Não sabe

DOENÇAS SISTÊMICAS E USO DE MEDICAMENTOS:

25. Você tem Diabetes ?

(0) nào

(1) $\operatorname{sim}$

26. Há quanto tempo (em meses) você tem diabetes?

27. Você usa alguma medicação para diabetes?

(0) não

(1) $\operatorname{sim}$

28. Você faz algum tratamento/acompanhamento com psiquiatra ou neurologista?

(0) não

(1) $\operatorname{sim}$

(9) Não se aplica

29. Há quanto tempo (em meses) você faz este acompanhamento?

30. Você está tomando calmante, remédios para depressão ou para dormir melhor, ou ainda algum medicamento para evitar convulsões?

$(0)$ não

(1) $\operatorname{sim}$

(9) Não sabe

31. Há quanto tempo (em meses) você faz uso destes medicamentos?

32. Você tem alguma doença auto-imune (artrite reumatóide, gota, lupus...)?

$(0)$ nào

(1) $\operatorname{sim}$

(9) Não sabe

(9) Não sabe

(9) Não sabe

33. Há quanto tempo (em meses) você tem este problema de saúde?

34. Você está tomando algum medicamento a base de cortisona ou similar (saber se o paciente está tomando medicamentos imunossupressores)?

(0) não

(1) $\operatorname{sim}$

35. Há quanto tempo (em meses) você faz uso destes medicamentos?

(9) Năo sabe

(9) Naัo sabe

Diabts 1

Neuro

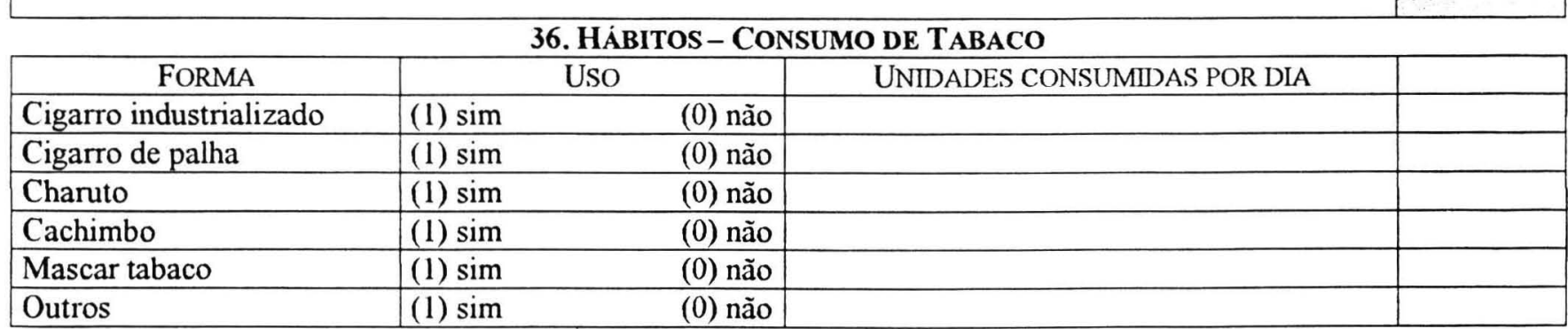

TESTE DE FAGERSTRÖN PARA DEPENDÊNCIA DE NICOTINA

37. Em relação ao hábito de fumar

(0) não fuma (1) sim, é fumante

38. Há quantos anos você é fumante'?

(2) Não sabe

(9)Não respondeu

38. Por que você não fuma?
(0) não gosta
(1) parou de fumar
(2)motivos religiosos
(9) não respondeu
(3) tem problemas de saúde
(4)não sabe 


\begin{tabular}{|c|c|}
\hline & 3 \\
\hline 39. Se abstinente especificar o tempo (dias ou meses) & Fumot \\
\hline 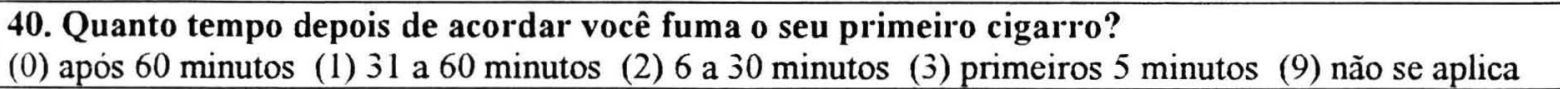 & Fumos \\
\hline $\begin{array}{l}\text { 41. Você encontra dificuldade em evitar o fumar em lugares onde é proibido, como por exemplo } \\
\text { igrejas, local de trabalho, cinemas, shoppings, etc? } \\
\begin{array}{lll}\text { (0) não } & \text { (1) sim } & \text { (9) não se aplica }\end{array}\end{array}$ & Fumo6 \\
\hline $\begin{array}{l}\text { 42. Qual é o cigarro mais difícil de largar ou de não fumar? } \\
\begin{array}{lll}\text { (0) qualquer um } & \text { (1) o primeiro da manhã } & \text { (9) não se aplica }\end{array}\end{array}$ & Fumo7 \\
\hline 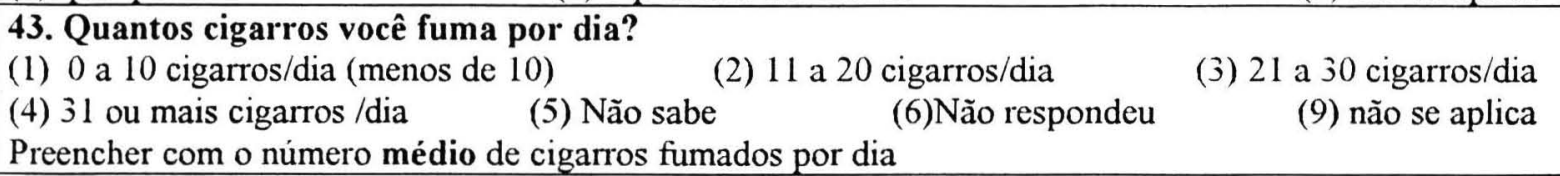 & Fumo8 \\
\hline $\begin{array}{l}\text { 44. Você fuma mais nas primeiras horas do dia do que durante o resto do dia? } \\
\begin{array}{ll}\text { (0) não } & \text { (1)sim }\end{array}\end{array}$ & Fumo9 \\
\hline $\begin{array}{l}\text { 45. Você fuma mesmo estando doente a ponto de ficar acamado(a) a maior parte do dia? } \\
\begin{array}{llll}(0) \text { não } & \text { (1)sim } & \text { (9) não se aplica }\end{array}\end{array}$ & Fumol0 \\
\hline $\begin{array}{l}\text { Pontuação: somar valores entre parênteses das questões } 40 \text { a } 45 \\
\begin{array}{llll}\text { (1) leve }(0-4) & \text { (2) médio }(5-7) & \text { (3) Alto }(8-11) & \text { (9) não se aplica }\end{array}\end{array}$ & \begin{tabular}{|l|} 
Fumoll \\
\end{tabular} \\
\hline
\end{tabular}

\section{HÁBITOS-CONSUMO DE ÁLCOOL}

\begin{tabular}{|c|c|c|c|c|}
\hline \multicolumn{2}{|l|}{ BEBDA } & QUANTIDADE & \multirow[t]{2}{*}{ VEZES POR SEMANA } & \multirow{2}{*}{$\begin{array}{l}\mathrm{N}^{0} \text { DOSES POR } \\
\text { SEMANA }\end{array}$} \\
\hline Cerveja lata & $\begin{array}{l}\text { (0)não } \\
\text { (1)sim }\end{array}$ & ( ) lata & & \\
\hline Cerveja copo & $\begin{array}{l}\text { (0)não } \\
(1) \text { sim }\end{array}$ & ( ) copo $340 \mathrm{ml}$ & & \\
\hline Cerveja garrafa & $\begin{array}{l}\text { (0)năo } \\
(1) \text { sim }\end{array}$ & ( ) garrafa $600 \mathrm{ml}$ & & \\
\hline Chopp & $\begin{array}{l}\text { (0)não } \\
\text { (1)sim }\end{array}$ & ( ) copo $340 \mathrm{ml}$ & & \\
\hline $\begin{array}{l}\text { Aguardente (pinga, caninha, } \\
\text { branquinha), caipirinha }\end{array}$ & $\begin{array}{l}\text { (0)naัo } \\
(1) \text { sim }\end{array}$ & ( ) copo $40 \mathrm{ml}$ & & \\
\hline Vodca & $\begin{array}{l}\text { (0)não } \\
\text { (1)sim }\end{array}$ & ( ) copo $40 \mathrm{ml}$ & & \\
\hline Rum, gim & $\begin{array}{l}\text { (0)não } \\
(1) \text { sim }\end{array}$ & ( ) copo $40 \mathrm{ml}$ & & \\
\hline Uisque & $\begin{array}{l}\text { (0)não } \\
\text { (1)sim }\end{array}$ & ( ) copo $40 \mathrm{ml}$ & & \\
\hline Grappa, bagaceira & $\begin{array}{l}\text { (0)não } \\
(1) \text { sim }\end{array}$ & ( ) copo $40 \mathrm{ml}$ & & \\
\hline Vinhos & $\begin{array}{l}\text { (0)não } \\
(1) \text { sim }\end{array}$ & ( ) taça $140 \mathrm{ml}$ & & \\
\hline Licor & $\begin{array}{l}\text { (0)não } \\
\text { (1)sim }\end{array}$ & ( ) cálice $85 \mathrm{ml}$ & & \\
\hline Champanhe & $\begin{array}{l}(0) \text { não } \\
(1) \text { sim }\end{array}$ & ( ) taça $140 \mathrm{ml}$ & & \\
\hline
\end{tabular}




\section{HISTÓRIA DE CONSUMO de ÁLCOOL}

47. Como foi seu consumo de álcool na última semana?

(1) bebendo "direto", com vários episódios de embriaguez (sem controle)

(2) bebendo diariamente, sem episódios de embriaguez (com controle)

(3) bebendo várias vezes na semana

(4) abstinência completa

(9) Não Sabe/Não responde - NSNR

48. Como foi seu consumo de álcool no último mês?

(1) bebendo "direto", com vários episódios de embriaguez (sem controle)

(2) bebendo diariamente, sem episódios de embriaguez (com controle)

(3) bebendo várias vezes na semana

(4) bebendo de forma ocasional (não semanalmente)

(5) abstinência completa

(9) Não Sabe/Não responde - NSNR

49. Como foi seu consumo de álcool no último ano?

(1) bebendo "direto", com vários episódios de embriaguez (sem controle)

(2) bebendo com bastante freqüência mas sem episódios de embriaguez (com controle)

(3) bebendo de forma ocasional (não semanalmente)

(4) abstinência completa

(9) Não Sabe/Não responde NSNR

50. Como foi seu consumo de álcool nos últimos cinco anos?

(1) bebendo "direto", com vários episódios de embriaguez (sem controle)

(2) bebendo, com bastante freqüência mas sem episódios de embriaguez (com controle)

(3) bebendo de forma ocasional (não semanalmente)

(4) abstinência completa

(9) Não Sabe/Não responde NSNR

51 .Como foi seu consumo de álcool nos últimos dez anos?

(1) bebendo "direto", com vários episódios de embriaguez (sem controle)

(2) bebendo com freqüência sem episódios de embriaguez (com controle)

(3) bebendo de forma ocasional (não semanalmente)

(4) abstinência completa

(9) Não Sabe/Não responde- NSNR

52. Como foi seu consumo de álcool nos últimos vinte anos?

(5) bebendo "direto", com vários episódios de embriaguez (sem controle)

(6) bebendo, com freqüência sem episódios de embriaguez (com controle)

(7) bebendo de forma ocasional (não semanalmente)

(8) abstinência completa

(9) Não Sabe/Não responde - NSNR

\section{CPI (COMMUNITY PERIOdONTAL INDEX)}

53. CONDIÇÃo PERIOdONTAL

(0) periodonto normal

(3) bolsas rasas (até $5,5 \mathrm{~mm}$ )

\begin{tabular}{|c|c|c|} 
(3) bolsas rasas (até 5,5mm) & (X) sextante nulo & \\
\hline 1716 & 11 & 2627 \\
\hline & & \\
\hline & 31 & 3637 \\
\hline
\end{tabular}


54. PIP (PERDA DE INSERÇÃo PERIOdONTAL):

(0) sem perda de inserção (1) perda de $4-5 \mathrm{~mm}$

(4) perda $>12 \mathrm{~mm}$

(X) sextante excluido

MAIOR PIP examinado

\begin{tabular}{|c|c|c|}
\hline 1716 & 11 & 2627 \\
\hline & & \\
\hline 4746 & 31 & 3637 \\
\hline & & \\
\hline
\end{tabular}

55. EXPERIÊNCIA DE CÁRIE:

\begin{tabular}{|l|l|l|l|l|l|l|l|l|l|l|l|l|l|l|l|}
\hline 18 & 17 & 16 & 15 & 14 & 13 & 12 & 11 & 21 & 22 & 23 & 24 & 25 & 26 & 27 & 28 \\
\hline & & & & & & & & & & & & & & & \\
\hline & & & & & & & & & & & & & & & \\
\hline 48 & 47 & 46 & 45 & 44 & 43 & 42 & 41 & 31 & 32 & 33 & 34 & 35 & 36 & 37 & 38 \\
\hline & & & & & & & & & & & & & & & \\
\hline & & & & & & & & & & & & & & & \\
\hline
\end{tabular}

\section{USO E TIPO DE PRÓTESE:}
(0) Não usa
(1) Usa só total superior
(2) Usa só total inferior removivel

(3) Usa total e

(4) Usa total, removivel e fixa com + de 3 elementos sendo pelo menos 1 pôntico

(5) Usa total e fixa com + de 3 elementos, sendo pelo menos um pôntico

(6) Usa removivel e fixa com + de 3 elementos sendo pelo menos um pôntico

(7) Usa removivel superior

(8)Usa removivel inferior

(9)Usa removivel superior e removivel inferior

57. ÍNDICE DE PLACA "IHOS"

(0) ausência de placa sob exame visual com uso de evidenciador

(1) presença de placa no $1 / 3$ cervical ou até em 3 coleções isoladas em outras regiões

(2) presença de placa no $1 / 3$ cervical e médio

(3) presença abundante de placa, tomando mais de $2 / 3$ da superficie

IP = Somatória dos valores obtidos para cada dente/ número de dentes examinados

\begin{tabular}{|c|c|c|}
\hline IP = Somatória dos valores obtidos para cada dente/ número de dentes examinados \\
\hline $16(\mathrm{~V})$ & $11(\mathrm{~V})$ & $26(\mathrm{~V})$ \\
\hline & & \\
\hline $46(\mathrm{~L})$ & $31(\mathrm{~V})$ & $36(\mathrm{~L})$ \\
\hline & & \\
\hline
\end{tabular}


ANEXO 6

\section{OCUPAÇÁO PAINCIPAL E NATUREZA DA OCUPAÇAO}

Locatize o nome e o codigo da sua ocupaçào principal (a de maior rendimento) e o da natureza da ocupaçăo nas tabelas a seguir.

\section{OCUPACAĀO PRINCIPAL - COOdIgOS}

1 TRABAL HaDORES DAS PROFISSOES ASSEMELHADOS

(8) Engenneiros, Flakcos. Quimicoso assemeinados

101 Engomporo

103 Agronom

at Ouimico

os Oesemmsta inoustrie

OS Fisco

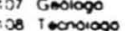

is Outros

(2) Madicos, Odontologos.

Enfermoiros o assemeinados

ii' Mation

112 Voterintirio o Zootecriveta

3 Entermero o Autricioniz:

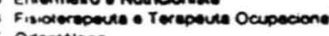

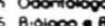

8 . 800000 e B.0matica

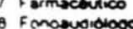

9 Outros
(2) Economistas, Estatisticos. Contadorea $\bullet$ assomeinado

121 Economusis

123 Aluario Morematico

124 contiodor

125 Nomimatredor

127 Geoprato

127. Aatronomo o metcorotopists

(1) Advogados. Psicologos. Blbliotecarios o ssememeingdos

131 Novogenos

132 Psiodloge

134 Aspistom Sociol

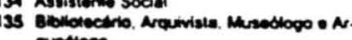
Combore

136 Comuniosilopo

130 Profissionass de Lotses a de Ares

139 Ourss
(D) Profossores e assemeinados

142 Prolessor na ansirm suberior.

mogungo ac aus

14. Diratior de estingelacimento da ensino

145 Outros

(1) Tecnicos

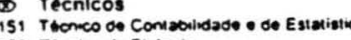

152 Teeniten de Alotogil

153 THenico am Agronomis o Normmensur

154 Tecnern de Ouimicia

is6 Tternico de Eloticiciade. Eletronica o Tete.

comenucactes

157 Tterico da Laboratorio e Ravios $x$

is Dosanhista Tánico

159 Outros

10 Trabalhadores llgados a

-presentaça de espetaculos

publicos e a pratica esportiva

161 Emcrestatio e Produtio

52 Alor Onieto

53 Camor - Composito

55 Cared

ish Leculor. Comenterista e Radialsta
167 Operedor de Cameres de cineme e

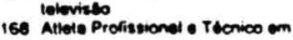

169 Demortos

(2) Jomathetas o espemethados

i7) Jomshista

170 ouros

(4) Trabelhadores ligadoe As atividedee de navegaçlo ebroe, martima o interlor

161 Plloto de neronewer

182 Comiservio de bordo

103 Comendeme de entoercescoses

189 Outros

(8) Outroe trabelhedoree do proflasoes clontificas. toenicas o artisticas

191 Escallo. Pintor o assementhedos

192 Dosomiste Comercie

193 Decorade
2 MEMGROS DOS TRES POOERES SERVIOORES CMS E MUITARES

(1) Memoros dos Poderes Legisistivo. Executivo - Judielario Sanacor Depurado Federat Oepurado Eslacual o Vercador

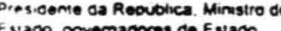

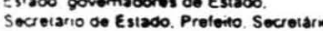
Muncioal , Momoros do Minisiorio Públicos - da Detensocia Púlica

Ministo de Tribunal Suderior

Outros

(3) Servidores Clvis aillares de nivel supertor

Dixurador assemeinacos

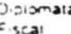

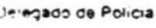

5 tFAGALHADORES OE SERVICOS E

ASSEMELMAOOS

D Serviços de adminiatraçá. conservaça ellimpeza de edificlos

of Patiano de edaticio. Asconsorista areosia o Fexinemio

Cutios

- Servicos de tratamento de beleza

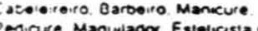
massagisia

5ig Ouvios

(18) Serviços de nospedagem. restaurante e assemethado Govemanta de nolet. Camareiro. Pontoro Cozinnoiro Garcom

3) Serviços de transporte Motorisis de verculos do transporte de pas. sagertos caros

J3 Conir amastre de embarcacbes

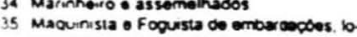
comotras o assomeinados

(2) Serviços de manutençao

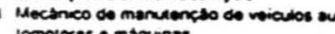
comorores o matounas

Eloincista do manutenctio de vaiculos auimpoldes macoumas o acar othos ielecomunicactes

isd 3 Lantomeiro o Pintor do veiculos meralices

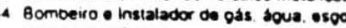
- assemeinados
215 Oavente de cargo de Directo Assessoramemto Suberior 219 ourros

(1) Outros Servidores Clvis a Milltares Agentes da Administracso Pública

1 Ocupente de Cargo de Oreceso.

Assistioncia intermediania

292 Agento Administrativo

293 Sementus

295 Miner om gerat

296 Somidor Publico Federa

29e Sonvidor Puotico Estadua

290 Oulros

3 TRagalmadores aOMINISTRaDORE S ASSEMELMADOS

(D) Diretor - Gerente

S49 Outros

Outros trabaihadores de serviços

591 Nitaicie

- incliasive o anvanaico

s94 Agente de Viegem e Guia Iuristico

95 Agentin de semvicos tuneratios. Embalsamador

396 Auxillar de Laboratorio

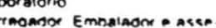
methedos

598 Emoregacos domastic

6 trabalmadores agricous FLORESTAIS. EXTRA
aSSEMELHMOSS

601 Trabainador agricola

502 Trabainador da decuara

603 Trabainador horesta

sos Trabainatix

609 Outios

7 TRABALHALORES DA PRODUCAO

INOUSTRIAL

701 Masire a Comiramestra

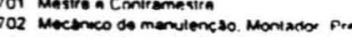
peracod - Operasor te maxamine

acoroms

702 Eleinosis 1 assemethados

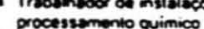

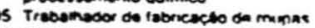

706 Traboenecor de tratemento de tumo da 1. rriescato de cigarros 0 chervios

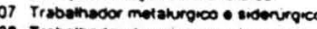

706 Trabainesor de Usinmgom do mell

10 Trabainador de labricacalo e or eoda acta drabainsoor de labricacto
301 Dutotor de Emoresas

303 Gerame

Outros Trabalhadores Administrativos e nssemelhados

crete intermediario

392 Tratiathado de sonicos da contabitidaco ou carva a asemmentinados

93 Secretario Estendorato natingrato Pecenrmonista Toletonista -

acsameinasoss

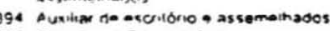

Seconomiarin

ac Oulrs

4 Trapal HaODRES DO COMERCIOE

assemel hauos

Supervisores. Corretorese assemeihados

401 Sudenvisor, insobtor o apente de compro

02 Vendedor oracista Reoresemante Cormer.

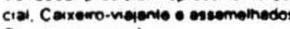

403 Coriter em geral

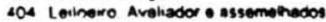

uns Agenciecor de propependa

109 Ouros 19

(8) Vendedor assemethados

11 Vendesor do comercio vareprsta.

12 atacatistin

112 Jornzlewero

419 Outros

(8) Outros trabalhadores do comorclo e assemelnados

$\Delta 91$ Oamonsiadod

492 Mortelo de modas

99 Outros

71. Trabaknador de artes praficas

Trabainader de tabricacad

Trabain madaus

Traosanach

SaIAn

traboinador couro

Dorrachaso olasicico

119 Outros

G Declarantes naO especificamos

vas CLLASSES ANTERIORES

(1) Proprietarios e Capitaliatas

का Troorietario on esiabelecimento agricola ya cocuaria o toresia

Tinmietarin de esiacelecimento comercial

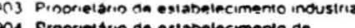

resiacao da sarvicos

ons pinoriatario de microemeress

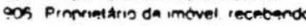

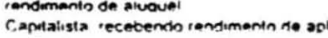

cacto de canitai em atiuns tinancairos

(1) Membros de ordens ou sellas relligiosas

ain secermes

010 comins:

(x) Trabalhadores eposantados a pensionistas

922 Funciombin Piblico civil acmsentiasto

924 Pensioniste

929 Outros

Estudantes

O31 Bolsisia Estaotario o assemeanecon

939 Outros

(8) Espollos

949 EsDorio

(x) Outros decierentes nas especificados nos grupos

999 Outros

\section{NATUAEZA DA OCUPACAO

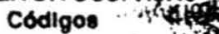

1. Empregedo om omprosa de getoo is ptivedo

2. Protiesional Liberal ou brabantion

sem vinculo de emprego

- Empregedor-lthidar ou proprieterio dós empresa

4- Sevvidor Dúbllico de adminisiraclo dinata

5 - Servidor publico de suterquid e undapelo

6 - Functondirio de emprese pública ou de economia mista

7 - Declerante que audertu rendimentos 

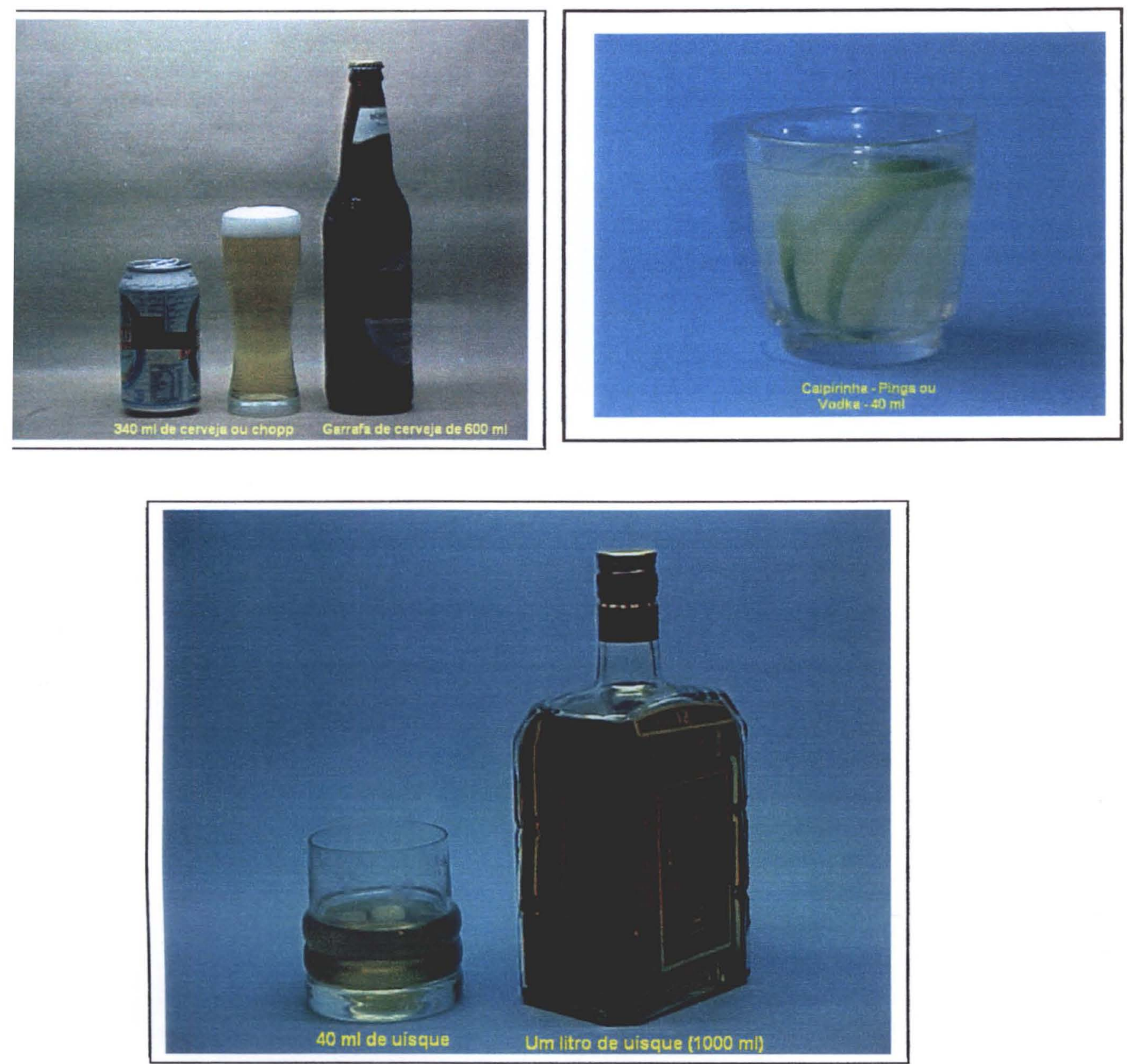

UMA DOSE DE UÍSQUE, VODKA OU AGUARDENTE - $40 \mathrm{ml}$ UMA DOSE DE CHOPE OU CERVEJA - $340 \mathrm{ml}$

UMA DOSE PADRÃO CONTÉM 13,6 gramas de ÁLCOOL ABSOLUTO 


\section{DOSES DE BEBIDAS ALCÓOLICAS}
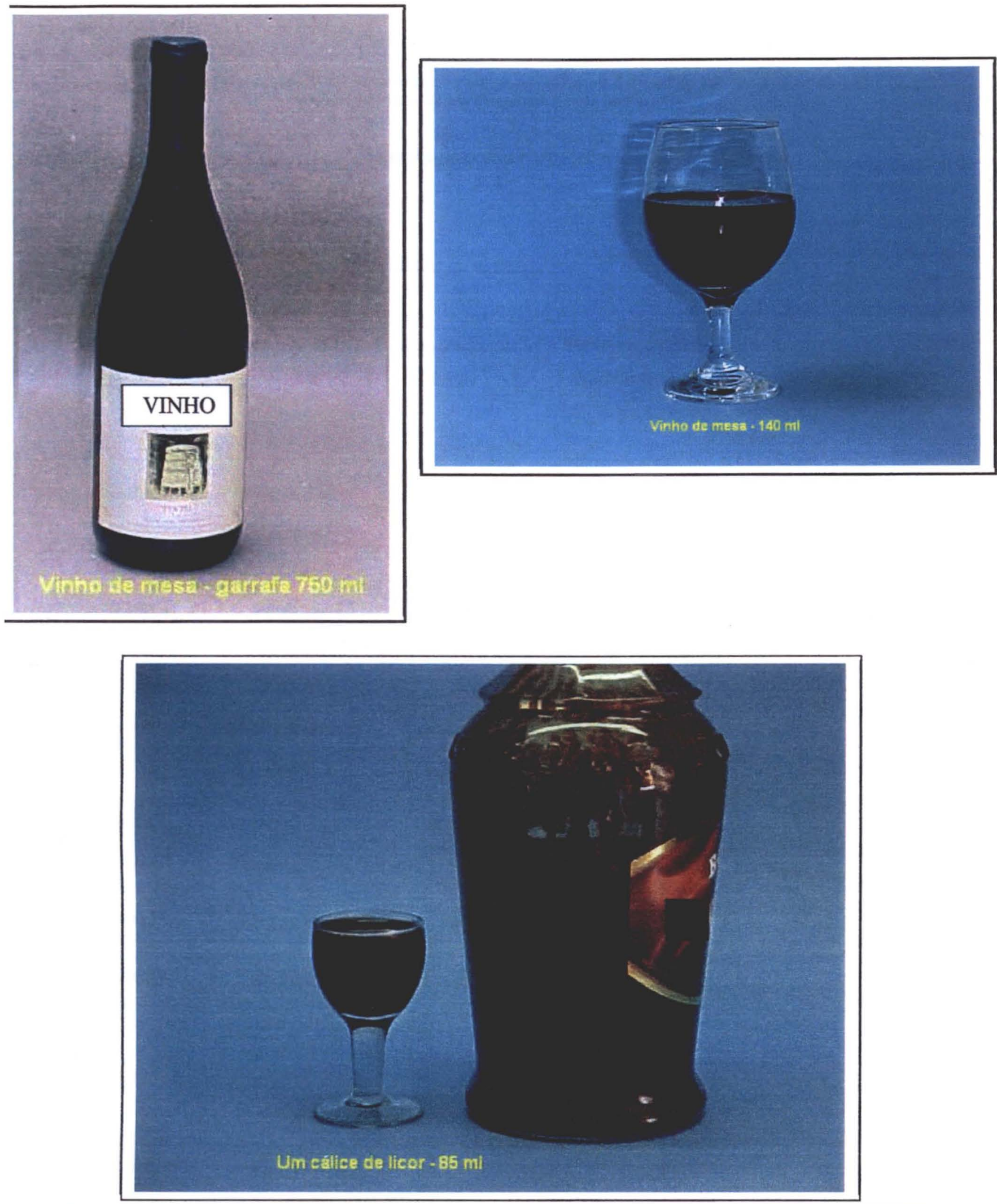

UMA DOSE DE VINHO DO PORTO OU LICORES - 40ml UMA DOSE DE VINHO DE MESA - $140 \mathrm{ml}$

UMA DOSE PADRÃO CONTÉM 13,6 gramas de ÁLCOOL ABSOLUTO 


\begin{abstract}
ANEXO 8
UNIVERSIDADE DE SĀO PAULO

FACIILUADE DE SAUDDE PUBBLICA

" $\Lambda$ valiação de fatores associados ao risco para doenças periodontais destrutivas em usuários adultos de serviços públicos de um Programa Saúde da Família
\end{abstract}

\title{
FORMULARIO DE ENTREVISTA
}

DATA

Us

EX $\square$ ANOT $\square$

PACIENTE SEXO

$N^{\circ}$ FICHA

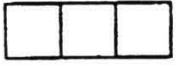

IDADE

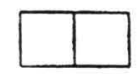

IP

CASO

CONTROLE NASC

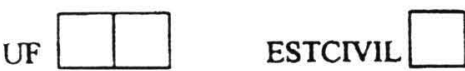

NATURAL

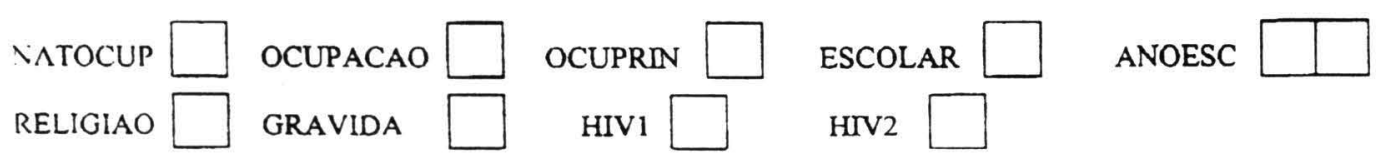

DLABIS2 $\square$ DLABETS3

NEURO1

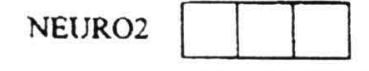

AUTMUTI

AUTMUT2

NEURO3

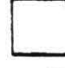

NEURO4

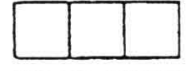

CIGARIND $\square$

CHARLTO

$N^{\circ}$ CIGND

AUTMUT3

AUTMUT4

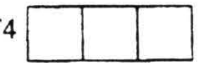

MASC:TABA

$N^{\circ}$ CHARUT

CIGARPA

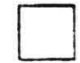

$N^{\circ}$ CIGAPA

\begin{tabular}{|l|l|}
\hline & \\
\hline
\end{tabular}

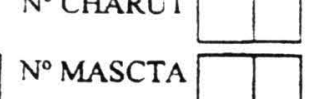

CACHIMBO

$N^{\circ}$ CACHIM

OUTROSTA

No OUTROS

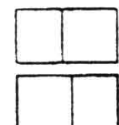

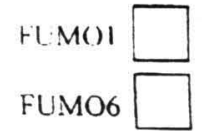
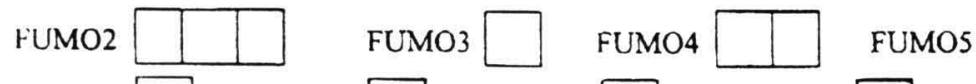

FUMO7 $\square$ FUMO8

FUMO9

FUMO10

FUMO11
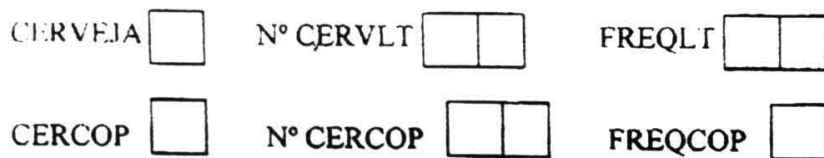

DOSEIT $\square$

CERCOP

$\mathrm{N}^{\circ}$ CERCOP

FREQCOP

DOSECOP 